\title{
Brominated Sorbents for Small Cold-Side ESPs, Hot-Side ESPs and Fly Ash Use in Concrete
}

\author{
Final Report
}

September 16, 2005 - December 31, 2008

Dr. Ronald R. Landreth, Recipient Project Director

September 21, 2011

DOE Award No. DE-FC26-05NT42308

Submitted by Albemarle Environmental $\mathrm{f} / \mathrm{k} / \mathrm{a}$ Sorbent Technologies Corporation 1664 E. Highland Road, Twinsburg, OH 44087 


\section{DISCLAIMER}

This report was prepared as an account of work sponsored by an agency of the United States Government. Neither the United States Government nor any agency thereof, nor any of their employees, makes any warranty, express or implied, or assumes any legal liability or responsibility for the accuracy, completeness, or usefulness of any information apparatus, product, or process disclosed, or represents that its use would not infringe privately owned rights. Reference herein to any specific commercial product, process, or service by trade name, trademark, manufacturer, or otherwise does not necessarily constitute or imply its endorsement, recommendation, or favoring by the United States Government or any agency thereof. The views and opinions of the authors expressed herein do not necessarily state or reflect those of the United States Government or any agency thereof. 


\begin{abstract}
This report summarizes the work conducted from September 16, 2005 through December 31, 2008 on the project entitled "Brominated Sorbents for Small Cold-Side ESPS, Hot-Side ESPs and Fly Ash Use in Concrete". The project covers testing at three host sites: Progress Energy H.F. Lee Station and the Midwest Generation Crawford and Will County Stations.
\end{abstract}

At Progress Energy Lee 1, parametric tests were performed both with and without $\mathrm{SO}_{3}$ injection in order to determine the impact on the mercury sorbent performance. In addition, tests were performed on the hot-side of the air preheater, before the $\mathrm{SO}_{3}$ is injected, with H-PAC ${ }^{\mathrm{TM}}$ sorbents designed for use at elevated temperatures. The B$\mathrm{PAC}^{\mathrm{TM}}$ injection provided the expected mercury removal when the $\mathrm{SO}_{3}$ injection was off. A mercury removal rate due to sorbent of more than $80 \%$ was achieved at an injection rate of $8 \mathrm{lb} /$ MMacf. The operation with $\mathrm{SO}_{3}$ injection greatly reduced the mercury sorbent performance.

An important learning came from the injection of $\mathrm{H}-\mathrm{PAC}{ }^{\mathrm{TM}}$ on the hot-side of the air preheater before the $\mathrm{SO}_{3}$ injection location. The H-PAC ${ }^{\mathrm{TM}}$ injected in this manner appeared to be independent of the $\mathrm{SO}_{3}$ injection and provided better mercury removal than with injecting on the cold-side with $\mathrm{SO}_{3}$ injection. Consequently, one solution for plants like Lee, with $\mathrm{SO}_{3}$ injection, or plants with $\mathrm{SO}_{3}$ generated by the SCR catalyst, is to inject $\mathrm{H}-\mathrm{PAC}{ }^{\mathrm{TM}}$ on the hot-side before the $\mathrm{SO}_{3}$ is in the flue gas. Even better performance is possible by injecting on the cold-side without the $\mathrm{SO}_{3}$, however.

During the parametric testing, it was discovered that the injection of B-PAC ${ }^{\mathrm{TM}}$ (or $\mathrm{H}-\mathrm{PAC}^{\mathrm{TM}}$ ) was having a positive impact upon ESP performance. It was decided to perform a 3-day continuous injection run with $\mathrm{B}-\mathrm{PAC}^{\mathrm{TM}}$ in order to determine whether Lee 1 could operate without $\mathrm{SO}_{3}$ injection. If the test proved positive, the continuous injection would continue as part of the long-term test. The injection of B-PAC ${ }^{\mathrm{TM}}$ did allow for the operation of Lee 1 without $\mathrm{SO}_{3}$ injection and the long-term test was conducted from March 8 through April 7, 2006. The total mercury removal for the 30-day long-term test, excluding the first day when $\mathrm{SO}_{3}$ was injected and the last day when a plain PAC was used, averaged $85 \%$. The achievement of $85 \% \mathrm{Hg}$ removal over the 30 days longterm test is another milestone in the history of achievement of the Albemarle Environmental f/k/a Sorbent Technologies Corporation B-PAC ${ }^{\mathrm{TM}}$ sorbent.

A clear indication of the impact of B-PAC ${ }^{\mathrm{TM}}$ on opacity came at the end of the long-term test. It was hoped that Lee 1 could be operated for several days after the end of the long-term test. It took less than a day before the opacity began to increase. The discovery that B-PAC ${ }^{\mathrm{TM}}$ can improve ESP performance while capturing a large amount of mercury is another milestone for the B-PAC ${ }^{\mathrm{TM}}$ mercury sorbent.

The parametric testing at the Midwest Generation Crawford Station was divided into two phases; the first using C-PAC ${ }^{\mathrm{TM}}$, the concrete friendly sorbent, and the other using nonconcrete friendly materials. The first phase of the parametric tests was conducted before the long-term test. The second phase of the parametric testing was performed after the long-term test in order to avoid contaminating the fly ash containing the concrete friendly sorbents. 
The parametric test began with an injection rate of $1 \mathrm{lb} / \mathrm{MMacf}$ and, after a period to allow the mercury concentration to stabilize, the rate was increased to $3 \mathrm{lb} / \mathrm{MMacf}$. The $\mathrm{Hg}$ removal for this test was about $60 \%$ due to sorbent and $69 \%$ total at the injection rate of $1 \mathrm{lb} /$ MMacf and $80 \%$ due to sorbent and $84 \%$ total for the $3 \mathrm{lb} /$ MMacf injection rate. The average total vapor phase mercury removal for the first 21 days of the long-term test was $82 \%$ at an injection rate of $4.6 \mathrm{lb} / \mathrm{MMacf}$. The last nine days of the long-term test was used for testing different sorbents.

A series of tests with different B-PAC ${ }^{\mathrm{TM}}$ sorbents followed the long-term test. All of the $\mathrm{B}^{-P A C}{ }^{\mathrm{TM}}$, sorbents had similar mercury performance, achieving about $70 \%, 80 \%$ and $90 \%$ mercury removal due to sorbent at injection rates of 2, 4 and $6 \mathrm{lb} / \mathrm{MMacf}$, respectively. It took $50 \%$ more of the Norit Hg LH sorbent to achieve $80 \%$ mercury removal than with the $\mathrm{B}-\mathrm{PAC}^{\mathrm{TM}}$, sorbents.

The impact of C-PAC ${ }^{\mathrm{TM}}$ on the properties of concrete was investigated by Lafarge (the fly ash seller at Crawford), by Albemarle Environmental f/k/a Sorbent Technologies, and by Headwaters Resources, a project partner. The properties evaluated include the concrete air content, air stability, air distribution, setting time, and strength. C-PAC ${ }^{\text {TM }}$ does not appear to deleteriously affect any of the important properties of concrete. It may even improve some properties.

The finding that C-PACTM does provide high levels of mercury removal without impacting the fly ash cement properties is a milestone in this project.

At Crawford 7 , the opacity would increase $3 \%$ to $5 \%$ over a period of hours from the time that the boiler first reached high load until the boiler load was reduced at night. For the parametric test, the opacity dropped when the C-PAC ${ }^{\mathrm{TM}}$ was turned on or when the injection rate was increased. As the long-term test progressed, the opacity for each successive period when at full load was lower than the previous one, so that at the end of the test the opacity at full load was averaging about $8 \%$ below that before the injection began.

The finding that a gas-phase brominated mercury sorbent such as B-PAC ${ }^{T M}$ or C-PAC ${ }^{T M}$ can positively impact ESP performance is another milestone for this project.

Midwest Generation Will County Unit 3 is equipped with a hot-side ESP and, thus, the injection temperature was about $700^{\circ} \mathrm{F}$. The high temperature version of C-PAC ${ }^{T M}$ was used in the trial since it was desired to maintain the fly ash for sale for cement use. The duration of the testing at the Will County Station was reduced from that originally planned, due to a reduction in DOE funding. The biggest changes were the shortening of the baseline period and the switch from a long-term 30-day test to a short continuous injection run.

The first phase of the parametric injection tests used only one sorbent (the high temperature version of C-PAC ${ }^{\mathrm{TM}}$ ) but different injection lances. Regular lances were used in the first day of this phase of testing and the X-a-Lances on the second day. The injection of the high temperature version of C-PAC ${ }^{\mathrm{TM}}$ with regular injection lances provided mercury removal rates of about $30 \%$ and $45 \%$ due to sorbent at the injection rates of 3 and $5 \mathrm{lb} / \mathrm{MMacf}$, respectively, based upon cold-side flow rates. This is very good performance considering that the injection temperature is about $700^{\circ} \mathrm{F}$ at full load. However, the same sorbent at the same injection rates provided mercury removal rates 
of about $50 \%$ and $67 \%$ when the X-a-Lances were utilized. This is an improvement of about $50 \%$ relatively. As a result of these findings, the $\mathrm{X}$-a-Lances were used for the rest of the test program.

The standard $\mathrm{H}-\mathrm{PAC}^{\mathrm{TM}}$ sorbent performed in the same manner as did the C-PAC ${ }^{\mathrm{TM}}$. The performance of the Norit Hg LH sorbent was poor in this application.

C-PAC ${ }^{\mathrm{TM}}$ did increase the foam index of the fly ash slightly, as was observed in the testing at the Midwest Generation Crawford Station, but the increase was small and predictable enough to allow for the use of the fly ash in cement. The impact of C-PACTM on the properties of concrete was not investigated due to the limitation of funds.

However, based upon past experience, it is highly likely that the concrete properties including the concrete air content, air stability, air distribution, setting time, and strength would have shown no impact based upon the minimal impact upon foam index. 


\section{TABLE OF CONTENTS}

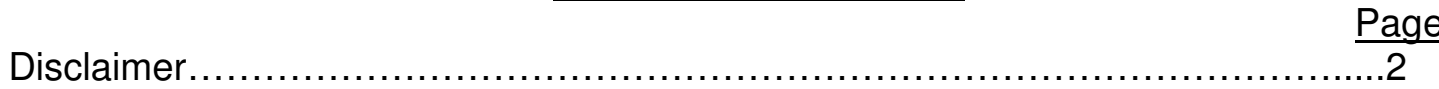

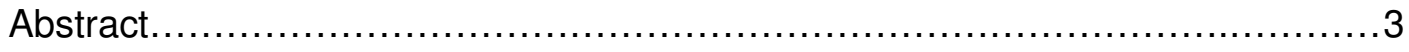

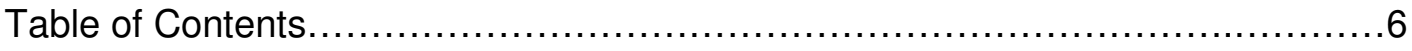

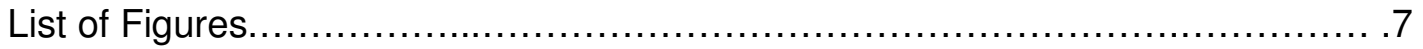

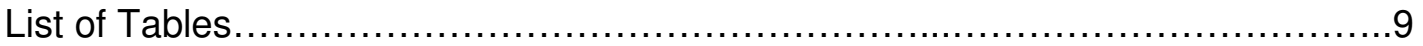

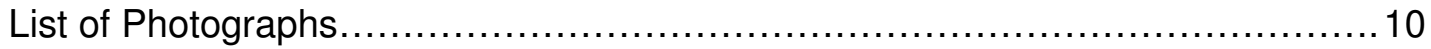

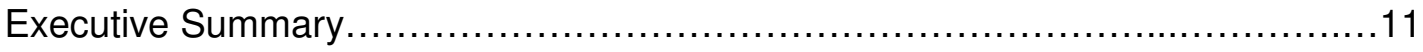

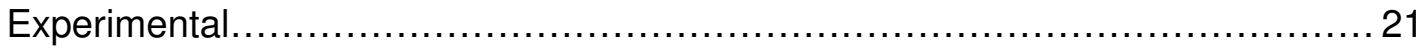

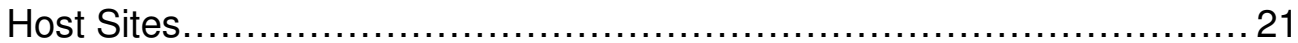

Pilot-Scale Duct-Injection System................................... 23

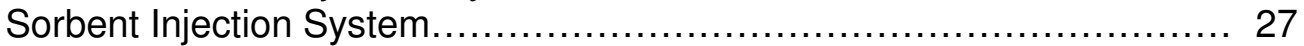

Mercury Monitoring Instruments.......................................... 28

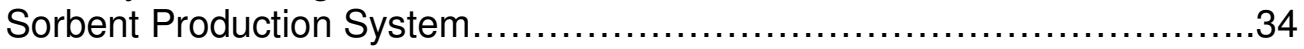

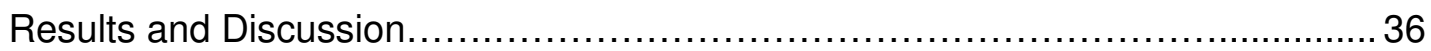

Progress Energy H.F. Lee Station.......................................... 36

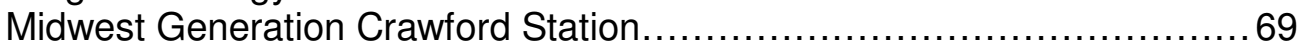

Midwest Generation Will County Station.................................... 107

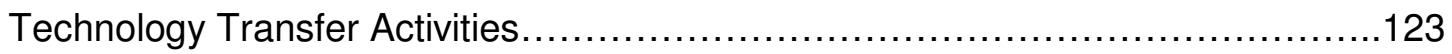

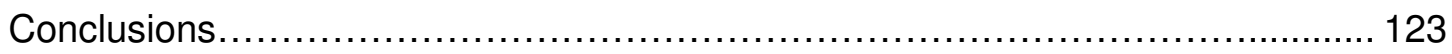

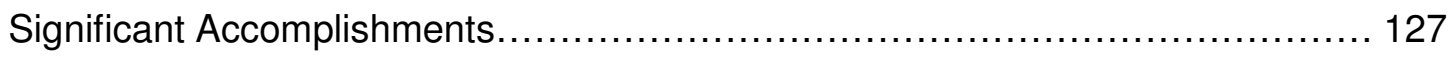

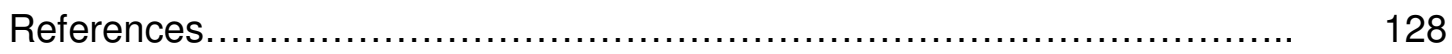




\section{니ST OF FIGURES}

1. Diagram of the Duct-Injection System

2. Pilot Duct-Injection System Hg Removal Results Plotted with the Results from Brayton Point and Pleasant Prairie

3. Diagram of the Sorbent Injection System

4. Diagram of Baldwin Inertial Separator

5. Diagram of the PS Analytical Dry Conversion Process

6. Diagram of the Sorbent Production System

7. CFD Modeled Flow in the Lee 1 Ductwork

8. Sorbent Distribution at the ESP Plenum with a 16 Lance Arrangement

9. PSA Hg Data from the First Baseline Period at Lee 1

10. PSA Hg Data from the Second Baseline Period at Lee 1

11. PSA and Ohio Lumex Hg Data from the First Baseline Period at Lee 1

12. PSA and Ohio Lumex $\mathrm{Hg}$ Data from the $2^{\text {nd }}$ Baseline Period at Lee 1

13. Method 324 Mercury Results from the Baseline Period at Lee 1

14. Lee 1 Load during the Baseline Periods

15. Opacity for Baseline Periods during the Testing at Lee 1

16. Hg Removal Due to Sorbent at Lee 1 with and without $\mathrm{SO}_{3}$ Injection

17. Mercury removal Rates Due to Sorbent for the Three Sorbents of Different Size

18. Impact of Sorbent Size upon Opacity at Lee 1

19. Mercury Monitor Data from the Wet and Dry Systems at Lee 1

20. Total Vapor Phase Hg Removal during the Long-Term Test at Lee 1

21. Lee 1 Fly Ash Leachate Data

22. Average Opacity during the Long-Term Test at Lee 1

23. Opacity Data after the End of the Long-Term Test at Lee 1

24. Crawford 7 Reheat Boiler Ductwork Modeled

25. Sorbent Distribution at Three Levels at Crawford 7 with a 10-Lance Arrangement

26. PSA Hg Data from the First Baseline Period at Crawford 7

27. Average Daily PSA Hg Data from the Baseline Period at Crawford 7

28. PSA and Ohio Lumex Inlet $\mathrm{Hg}$ Data from the Baseline Period

29. 6-Minute Average Opacity and Boiler Load for Part of the Baseline Period at Crawford 7

30. Mercury Concentration at ESP Inlet and Outlet at Crawford 7 on August 5, 2006 during a Parametric Test Using C-PAC1

31. Comparison of the Performance of Norit $\mathrm{Hg} \mathrm{LH}$ to B-PAC ${ }^{\mathrm{TM}}$

32. Opacity and Load at Crawford 7 during the First Parametric Test Period

33. First 21 Days of the Long-Term Test at Crawford 7

34. Last 9 Days of the Long-Term Test at Crawford 7

35. Ohio Lumex and PSA Inlet Vapor Phase Hg Data from the Long-Term Test at Crawford 7

36. Total Vapor Phase Hg Removal as Determined by the PSA and Method 324 Data from the Long-Term Test at Crawford 7

37. Crawford 7 Long-Term Fly Ash Average LOI content by Hopper

38. Crawford 7 Long-Term Fly Ash Average Hg content by Hopper

39. Crawford 7 Fly Ash LOI and Hg Contents during the Long-Term Test

40. Foam Indices of Fly Ash from the Long-Term Test at Crawford 7

41. Foam Index Distribution of Fly Ash from the Baseline and Long-term Test Periods at Crawford 7

42. Foam Indices of the Long-Term Fly Ash Samples Using Different AEAs

43. Ingredients of the Concrete Mix 
44. Concrete Air Stability Data

45. Penetration Resistance of Concrete Mixes with Either Crawford Baseline or Long-Term Fly Ash

46. Unconfined Compressive Strength of Concrete Samples Made by Headwaters (Top) or STC (Bottom).

47. 6-Minute Average Opacity versus Boiler Load

48. Will County 3 Superheat Boiler Ductwork Modeled

49. Velocity Profile in the Will County 3 Ductwork

50. Sorbent Distribution at Two Locations at Will County 3 Using Either Regular Lances or X-a-Lances

51. PSA and Appendix K Hg Data from the Baseline Period at Will County 3

52. 6-Minute Average Opacity and the Boiler Load for the Baseline Period at Will County 3

53. Mercury Removal Results from the First Phase of the Parametric Tests at Will County 3

54. Comparison of the Hg Performance of Norit $\mathrm{Hg} \mathrm{LH}$ to Albemarle Environmental $\mathrm{f} / \mathrm{k} / \mathrm{a}$ Sorbent Technologies' C-PAC ${ }^{\mathrm{TM}}$ and H-PAC ${ }^{\mathrm{TM}}$ Sorbents

55. Comparison of the Mercury Performance of Three Sorbents

56. Hg Monitor Data During the Continuous Run at Will County 3

57. Boiler Load and 6-Minute Opacity at Will County 3 During the Continuous Run 


\section{LIST OF TABLES}

1. Lee 1 Baseline OHM, PSA, Ohio Lumex and Appendix K Data from 1/18/06

2. Lee 1 Baseline Coal Proximate Analyses - Dry Basis

3. Lee 1 Baseline Coal Moisture and $\mathrm{Hg}$ Analyses

4. Lee 1 Fly Ash Mercury Data from the Baseline Period

5. Lee 1 Parametric B-PAC Sorbent Injection Testing Results

6. Lee 1 Parametric Test Coal Proximate Analyses - Dry Basis

7. Lee 1 Parametric Test Coal Moisture and $\mathrm{Hg}$ Analyses

8. Lee 1 Fly Ash Mercury Data from the First Parametric Test Period

9. Lee 1 Fly Ash Mercury Data from the Second Parametric Test Period

10. Fly Ash LOI from the First Parametric Test Period

11. Fly Ash LOI from the Second Parametric Test Period

12. Method 324 and PSA Data from the Lee 1 Long-Term Test

13. Lee 1 Long-Term OHM Test Data

14. Lee 1 Long-Term OHM and Monitor Data Comparison

15. Lee 1 Long-Term Test Coal Proximate Analyses - Dry Basis

16. Lee 1 Long-Term Test Coal Moisture and Mercury

17. Lee 1 Fly Ash Elemental Analyses

18. Fly Ash LOI during the Long-Term Test

19. Lee 1 Fly Ash Mercury Data from the Long-Term Test

20. Lee 1 Long-Term Halogen Test Results

21. Lee 1 Corrosion Testing Results

22. Crawford 7 Baseline OHM Test Data

23. Crawford 7 Baseline OHM and Hg Monitor Data Comparison

24. Crawford 7 Baseline Coal Data

25. Crawford 7 Baseline Fly Ash Hg Data

26. Crawford 7 Baseline Halogen Data

27. Crawford 7 Phase I Parametric Test Results

28. Crawford 7 Phase II Parametric Test Results

29. Crawford 7 Coal Data from the First Parametric Test Period

30. Crawford 7 Coal Data from the Second Parametric Test Period

31. Crawford 7 Fly Ash Mercury Data from the First Parametric Test Period

32. Crawford 7 Long-Term OHM Test Data

33. Crawford 7 Long-Term OHM and Monitor Data Comparison

34. Method $324 \mathrm{Hg}$ Trap Data for the Long-Term Test at Crawford 7

35. Crawford 7 Long-Term Test Coal Data

36. Crawford 7 Long-Term Test Fly Ash LOI and Hg Data

37. Crawford 7 Fly Ash and Sorbent Selenium, Chromium, and Barium Analyses

38. Air Properties of the Concretes

39. Concrete Air Void and Hardened Concrete Parameters

40. Crawford 7 Fly Ash Leaching Data

41. Crawford 7 Long-Term Halogen Data

42. Crawford 7 Corrosion Testing Results

43. Will County 3 Coal Proximate Analyses (As Received)

44. Will County 3 Coal Mercury Data

45. Will County 3 Baseline Fly Ash $\mathrm{Hg}$ and LOI Data

46. Second Phase Parametric Test Results from Will County 3

47. Will County 3 Continuous Run Fly Ash $\mathrm{Hg}$ and LOI Data

48. Foam Index of Fly Ash Samples During the Continuous Run 


\section{니ST OF PHOTOGRAPHS}

1. Progress Energy H.F. Lee Station

2. Midwest Generation Crawford Station

3. Midwest Generation Will County Station

4. View of the Duct-Injection System

5. Analytical Portion of the Duct-Injection System

6. Albemarle Sorbent Injection Trailer

7. PS Analytical Wet/Dry Mercury Conversion Module

8. Ohio Lumex Mercury CEM

9. Appendix K Sorbent Trap Sampler

10. Ohio Lumex Model RA-915+ Mercury Analyzer

11. PAC being Unloaded at the Sorbent Production Facility

12. Lee 1 with Injection Trailer

13. Lee 1 Injection Lance Arrangement

14. Crawford Station with Injection Trailer and Sorbent Tanker

15. Section of Concrete Made with Crawford Baseline Fly Ash

16. Section of Concrete Made with Crawford Long-Term Fly Ash

17. Will County Station with Injection Trailer and Sorbent Tanker 


\section{EXECUTIVE SUMMARY}

This report summarizes the work on this project conducted from September 16, 2005 through December 31, 2008 at Progress Energy's Lee Station Unit 1 and at Midwest Generation's Crawford Unit 7 and Will County Unit 3.

The Albemarle Environmental f/k/a Sorbent Technologies Corporation (STC) sorbent production facilities in Twinsburg, Ohio were used to manufacture the gas-phase brominated sorbents for this test program. The Albemarle Environmental $\mathrm{f} / \mathrm{k} / \mathrm{a}$ Sorbent Technologies sorbent injection trailer was used to inject the mercury sorbents into the ductwork at all three plants. The injection lance arrangements were determined by CFD modeling performed by Fuel Tech.

PS Analytical and Ohio Lumex mercury monitors were used throughout the test program to monitor the flue gas mercury content. Method 324/Appendix K sorbent trap samples were taken during the tests as a check on the mercury monitors. Method 26A halogen and $\mathrm{OHM}$ mercury measurements were made during test programs at Lee and Crawford Stations but were eliminated for the testing at Will County due to a lack of funding.

Coal and fly ash samples were collected throughout the test programs. The mercury content of these materials was measured by Albemarle Environmental $\mathrm{f} / \mathrm{k} / \mathrm{a}$ Sorbent Technologies personnel using a laboratory version of the Ohio Lumex mercury analyzer. Selected coal and fly ash samples were sent to SGS NA for further analyses.

The mercury testing at Progress Energy Lee 1 was comprised of baseline measurements, parametric injection tests and a 30-day long-term test. Lee 1 burns bituminous coal and uses a cold-side ESP to collect particulate emissions. The standard $\mathrm{B}-\mathrm{PAC}$ sorbents were used in the trials at this plant since the fly ash was not sold.

It was discovered in the baseline measurements that the bituminous coal fired at Lee 1 had a low mercury content, relative to other bituminous coals, averaging about $0.06 \mathrm{ppm}$ on a dry basis. The native mercury removal at Lee 1 varied between $20 \%$ and $30 \%$ in the baseline period, as is typical of facilities using bituminous coal.

The parametric tests were performed both with and without $\mathrm{SO}_{3}$ injection in order to determine the impact on the mercury sorbent performance. In addition, tests were performed on the hot-side of the air preheater, before the $\mathrm{SO}_{3}$ is injected, with the STC $\mathrm{H}-\mathrm{PAC}^{\mathrm{TM}}$ sorbents designed for use at elevated temperatures. The results of these tests are summarized in the next figure. 


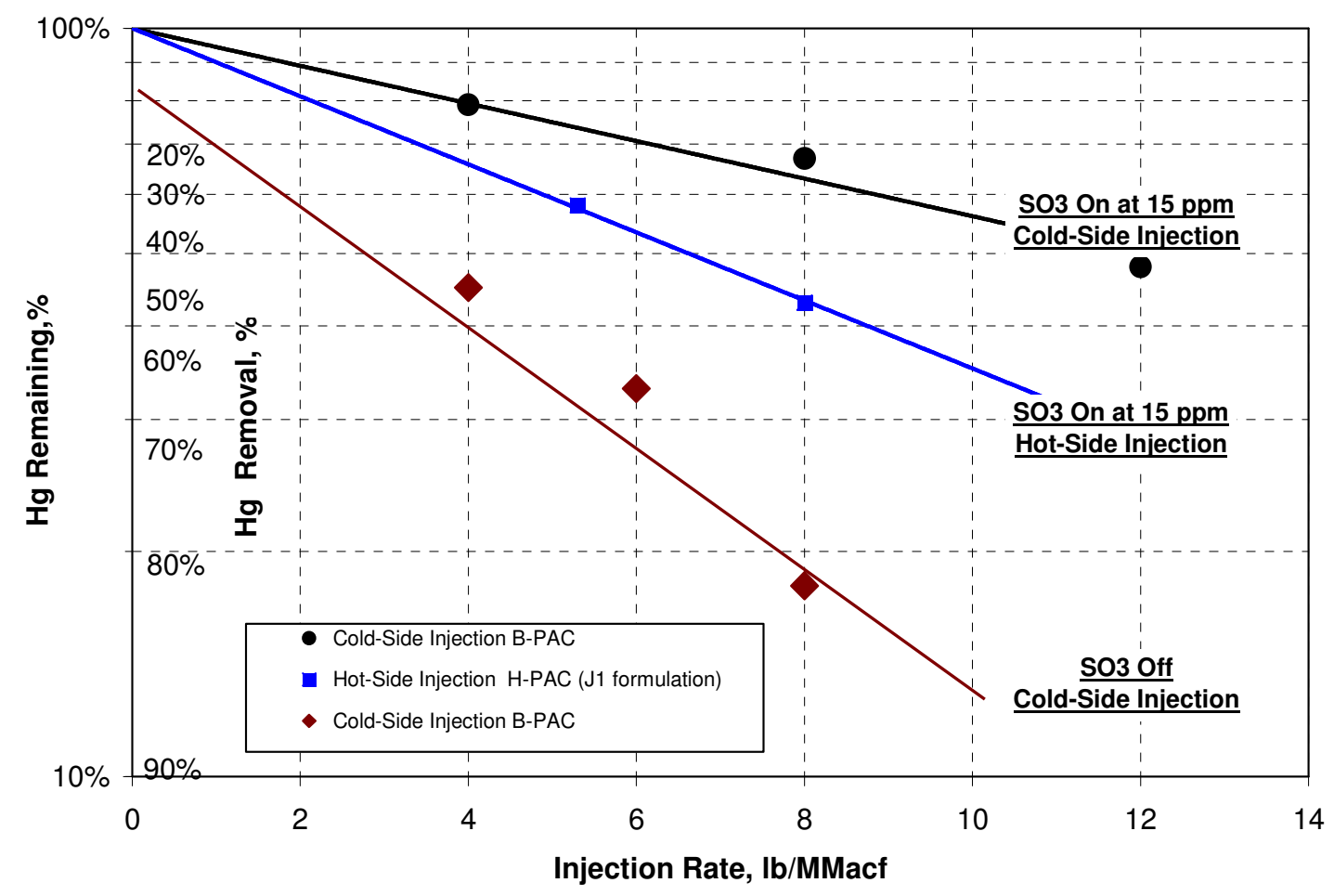

The B-PAC ${ }^{\mathrm{TM}}$ injection provided the expected mercury removal when the $\mathrm{SO}_{3}$ injection was off. A mercury removal rate due to sorbent of more than $80 \%$ was achieved at an injection rate of $8 \mathrm{lb} / \mathrm{MMacf}$. The operation with $\mathrm{SO}_{3}$ injection greatly reduced the mercury sorbent performance.

An important learning came from the injection of $\mathrm{H}-\mathrm{PAC}^{\mathrm{TM}}$ on the hot-side of the air preheater before the $\mathrm{SO}_{3}$ injection location. The H-PAC ${ }^{\mathrm{TM}}$ injected in this manner appeared to be independent of the $\mathrm{SO}_{3}$ injection and provided better mercury removal than with injecting on the cold-side with $\mathrm{SO}_{3}$ injection. Consequently, one solution for plants like Lee, with $\mathrm{SO}_{3}$ injection, or plants with $\mathrm{SO}_{3}$ generated by the SCR catalyst, is to inject $\mathrm{H}-\mathrm{PAC}{ }^{\mathrm{TM}}$ on the hot-side before the $\mathrm{SO}_{3}$ is in the flue gas. Even better performance is possible by injecting on the cold-side without the $\mathrm{SO}_{3}$, however.

During the parametric testing, it was discovered that the injection of B-PAC ${ }^{T M}$ (or $\mathrm{H}-\mathrm{PAC}{ }^{\mathrm{TM}}$ ) was having a positive impact upon ESP performance. It was decided to perform a 3-day continuous injection run with $\mathrm{B}-\mathrm{PAC}^{\mathrm{TM}}$ in order to determine whether Lee 1 could operate without $\mathrm{SO}_{3}$ injection. If the test proved positive, the continuous injection would continue as part of the long-term test.

The injection of B-PAC ${ }^{\mathrm{TM}}$ did allow for the operation of Lee 1 without $\mathrm{SO}_{3}$ injection and the long-term test was conducted from March 8 through April 7, 2006. A total of 84,292 pounds of B-PAC ${ }^{\mathrm{TM}}$ was used in the long-term test. The mercury removal results of the long-term test are shown in the next figure. 


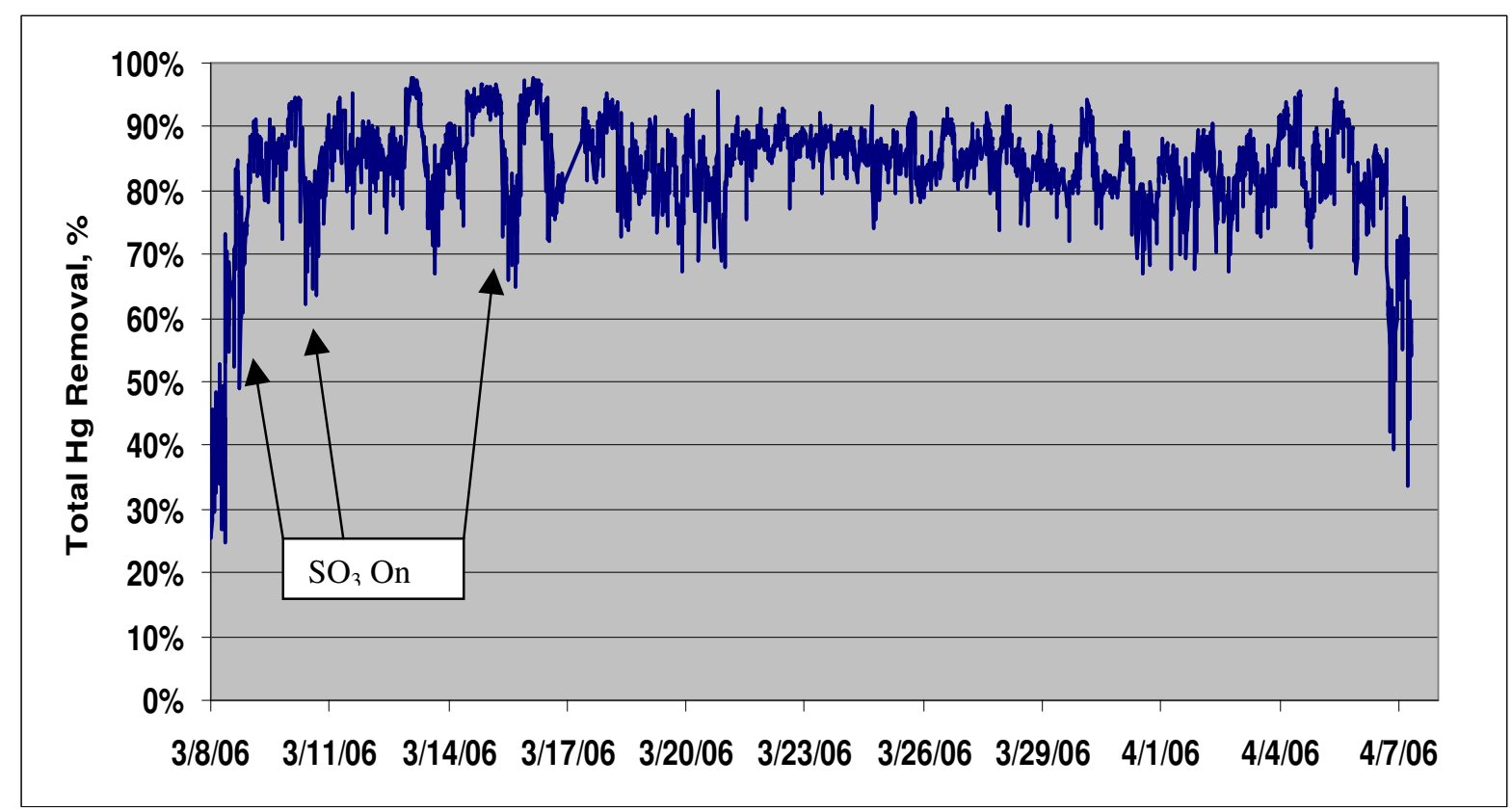

The total mercury removal for the 30-day long-term test, excluding the first day when $\mathrm{SO}_{3}$ was injected and the last day when a plain PAC was used, averaged $85 \%$. The achievement of $85 \% \mathrm{Hg}$ removal over the 30 days long-term test is another milestone in the history of achievement of the Albemarle Environmental $\mathrm{f} / \mathrm{k} / \mathrm{a}$ Sorbent Technologies Corporation B-PAC ${ }^{\mathrm{TM}}$ sorbent.

The impact of the B-PAC ${ }^{T M}$ on opacity is shown in the next figure.

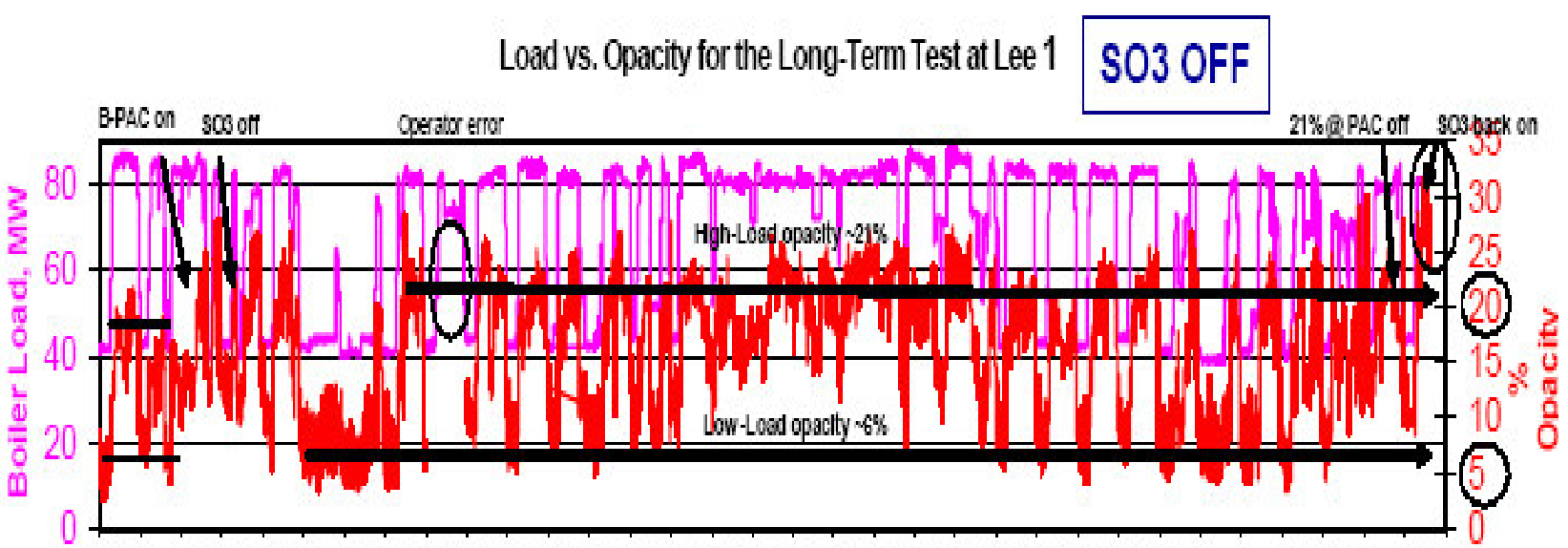

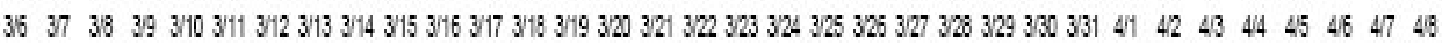

$$
\text { — Load — Load — Opacity _ Opacity }
$$

The opacity of Lee 1 is directly related to boiler load, with higher opacities being observed at higher operating rates. The average opacity observed during full load during the long-term test was $21 \%$ without $\mathrm{SO}_{3}$ injection, as compared to the $\sim 30 \%$ opacity observed at full load during the baseline periods. This is the first time that this boiler had operated that long without $\mathrm{SO}_{3}$ injection. 
Another clear indication of the impact of B-PAC ${ }^{\mathrm{TM}}$ on opacity came at the end of the long-term test. It was hoped that Lee 1 could be operated for several days after the end of the long-term test without $\mathrm{SO}_{3}$ injection. The test ended at night when the boiler was at low load. The next morning the opacity spiked over $30 \%$ before the $\mathrm{SO}_{3}$ injection could be resumed.

The discovery that B-PAC ${ }^{\mathrm{TM}}$ can improve ESP performance while capturing a large amount of mercury is another milestone for the B-PAC ${ }^{\mathrm{TM}}$ mercury sorbent.

Sorbents of different mean size were tested at Lee 1. One brominated sorbent having a mean size of 18 microns was ground to both 10 micron mean size and 5 micron mean size and evaluated in the second phase of the parametric testing at Lee 1 . The finer grind did provide some improved mercury performance as shown in the figure below.

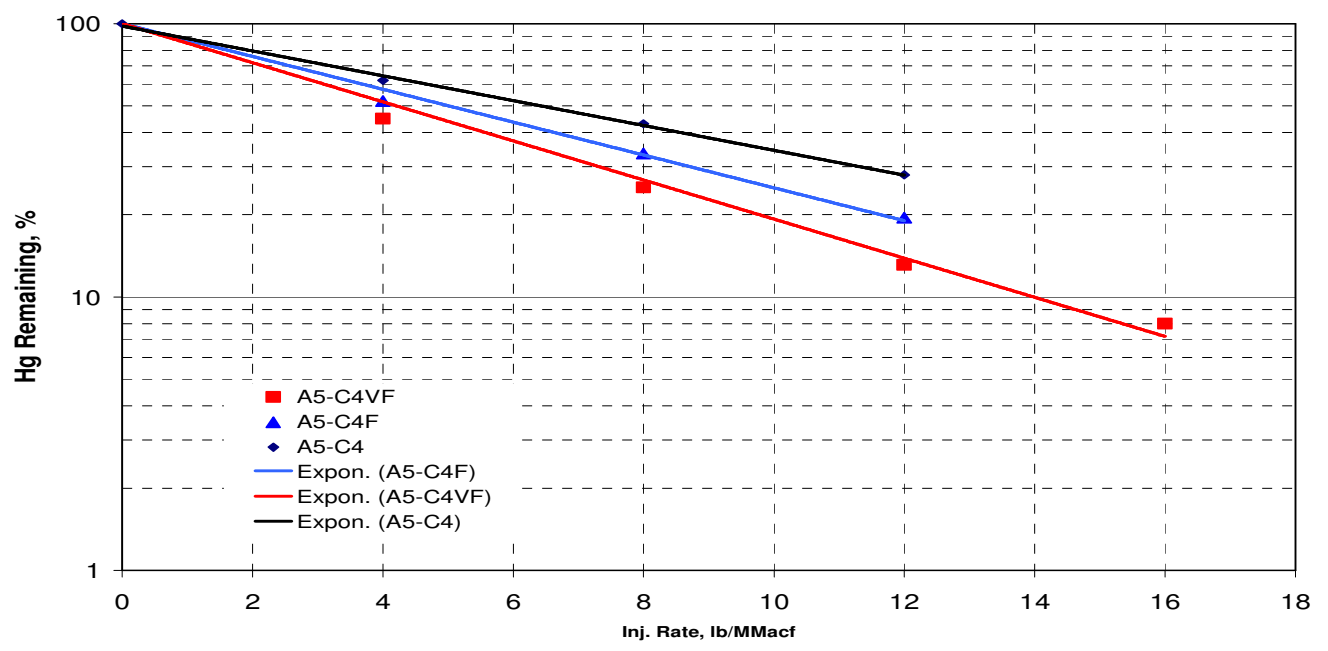

However, there was a significant price to pay in terms of opacity in order to achieve the gain in mercury removal performance. The opacity measured while each one of the mercury sorbents was being injected is shown in the next figure. 


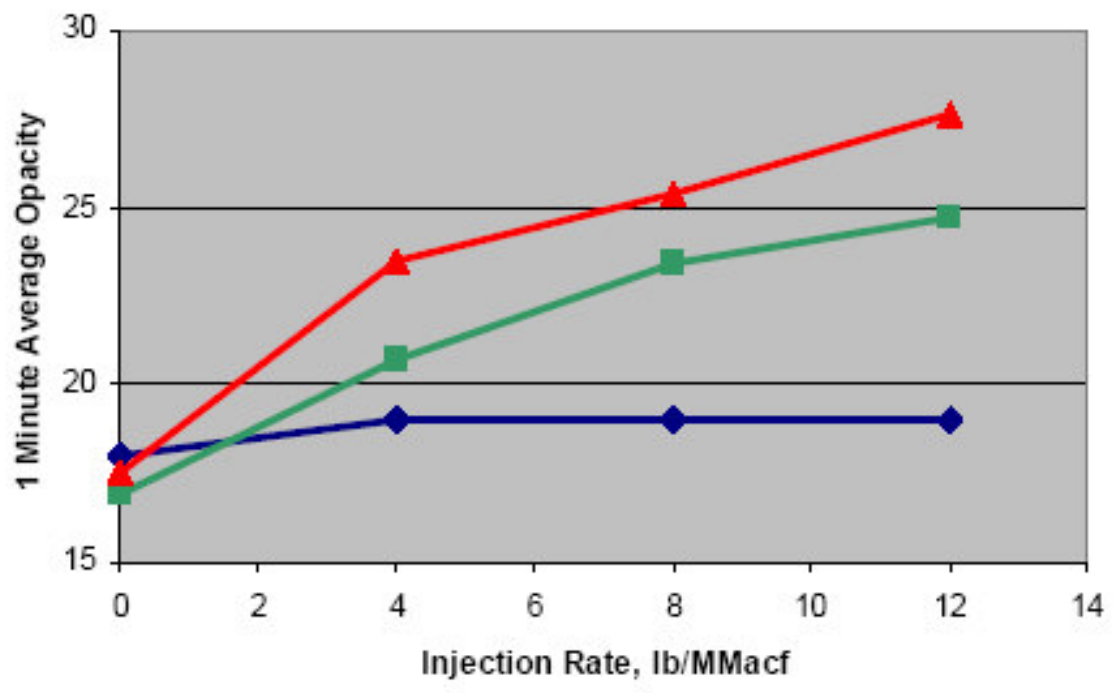

18 Micron Mean $=10$ Micron Mean $=5$ Micron Mean

This opacity increase would not be acceptable at Lee 1 and at most plants.

The second host site was Midwest Generation Crawford Station Unit 7. The test was comprised of baseline measurements, phase I parametric injection tests, a 30-day longterm test, and phase II parametric tests. The parametric tests were divided into two phases, one for concrete friendly mercury sorbents before the long-term test and one for non-concrete friendly sorbents after the long-term test. Testing in this manner minimized the amount of fly ash that could not be sold.

Crawford 7 burns subbituminous PRB coal and uses a very small cold-side ESP (SCA $120)$ to collect particulate emissions. The C-PAC ${ }^{T M}$ mercury sorbents were primarily used at this plant since they sell much of their fly ash.

Before the parametric test began, the native mercury removal was about $20 \%$, within the range seen in the baseline period. The parametric test began with an injection rate of 1 $\mathrm{lb} /$ MMacf and, after a period to allow the mercury concentration to stabilize, the rate was increased to $3 \mathrm{lb} / \mathrm{MMacf}$. The $\mathrm{Hg}$ removal for this test was about $60 \%$ due to sorbent and $69 \%$ total at the injection rate of $1 \mathrm{lb} /$ MMacf and $80 \%$ due to sorbent and $84 \%$ total for the $3 \mathrm{lb} / \mathrm{MMacf}$ injection rate. The results from the first 21 days of the long-term test are shown in the next figure. 


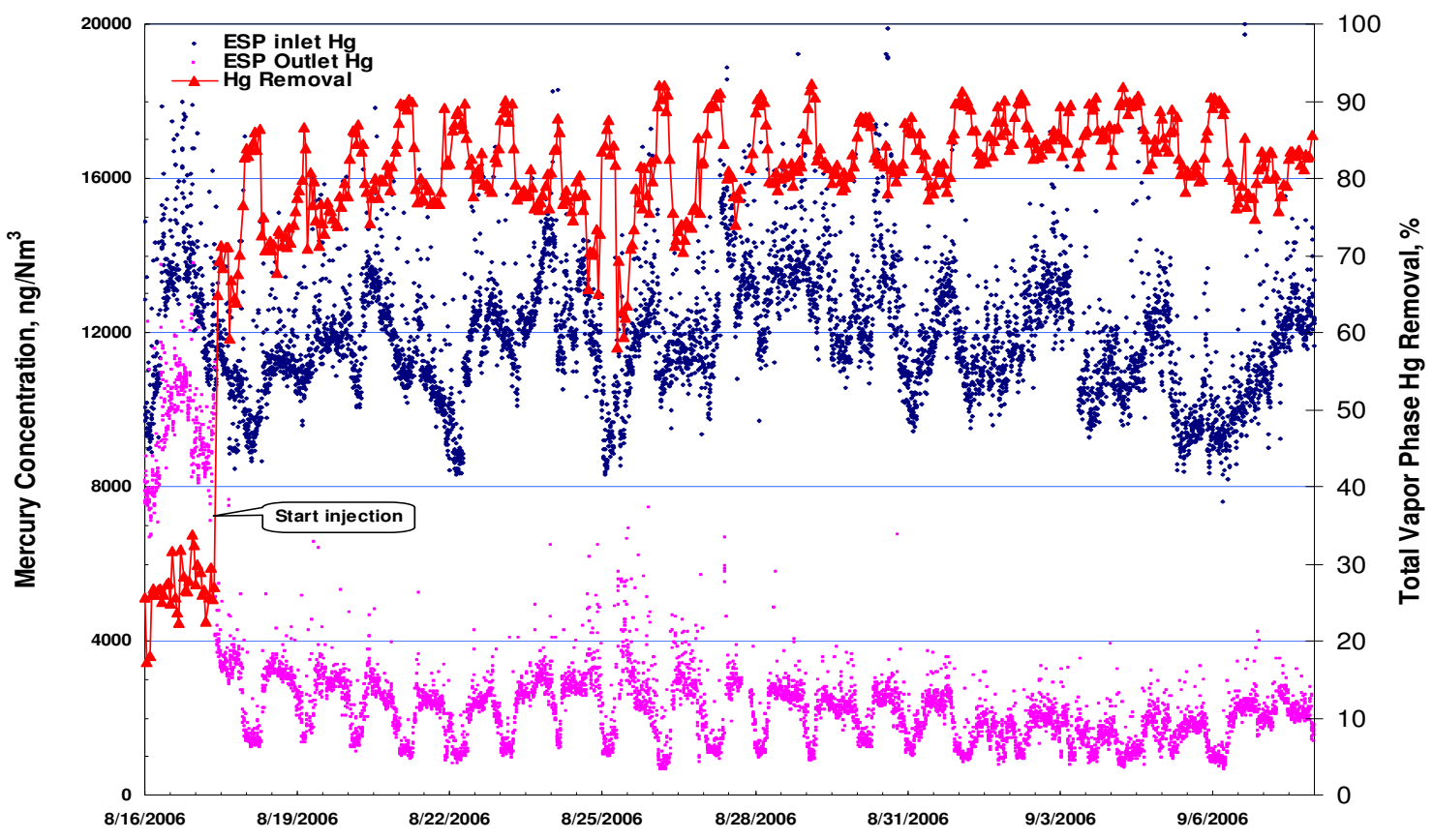

The average total vapor phase mercury removal for the first 21 days of the long-term test was $82 \%$ at an injection rate of $4.6 \mathrm{lb} / \mathrm{MMacf}$. The last nine days of the long-term test was used for testing different sorbents and injection rates.

A series of tests with different B-PAC ${ }^{T M}$ sorbents followed the long-term test. All of the B-PAC $^{\mathrm{TM}}$, sorbents had similar mercury performance, achieving about $70 \%, 80 \%$ and $90 \%$ mercury removal due to sorbent at injection rates of 2, 4 and $6 \mathrm{lb} / \mathrm{MMacf}$, respectively. The Norit $\mathrm{Hg} \mathrm{LH}$ sorbent did not perform as well as did the B-PAC ${ }^{\mathrm{TM}}$, sorbents. It took $50 \%$ more of the Norit $\mathrm{Hg}$ LH sorbent to achieve $80 \%$ mercury removal than with the B-PAC ${ }^{\mathrm{TM}}$ sorbents. The results of these tests are shown in the next figure. 


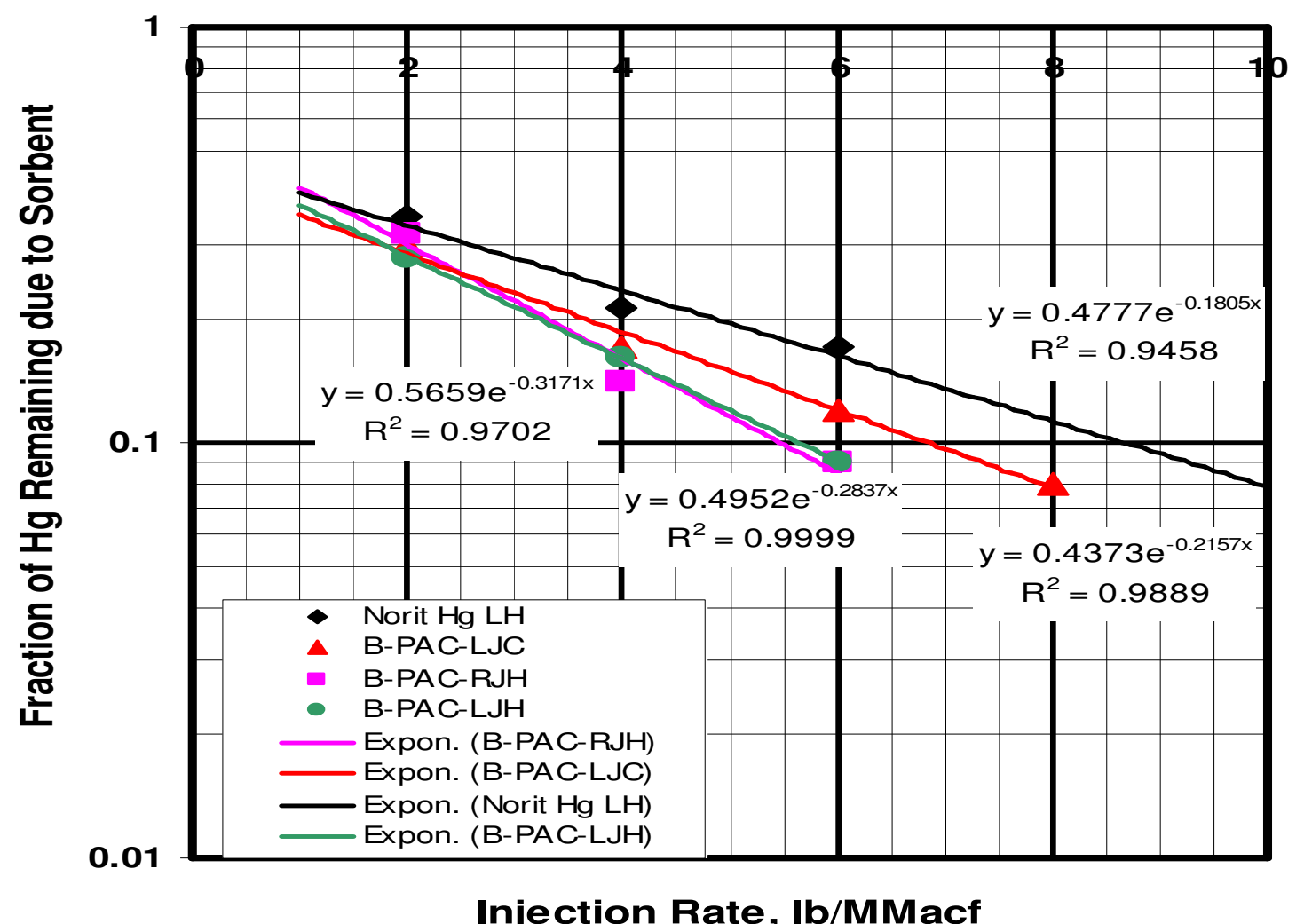

The impact of C-PAC ${ }^{\mathrm{TM}}$ on the properties of concrete was investigated by Lafarge, the seller of the Midwest Generation fly ash, Albemarle Environmental $\mathrm{f} / \mathrm{k} / \mathrm{a}$ Sorbent Technologies and Headwaters Resources, a project partner. The properties evaluated included the concrete air content, air stability, air distribution, setting time, and strength. C-PAC ${ }^{\mathrm{TM}}$ does not appear to deleteriously affect any of the important properties of concrete. It may even improve some properties.

The finding that C-PAC ${ }^{\mathrm{TM}}$ does provide high levels of mercury removal without impacting the fly ash cement properties is a milestone in this project.

At Crawford 7, the opacity would increase $3 \%$ to $5 \%$ over a period of hours from the time that the boiler first reached high load first reached until the boiler load was reduced at night. For the parametric test, the opacity dropped when the C-PAC ${ }^{\mathrm{TM}}$ was turned on or when the injection rate was increased. As the long-term test progressed, the opacity for each successive period was lower than the previous one.

The opacity trends for different time periods during the long-term trial are shown in the next figure. 


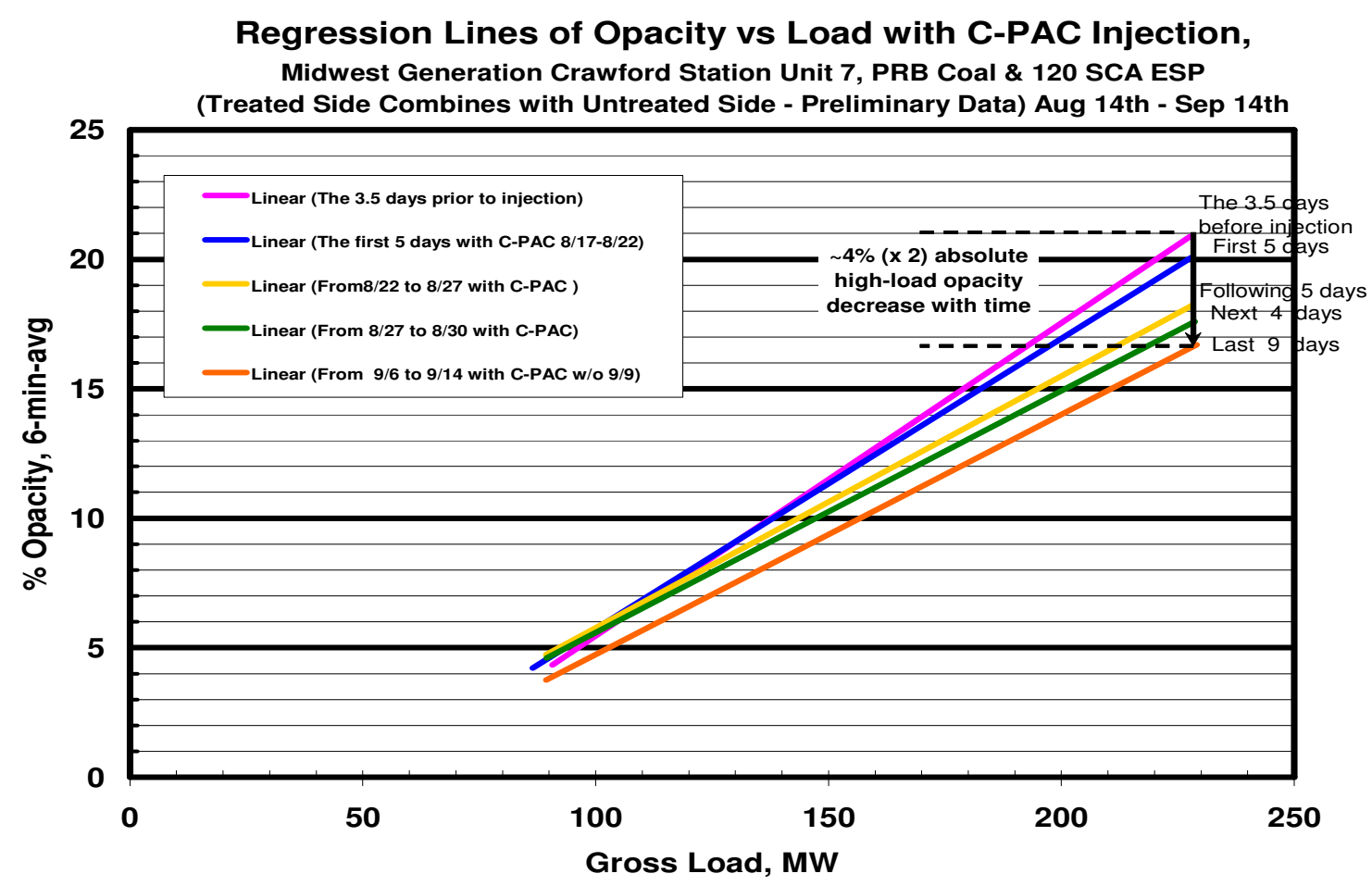

The end of the test the opacity at full load was averaging about $8 \%$ below that before the injection began.

This phenomenon of reducing opacity because of B-PAC ${ }^{T M}$ or C-PAC ${ }^{T M}$ injection was seen previously at the Progress Energy Lee Station, where the boiler could only operate without $\mathrm{SO}_{3}$ injection during the continuous injection of $\mathrm{B}-\mathrm{PAC}{ }^{\mathrm{TM}}$.

The third host site was Midwest Generation Will County Unit 3. The duration of the testing at the Will County Station was reduced from that originally planned, due to a reduction in DOE funding. The biggest changes were the shortening of the baseline period and the switch from a long-term 30-day test to a short continuous injection run that lasted only a few days. The parametric tests before and after the continuous run were essentially unchanged. The mercury measurements were all made using monitors. No OHM Hg measurements were made.

The first phase of the parametric injection tests used only one sorbent (the high temperature version of C-PAC ${ }^{\mathrm{TM}}$ ) but different injection lances. Regular lances were used in the first day of this phase of testing and the X-a-Lances on the second day. The $\mathrm{X}$-a-Lances were designed to provide better sorbent distribution in ducts with poor geometries and/or short residence times. The mercury removal results from the first phase of the parametric injection tests are shown in the next figure. 


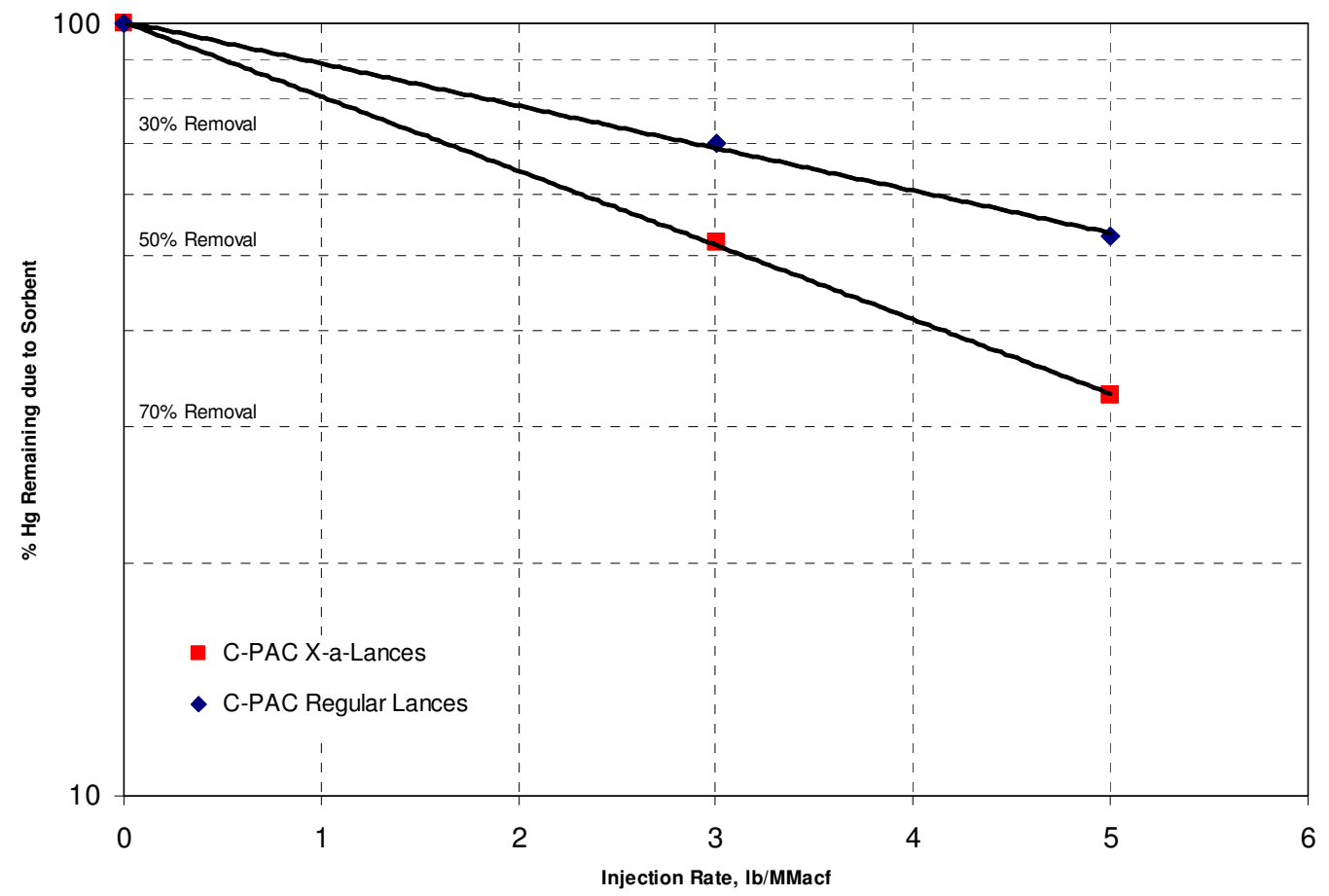

The injection of the high temperature version of C-PAC ${ }^{\mathrm{TM}}$ with regular injection lances provided mercury removal rates of about $30 \%$ and $45 \%$ due to sorbent at the injection rates of 3 and $5 \mathrm{lb} / \mathrm{MMacf}$, respectively. This is very good performance considering that the injection temperature is about $700^{\circ} \mathrm{F}$ at full load. However, the same sorbent at the same injection rates provided mercury removal rates of about $50 \%$ and $67 \%$ when the $\mathrm{X}$-a-Lances were utilized. This is an improvement of about $50 \%$ relatively. As a result of these findings, the $\mathrm{X}$-a-Lances were used for the rest of the test program.

Albemarle Environmental f/k/a Sorbent Technologies was interested in discovering which was more important in generating a good high temperature sorbent: the base carbon or the method of bromination. Therefore, plain Norit $\mathrm{Hg}$ was brominated at Albemarle Environmental $\mathrm{f} / \mathrm{k} / \mathrm{a}$ Sorbent Technologies using our patented gas-phase bromination process. Plain Norit $\mathrm{Hg}$ has been used as the baseline sorbent for many mercury test programs. The sorbent produced from the gas-phase bromination of Norit $H G$ is entitled H-PAC3.

It was already known that the standard H-PAC ${ }^{T M}$ (H-PAC1) greatly outperforms the saltimpregnated Norit $\mathrm{Hg}$ LH sorbent. These two sorbents have different base carbons and different bromination methods. This test was devised so that two of the sorbents (H-PAC1 and H-PAC3) were produced by the same method, gas-phase bromination.

The mercury removal results of H-PAC1, H-PAC3, and salt-impregnated Norit $\mathrm{Hg} \mathrm{LH}$ are presented in the next figure. 


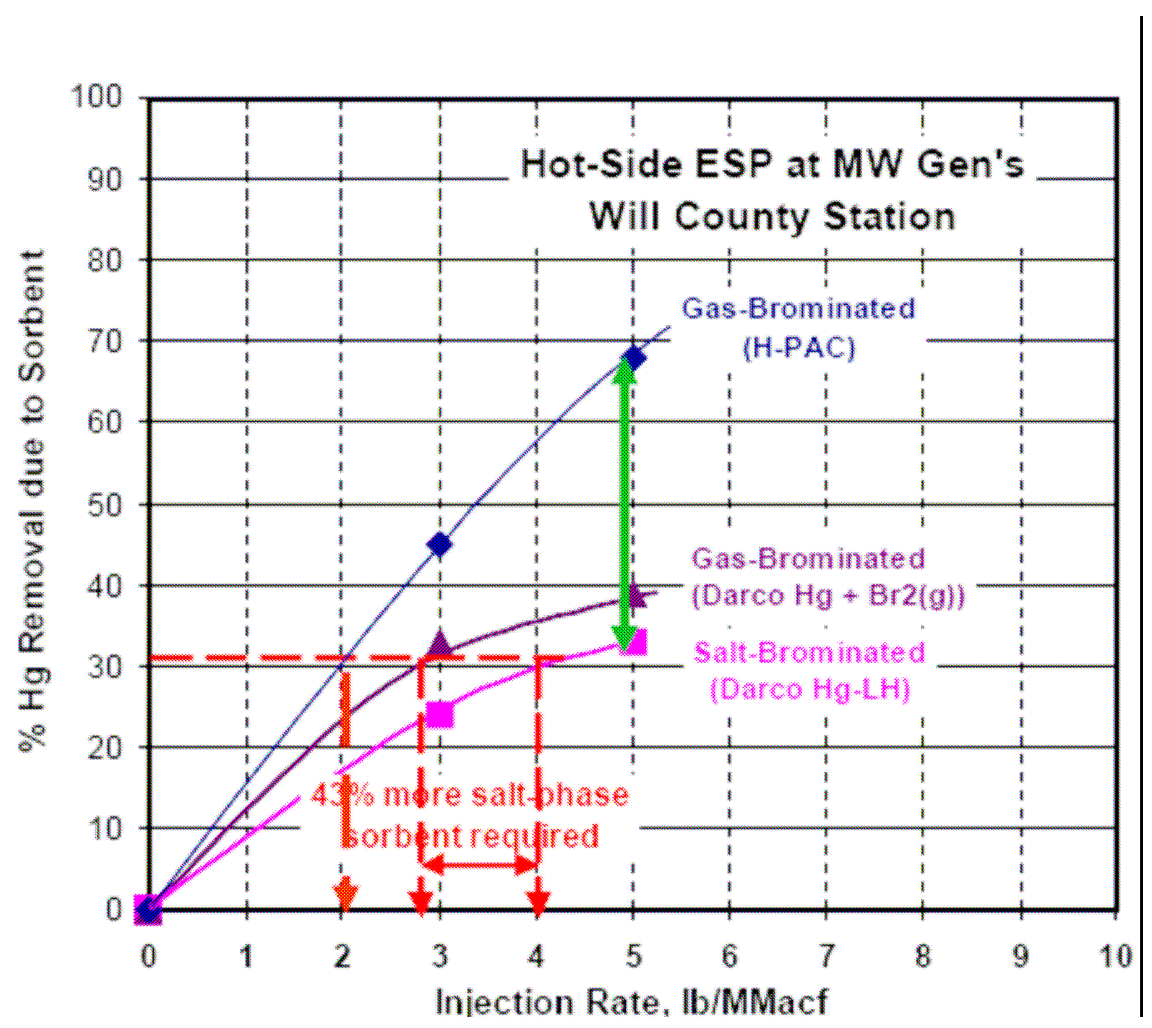

The gas-phase brominated Norit $\mathrm{Hg}(\mathrm{H}-\mathrm{PAC} 3)$ performed better than did the saltimpregnated Norit $\mathrm{Hg} \mathrm{LH}$ but worse that the standard H-PAC1. The performance of the three sorbents can only be compared at low mercury removal levels since the Norit $\mathrm{Hg}$ $\mathrm{LH}$ only achieved a maximum of $33 \%$ removal at an injection rate of $5 \mathrm{lb} / \mathrm{MMacf}$. In order to achieve a mercury removal rate of $33 \%$, an injection rate of about $4 \mathrm{lb} / \mathrm{MMacf}$ of Norit $\mathrm{Hg} \mathrm{LH}$ was required compared to injection rates of $2.8 \mathrm{lb} / \mathrm{MMacf}$ for H-PAC3 (gasphase brominated Norit $\mathrm{Hg}$ ) and $2.0 \mathrm{lb} / \mathrm{MMacf}$ of $\mathrm{H}-\mathrm{PAC} 1$ in order to achieve the same $30 \%$ mercury removal rate.

From these results, it is clear that gas-phase bromination is responsible for part of the improved mercury removal performance compared to the salt-impregnated Norit $\mathrm{Hg} \mathrm{LH}$ but that the base PAC selection appears to have a great impact. 
[This page intentionally blank.] 


\section{EXPERIMENTAL}

\section{HOST SITES}

Brief descriptions of each the three host sites are provided below.

\section{Progress Energy H.F. Lee Station}

The Progress Energy H.F. Lee Station was the first host site covered by this project at which tests were conducted. This plant is located in Goldsboro, North Carolina, and is shown in Photograph 1.

\section{Photograph 1. Progress Energy H.F. Lee Station}

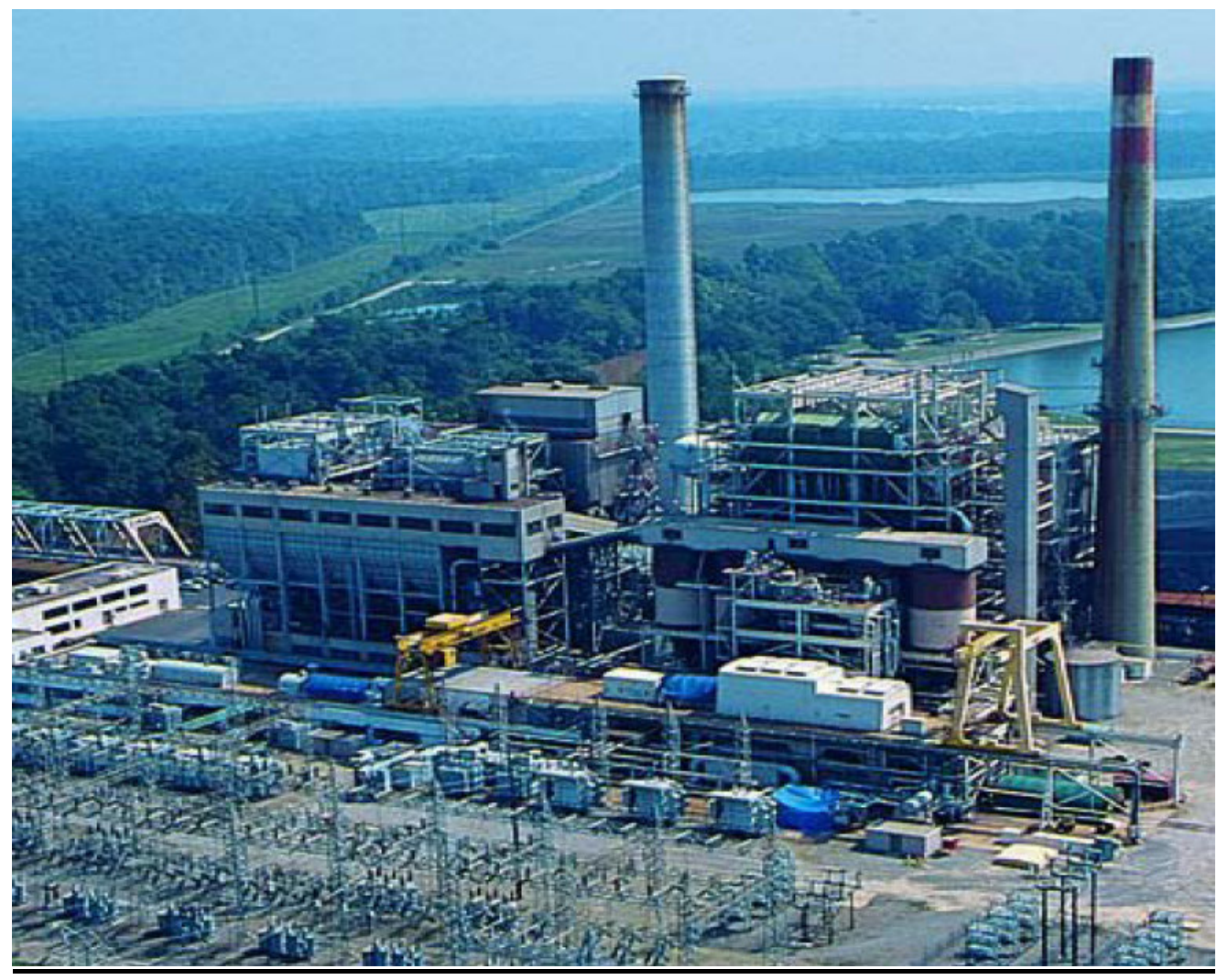

Lee Unit 1, on which the testing was performed, is the first unit on the left. This boiler was built in 1952 and has a capacity of $79 \mathrm{MW}$. The boiler is not base loaded but has an operating factor of about $56 \%$. The boiler is tangentially fired and uses low sulfur $(\sim 0.8 \%$ as received) bituminous coal from the Eastern United States. The coal is typical of bituminous coal and contains, on an as received basis, approximately $10 \%$ ash, $7 \%$ moisture, $1500 \mathrm{ppm}$ of chlorine, $12,500 \mathrm{Btu} / \mathrm{lb}$ and $0.07 \mathrm{ppm}$ of mercury. The unit is not equipped for $\mathrm{SO}_{2}$ or $\mathrm{NO}_{x}$ control. A cold-side ESP with an SCA of 329 is used for particulate control. The inlet temperature to the ESP is generally less than $300^{\circ} \mathrm{F}$, while the flue gas flow rate is about 300,000 acfm at full load. $\mathrm{SO}_{3}$ injection is used to condition the fly ash to improve ESP performance. The fly ash contains more than the maximum LOI limit of $5 \%$ for use in concrete and, therefore, it is not sold. 


\section{Midwest Generation Crawford Station}

The second host site was the Midwest Generation Crawford Station located in Chicago, Illinois. The Crawford Plant is shown in the Photograph 2.

\section{Photograph 2. Midwest Generation Crawford Station}

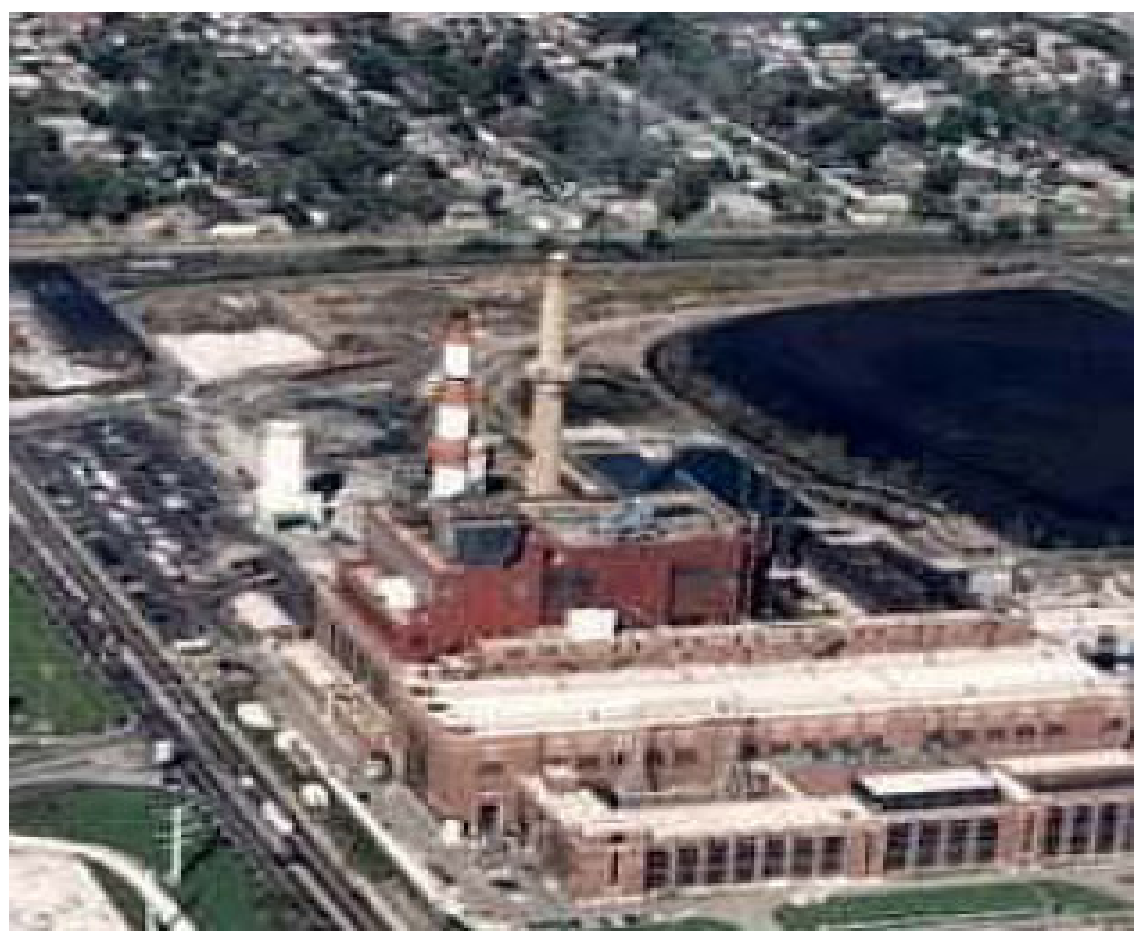

Two boilers with separate ductwork and ESPs are used in combination to perform the function of one boiler at Crawford. One boiler is used to preheat the steam while the other superheats it. Both boilers are fired at the same rate. The tests at Crawford were focused on the combined boilers named Crawford 7. They were commissioned in 1958. Crawford 7 is tangentially fired with a capacity of $234 \mathrm{MW}$. The testing was on essentially half of this capacity or $117 \mathrm{MW}$. The boilers are not base-loaded but have an operating factor of about $50 \%$.

The boilers fire PRB coal with an as received moisture, ash and sulfur contents of about $28 \%, 5 \%$ and $0.3 \%$, respectively. The as received heat content of the coal is about 8500 $\mathrm{Btu} / \mathrm{lb}$. The mercury content of the coal is about $0.10 \mathrm{ppm}$. The boilers are equipped with low $\mathrm{NO}_{x}$ burners designed to keep the $\mathrm{NO}_{x}$ below $0.13 \mathrm{lb} / \mathrm{MMBtu}$ heat input.

Each ESP is small with an SCA of only 118. The inlet temperature to the ESPs is about $310^{\circ} \mathrm{F}$. The flue gas flow rate to each ESP is approximately $460,000 \mathrm{acfm}$. A dry ash removal system is used since most of the fly ash is sold and, thus, C-PAC ${ }^{\mathrm{TM}}$ was the main sorbent used at this plant. Other, non-concrete friendly sorbents were tested in a short parametric program after the long-term test was completed. The period during which non-concrete friendly sorbents was tested in order to limit the amount of fly ash that would be impacted and could not be sold for use in cement. 


\section{Midwest Generation Will County Station}

The third host site was the Midwest Generation Will County Station. The plant is located in Romeoville, Will County, Illinois, just outside of Chicago. The station is shown in Photograph 3.

\section{Photograph 3. Midwest Generation Will County Station}

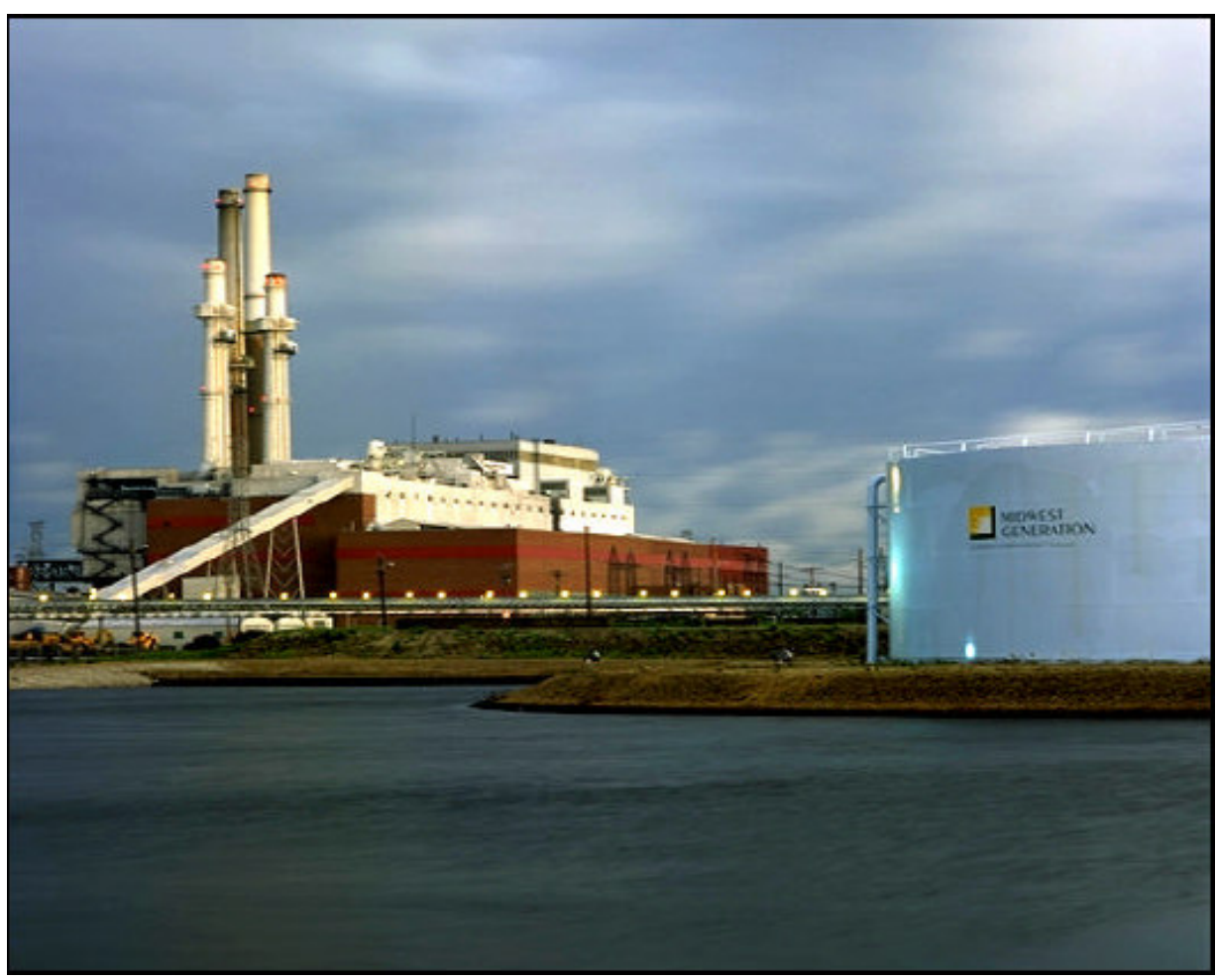

Two boilers are combined to form one at this plant also, as it was at the Crawford Plant. The tests will be performed on the boilers named Will County 3. They were commissioned in 1955 and are identical to the boilers at Crawford 7, except that they use hot-side ESPs for particulate control. Will County 3 is tangentially fired with a capacity of $278 \mathrm{MW}$. The testing was performed on essentially half of this capacity or $139 \mathrm{MW}$. The boilers are not base-loaded but have an operating factor of about $50 \%$.

The boilers fire the same PRB coal as used at the Crawford Plant. The boilers are equipped with low $\mathrm{NO}_{x}$ burners and each boiler has a hot-side ESP with an SCA of 233. The inlet temperature to the ESPs varies between $550^{\circ} \mathrm{F}$ and $700^{\circ} \mathrm{F}$, depending upon load. The flue gas flow rate to each ESP is approximately 500,000 acfm at full load. A dry ash removal system is used since most of the fly ash is sold. The high temperature version of C-PAC ${ }^{\mathrm{TM}}$ was the primary sorbent used in this test although other nonconcrete friendly sorbents were tested in a parametric program after the continuous injection run.

\section{PILOT-SCALE DUCT-INJECTION SYSTEM}

Albemarle Environmental $\mathrm{f} / \mathrm{k} / \mathrm{a}$ Sorbent Technologies Corporation's duct-injection system tests mercury sorbents in the actual in-flight mode. This system was in operation for a 
number of years before the DOE project began. The system is used to screen new sorbents and provide quality control for those produced in the Sorbent Production System.

The installed components included a:

- Humidifier/cooler;

- Insulated pipe "ducting" to provide sorbent residence time and wall contact area;

- Sorbent feeding system to accurately feed at very low rates without agglomeration; and

- Cold-Side ESP (without rapping) to remove any sorbent from the sample stream.

A diagram of the duct-injection system is presented in Figure 1. The system is also shown in Photographs 4 and 5.

Figure 1. Diagram of the Duct-Injection System

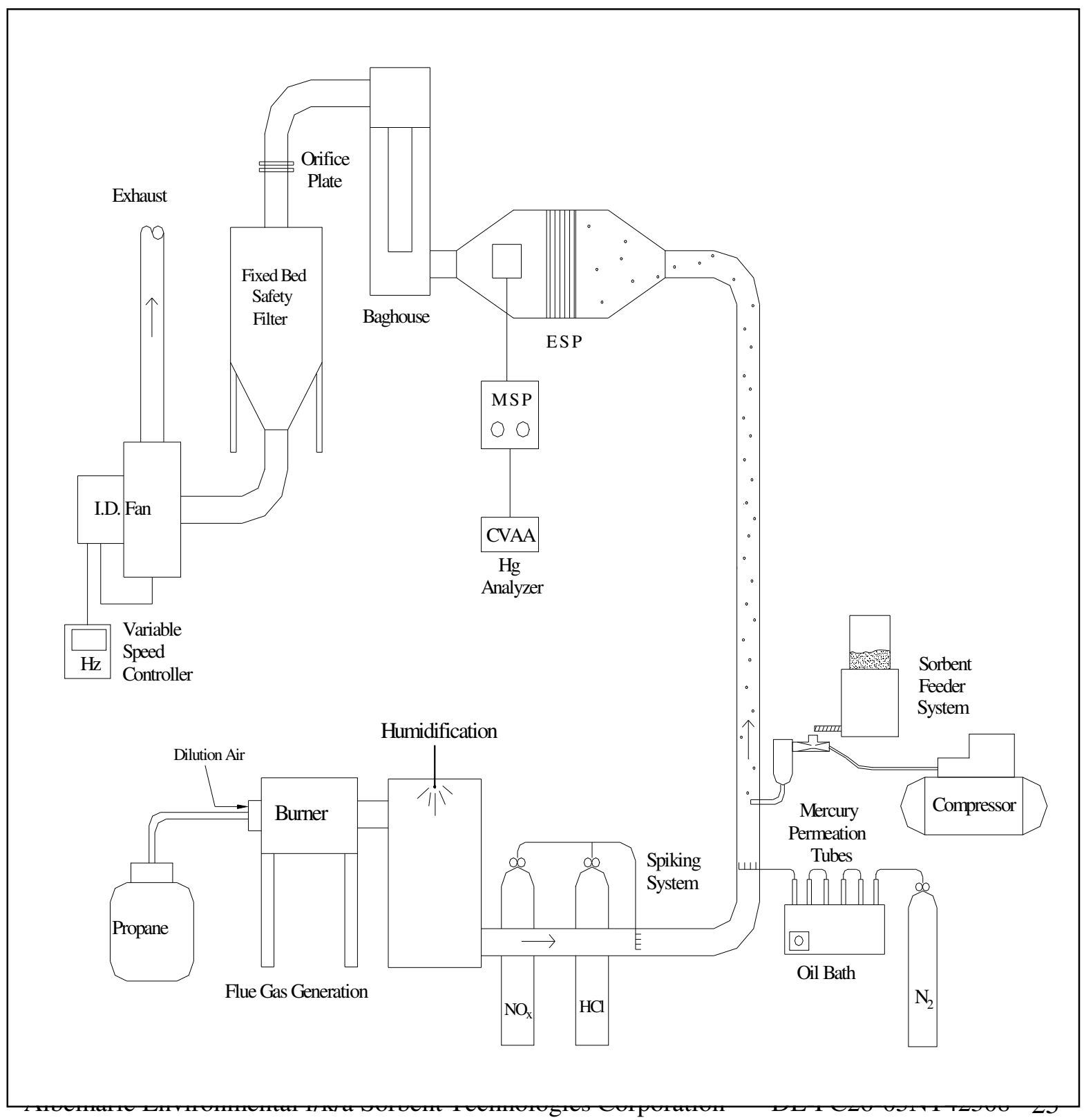


The following operating parameters are typically utilized in the duct-injection system:

- Flow Rate:

- Sorbent residence time:

- $\mathrm{Hg}$ concentration:

- $\mathrm{SO}_{2}$ concentration:

- $\mathrm{NO}_{\mathrm{x}}$ concentration:

- $\mathrm{HCl}$ concentration:

- $\mathrm{H}_{2} \mathrm{O}$ concentration:

- Temperature at injection point:

- Temperature at outlet sampling point:
55 to $60 \mathrm{acfm}$

$2-2.5$ seconds

$22-26 \mu \mathrm{g} / \mathrm{Nm}^{3}$

variable up to $1400 \mathrm{ppmv}$ variable up to $600 \mathrm{ppmv}$ variable up to $50 \mathrm{ppmv}$

$4 \mathrm{wt} \%, 6.5$ vol\% $330 \pm 10^{\circ} \mathrm{F}$ $270 \pm 10^{\circ} \mathrm{F}$

The duct-injection system provides a simulated flue gas comparable to that from a coal fired boiler, with the exception of fly ash. An Ohio Lumex Zeeman-corrected mercury analyzer has been adapted by its manufacturer for use in monitoring the gas-phase mercury concentrations in the system.

Photograph 4. View of the Duct-Injection System

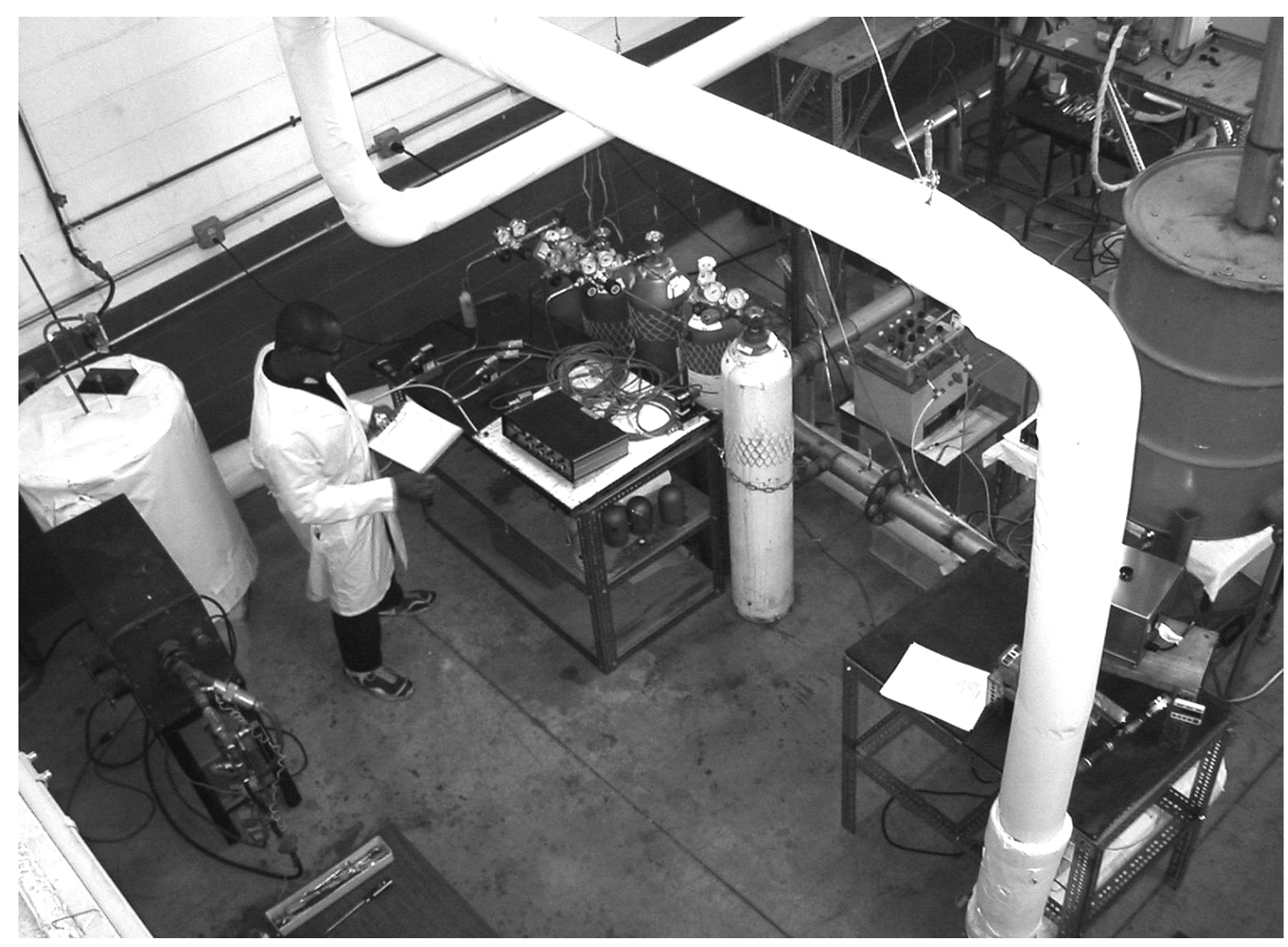




\section{Photograph 5. Analytical Portion of the Duct-Injection System}

(ESP Top Right)

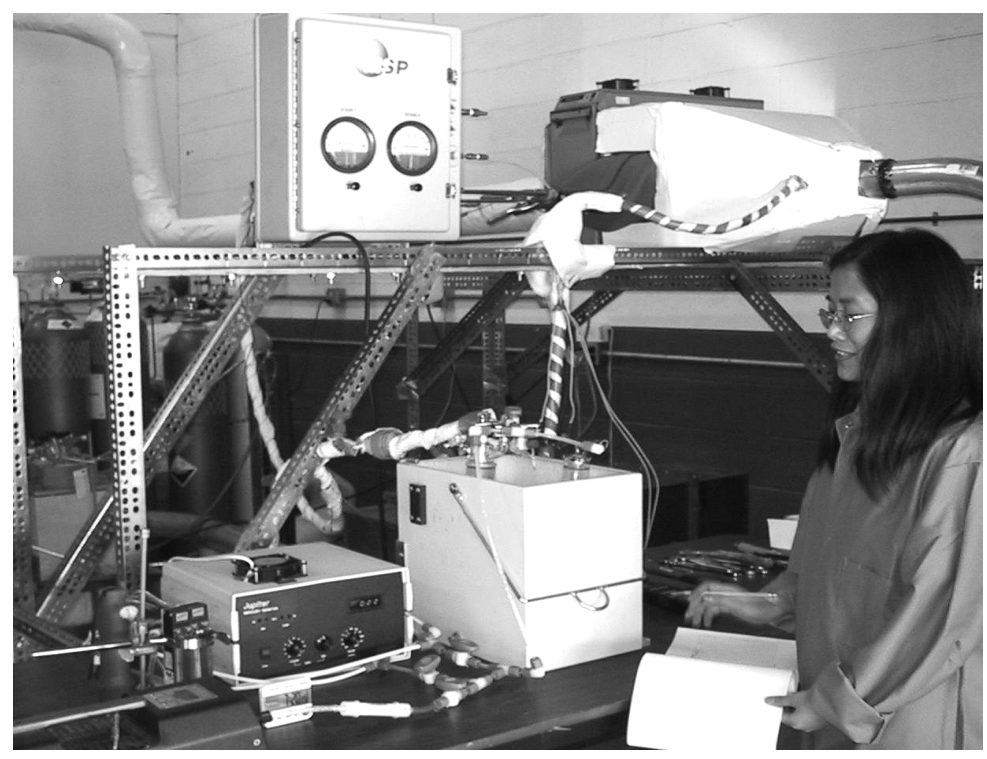

Norit Darco FGD PAC (now Norit Darco Hg) was tested in the duct-injection system to provide a yardstick for mercury removal comparisons with system to performance to that observed in full-scale field tests. The mercury removal results for the Norit Darco FGD PAC in the duct-injection system and two full-scale field trials are presented in Figure 2.

Figure 2. Pilot Duct-Injection System Hg Removal Results Plotted with the Results from Brayton Point and Pleasant Prairie

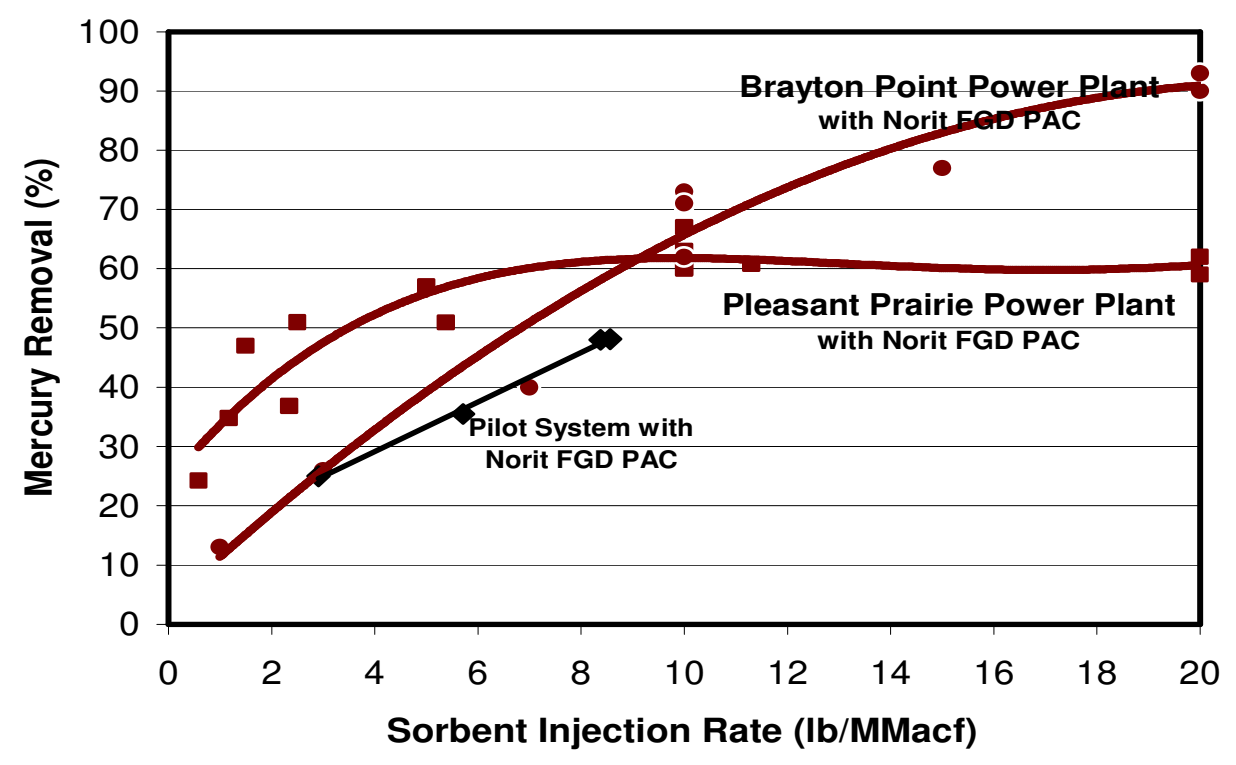


The mercury removal results using the same plain PAC sorbent that was used in the earlier Brayton Point and Pleasant Prairie full-scale tests are presented in Figure 2 for comparison purposes. The mercury removal results from the duct-injection system are slightly below those achieved in the two full-scale tests. It is believed that the difference is due, in large part, to the added mercury removal that comes from the build-up of sorbent deposits as full-scale tests continue. These deposits have been found to provide as much as $10 \%$ extra mercury removal. The Albemarle Environmental $\mathrm{f} / \mathrm{k} / \mathrm{a}$ Sorbent Technologies' duct-injection system is not operated long enough to allow for the build-up of deposits. Any sorbent remaining in the pilot system after a run is either removed or saturated with mercury so that it will not have any impact on the next test. Still, the duct-injection system does provide results comparable to full-scale tests.

\section{SORBENT INJECTION SYSTEM}

The functions of the sorbent injection system are:

1. To provide for sorbent loading to day storage hopper from either super sacks or pneumatic trucks.

2. To deliver the sorbent from the day hopper to a feeder system hopper.

3. To gravimetrically feed sorbent at selected rates into an eductor system.

4. To provide dilute phase conveying of the sorbent through the sorbent distributor and to the injection lances.

The operating principals behind the sorbent injection system are the same as have been used in other full-scale mercury sorbent injection trials. These injection systems are based upon dilute phase injection, as is this one. The only significant change is that, for the sake of feeding accuracy, gravimetric control is used instead of volumetric control. The bulk density of PAC based sorbents varies greatly causing the injection rate to vary in volumetrically controlled systems. The gravimetric design of this injection system overcomes this issue. The layout of the Albemarle Environmental $\mathrm{f} / \mathrm{k} / \mathrm{a}$ Sorbent Technologies sorbent injection system is shown in Figure 3.

Figure 3. Diagram of the Sorbent Injection System

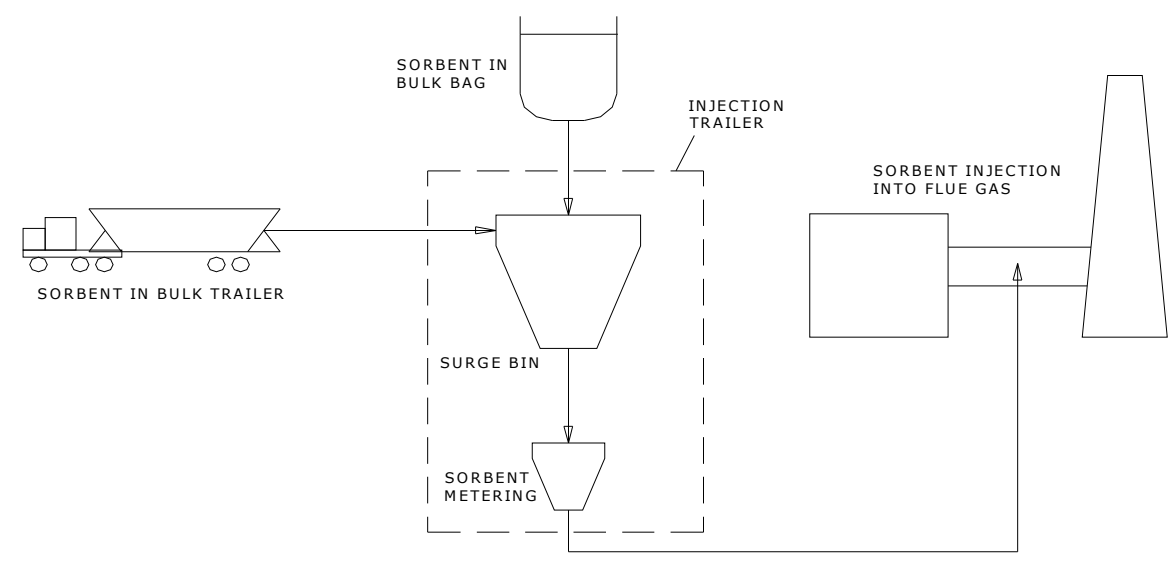


The day storage hopper, feeder hopper, gravimetric feeder and eductor are all enclosed in a trailer. A bin vent filter is provided to capture any dust generated by material handling. This filter is located on top of the day hopper. Blowers are used to provide the air flow necessary to convey the sorbent from a tanker to the day storage hopper and to convey the sorbent from the feeder to the injection lances. The first of these blowers is located outside of the trailer. All controls for the operation of the injection system are in an isolated area within the trailer. An inside view of the injection trailer is presented in Photograph 6.

\section{Photograph 6. Sorbent Injection Trailer}

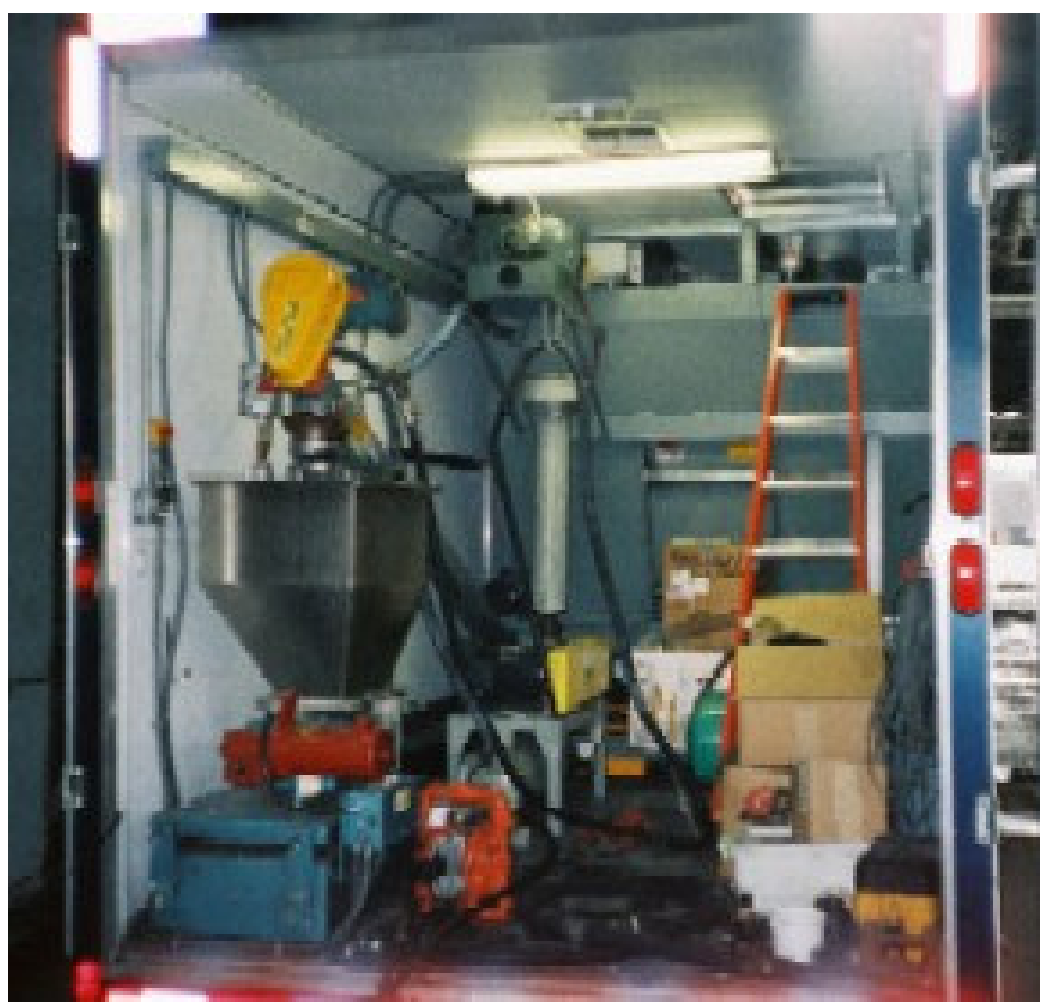

The injection system was designed with the ease of installation and disassembly in mind. Only electricity and injection ports are required from the host site to support its operation. Most of the key components are installed in a movable trailer. The injection system was designed to have a sorbent injection rate range from as low as $15 \mathrm{lb} / \mathrm{hr}$ to a high of over $600 \mathrm{lb} / \mathrm{hr}$. In this manner, the same injection system was used at the all three of the host sites.

\section{MERCURY MONITORING INSTRUMENTS}

The mercury continuous emission monitors (CEMs) are from PS Analytical and Ohio Lumex. The equipment includes three semi-continuous mercury emission monitors, two wet/dry mercury conversion modules and four inertial sampling probes. Also used for mercury monitoring are two Method 324/Appendix K sorbent trap samplers. 


\section{Flue Gas Sampling}

The flue gas sample and particulate matter must be separated before the sample enters the analysis train. The Baldwin Model 3300 inertial separator was one of the separators used in this program. A diagram of the device is shown in Figure 4.

Figure 4. Diagram of Baldwin Inertial Separator

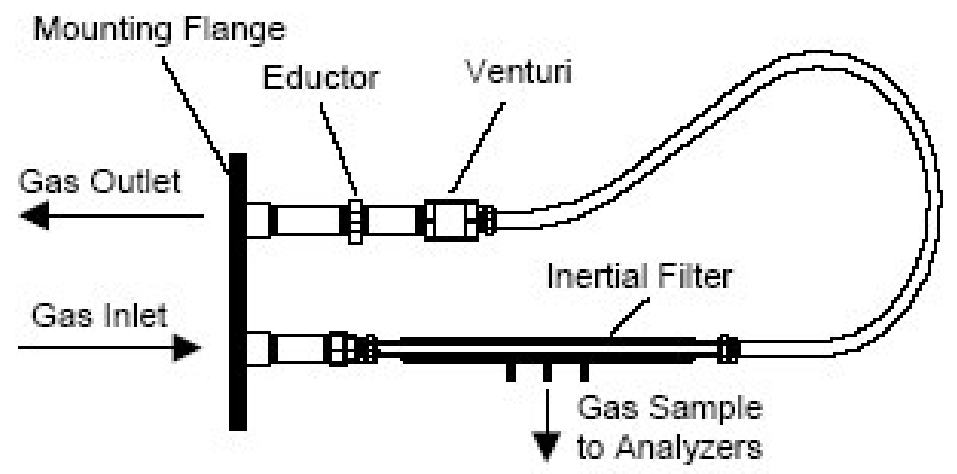

Flue gas is drawn into the system by means of an eductor. The flow rate is measured by a Venturi meter and adjusted to provide an axial gas flow through the inertial separator of 70 to 100 feet per second. A gas sample is extracted at a low inertial filter face velocity of 0.006 feet per second. The particulate matter follows the gas streamline and is thus separated from the gas sample. The gas removed from the duct is returned after use. The entire inertial separator is in an enclosure and maintained at $400^{\circ} \mathrm{F}$ to avoid any condensation issues.

The conventional design Apogee QSIS probes were also used in these tests. These probes work on the same principle as the Baldwin probe.

\section{Mercury CEMs}

The sample gas was conveyed through a heated line from the inertial separator to the conversion module where the oxidized mercury species were either converted to elemental mercury in order to provide a total gas phase mercury measurement or removed from the gas to allow for the measurement of elemental mercury. The PS Analytical mercury conversion modules can operate in the traditional wet chemistry method, as well as by a new, parallel dry method. The dry system uses a thermolytic converter to convert the oxidized mercury to elemental. The conversion modules could be operated in the wet mode, the dry mode or alternating back and forth.

A diagram of the dry conversion process is shown in Figure 5. 
Figure 5. Diagram of the PS Analytical Dry Conversion Process

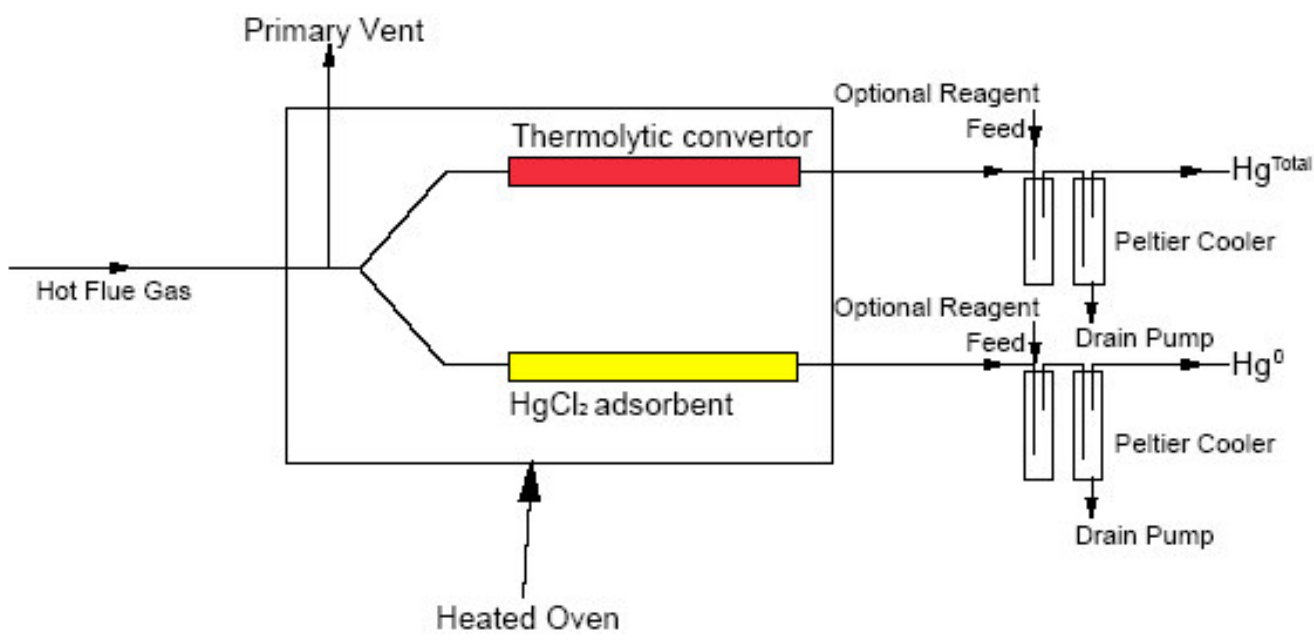

The wet/dry mercury conversion modules used in this project were Serial Numbers 001 and 002. One of the wet/ dry conversion modules is shown in Photograph 7.

Photograph 7. PS Analytical Wet/Dry Mercury Conversion Module

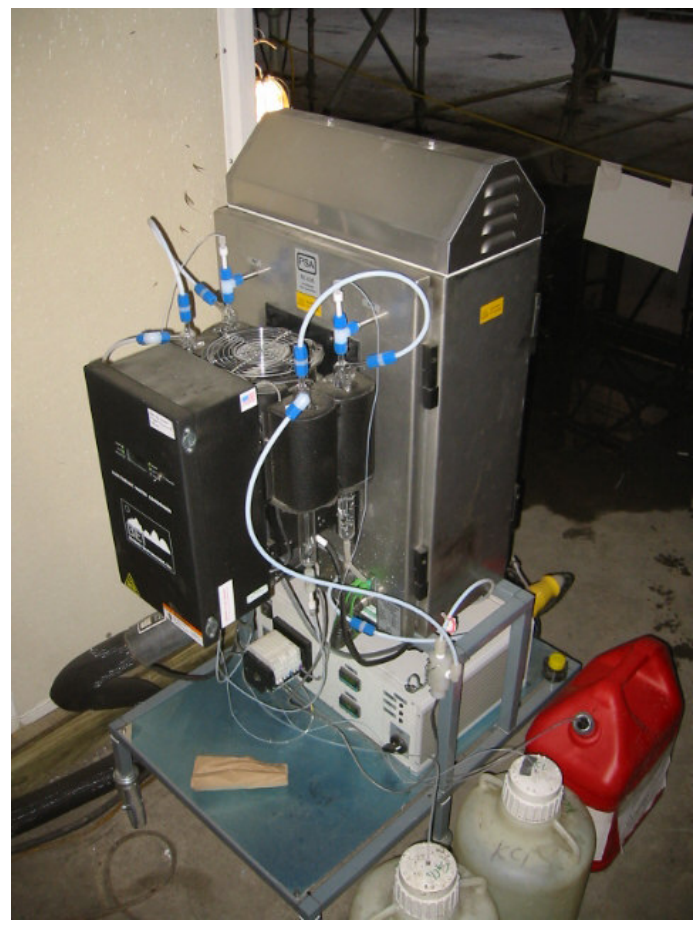

The dry conversion process is being developed to eliminate two of the main problems associated with mercury CEMs; wet chemicals and their wastes. 
The gas from the mercury conversion module was directed to a PS Analytical Sir Galahad II EX mercury analyzer. The gas sample is drawn across a gold trap on which the mercury is collected. After a prescribed sampling time, the trap is heated in order to release the mercury which is measured by atomic fluorescence. The system is calibrated at least once per day using mercury standards. The analyzer provides one mercury measurement every five minutes, thus it is a semi-continuous emission monitor. If both elemental and oxidized mercury are being analyzed, repeat measurements are ten minutes apart.

In addition to the PS Analytical instruments, an experimental version of the Ohio Lumex mercury CEM was also tested. This monitor is the field version of the laboratory instrument which has been widely used to measure mercury in solid and liquid samples.

The instrument is shown in Photograph 8.

\section{Photograph 8. Ohio Lumex Mercury CEM}

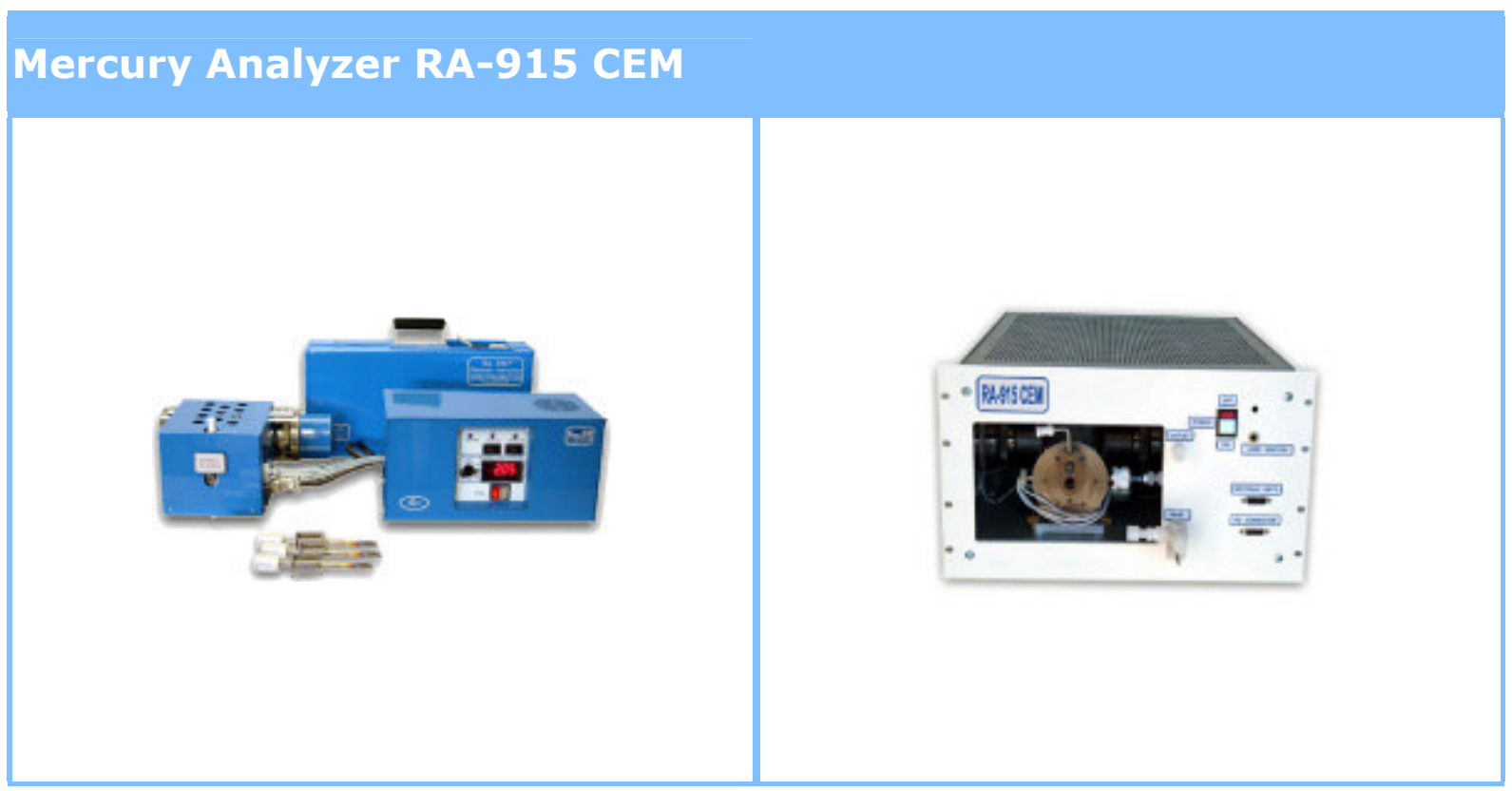

The instrument is based upon thermo-catalytic conversion and cold vapor atomic absorption spectroscopy with Zeeman background correction. The instrument, in its current configuration, can only be used to measure total vapor phase mercury and has $\mathrm{Hg}$ measurement sensitivity of $\sim 100 \mathrm{ng} / \mathrm{Nm}^{3}$. The instrument has several potential major advantages over conventional $\mathrm{Hg}$ semi-continuous monitors (SCEMs). First, the instrument does not require any chemicals and does not produce any wastes, as the conversion of oxidized mercury to elemental mercury is performed catalytically. Second, the instrument is much closer to a true continuous emission monitor (CEM), since it provides a measurement every 15 seconds rather than every five minutes as do the gold trap mercury monitors. Finally, there are fewer parts to install and maintain.

Western Kentucky University, a project partner, provided the personnel to operate the mercury CEMs during the tests at the Lee Station and the Crawford Station. STC 
personnel operated the monitors during the testing at Will County. The mercury data collected was all corrected to $3 \%$ oxygen.

\section{Appendix K Testing}

An Appendix $\mathrm{K}$ mercury trap sampler was also used in these tests. These dual trap mercury samplers are replacing the single trap Method 324 samplers in current use. The Environmental Supply Inc. instrument is shown in the Photograph 9.

\section{Photograph 9. Appendix K Sorbent Trap Sampler}

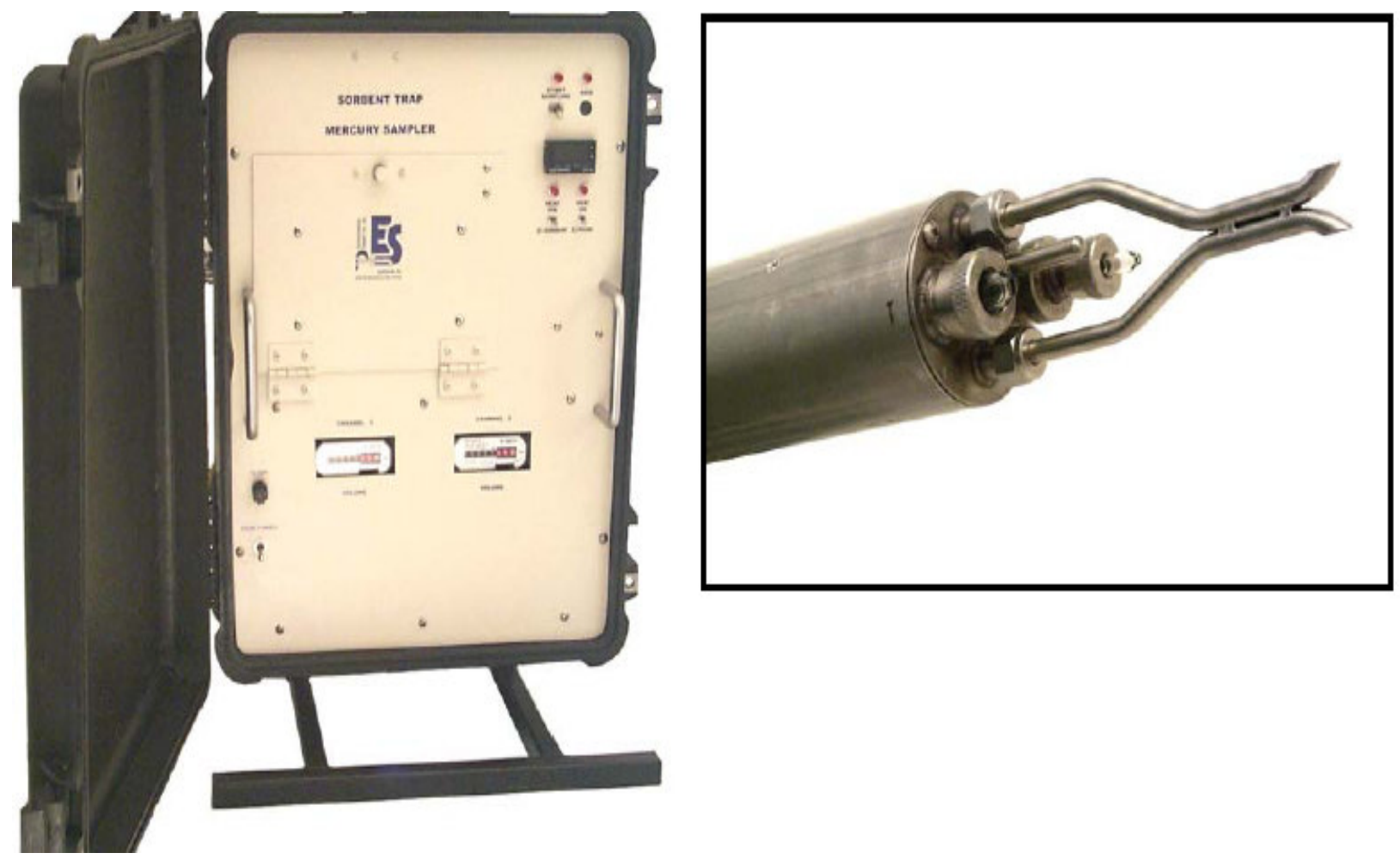

The sampler has proportional flow control to allow for the sampling of flue gas over an extended period during which time the boiler is changing load and flue gas flow rate. The instrument is designed with a removable flash memory card for storing operating programs and data files.

\section{Coal and Fly Ash Mercury Analyses}

Coal and fly ash samples were taken throughout the baseline, parametric, and long-term testing at the power plants. The coal samples were analyzed for mercury in the utility laboratories or by SGS NA using ASTM techniques.

The fly ash samples were analyzed for mercury by Albemarle Environmental $\mathrm{f} / \mathrm{k} / \mathrm{a}$ Sorbent Technologies using an Ohio Lumex Model RA-915+ Mercury Analyzer (Photograph 10). 


\section{Photograph 10. Ohio Lumex Model RA-915+ Mercury Analyzer}

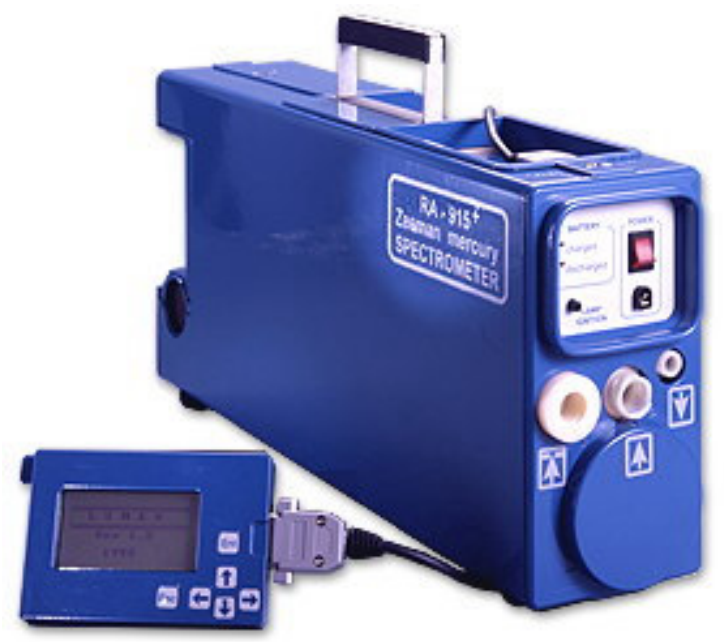

The Ohio Lumex mercury analyzer is an atomic absorption spectrometer with Zeeman background correction. The Zeeman background correction eliminates the need for gold traps to concentrate the mercury. The instrument is calibrated with NIST standards and has a detection limit of $500 \mathrm{ng} / \mathrm{Kg}$.

\section{$\underline{\text { OHM Testing }}$}

The Ontario Hydro Method (OHM) mercury testing was contracted to URS Corporation for the program at the Progress Energy Lee Station and to GE Energy for the program at the Midwest Generation Crawford Station. These companies provided the lowest bid in response to a Request for Proposal covering this testing. There were no OHM tests performed at the Midwest Generation Will County Station due to budgetary constraints.

The sampling followed the procedures set forth in the Code of Federal Regulations, Title 40, Chapter I, Part 60, Appendix A, Methods 1, 2, 3B, 4 and 5, and the Ontario Hydro Method, revised July 7, 1999. Simultaneous triplicate two- hour tests were performed at the gas "inlet" (before the sorbent Injection) and "outlet" locations.

Method 26A tests for halogens in the flue gas were also performed on the flue gas from the Lee and Crawford Stations. 


\section{SORBENT PRODUCTION SYSTEM}

Albemarle Environmental $\mathrm{f} / \mathrm{k} / \mathrm{a}$ Sorbent Technologies manufacturers all of its sorbents in its facility located in Twinsburg, Ohio.

A general diagram of the sorbent preparation system is shown in Figure 6.

Figure 6. Diagram of the Sorbent Production System

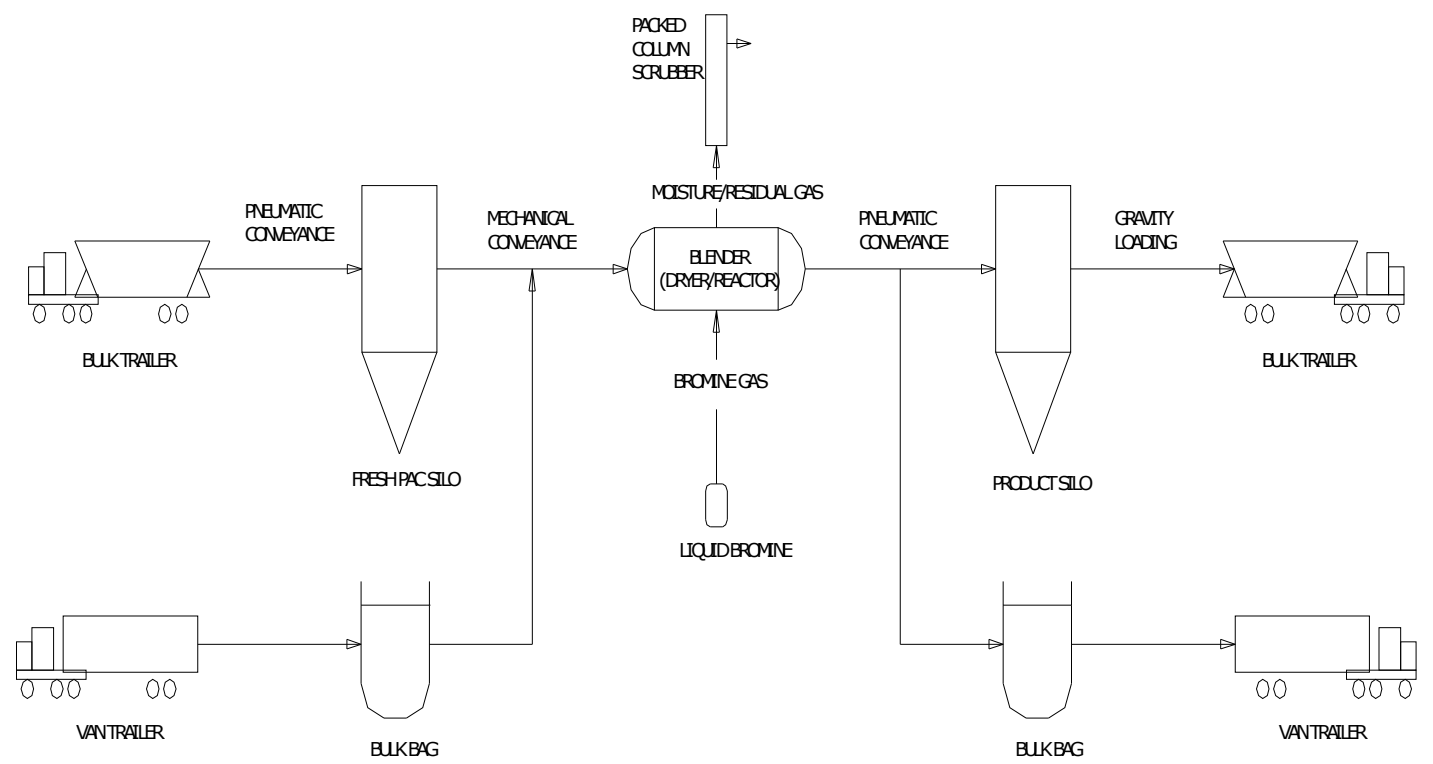

The sorbent production system was developed by Albemarle Environmental $\mathrm{f} / \mathrm{k} / \mathrm{a}$ Sorbent Technologies through over seven years of experimentation prior to the DOE demonstration projects. The detailed operation of the system is proprietary and is covered by a patent ${ }^{(1)}$, however, the concept is fairly simple. Albemarle Environmental $\mathrm{f} / \mathrm{k} / \mathrm{a}$ Sorbent Technologies' sorbents (trademarked B-PAC ${ }^{\mathrm{TM}}$ ) are powdered activated carbons (PACs) which have been processed through a bromine treatment to greatly enhance their mercury performance and cost-effectiveness.

The substrate PAC can be received by either super sack or bulk tanker and the processed B-PAC ${ }^{\mathrm{TM}}$ can be shipped to the power plant in either super sacks or by bulk tanker. This dual material handling capability is necessary to facilitate the smaller quantities of several sorbents that are required during the parametric testing portions of the program and the larger quantities that are required of a single sorbent during the long-term tests and commercial applications.

The PAC from either the fresh storage silo or a super sack is conveyed mechanically to the bromination reactor. The plain PAC is reacted with bromine in this device. The finished sorbent is conveyed pneumatically either to a finished-product silo before loading into a bulk tanker or into super sacks and into a van trailer for shipment to the test sites. 
A truckload of PAC is shown being unloaded into the raw material silo in Photograph 11. The elevated product silo used for filling tanker trucks is in the background.

\section{Photograph 11. PAC being Unloaded at the Sorbent Production Facility}

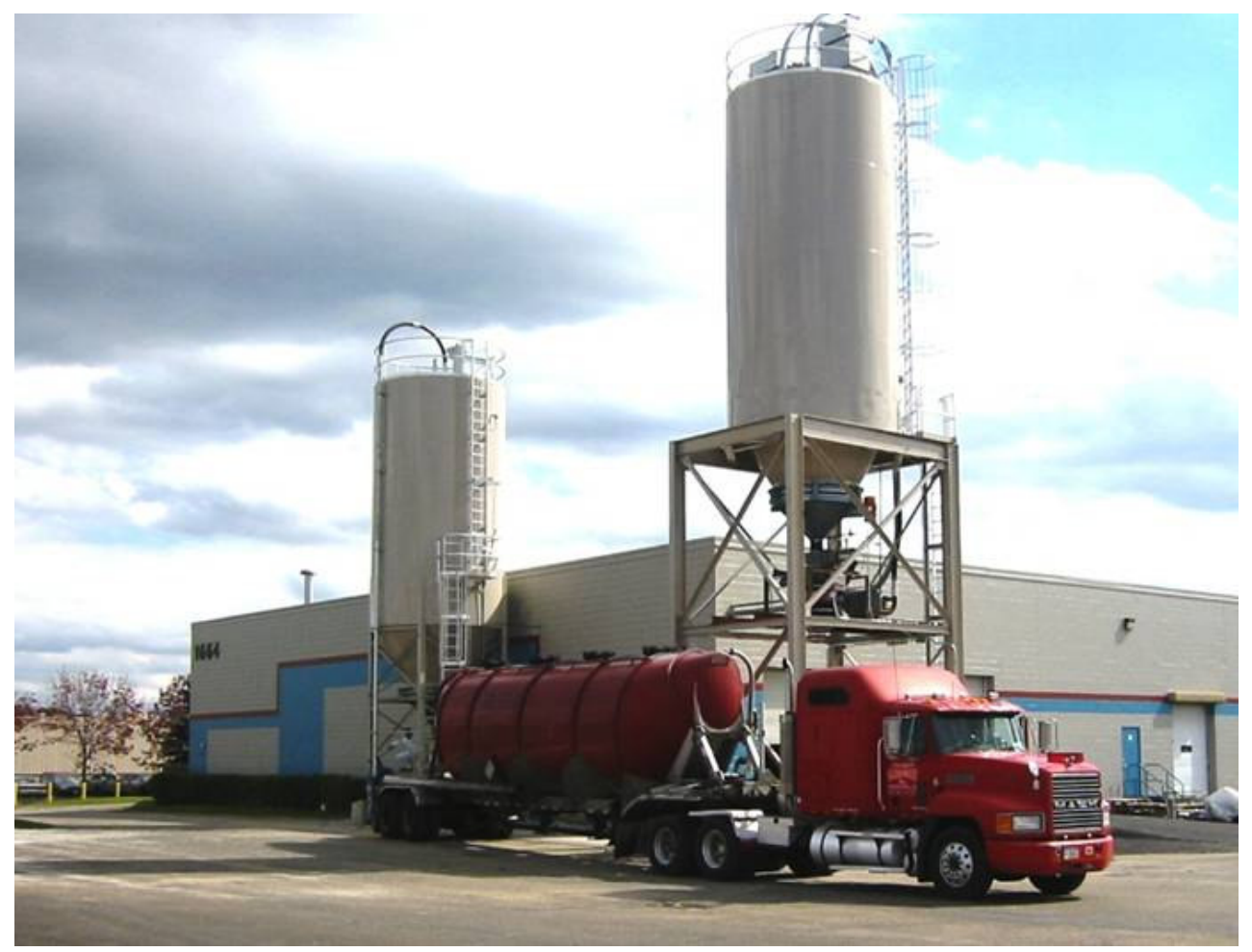




\section{RESULTS AND DISCUSSION}

The results and discussion section will divided into three parts; one for each of the host sites. The discussion on the work conducted at each host site will cover the data collected during the baseline, parametric and long-term test periods.

\section{PROGRESS ENERGY H.F. LEE STATION}

The testing at Progress Energy H. F. Lee Unit 1 began with equipment set-up on January 3, 2006. The baseline measurements, parametric injection tests and long-term 30-day injection tests followed.

A photograph of Lee 1 with the Albemarle Environmental f/k/a Sorbent Technologies' injection trailer situated below is shown in Photograph 12.

\section{Photograph 12. Lee 1 with Injection Trailer}

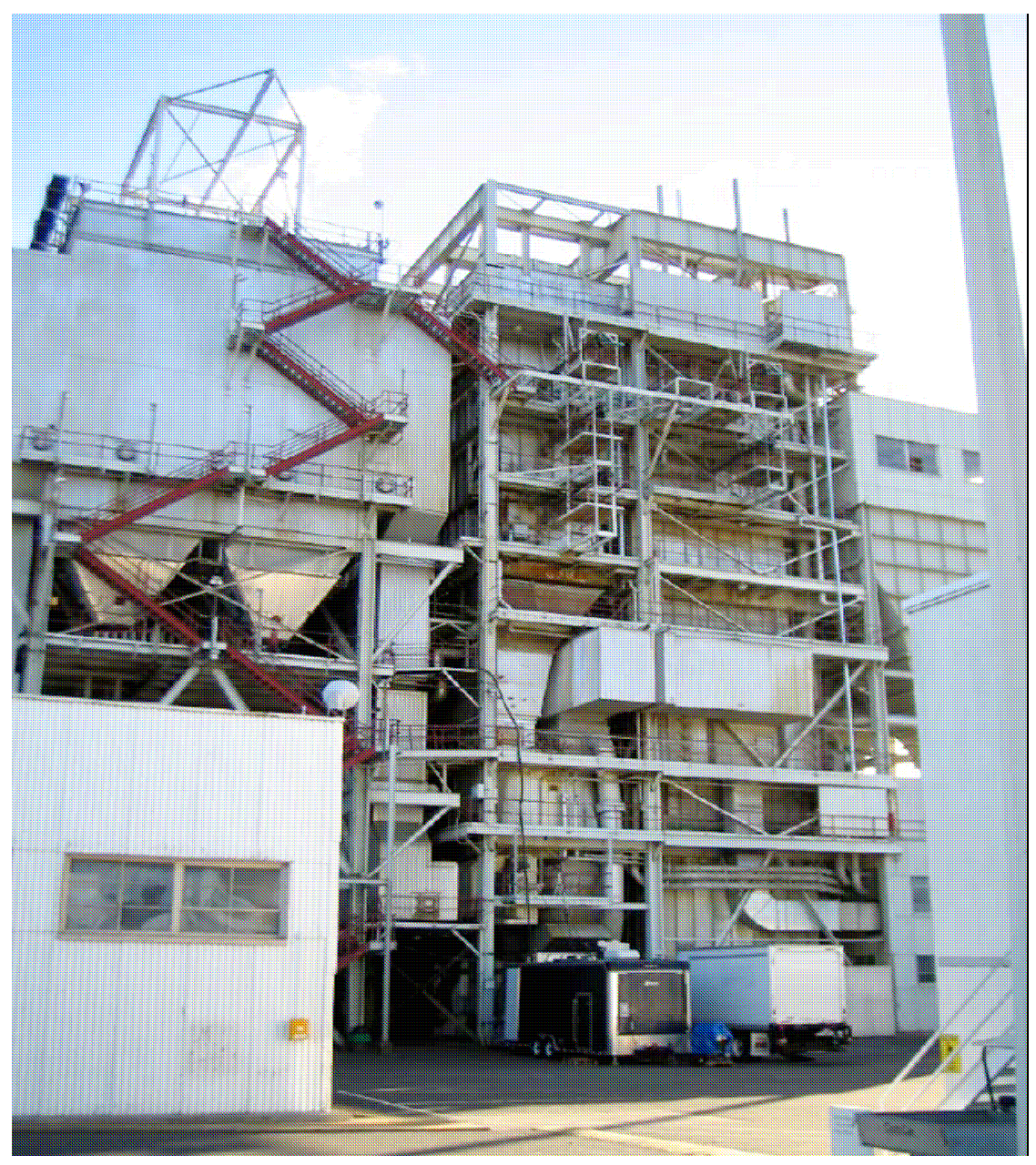

In this photograph, the Lee 1 boiler is on the right and the cold-side ESP is on the left side. The flue gas flow is down through the air preheater and then up to the ESP. Note that this boiler is of the outside design with no walls surrounding the equipment. 


\section{CFD Modeling}

Fuel Tech personnel collected flue gas flow and temperature measurements from Lee 1 in order to develop the CFD model. They used the facility blueprints to construct a computer model of the Lee 1 ductwork after the air preheater and before the ESP. The numeric model of this ductwork was used in a CFD model in order to predict the flue gas flow pattern throughout the ductwork. The flow and temperature data was used to verify the modeling results. The result of the modeling effort is shown in Figure 7.

Figure 7. CFD Modeled Flow in the Lee 1 Ductwork
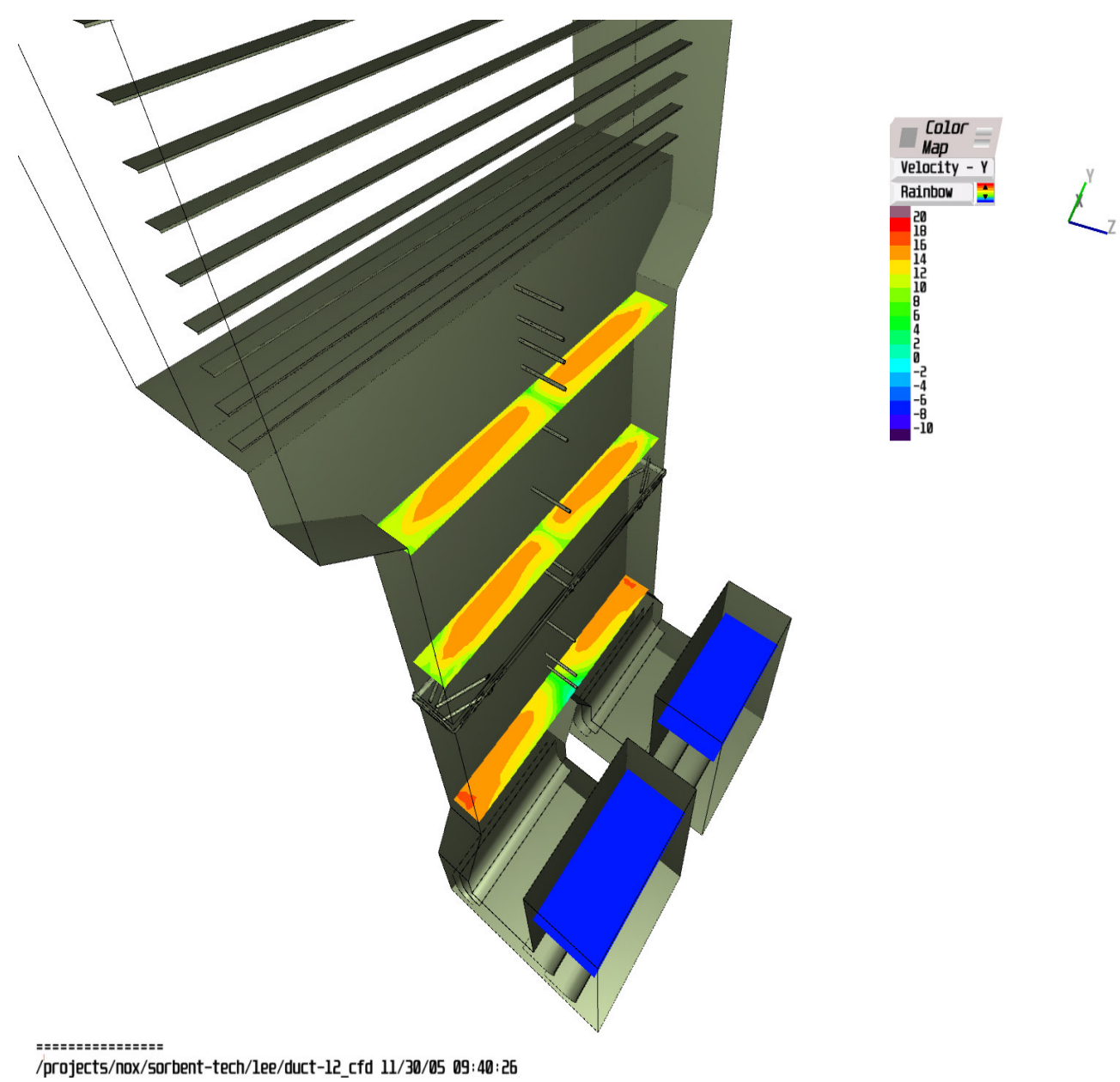

Two ducts lead from the air preheaters before combining into one duct as the flue gas rises up to the ESP. The flue gas flow is fairly evenly distributed across the ductwork except in the middle where internal duct supports act like a partition. The ductwork at the cold-side point of injection (the second flow plane from the bottom) measures 30 feet by 4 feet. Injection on the hot-side occurred a few feet above the air preheaters.

Albemarle Environmental f/k/a Sorbent Technologies evaluated numerous injection lance arrangements before we found the best for injecting on the cold-side of the ESP. This arrangement called for 16 injection lances, two in each of eight ports. The lances were placed 12" and 30" into the ductwork. The sorbent distribution before the ESP plenum for this arrangement is shown in Figure 8. 
Figure 8. Sorbent Distribution at the ESP Plenum with a 16 Lance Arrangement

$1.00 \mathrm{e}-04$

$9.50 \mathrm{e}-05$

$9.00 \mathrm{e}-05$

$8.50 \mathrm{e}-05$

$8.00 \mathrm{e}-05$

$7.50 \mathrm{e}-05$

$7.00 \mathrm{e}-05$

$6.50 \mathrm{e}-05$

$6.00 \mathrm{e}-05$

$5.50 \mathrm{e}-05$

$5.00 \mathrm{e}-05$

$4.51 \mathrm{e}-05$

$4.01 \mathrm{e}-05$

3.51e-05

$3.01 \mathrm{e}-05$

$2.51 \mathrm{e}-05$

$2.01 \mathrm{e}-05$

$1.51 \mathrm{e}-05$

$1.01 \mathrm{e}-05$

$5.09 \mathrm{e}-06 \mathrm{X}-\mathrm{Z}$

$1.00 \mathrm{e}-07$

Contours of DPM Concentration $(\mathrm{kg} / \mathrm{m} 3)$

Dec 30, 2005

FLUENT 6.2 (3d, segregated, RSM)

The color of the plume indicates the concentration of the sorbent in terms of $\mathrm{kg} / \mathrm{m}^{3}$. The sixteen lance arrangement provides a fair, but certainly not perfect, sorbent coverage across the opening of the plenum. The plenum provides even more opportunity for the sorbent to be evenly distributed before it enters the ESP.

The cold-side injection location is shown in Photograph 13. The flue gas flow is vertical at this location. The sorbent distributor can be seen in the center of the photograph just above and left of the ladder. Flexible hoses connected the distributor to the sixteen injection lances. It should be noted that the inertial separator for the inlet mercury analyzer is located on the deck below the lance level. Inlet Appendix $\mathrm{K}$ sampling and OHM testing were also performed through ports on the lower level. The outlet mercury testing was performed through ports at the same level of the injection ports but on the outlet side of the ESP. 
Photograph 13. Lee 1 Injection Lance Arrangement

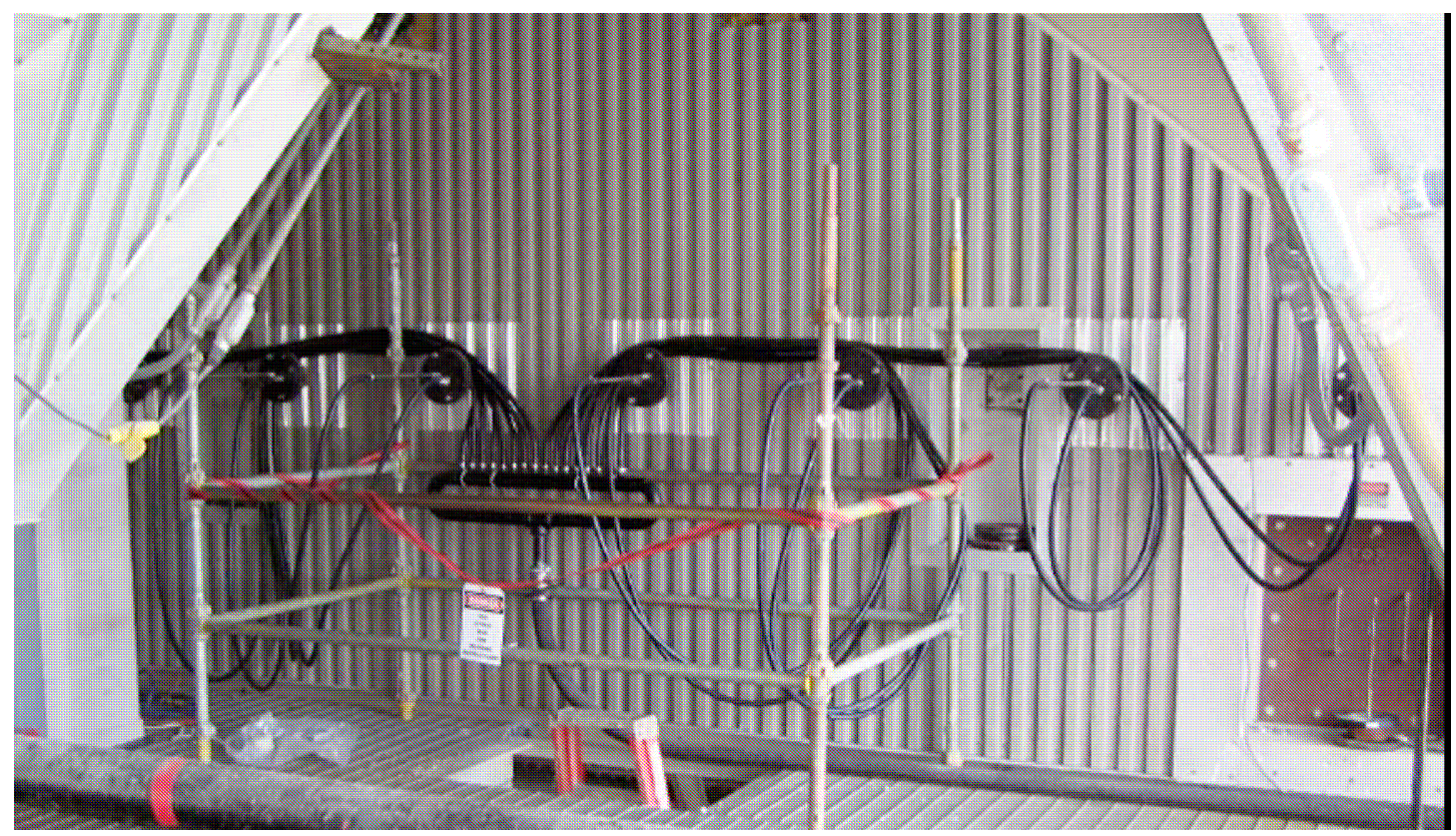

\section{Baseline Measurements}

\section{Mercury Monitor Data}

Due to the availability of Lee 1 , the baseline measurements were divided into two periods. The mercury data from the PS Analytical monitor for the first part of the baseline period is presented in Figure 9.

Figure 9. PSA Hg Data from the First Baseline Period at Lee 1

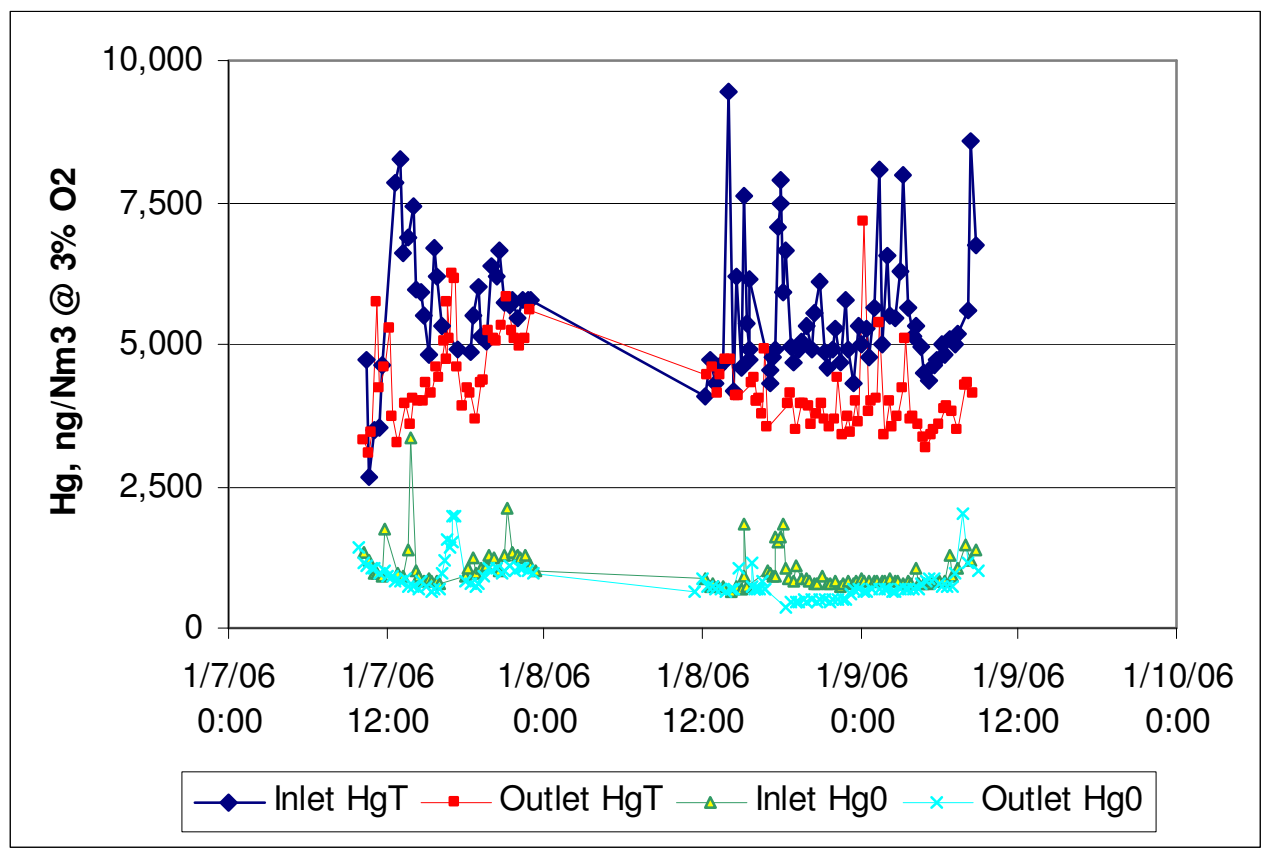


Lee 1 operates in a manner such that the flue gas flow rate is proportional to boiler load. As a result, the flue gas mercury concentration does not vary much with changing load. During the first baseline period, the total vapor phase mercury $\left(\mathrm{Hg}^{\top}\right)$ at the inlet to the ESP averaged $5530 \mathrm{ng} / \mathrm{Nm}^{3}$ at $3 \%$ oxygen, while the outlet averaged $4240 \mathrm{ng} / \mathrm{Nm}^{3}$ at the same oxygen level. This represents a native removal of about $23 \%$. The elemental mercury $\left(\mathrm{Hg}^{0}\right)$ content of the flue gas was less than $20 \%$ of the $\mathrm{Hg}^{\top}$. The $\mathrm{Hg}^{0}$ content of the inlet flue gas averaged $1020 \mathrm{ng} / \mathrm{Nm}^{3}$, while that of the outlet flue gas $\mathrm{Hg}^{0}$ content averaged $830 \mathrm{ng} / \mathrm{Nm}^{3}$, both values being at $3 \%$ oxygen.

The PSA mercury monitor data for the second baseline period is presented in Figure 10.

Figure 10. PSA Hg Data from the Second Baseline Period at Lee 1

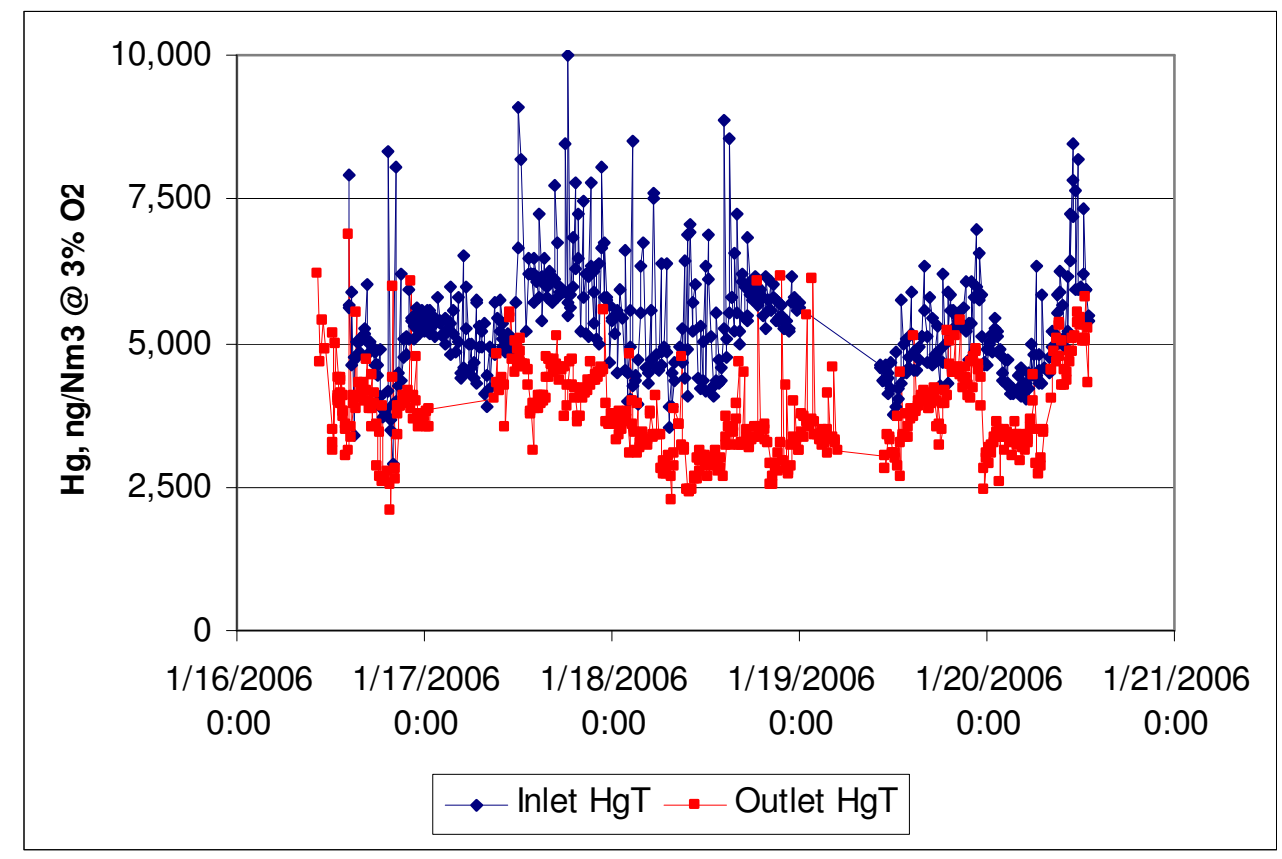

The $\mathrm{Hg}^{0}$ channel was turned off during this period to allow for the collection of more $\mathrm{Hg}^{\top}$ data. The $\mathrm{Hg}^{\top}$ content of the inlet flue gas during the second baseline period averaged $5340 \mathrm{ng} / \mathrm{Nm}^{3}$ at $3 \%$ oxygen, while the outlet averaged $3810 \mathrm{ng} / \mathrm{Nm}^{3}$ at the same oxygen level. This represents a native mercury removal of nearly $30 \%$.

Over both periods, native removal appeared to be relatively consistent, varying from about $20 \%$ to $30 \%$, depending upon plant operation (and possibly the coal being burned).

An experimental Ohio Lumex RA-915 monitor was also used to measure the inlet mercury during the baseline period. The instrument is based upon thermo-catalytic conversion and cold vapor atomic absorption spectroscopy with Zeeman background correction. The instrument, in its current configuration, can only be used to measure total vapor phase mercury.

The instrument has several potential major advantages over conventional semicontinuous $\mathrm{Hg}$ monitors. Most importantly the instrument is much closer to a true continuous emission monitor (CEM) such as used to measure other flue gas 
constituents. The Ohio Lumex $\mathrm{Hg}$ analyzer provides a measurement every 15 seconds rather than every five minutes as do the gold trap mercury monitors. The PSA and the Ohio Lumex $\mathrm{Hg}^{\top}$ data are presented for the two baseline periods in the Figures 11 and 12.

Figure 11. PSA and Ohio Lumex $\mathrm{Hg}$ Data from the First Baseline Period at Lee 1

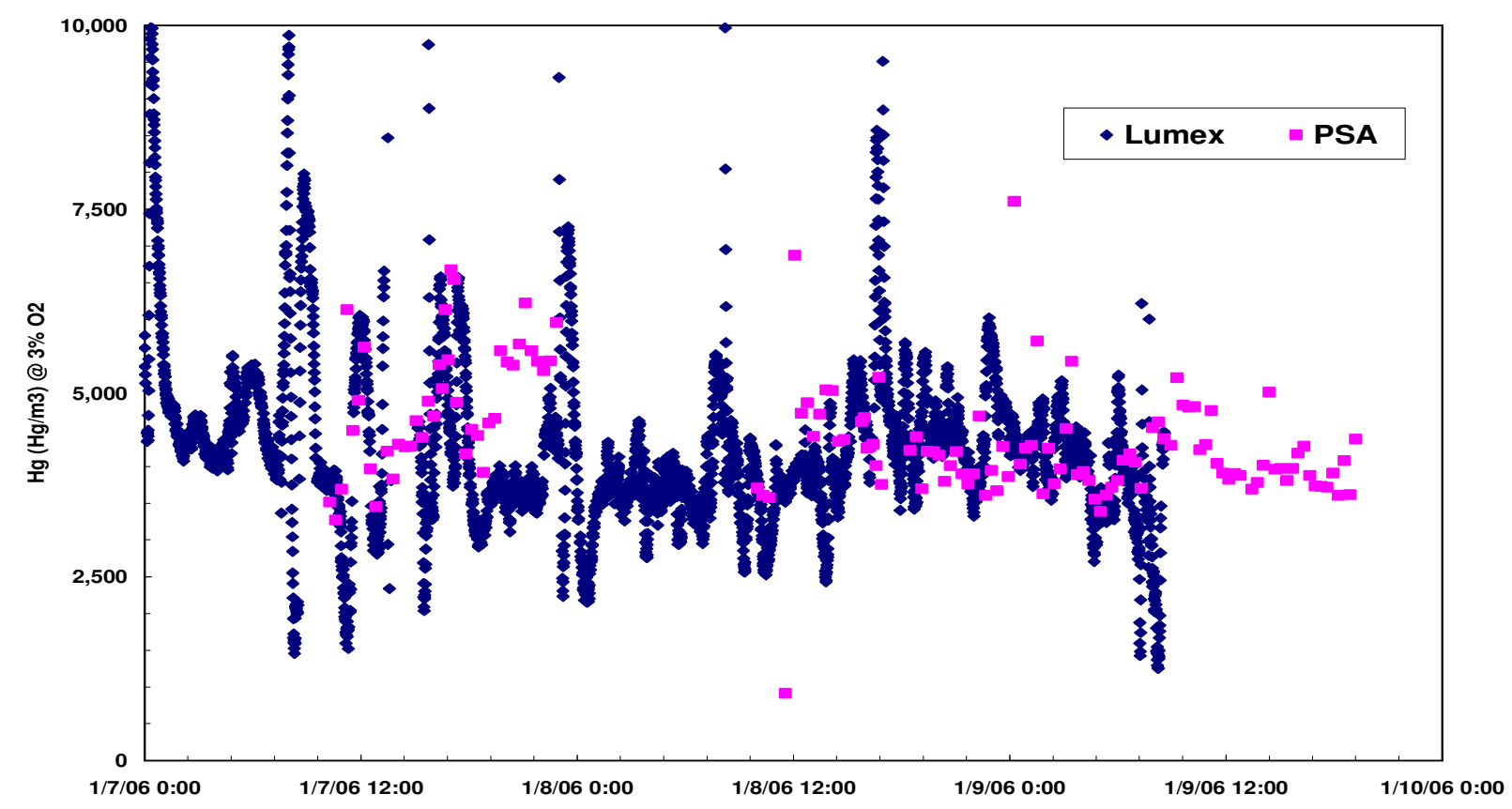

Figure 12. PSA and Ohio Lumex $\mathrm{Hg}$ Data from the 2nd Baseline Period at Lee 1

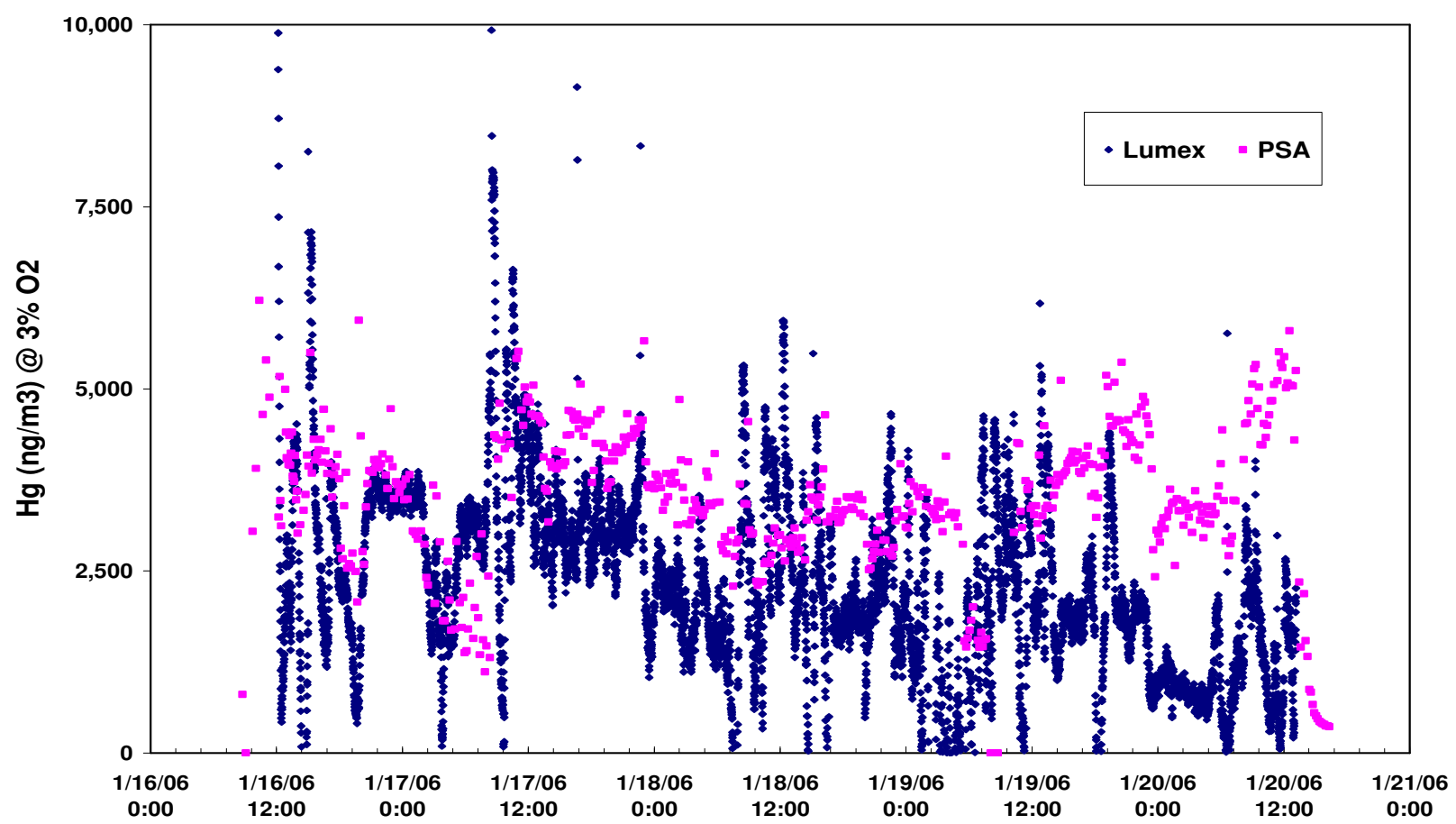


The agreement between the PSA and Ohio Lumex monitors is good except for the end of the second baseline period when the Ohio Lumex readings fell off. Interestingly, frequently when the PSA analyzer would record a five-minute-spike, the more frequent sampling of the Ohio Lumex, even with its completely different and separate sampling system, would detect it also with multiple points. This suggests that most of the PSA Hg spikes are real, and not just an artifact of this particular instrument, which is what had been believed. After the baseline measurement period, the experimental Ohio Lumex monitor was returned to the manufacturer for modification and it was not available for the rest of the testing.

Several Method 324 samples were also taken during the baseline testing. The results are presented in Figure 13, along with the measurements from the mercury analyzers for the same time period.

Figure 13. Method 324 Mercury Results from the Baseline Period at Lee 1

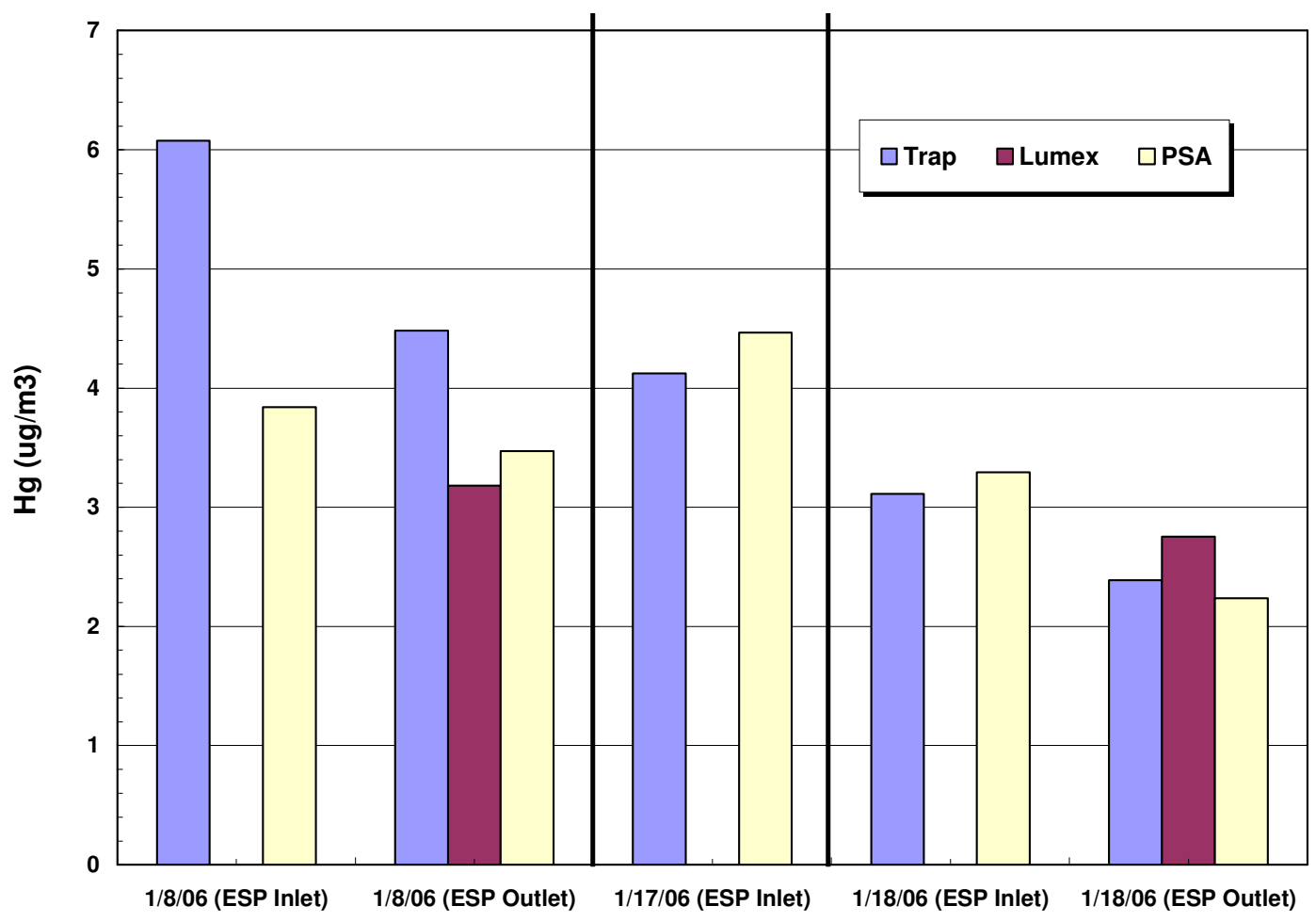

The results from the mercury traps compare favorably to the data from the monitors except for the sample taken at the inlet on 1/8/06. The samples taken on 1/18/06 were collected simultaneously at the ESP inlet and outlet during the OHM testing.

Simultaneous triplicate inlet and outlet OHM mercury tests were performed by URS Corporation on Wednesday January 18. There were some testing issues in conducting these tests, but none invalidated any of the samples. Lee 1 was at full load during the $\mathrm{OHM}$ tests. The OHM results are presented along with those for the mercury monitors and the Method 324 tests in Table 1. 


\begin{tabular}{|c|c|c|c|c|c|c|c|}
\hline \multirow[b]{3}{*}{ Species } & \multicolumn{6}{|c|}{ (ng/Nm3 @ 3\% O2) } & \multirow[b]{3}{*}{ Method 324} \\
\hline & \multicolumn{3}{|c|}{ ESP Inlet Data } & \multicolumn{3}{|r|}{ ESP Outlet Data } & \\
\hline & OHM & PSA & Method 324 & OHM & PSA & Ohio Lumex & \\
\hline $\mathrm{HgP}$ & $\overline{2,973}$ & & & 363 & & & \\
\hline $\mathrm{HgO}$ & 527 & & & 1,173 & & & \\
\hline $\mathrm{Hg}+2$ & $\underline{1,699}$ & & & $\underline{3,830}$ & & & \\
\hline Total Vapor & $\overline{2,226}$ & 4,825 & 4,099 & $\overline{5,003}$ & 2,782 & 3,102 & 3,142 \\
\hline
\end{tabular}

The $\mathrm{OHM}$ results are challenging to interpret. At face value, they indicate that there was more than twice as much vapor phase mercury in the outlet flue gas as in the inlet flue gas. A possible explanation lies in the large particulate mercury number that was measured. URS experienced plugging problem at several locations and the filter may have acted as a fixed bed and captured vapor phase mercury on the ash. More problematic is the outlet vapor phase data relative to all of the other mercury measurements. The two mercury monitors and the Appendix $\mathrm{K}$ sampler all provided similar outlet mercury values but the OHM value was far distant from these values. The reason for the difference in these measurements is unknown.

$\underline{\text { Coal and Fly Ash Data }}$

Two coal samples from the baseline period were sent to SGS NA for proximate analysis. The results of these analyses are presented in Table 2.

\begin{tabular}{|cccccc|}
\hline \multicolumn{6}{c|}{ Table 2. Lee 1 Baseline Coal Proximate Analyses - Dry Basis } \\
$\begin{array}{c}\text { Date } \\
1 / 7 / 06\end{array}$ & $\frac{\text { Ash, \% }}{10.4}$ & $\frac{\text { Volatile Matter, \% }}{37.9}$ & $\frac{\text { Fixed C, \% }}{51.7}$ & $\frac{\text { Sulfur, \% }}{0.83}$ & $\begin{array}{c}\text { Heating Value } \\
\text { BTU/lb }\end{array}$ \\
$1 / 9 / 06$ & 9.9 & 37.9 & 52.1 & 0.83 & 13,263 \\
\hline
\end{tabular}

The Progress Energy Lee Plant normally uses a single source of coal, which is consistent in its properties. The samples collected during the baseline period had about $10 \%$ ash, about $38 \%$ volatile matter, about $52 \%$ fixed carbon and $0.83 \%$ sulfur, all on a dry basis. The heating value, on a dry basis, was slightly more than 13,000 BTU per pound. These values are all typical of a quality bituminous coal.

The coal moisture and mercury analyses are presented in Table 3. The coal samples were analyzed by both Albemarle Environmental $\mathrm{f} / \mathrm{k} / \mathrm{a}$ Sorbent Technologies using an Ohio Lumex analyzer and by SGS NA using an ASTM LECO analyzer. The coal moisture data measured by SGS NA is included in the table. 


\begin{tabular}{|cccc|}
\hline \multicolumn{4}{|c|}{ Table 3. Lee 1 Baseline Coal Moisture and Hg Analyses } \\
Date & $\begin{array}{c}\text { Coal } \\
\text { Moisture, \% }\end{array}$ & $\begin{array}{c}\text { STC Hg } \\
\text { ppm, Dry }\end{array}$ & $\begin{array}{c}\text { SGS Hg } \\
\text { ppm, Dry }\end{array}$ \\
$\frac{1 / 7 / 06}{1 / 8 / 06}$ & 8.2 & 0.090 & 0.092 \\
$1 / 9 / 06$ & 6.0 & 0.061 & 0.067 \\
$1 / 18 / 06$ & 6.9 & 0.062 & 0.054 \\
$1 / 19 / 06$ & 6.8 & 0.061 & 0.052 \\
& 8.5 & 0.055 & 0.041 \\
Average & & & \\
\hline
\end{tabular}

The coal averaged about $7 \%$ moisture during the baseline period. The coal mercury data was very comparable from both laboratories. The coal mercury as measured by Albemarle Environmental f/k/a Sorbent Technologies (STC) averaged $0.066 \mathrm{ppm}$ on a dry basis, while the coal mercury as measured by SGS NA averaged $0.061 \mathrm{ppm}$. This coal has a mercury content in the lower quartile of bituminous coals, as determined in the ICR testing; considerably below the average bituminous coal which contains about $0.10 \mathrm{ppm}$ mercury on a dry basis.

The ESP associated with Lee 1 uses six hoppers to collect fly ash. The inlet hoppers are numbered 16-18, while the outlet hoppers are numbered 13-15. The results from the baseline fly ash mercury analyses are shown in Table 4.

Table 4. Lee 1 Fly Ash Mercury Data from the Baseline Period

Average $\mathrm{Hg}$ Concentration in fly ash (ppb)

\begin{tabular}{|c|c|c|c|c|c|c|c|c|c|}
\hline \multirow[b]{2}{*}{ Date } & \multirow[b]{2}{*}{ Period } & \multicolumn{4}{|c|}{ Inlet Hoppers } & \multicolumn{4}{|c|}{ Outlet Hoppers } \\
\hline & & $\underline{16}$ & 17 & $\underline{18}$ & Average & $\underline{13}$ & $\underline{14}$ & $\underline{15}$ & Average \\
\hline $1 / 7 / 2006$ & Baseline & 292 & 211 & 208 & 237 & $\overline{464}$ & 348 & $\overline{466}$ & 426 \\
\hline $1 / 8 / 2006$ & Baseline & 252 & 177 & 174 & 201 & 810 & 517 & 715 & 681 \\
\hline $1 / 9 / 2006$ & Baseline & 181 & 161 & 161 & 167 & 496 & 416 & 401 & 438 \\
\hline $1 / 17 / 2006$ & Baseline & 172 & 99 & 154 & 142 & 968 & 383 & 315 & 555 \\
\hline $1 / 18 / 2006$ & Baseline & 190 & 149 & 157 & 165 & 507 & 333 & 298 & 379 \\
\hline $1 / 19 / 2006$ & Baseline & 209 & 147 & 160 & 172 & 454 & 459 & 467 & 460 \\
\hline $1 / 20 / 2006$ & Baseline & 217 & 163 & 144 & $\underline{174}$ & 720 & 402 & 244 & $\underline{455}$ \\
\hline & & & & & 180 & & & & 485 \\
\hline
\end{tabular}

The mercury content of the fly ash in the back hoppers is higher as expected, since the LOI of the fly ash collected in these fields is always higher than that of the fly ash from the front hoppers. It is assumed that about $70 \%$ of the fly ash is deposited in the front hoppers and $30 \%$ in the back hoppers, as is typical of cold-side ESPs. However, there is no definitive data on the fly ash distribution. With a $70 \% / 30 \%$ split, the baseline fly ash would contain $271 \mathrm{ppb}$ on average.

\section{Mercury Mass Balance}

The coal composition and the coal usage rate can be used to calculate the fly ash mercury content if $100 \%$ of the mercury were captured by the ash. This calculation 
indicates that the fly ash mercury content would be about $710 \mathrm{ppb}$ in this case. The average fly ash composition in the baseline period was about $271 \mathrm{ppb}$ or a native mercury removal of $38 \%$. This is higher than the $20 \%$ to $30 \%$ native removal predicted by the mercury monitors. However, the higher value predicted by the fly ash data could be correct since the monitors only measure vapor phase mercury. Any mercury in the particulate form at the inlet monitor location would not be seen by the monitors.

At full load, the Lee 1 boiler generated about 300,000 acfm at the mercury monitor locations. This information, in conjunction with the coal composition and usage data, can be used to predict the mercury concentration at the inlet location. The calculation predicts that the mercury concentration would be about $6200 \mathrm{ng} / \mathrm{Nm}^{3}$ at $3 \%$ oxygen at the inlet monitor. This is slightly higher than the approximate $5500 \mathrm{ng} / \mathrm{Nm}^{3}$ at $3 \%$ oxygen measured by the PSA monitors during the baseline period. However, the predicted mercury concentration can be brought into line with that actually measured if it is assumed that $10 \%$ of the mercury is in the particulate form at the inlet location.

The mercury values as measured by the monitors at both the inlet and outlet locations are consistent with the fly ash mercury data but not the OHM data. However, it should be noted that all of these calculations have large error bars. For example, the coal mercury content varied by as much as $50 \%$ from the lowest to the highest individual value during the baseline period.

\section{Boiler Operation}

Lee 1 is not a base loaded unit, but rather, operates at varying loads in order to meet demand. The boiler load during the baseline periods is shown in Figure 14.

Figure 14. Lee 1 Load during the Baseline Periods

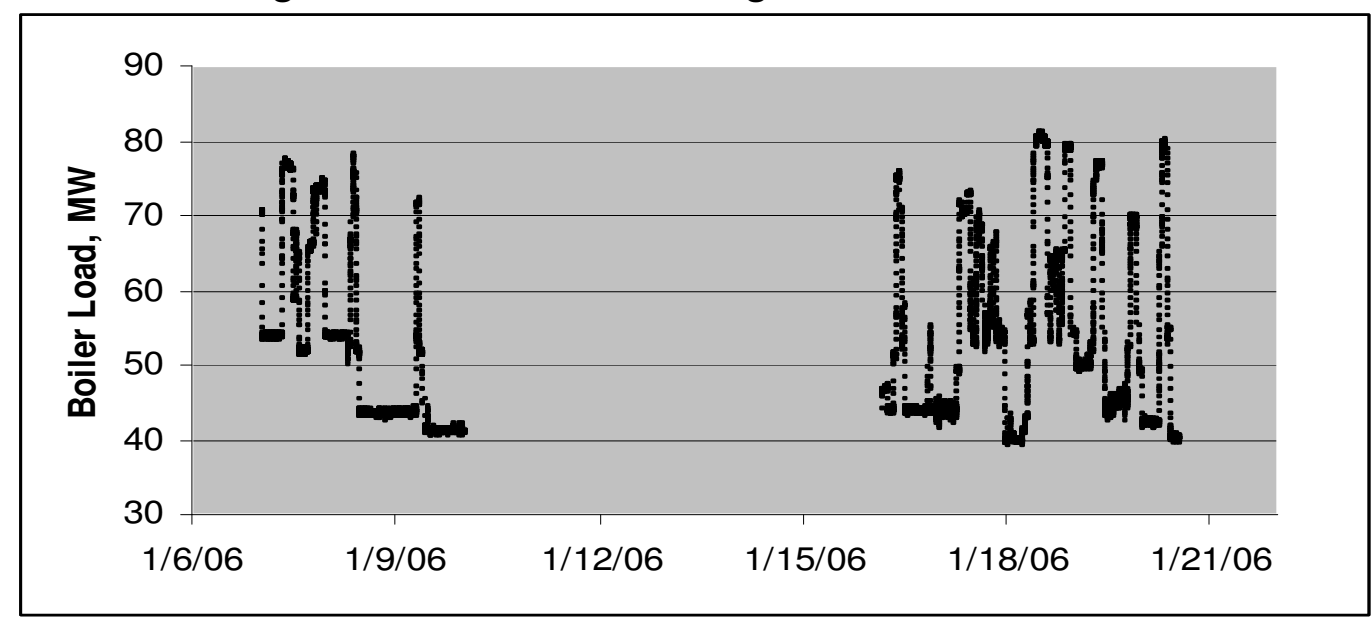

On most days, there are two peak load periods, one in the morning and one at night. This pattern is present in the data presented in Figure 12. This boiler is also shutdown completely for periods of time due to lack of demand. This can be observed in the figure above by the gap between operating periods. In fact, Lee 1 was shutdown again after the second baseline period and before the parametric testing began. The high demand periods are generally in the summer and winter. However, the experience during this test program indicates that that is not always the case. 
Lee 1 uses a cold-side ESP to capture the fly ash emissions. $\mathrm{SO}_{3}$ is injected before the ESP for most of the time in order to modify the fly ash resistivity to allow for better ESP performance. The opacity limits for Lee 1 are no greater than $40 \%$ opacity on a six minute average and $18 \%$ on an annual average.

The stack opacity at Lee 1 is highly dependent upon load. A plot of boiler load versus the opacity for baseline periods is presented in Figure 15.

Figure 15. Opacity for Baseline Periods during the Testing at Lee 1

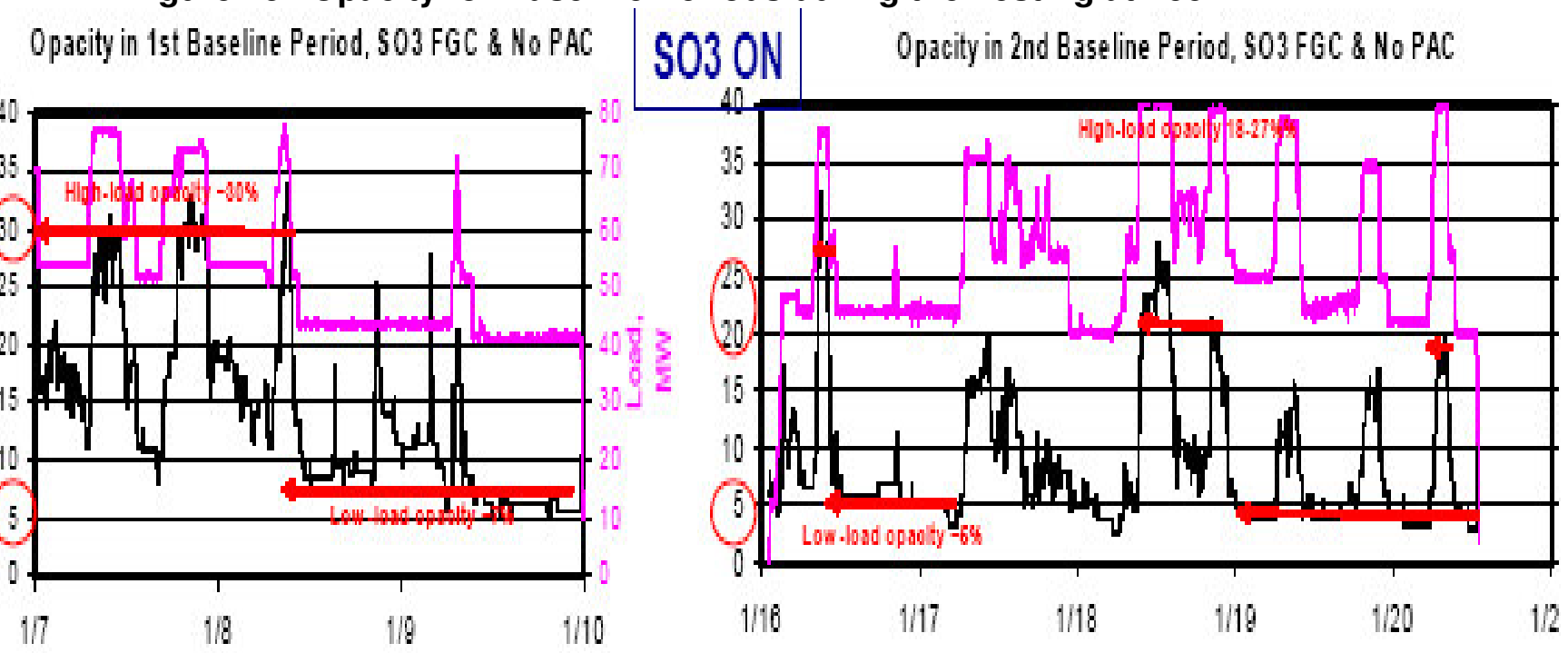

At the minimum load of about $40 \mathrm{MW}$, the opacity is usually below $10 \%$ but this increased to near $30 \%$ at full load during the first baseline period and over $20 \%$ during the second baseline period. All of this data was collected when the $\mathrm{SO}_{3}$ injection system was in operation and is somewhat higher than normal. 


\section{Parametric Tests}

Lee 1 resumed operation on Monday January 23 and the first part of the parametric testing ran through Friday February 3, 2006. Progress Energy had requested a break in the testing to allow for extensive boiler testing during February 2006. The final part of the parametric tests were conducted in early June 2006, since an opportunity became available to perform the long-term test starting on March 8, when the parametric tests were originally scheduled to resume. More about the reasoning of this switch is presented in the section on the long-term test at Lee 1.

\section{Mercury Monitor Data}

The parametric injection tests were conducted using the PS Analytical mercury monitor as the only instrument measuring flue gas mercury. Coal and fly ash samples were taken during the testing but there was no attempt to calculate mercury mass balances since parametric fly ash samples are not representative of the fly ash which will be produced in a long-term test. The reason for this is that parametric fly ash samples are always diluted with an unknown amount of untreated ash. There were no Method 324 or $\mathrm{OHM}$ tests performed during the parametric testing.

Testing was performed by injecting mercury sorbent both with, and without, $\mathrm{SO}_{3}$ injection in order to determine the degree of impact on sorbent performance. The $\mathrm{SO}_{3}$ is injected just before the air preheater at Lee 1. The original concept was to turn off the $\mathrm{SO}_{3}$ for an hour before the sorbent injection began to allow the mercury levels to equilibrate. The B-PAC ${ }^{\mathrm{TM}}$ injection would begin and continue for about two hours before the $\mathrm{SO}_{3}$ injection was resumed, while continuing the sorbent injection. This did not turn out to be a viable test method, because the resumption of $\mathrm{SO}_{3}$ injection affected many parameters. It was decided to perform the tests with the $\mathrm{SO}_{3}$ injection either on or off the entire test period. In addition, it was found that both the stabilization and injection periods would have to be longer.

Sorbent was injected at two locations at different times during the parametric testing. The first location is referred to as the "cold-side" and is in the ductwork after the air preheater and before the ESP. The flue gas flow and injection lance arrangement at this location was evaluated by CFD modeling. The second injection location is referred to as "hot-side" and is before the air preheater at a location either 7 feet (lower) or 12 feet (upper) upstream of the location at which the $\mathrm{SO}_{3}$ is injected.

One reason for testing in the manner described above was to determine whether the $\mathrm{SO}_{3}$ injection location had to be moved to allow for good mercury sorbent performance while the fly ash resistivity is being modified, or if one of the current injection locations was satisfactory. The sorbent residence time on the hot-side was a concern, since the distance upstream of the $\mathrm{SO}_{3}$ injection location and the air preheater was very limited. The injection on the cold-side at Lee 1 may well have been the first time that mercury sorbents were used in a gas stream where the ESP was below the acid dew point and contained sulfuric acid either condensed on the fly ash or as a mist.

The results from the first part of the parametric testing at Lee 1 are shown in the Table 5. 


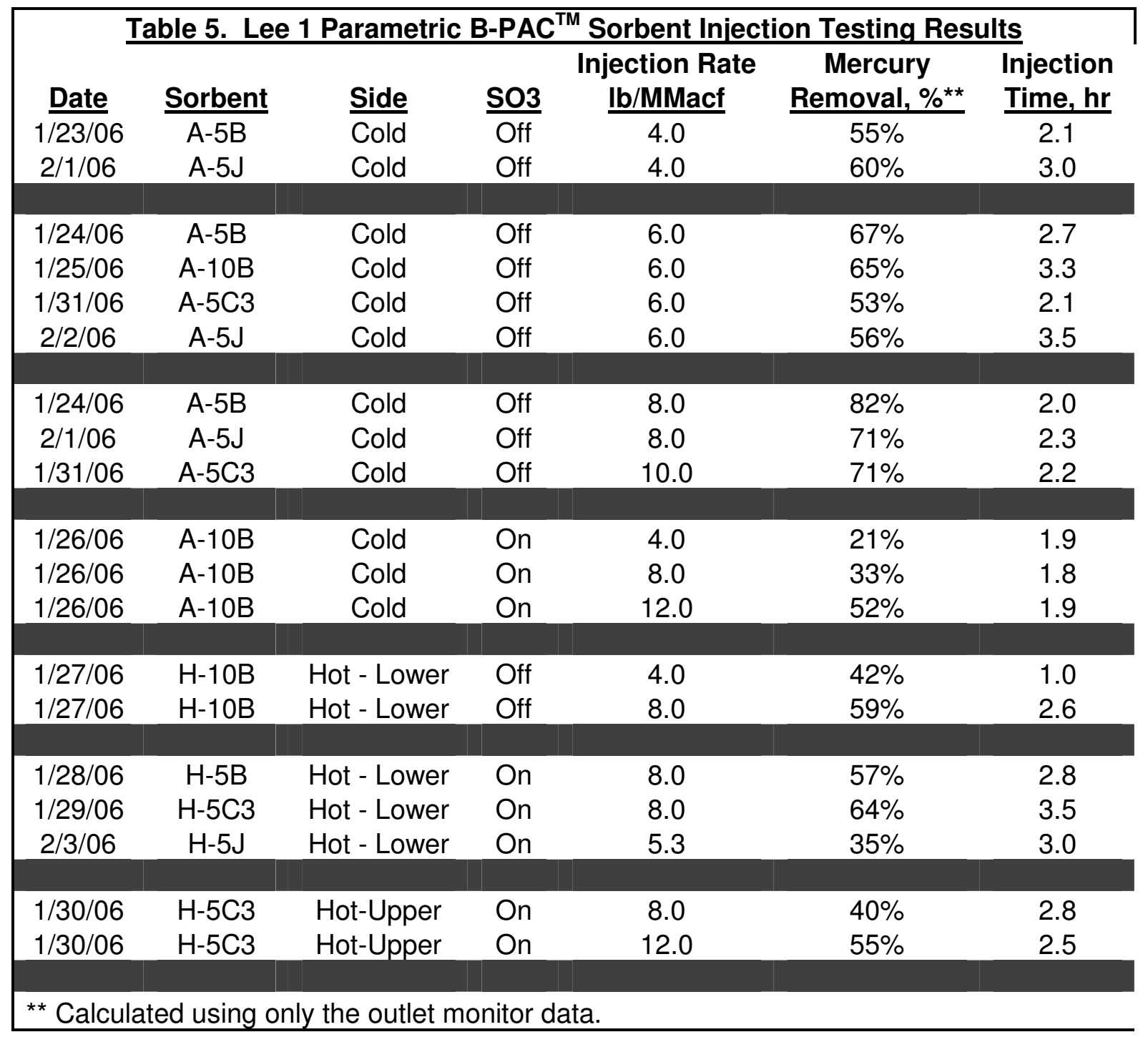

The data is divided into periods of similar injection rates for the same injection location and operating condition. The A-5B sorbent (the current standard $\mathrm{B}-\mathrm{PAC}{ }^{\mathrm{TM}}$ ) when injected on the cold-side with the $\mathrm{SO}_{3}$ injection off provided mercury removal rates comparable to that found in the testing at the Duke Power Allen Station, which used a similar bituminous coal. However, the Hg performance of the sorbent injection with the $\mathrm{SO}_{3}$ injection operating was reduced by more than a factor of two.

The mercury removal results for three conditions are shown in Figure 16. The results for B-PAC ${ }^{\mathrm{TM}}$ sorbent injected on the cold-side, both with and without $\mathrm{SO}_{3}$ injection, and for $\mathrm{H}-\mathrm{PAC}{ }^{\mathrm{TM}}$ sorbent injection (the high temperature version of $\mathrm{B}-\mathrm{PAC}^{\mathrm{TM}}$ ) with $\mathrm{SO}_{3}$ injection. 
Figure 16. $\mathrm{Hg}$ Removal Due to Sorbent at Lee 1 with and Without $\mathrm{SO}_{3}$ Injection

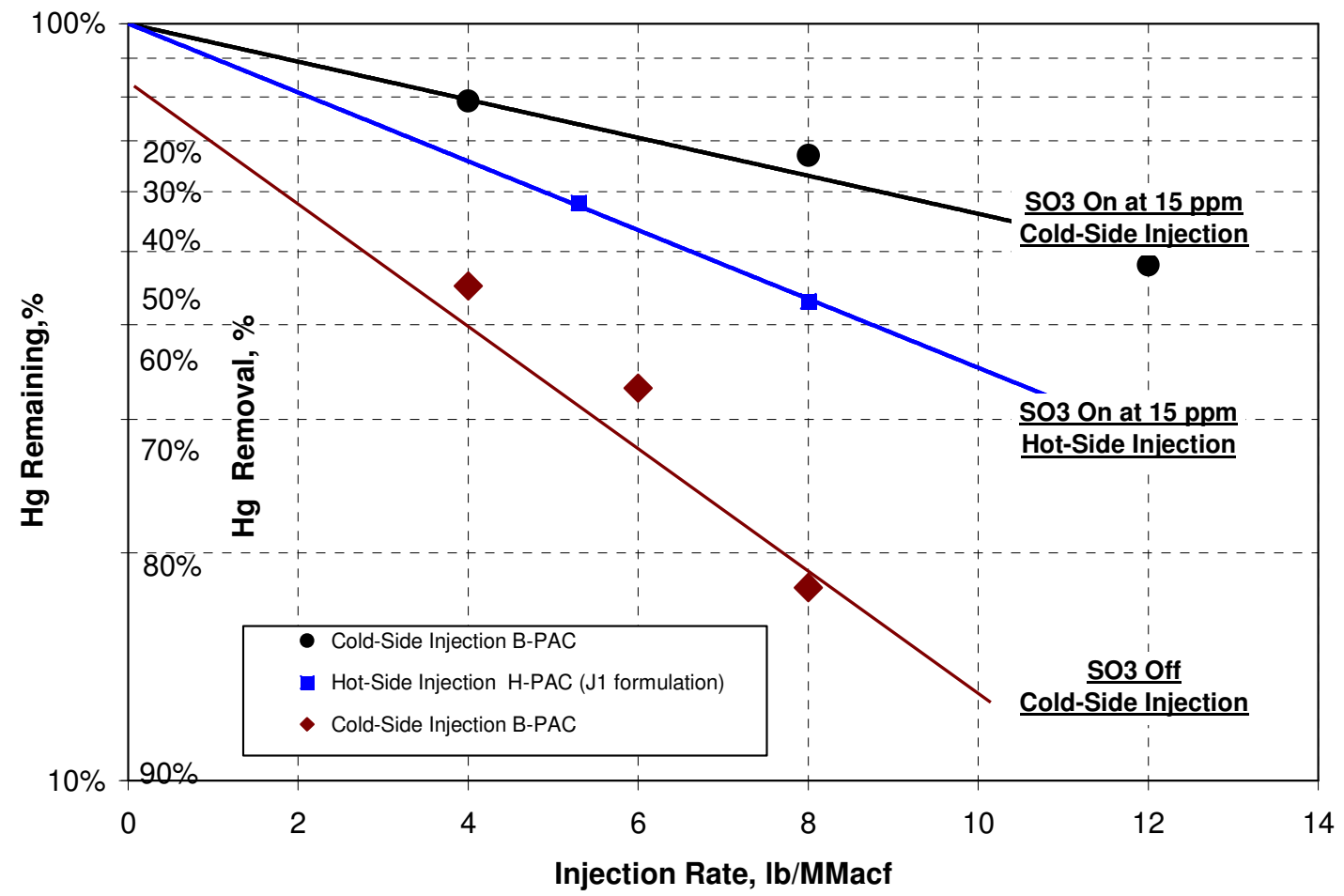

The injection of B-PAC ${ }^{\mathrm{TM}}$ on the cold-side without $\mathrm{SO}_{3}$ injection provided a mercury removal rate higher than $80 \%$ at an injection rate of $8 \mathrm{lb} / \mathrm{MMacf}$. When the $\mathrm{SO}_{3}$ injection was operating, the mercury removal rate was cut by more than half at the same injection rate. With the $\mathrm{SO}_{3}$ on, promising mercury removal rates were achieved by injecting on the hot-side. The mercury removal rates achieved by injecting on the hot-side with $\mathrm{SO}_{3}$ were higher than those achieved with cold-side injection and the $\mathrm{SO}_{3}$ on. Consequently, one solution for plants with $\mathrm{SO}_{3}$ injection, or plants with $\mathrm{SO}_{3}$ generated by the SCR catalyst, is to inject $\mathrm{H}-\mathrm{PAC}{ }^{\mathrm{TM}}$ on the hot-side before the $\mathrm{SO}_{3}$ is in the flue gas. Even better performance is possible by injecting on the cold-side without the $\mathrm{SO}_{3}$, however.

The Lee 1 test program was completed with the final parametric tests being performed in June. These tests were displaced by the long-term testing during March and April and they could not be completed until June due to a series of outages and coal trials at the Lee Station. Only an outlet monitor was used for these last tests since only this data is used to calculate the mercury removal due to sorbent. The dry conversion method was again tested but this time with a dilution sampler.

The first parametric tests were conducted when outlet mercury readings were about $3500 \mathrm{ng} / \mathrm{Nm}^{3}$ at $3 \%$ oxygen. These tests were conducted with a mercury concentration of about $2500 \mathrm{ng} / \mathrm{Nm}^{3}$ or $30 \%$ less mercury in the outlet flue gas. The flue gas temperature during the first set of parametric tests conducted in January and February 2006 was about $270^{\circ} \mathrm{F}$ as compared to about $310^{\circ} \mathrm{F}$ during the second set of parametric tests in June 2006.

All of the tests during the second parametric test period were conducted on the cold-side of the ESP and, with the exception of the first test, the $\mathrm{SO}_{3}$ injection system was off for 
the duration of each test. In fact, the $\mathrm{SO}_{3}$ injection system was left off for all of the testing days after the first day of testing. The first parametric test in the last series was with an experimental sorbent which was expected to perform somewhat better than standard B-PAC ${ }^{\mathrm{TM}}$ when used with the $\mathrm{SO}_{3}$ injection system on. This sorbent did perform slightly better than the standard B-PAC ${ }^{\mathrm{TM}}$ but the $\mathrm{SO}_{3}$ concentration, as measured on the hot-side of the air preheater, was lower during these tests than in the previous test making interpretation of the data problematic.

The standard B-PAC ${ }^{\mathrm{TM}}$ was tested at an injection rate of $8 \mathrm{lb} / \mathrm{MMacf}$. In this test, the ${\mathrm{B}-P A C^{\mathrm{TM}}}^{\mathrm{M}}$ sorbent achieved a mercury removal rate $10 \%$ lower than that achieved by the $\mathrm{B}^{-P A C}{ }^{\mathrm{TM}}$ in the first set of parametric tests. The reason for this difference is unknown but it does appear that there was a much higher native removal during this period. Thus, the total mercury removal was about the same.

The last tests were performed with a single sorbent which had been ground to different sizes. The A-5C4VF had a mean size of 5 microns and was the best performing sorbent in the second round of parametric tests. The A-5C4F had a mean size of 10 microns and performed similarly to the standard B-PAC ${ }^{\mathrm{TM}}$. The A-5C4 sorbent had a mean size of about 20 microns about the same size as B-PAC ${ }^{\mathrm{TM}}$. The performance curves for these three sorbents are shown in Figure 17.

Figure 17. Mercury removal Rates Due to Sorbent for the Three Sorbents of Different Size

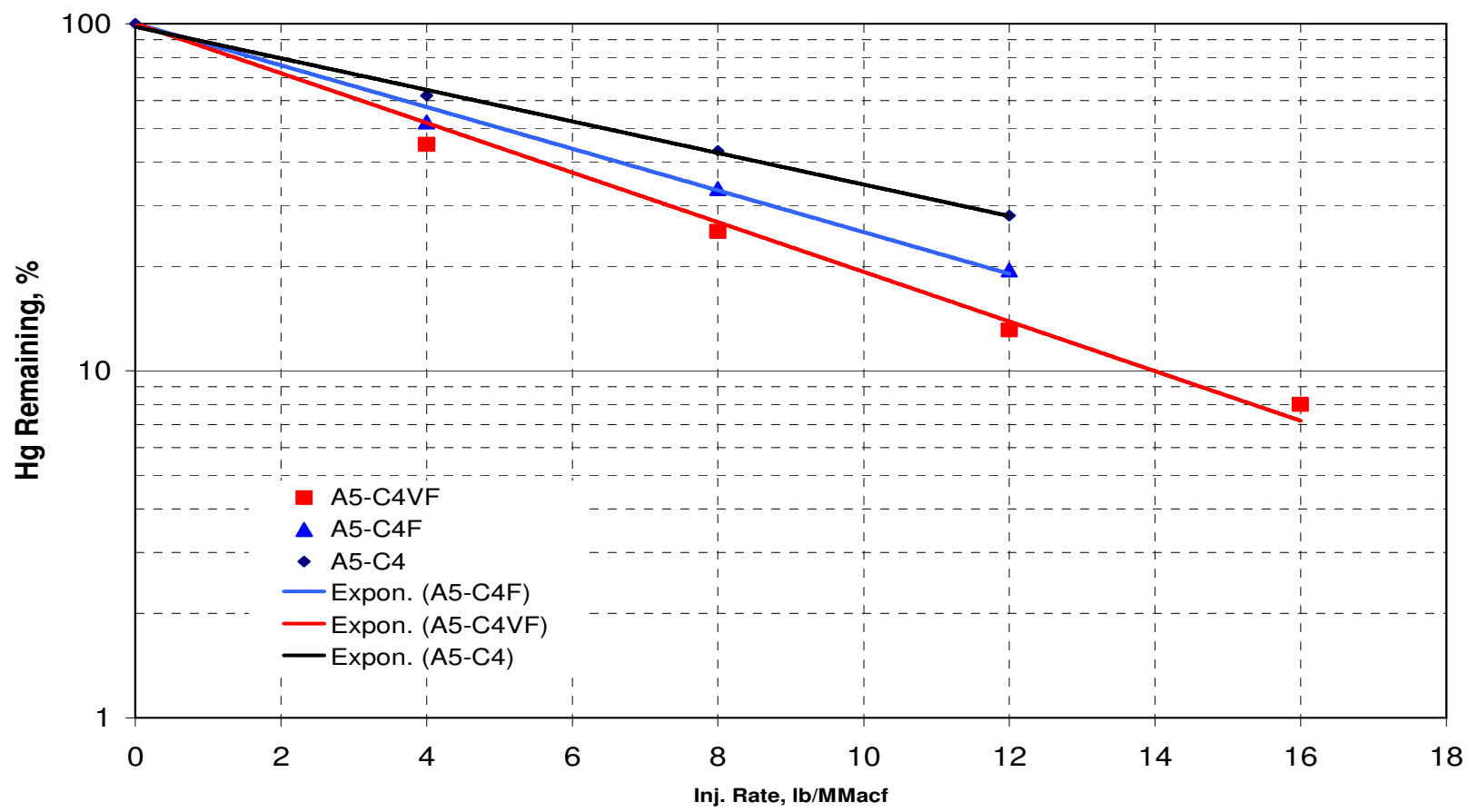

The A-5C4VF is the clear winner in this contest, achieving $75 \%$ mercury removal at an injection rate of $8 \mathrm{lb} / \mathrm{MMacf}$ and $87 \%$ mercury removal at an injection rate of 12 $\mathrm{lb} /$ MMacf. Coupled with the native removal, the total mercury removal for these injection 
levels is well over $90 \%$. The A-5C4F performed in a similar manner to the standard BPAC under these boiler operating conditions, while the A-5C4 performed the worst.

The downside of the finer sorbents is twofold. First, these sorbents are more expensive to produce, since the raw material cannot be purchased this fine and must be ground by a toll processor. Second, the fine sorbents did impact the opacity. The impact of these sorbents on opacity is shown in Figure 18.

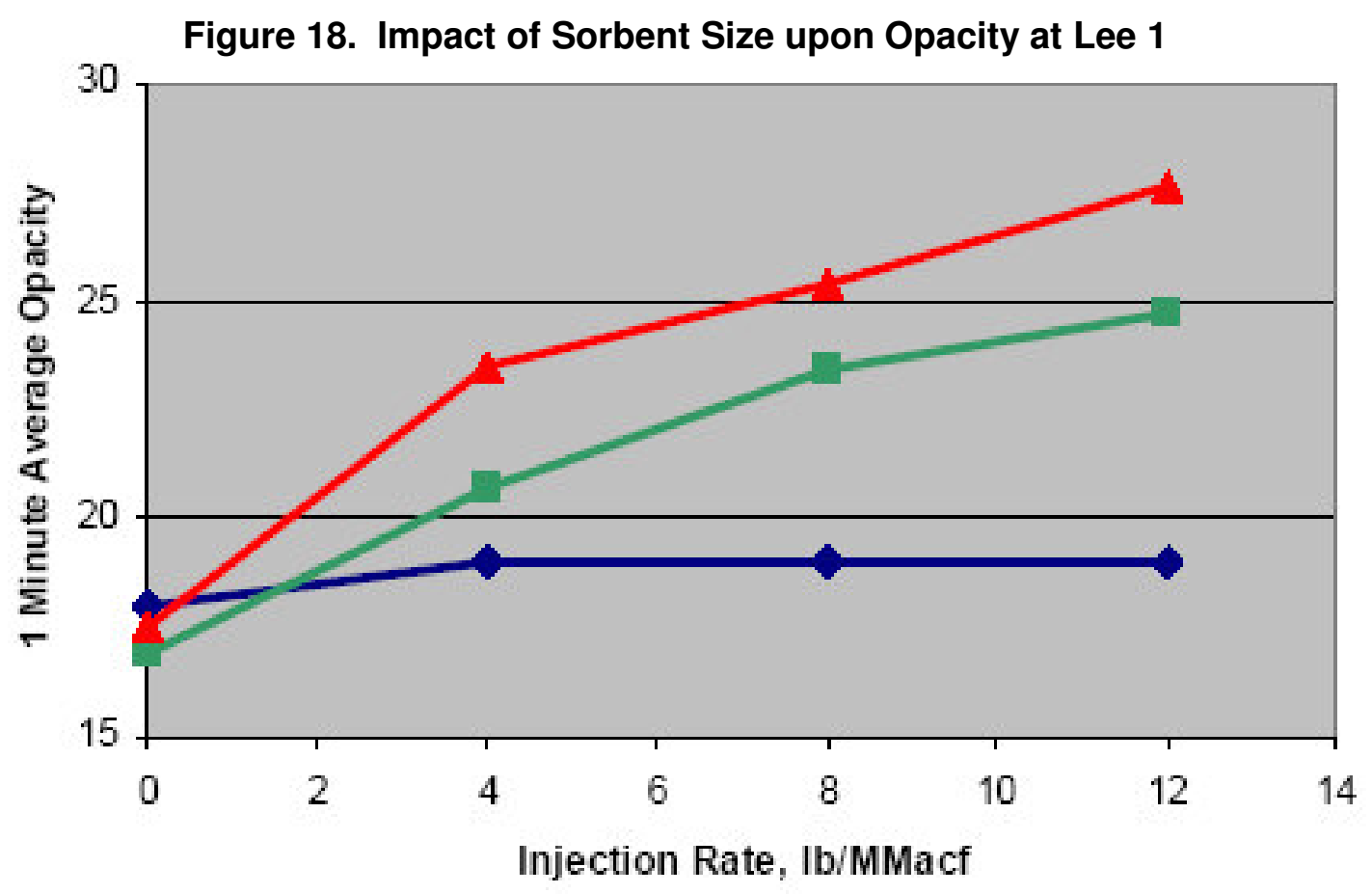

The starting opacity for these tests was about $18 \%$. The A-5C4 (20 micron) sorbent didn't have a significant impact on opacity. The A-5C4F (10 micron) sorbent increased the six minute opacity to about $23 \%$ at an injection rate of $8 \mathrm{lb} / \mathrm{MMacf}$. The A-5C4VF ( 5 micron) sorbent had the greatest impact on opacity increasing it to over $25 \%$ at the same injection rate. The reason for opacity increase is that a significant sub-micron fraction is generated in the grinding process and this sub-micron fraction is not easily captured by the ESP. The A-5CVF had $10 \%$ of the sorbent with a particle size of 1 micron or less. The A-5C4F had less material below one micron in size and, thus, had a smaller impact on opacity. The increases in opacity caused by these fine sorbents could not be tolerated at Lee 1 or at most plants.

The dry conversion system was again tested during the last of the parametric tests at Lee 1. The dry conversion system had had some success in operating at the Detroit Edison St. Clair Plant, where subbituminous coal is primarily used, but no success at the Duke Power Buck Station were bituminous coal is fired. It was thought that the difference in performance was due to the acid gases in the flue gas. Therefore, the dry conversion system was coupled with a dilution sampler in an attempt to overcome this 
problem. The data from the PS Analytical mercury monitors is presented in Figure 18 for one day of the parametric tests when both systems were in operation.

Figure 19. Mercury Monitor Data from the Wet and Dry Systems at Lee 1

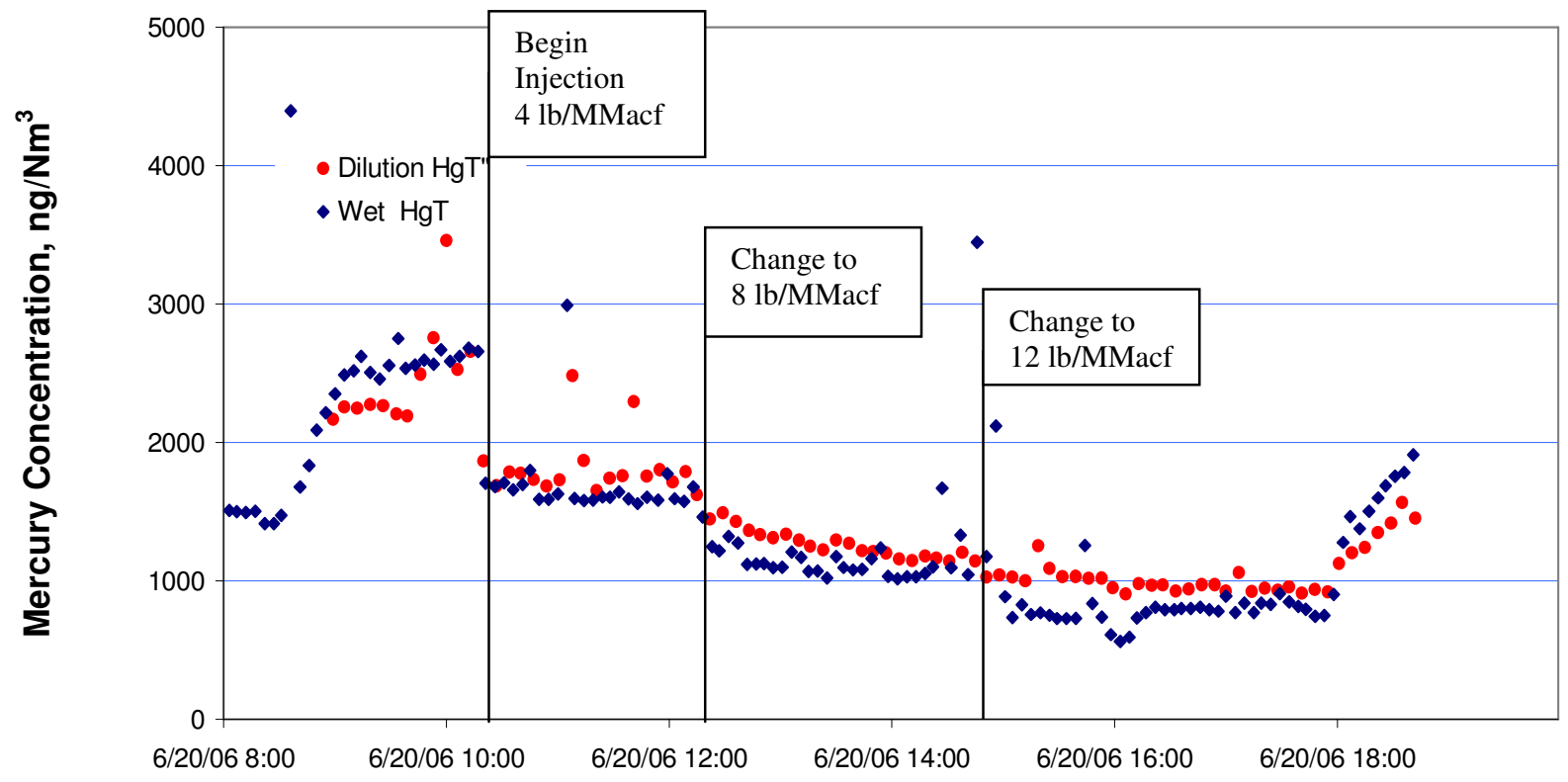

The data from the dry system closely followed that of the wet system as first the boiler was brought up to load and the flue gas mercury increased due to lessened dilution, and then the mercury was reduced by successive increases in sorbent injection rate.

\section{Coal and Fly Ash Data}

Coal and fly ash samples were collected during both parametric test periods. These samples are of less importance than those collected during the baseline period and longterm test since mercury mass balances are not created but the data does provide an indication of the trend of the mercury behavior.

The results of the coal proximate analyses are shown in Table 6.

\begin{tabular}{|cccccc|}
\hline \multicolumn{5}{|c|}{ Table 6. Lee 1 Parametric Test Coal Proximate Analyses - Dry Basis } \\
& $\frac{\text { Ash, }}{\%}$ & Volatile Matter, \% & $\frac{\text { Fixed C, }}{\%}$ & $\underline{\text { Sulfur, }}$ & Heating Value \\
$\frac{\text { Date }}{1 / 26 / 06}$ & 11.9 & 38.0 & 50.1 & 0.88 & $\frac{1}{12,999}$ \\
$1 / 28 / 06$ & 10.2 & 38.3 & 51.5 & 0.84 & 13,252 \\
$6 / 15 / 06$ & 9.8 & 37.8 & 52.4 & 0.81 & 13,398 \\
$6 / 17 / 06$ & 9.0 & 38.4 & 52.5 & 0.81 & 13,528 \\
$6 / 19 / 06$ & 10.6 & 37.5 & 52.0 & 0.82 & 13,258 \\
\hline
\end{tabular}


The proximate analyses of the coal used during the two parametric testing periods had very similar characteristics to that used in the baseline testing. The coal mercury analyses for the parametric testing are presented in Table 7.

\begin{tabular}{|c|c|c|c|}
\hline$\frac{\text { Date }}{1 / 23 / 06}$ & $\begin{array}{c}\text { Coal } \\
\text { Moisture, \% } \\
\end{array}$ & $\begin{array}{c}\text { STC Hg } \\
\text { ppm, Dry }\end{array}$ & $\begin{array}{c}\begin{array}{c}\text { SGS Hg } \\
\text { ppm, Dry }\end{array} \\
0.063\end{array}$ \\
\hline $1 / 24 / 06$ & 7.9 & 0.043 & \\
\hline $1 / 26 / 06$ & 7.1 & & 0.036 \\
\hline $1 / 28 / 06$ & 8.0 & 0.050 & 0.054 \\
\hline $1 / 30 / 06$ & 7.1 & 0.056 & \\
\hline $1 / 31 / 06$ & 7.8 & 0.066 & 0.073 \\
\hline $2 / 1 / 06$ & 8.0 & 0.043 & 0.051 \\
\hline $2 / 2 / 06$ & 9.3 & 0.058 & 0.058 \\
\hline $2 / 3 / 06$ & $\underline{7.6}$ & $\underline{0.062}$ & $\underline{0.060}$ \\
\hline $1^{\text {st }}$ Average & $\overline{7.8}$ & $\overline{0.054}$ & $\overline{0.056}$ \\
\hline $6 / 14 / 06$ & & NA & 0.053 \\
\hline $6 / 15 / 06$ & 10.2 & NA & 0.056 \\
\hline 6/16/06 & & NA & 0.058 \\
\hline $6 / 17 / 06$ & 7.1 & NA & 0.049 \\
\hline $6 / 18 / 06$ & & NA & 0.034 \\
\hline 6/19/06 & $\underline{7.4}$ & NA & $\underline{0.042}$ \\
\hline $2^{\text {nd }}$ Average & 8.2 & $\overline{\mathrm{NA}}$ & 0.049 \\
\hline
\end{tabular}

The moisture content of the coal samples from the parametric testing periods was a little higher than that for the baseline samples. The coal mercury content was slightly lower during the parametric testing that during the baseline period. The coal mercury data from the two laboratories agreed very well.

A few fly ash samples were taken before the injection tests began in order to provide a comparison to the baseline fly ash samples. During each parametric injection run, normally near the end of the run, fly ash samples were collected. Fly ash was collected from all six hoppers. The inlet hoppers are numbered 16-18 while the outlet hoppers are numbered 13-15.

The mercury analyses of fly ash collected during the first parametric test period are presented in Table 8. 


\begin{tabular}{|c|c|c|c|c|c|c|c|c|c|}
\hline \multicolumn{10}{|c|}{$\begin{array}{c}\text { Table 8. Lee 1 Fly Ash Mercury Data } \\
\text { Average Hg Concentration in fly ash (ppb) }\end{array}$} \\
\hline Date & Period & $\underline{16}$ & $1 \overline{7}$ & $\underline{18}$ & Average & 13 & $\underline{14}$ & $\underline{15}$ & Average \\
\hline $1 / \overline{23 / 2006}$ & Before Injection & $\overline{214}$ & $\overline{182}$ & $\overline{206}$ & 200 & $\overline{971}$ & $\overline{377}$ & $\overline{347}$ & 565 \\
\hline $\begin{array}{c}\text { 1/23/2006 } \\
\text { Average }\end{array}$ & Before Injection & 199 & 92 & 112 & $\frac{134}{167}$ & 548 & 344 & 388 & $\begin{array}{l}427 \\
496\end{array}$ \\
\hline $1 / 24 / 2006$ & During Injection & 346 & 296 & 362 & 335 & 799 & 650 & 594 & 681 \\
\hline $1 / 25 / 2006$ & During Injection & 309 & 249 & 314 & 291 & 695 & 731 & 596 & 674 \\
\hline $1 / 25 / 2006$ & During Injection & 271 & 183 & 286 & 246 & 784 & 855 & 721 & 786 \\
\hline $1 / 26 / 2006$ & During Injection & 290 & 237 & 233 & 253 & 876 & 871 & 723 & 823 \\
\hline $1 / 28 / 2006$ & During Injection & 393 & 399 & 367 & 386 & 840 & 583 & 509 & 644 \\
\hline $1 / 30 / 2006$ & During Injection & 257 & 231 & 217 & 235 & 292 & 331 & 638 & 420 \\
\hline $1 / 30 / 2006$ & During Injection & 272 & 349 & 210 & 277 & 826 & 753 & 637 & 738 \\
\hline $1 / 31 / 2006$ & During Injection & 323 & 333 & 278 & 311 & 756 & 603 & 482 & 613 \\
\hline $1 / 31 / 2006$ & During Injection & 331 & 366 & 348 & 348 & 917 & 771 & 595 & 761 \\
\hline 2/1/2006 & During Injection & 414 & 351 & 488 & 418 & 635 & 697 & 540 & 624 \\
\hline 2/1/2006 & During Injection & 427 & 356 & 502 & 428 & 702 & 643 & 580 & 641 \\
\hline 2/2/2006 & During Injection & 243 & 304 & 502 & 350 & 714 & 564 & 287 & 522 \\
\hline 2/2/2006 & During Injection & 406 & 442 & 463 & 437 & 805 & 709 & 720 & 745 \\
\hline $\begin{array}{l}2 / 3 / 2006 \\
\text { Averaqe }\end{array}$ & During Injection & 427 & 337 & 338 & $\frac{367}{334}$ & 934 & 796 & 552 & $\frac{761}{674}$ \\
\hline
\end{tabular}

The average mercury content of the fly ash samples before the parametric testing began was somewhat lower that that of the baseline period samples assuming that $70 \%$ of the ash reports to the front hoppers.

The fly ash mercury data for the second parametric test period are shown in Table 9.

\begin{tabular}{|c|c|c|c|c|c|c|c|c|c|}
\hline \multirow[b]{2}{*}{ Date } & \multirow[b]{2}{*}{ Condition } & \multicolumn{4}{|c|}{ Inlet Hoppers } & \multicolumn{4}{|c|}{ Outlet Hoppers } \\
\hline & & $\underline{16}$ & 17 & $\underline{18}$ & Average & $\underline{13}$ & 14 & $\underline{15}$ & Average \\
\hline $6 / 14 / 2006$ & Before Injection & $\overline{334}$ & $\overline{351}$ & $\overline{347}$ & 344 & $\overline{754}$ & $\overline{583}$ & $\overline{577}$ & 638 \\
\hline $6 / 15 / 2006$ & During Injection & 354 & 293 & 330 & 325 & 691 & 551 & 712 & 651 \\
\hline 6/16/2006 & During Injection & 316 & 393 & 375 & 361 & 788 & 712 & 686 & 729 \\
\hline $6 / 17 / 2006$ & During Injection & 304 & 338 & 277 & 306 & 654 & 676 & 713 & 681 \\
\hline $6 / 18 / 2006$ & During Injection & 416 & 363 & 463 & 414 & 743 & 814 & 862 & 806 \\
\hline 6/19/2006 & During Injection & 408 & 424 & 442 & 424 & 1002 & 912 & 885 & 933 \\
\hline $6 / 20 / 2006$ & During Injection & $\underline{389}$ & $\underline{250}$ & $\underline{355}$ & $\frac{331}{360}$ & $\underline{921}$ & $\underline{851}$ & $\underline{1011}$ & $\frac{928}{788}$ \\
\hline
\end{tabular}

The fly ash mercury content was much higher before the second set of parametric injection tests began but the fly ash mercury content did increase throughout this test period.

Parametric fly ash samples must be viewed with caution since there is an unknown amount of untreated fly ash collected in each sample. Only during the continuous longterm run can representative fly ash samples be collected from the fly ash hoppers. There was a significant increase in fly ash mercury content in the parametric samples as compared to the baseline samples indicating that a significant amount of mercury was 
being removed from the flue gas by the sorbent as the $\mathrm{Hg}$ monitors indicated. The mercury concentrations may be trending upward over the period of the trials.

The results of the LOI of selected fly ash samples from both parametric test periods are presented in Tables 10 and 11.

\begin{tabular}{|c|c|c|c|}
\hline \multicolumn{4}{|c|}{ Table 10. Fly Ash LOI from the First Parametric Test Period } \\
\hline & & Inlet & Outlet \\
\hline Sample & Condition & Hopper & Hopper \\
\hline $1 / 24 \overline{200616: 50}$ & During Injection & $10.6 \%$ & $21.0 \%$ \\
\hline 1/26/2006 10:00 & Before Injection & $11.1 \%$ & $17.1 \%$ \\
\hline 1/26/2006 16:00 & During Injection & $9.3 \%$ & $16.5 \%$ \\
\hline 1/30/2006 16:35 & During Injection & $10.0 \%$ & $10.3 \%$ \\
\hline 2/2/2006 10:00 & Before Injection & $9.5 \%$ & $19.3 \%$ \\
\hline 2/2/2006 16:15 & During Injection & $11.8 \%$ & $12.4 \%$ \\
\hline Average & & $\overline{10.4 \%}$ & $\overline{16.1 \%}$ \\
\hline
\end{tabular}

\begin{tabular}{|c|c|c|c|c|c|c|}
\hline \multicolumn{7}{|c|}{$\begin{array}{c}\text { Table 11. Fly Ash LOI from the Second Parametric Test Period } \\
\text { Inlet Hoppers }\end{array}$} \\
\hline Date & $\underline{16}$ & 17 & 18 & $\underline{13}$ & 14 & 15 \\
\hline $6 / \overline{14 / 0} 6$ & $9 . \overline{8} \%$ & $13 . \overline{8} \%$ & $10.9 \%$ & $18 . \overline{0} \%$ & $24 . \overline{4} \%$ & $15.3 \%$ \\
\hline 6/16/06 & $10.6 \%$ & $14.4 \%$ & $11.1 \%$ & $13.5 \%$ & $17.0 \%$ & $16.3 \%$ \\
\hline $6 / 18 / 06$ & $11.0 \%$ & $11.9 \%$ & $12.0 \%$ & $17.5 \%$ & $19.0 \%$ & $16.2 \%$ \\
\hline Average & $\overline{10.5 \%}$ & $\overline{13.4 \%}$ & $\overline{11.3 \%}$ & $\overline{16.3 \%}$ & $\overline{20.1 \%}$ & $15.9 \%$ \\
\hline Inlet Average = & & $11.7 \%$ & & $\begin{array}{l}\text { Outlet } \\
=\end{array}$ & erage & $17.5 \%$ \\
\hline
\end{tabular}

Samples in the first test period were collected both before and during sorbent injection, while those from the second test period were all collected during sorbent injection. There does not appear to be much difference between the samples. The average LOI for all the samples collected during the first parametric test period averaged $10.4 \%$ for the front fields and $16.1 \%$ for the back fields as compared to $11.7 \%$ and $17.5 \%$, respectively, for the second test period. These values are close to the historical baseline values of $10 \%$ in the front hoppers and $15 \%$ in the back. This also brings into question the representative nature of the samples. A better indication of the impact of sorbent injection on fly ash LOI should come from the samples from the long-term test.

\section{Boiler Operation}

For the parametric tests, Lee 1 was maintained at a load of $56 \mathrm{MW}$. Progress Energy Lee personnel did not want to take the chance of increased opacity while operating at full load and no $\mathrm{SO}_{3}$ injection. The mercury level at this load is nearly identical to that at full load since the boiler varies flue gas flow rate directly with load. For example, the flue gas flow rate at full load is about 300,000 acfm whereas it is 200,000 acfm at two thirds boiler load. 
There was an important observation in regard to the operation of Lee 1 during the parametric testing. Usually, the longer this boiler operates under a given set of conditions, even with $\mathrm{SO}_{3}$ injection, the more the opacity deteriorates. This is true both for the average opacity and for the spikes when changing loads. However, stack opacity during the parametric tests got better the longer the tests ran, even though the $\mathrm{SO}_{3}$ injection was off for significant periods of time over these days of testing. The operating parameters of the ESP appeared to improve throughout the testing as well. (This is not the first time that B-PAC ${ }^{T M}$ has been suspected of improving ESP performance. The first time was at the Duke Power Buck Station.)

It was decided to perform additional tests in order to determine if this effect was caused by the injection of the mercury sorbents. A short three-day continuous run was to be conducted to determine whether the boiler could operate without $\mathrm{SO}_{3}$ injection while injecting B-PAC ${ }^{T M}$. This could be an important finding about the B-PAC ${ }^{\mathrm{TM}}$ sorbent, if it provides a co-benefit avoiding the use of $\mathrm{SO}_{3}$ injection for fly ash modification, while also capturing mercury. The three day continuous run was scheduled before the parametric testing resumed since it had a direct impact on the possible need to move the $\mathrm{SO}_{3}$ injection location for the 30-day continuous run. 


\section{Long-Term Test}

A three-day continuous injection run was scheduled to begin on March 8, 2006. It was decided that, if Lee 1 could operate without $\mathrm{SO}_{3}$ injection, the three-day continuous run would become the start of the 30-day long-term test. Boiler availability was one of the reasons for this plan, since Lee 1 would be available for 30 days starting March 8 but probably would not be again until June.

The three-day run was designed to inject B-PAC ${ }^{\mathrm{TM}}$ at a rate of $8 \mathrm{lb} / \mathrm{MMacf}$. This injection rate and sorbent had been found to provide a mercury removal rate due to sorbent of over $80 \%$ in the parametric tests. On the morning of March 8 , the B-PAC ${ }^{\mathrm{TM}}$ injection began with the $\mathrm{SO}_{3}$ injection still in operation. On the second day, the $\mathrm{SO}_{3}$ injection was turned off but the boiler remained at low to medium loads. The third day was to be the test of the ability of Lee 1 to stay at full load with B-PAC ${ }^{\mathrm{TM}}$ injection but without $\mathrm{SO}_{3}$ injection. The $\mathrm{SO}_{3}$ injection system was not reactivated until after the end of the longterm test.

One challenge to performing the long-term test was making the sorbent and getting it to Lee in time. The production facility was more than up to the task, as it could easily provide more than a week's supply of sorbent in only four operating shifts. The problem was in obtaining the raw materials and delivery services in the time frame needed. These obstacles were overcome and the long-term test was conducted without an interruption. An Albemarle Environmental $\mathrm{f} / \mathrm{k} / \mathrm{a}$ Sorbent Technologies tanker was pressed into service for the long-term test. The first large load of sorbent for the longterm test was taken to Lee in the tanker and, subsequently, other tankers were used to refill this tanker with the B-PAC ${ }^{\mathrm{TM}}$ sorbent. A total of 84,292 pounds of $\mathrm{B}-\mathrm{PAC} \mathrm{C}^{\mathrm{TM}}$ was used in the long-term test, which ran from March 8 to April 7, 2006.

\section{Mercury Monitor Data}

During the long-term test, the PS Analytical mercury monitor was used to measure the vapor phase mercury content of the ESP inlet flue gas, before sorbent injection, and in the ESP outlet flue gas. The Ohio Lumex monitor was not available for this test period. In addition, there were Method 324 sorbent trap mercury samples taken as well as one set of OHM mercury tests performed.

The PS Analytical data was used to calculate the total vapor phase mercury removal rate during the long-term test. The test began with the native $\mathrm{Hg}$ removal in the $30 \%$ range, as is typical for boilers using bituminous coal. The total mercury removal increased to the $60 \%$ range on the first day of the test when $\mathrm{SO}_{3}$ injection was operating. This increased to $85 \%$ mercury removal for all but the very end of the test, when a plain activated carbon was used. The total mercury removal for the 30-day long-term test, excluding the first and last days, averaged $85 \%$.

The mercury removal results are shown in Figure 20. 
Figure 20. Total Vapor Phase Hg Removal during the Long-Term Test at Lee 1

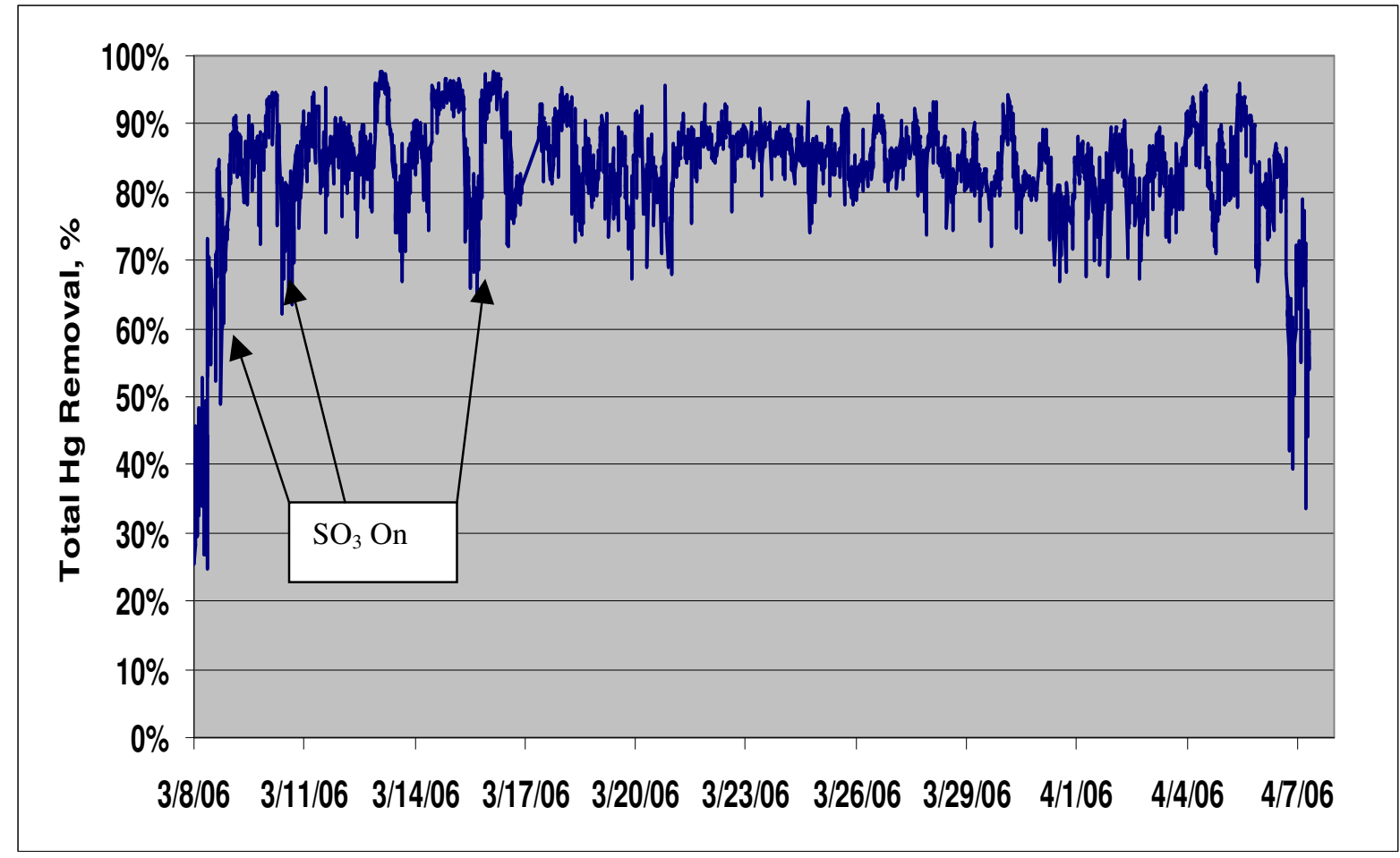

The B-PAC ${ }^{T M}$ sorbent was expected to have a long-lasting impact on mercury emissions at Lee 1 since the flue gas is always below $300^{\circ} \mathrm{F}$, and many times well below. This turned out to be the case, as the mercury levels at the end of the long-term test had not recovered to baseline after 15 hours without injection.

The achievement of $85 \% \mathrm{Hg}$ removal over the 30 days long-term test is another milestone in the history of achievement of the Albemarle Environmental $\mathrm{f} / \mathrm{k} / \mathrm{a}$ Sorbent Technologies' B-PAC ${ }^{\top M}$ sorbent.

\section{Method 324 Data}

Method 324 mercury trap samples were collected periodically throughout the long-term test at Lee 1. Generally, the samples were collected simultaneously at the inlet and outlet of the ESP.

The mercury data from the Method 324 testing agreed very well with that of the PS Analytical mercury monitor. The Method 324 data indicated that the mercury removal for the periods when both sets of data was available was $87.7 \%$, compared to the $85.2 \%$ determined by the PS Analytical data. This slight difference in mercury removal rates can be seen in the mercury data where the inlet data from both instruments are nearly the same but the Method 324 test measured a slightly lower mercury outlet level than did the PS Analytical monitor.

The results of the Method 324 tests are presented in Table 12, along with the mercury data from the PS Analytical monitor for the same time periods as the Method 324 testing. 


\begin{tabular}{|c|c|c|c|c|c|c|}
\hline \multirow[b]{2}{*}{ Date } & \multicolumn{2}{|c|}{ Method 324} & \multicolumn{2}{|c|}{ PSA } & \multicolumn{2}{|c|}{ Hg Removal, \% } \\
\hline & Inlet & Outlet & Inlet & Outlet & Method 324 & PSA \\
\hline$\overline{3 / 8 / 06}$ & & 1348 & $\overline{4707}$ & 1682 & & \\
\hline $3 / 9 / 06$ & 5396 & 782 & 5871 & 829 & $85.5 \%$ & $85.9 \%$ \\
\hline $3 / 11 / 06$ & 5932 & 779 & 3317 & 576 & $86.9 \%$ & $82.6 \%$ \\
\hline 3/14/06 & & 726 & 6112 & 466 & & \\
\hline 3/16/06 & 4997 & 936 & 5917 & 1207 & $81.3 \%$ & $79.6 \%$ \\
\hline 3/17/06 & 3987 & 872 & 5366 & 542 & $78.1 \%$ & $89.9 \%$ \\
\hline 3/20/06 & & 810 & 6087 & 1146 & & $81.2 \%$ \\
\hline 3/22/06 & 7417 & 530 & 7126 & 744 & $92.9 \%$ & $89.6 \%$ \\
\hline 3/23/06 & 6713 & 494 & 6507 & 774 & $92.6 \%$ & $88.1 \%$ \\
\hline $3 / 24 / 06$ & 6971 & 630 & 5338 & 704 & $91.0 \%$ & $86.8 \%$ \\
\hline 3/26/06 & 4340 & 419 & 6475 & 863 & $90.3 \%$ & $86.7 \%$ \\
\hline 3/29/06 & & 1031 & 7608 & 1330 & & \\
\hline 3/30/06 & 6419 & & 7138 & 1299 & & \\
\hline 3/31/06 & 7019 & 973 & 6721 & 1406 & $86.1 \%$ & $79.1 \%$ \\
\hline $4 / 1 / 06$ & 5937 & 835 & 5817 & 1248 & $85.9 \%$ & $78.5 \%$ \\
\hline $4 / 3 / 06$ & 6939 & 1127 & 5696 & 1102 & $83.8 \%$ & $80.6 \%$ \\
\hline $4 / 4 / 06$ & 5266 & 170 & 5277 & 363 & $96.8 \%$ & $93.1 \%$ \\
\hline $4 / 5 / 06$ & 3782 & 281 & 4581 & 393 & $92.6 \%$ & $91.4 \%$ \\
\hline 4/6/06 & 7209 & 1167 & 5689 & 889 & $83.8 \%$ & $84.4 \%$ \\
\hline Average & $\overline{5888}$ & 773 & $\overline{5861}$ & $\overline{924}$ & $\overline{87.7 \%}$ & $\overline{85.2 \%}$ \\
\hline
\end{tabular}

All of the tubes were analyzed for particulate mercury and little to none was found in this test. A few tubes had the back sections spiked with a known amount of mercury. All of the recoveries were within the acceptable limits. The use of spiked tubes is now referred to as Appendix K or Method 30B sampling.

\section{$\underline{\text { OHM Data }}$}

OHM mercury testing was performed on March 29, 2006 during the long-term test at Lee 1. The OHM tests were conducted in triplicate simultaneously at the inlet and outlet locations. These tests were performed by URS Corporation of Morrisville, North Carolina.

The mercury results of the OHM testing at Lee 1 during the long-term test are presented in Table 13.

\begin{tabular}{|c|c|c|c|c|c|}
\hline \multicolumn{6}{|c|}{$\begin{array}{l}\text { Table 13. Lee 1 Long-Te } \\
\text { (All concentrations in ng/Nm3 at 3\% } \\
\text { O2) }\end{array}$} \\
\hline Location & $\mathrm{HgP}$ & $\mathrm{Hg}+2$ & $\mathrm{HgO}$ & $\begin{array}{c}\text { Total Vapor } \\
\text { Phase Hg }\end{array}$ & $\begin{array}{c}\text { Total } \\
\underline{\mathrm{Hg}}\end{array}$ \\
\hline Inlet & 3111 & 2792 & 558 & 3350 & 6461 \\
\hline Inlet & 782 & 1280 & 569 & 1849 & 2631 \\
\hline Inlet & 1245 & 2125 & $\underline{659}$ & 2784 & 4029 \\
\hline Average & 1713 & 2066 & 595 & 2661 & 4374 \\
\hline STD & 1233 & 758 & 55 & 758 & 1938 \\
\hline
\end{tabular}

Albemarle Environmental f/k/a Sorbent Technologies Corporation $\quad$ DE-FC26-05NT42308 60 


\begin{tabular}{|cccccc|} 
Outlet & ND & 522 & ND & $>522$ & $>522$ \\
Outlet & ND & 769 & ND & $>769$ & $>769$ \\
Outlet & $\frac{\text { ND }}{N D}$ & $\frac{686}{659}$ & $\frac{\text { ND }}{\text { ND }}$ & $\frac{>686}{>659}$ & $>686$ \\
Average & ND & $\mathbf{1 2 6}$ & & & $>659$ \\
STD & & & & & \\
ND $=$ Not Detected & & & & \\
\hline
\end{tabular}

The inlet total mercury concentration varied by more than a factor of two among the three samples. This variation is primarily due to the large variation in the particulate mercury measurement by nearly a factor of three and the variation in the oxidized mercury concentration by more than a factor of two. STC believes that the filter in the $\mathrm{OHM}$ system was acting as a fixed-bed reactor in which much of the gas phase mercury, probably mostly oxidized mercury, is being captured. Thus, the oxidized mercury value should include most, if not all, of the mercury measured as particulate mercury. This position is supported by the Method 324 testing and this issue was noted in the baseline testing.

Both the outlet particulate and elemental mercury concentration were below the detection limit of the test. Therefore, the exact concentration of the outlet emissions is presented as a greater than value. The OHM data is presented along with the mercury data from the other instruments in Table 14.

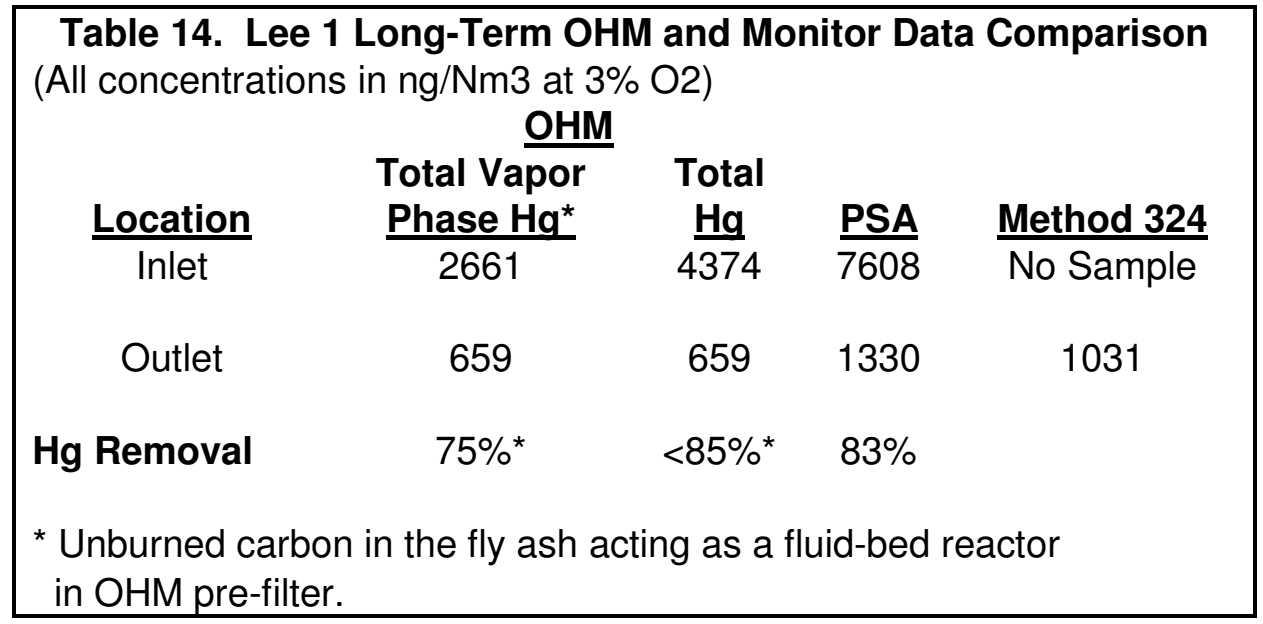

The $\mathrm{OHM}$ total vapor phase mercury data indicates that the mercury removal rate for the time period of the test was $75 \%$, while the total mercury data indicates that the mercury removal was less than $85 \%$. STC believes that the latter mercury removal is closer to the actual gas phase mercury removal since much of the measured particulate mercury is really vapor phase mercury. The PS Analytical monitor measured a vapor phase mercury removal of $83 \%$ during this test period. Unfortunately, there was only an outlet Method 324 sample taken during this time period and, thus, no removal rate can be calculated from this data.

The outlet total mercury concentration measured by the OHM test is considerably lower than that measured by the PS Analytical monitor. The data from the Method 324 test 
does not support either value, but rather, is nearly half way in between the two outlet mercury values.

\section{Coal and Fly Ash Data}

The proximate analyses of coal samples taken during the long-term test at Lee 1 are shown in Table 15.

\begin{tabular}{|c|c|c|c|c|c|}
\hline Date & Ash, $\%$ & Volatile Matter, \% & Fixed C, \% & Sulfur, \% & $\begin{array}{c}\text { Heating Value } \\
\text { BTU/lb }\end{array}$ \\
\hline$\overline{3 / 8 / 06}$ & 10.7 & 38.5 & 50.8 & 0.84 & $\overline{13,238}$ \\
\hline $3 / 11 / 06$ & 12.8 & 37.5 & 49.7 & 0.87 & 12,836 \\
\hline $3 / 14 / 06$ & 9.7 & 38.6 & 51.7 & 0.86 & 13,364 \\
\hline $3 / 17 / 06$ & 10.7 & 38.9 & 50.4 & 0.84 & 13,227 \\
\hline $3 / 21 / 06$ & 10.5 & 37.6 & 51.9 & 0.83 & 13,235 \\
\hline 3/23/06 & 10.7 & 38.0 & 51.4 & 0.82 & 13,168 \\
\hline 3/26/06 & 10.9 & 37.8 & 51.3 & 0.79 & 13,169 \\
\hline $3 / 27 / 06$ & 10.5 & 38.7 & 50.8 & 0.86 & 13,253 \\
\hline $4 / 1 / 06$ & 9.8 & 38.9 & 51.3 & 0.82 & 13,366 \\
\hline $4 / 5 / 06$ & $\underline{10.8}$ & $\underline{38.0}$ & $\underline{51.2}$ & $\underline{0.83}$ & $\underline{13,151}$ \\
\hline Average & $\overline{10.7}$ & $\overline{38.3}$ & $\overline{51.1}$ & $\overline{0.84}$ & 13,201 \\
\hline
\end{tabular}

The coal used during the long-term test at Lee 1 had consistent properties averaging slightly less than $11 \%$ ash, about $38 \%$ volatile matter and about $51 \%$ fixed carbon, on a dry basis. Coal averaged $0.84 \%$ sulfur and a heating value of about $13,000 \mathrm{BTU} / \mathrm{lb}$, both on a dry basis. These values are very similar to those measured during the baseline and parametric testing. The coal moisture and mercury content of samples collected during the long-term test at Lee 1 are presented in Table 16.

\begin{tabular}{|ccc|}
\hline \multicolumn{3}{|c|}{ Table 16. Lee 1 Long-Term Test } \\
\cline { 2 - 3 } Coal Moisture and Mercury \\
Date & $\begin{array}{c}\text { Coal } \\
\text { Moisture, \% }\end{array}$ & $\begin{array}{c}\text { SGS Hg } \\
\text { ppm, Dry }\end{array}$ \\
$3 / 8 / 06$ & 6.4 & 0.073 \\
$3 / 9 / 06$ & & 0.028 \\
$3 / 11 / 06$ & 7.5 & 0.064 \\
$3 / 12 / 06$ & & 0.030 \\
$3 / 14 / 06$ & 6.8 & 0.042 \\
$3 / 15 / 06$ & & 0.030 \\
$3 / 17 / 06$ & 7.4 & 0.032 \\
$3 / 18 / 06$ & & 0.046 \\
$3 / 20 / 06$ & & 0.036 \\
$3 / 21 / 06$ & & 0.053 \\
$3 / 23 / 06$ & 7.8 & 0.044 \\
$3 / 24 / 06$ & 8.2 & 0.032 \\
$3 / 26 / 06$ & & 0.023 \\
$3 / 27 / 06$ & 7.3 & 0.072 \\
$3 / 29 / 06$ & 6.6 & 0.051 \\
$3 / 31 / 06$ & & 0.032
\end{tabular}




\begin{tabular}{|ccc|}
$4 / 1 / 06$ & 6.5 & 0.090 \\
$4 / 2 / 06$ & & 0.031 \\
$4 / 4 / 06$ & & 0.033 \\
$4 / 5 / 06$ & 7.7 & 0.042 \\
$4 / 6 / 06$ & & 0.041 \\
Average & 7.2 & $\mathbf{0 . 0 4 4}$ \\
\hline
\end{tabular}

The coal moisture content during the long-term test was $7.2 \%$, about the same as in the baseline and parametric testing. The coal mercury content, however, was significantly lower than in either of the previous periods averaging $0.044 \mathrm{ppm}$ on a dry basis. The coal mercury content had a large range from a low of $0.028 \mathrm{ppm}$ to a high of $0.090 \mathrm{ppm}$. The inlet mercury value, as measured by the PS Analytical monitor, did show a variation in concentration nearly as large as that in the coal but not on a day-to-day basis. It is assumed that some of the coal $\mathrm{Hg}$ variation was eliminated by blending in the bunker.

Fly ash samples were taken throughout the long-term test at Lee 1. A few of the fly ash samples for specific dates were made into composite samples and sent to SGS NA for principle component analysis. The data from these analyses are presented in Table 17. The data for the samples from the baseline measurement period is included in this table.

\begin{tabular}{|c|c|c|c|c|c|c|c|}
\hline \multicolumn{8}{|c|}{ Table 17. Lee 1 Fly Ash Elemental Analyses } \\
\hline Date & Period & Sample & $\frac{\mathrm{LOI}}{\%}$ & $\frac{\mathrm{SiO2}}{\%}$ & $\frac{\mathrm{Al} 2 \mathrm{O3}}{\%}$ & $\frac{\mathrm{TiO}_{2}}{\%}$ & $\frac{\mathrm{Fe} 2 \mathrm{O} 3}{\%}$ \\
\hline$\overline{1 / 18 / 06}$ & Baseline & Front Hopper & $\overline{10.1}$ & $5 \overline{7.1}$ & $3 \overline{2.5}$ & $\overline{1.5}$ & $\overline{4.1}$ \\
\hline $1 / 18 / 06$ & Baseline & Back Hopper & 13.2 & 55.5 & 32.7 & 1.6 & 5.2 \\
\hline $3 / 9 / 06$ & Long-Term & Front Hopper & 15.2 & 57.4 & 32.7 & 1.5 & 3.8 \\
\hline $3 / 9 / 06$ & Long-Term & Back Hopper & 28.2 & 55.0 & 33.5 & 1.6 & 4.7 \\
\hline 3/16/06 & Long-Term & Front Hopper & 10.8 & 57.5 & 33.0 & 1.5 & 3.5 \\
\hline $3 / 16 / 06$ & Long-Term & Back Hopper & 35.4 & 55.9 & 32.6 & 1.5 & 5.2 \\
\hline $3 / 26 / 06$ & Long-Term & Front Hopper & 11.7 & 57.3 & 32.9 & 1.5 & 3.6 \\
\hline $3 / 26 / 06$ & Long-Term & Back Hopper & 27.8 & 55.4 & 33.2 & 1.5 & 4.7 \\
\hline Date & Period & Sample & $\frac{\mathrm{CaO}_{1}}{\frac{\%}{6}}$ & $\frac{\mathrm{MgO}_{1}}{\frac{\%}{6}}$ & $\mathrm{~K} 20, \%$ & $\frac{\mathrm{Na} 2 \mathrm{O}}{\%}$ & SO3, \% \\
\hline $1 \overline{18 / 06}$ & Baseline & Front Hopper & $\overline{1.0}$ & $\overline{0.8}$ & 2.3 & $\overline{0.4}$ & 0.04 \\
\hline $1 / 18 / 06$ & Baseline & Back Hopper & 1.2 & 0.8 & 2.4 & 0.5 & 0.01 \\
\hline 3/9/06 & Long-Term & Front Hopper & 0.9 & 0.8 & 2.3 & 0.4 & 0.01 \\
\hline $3 / 9 / 06$ & Long-Term & Back Hopper & 1.1 & 0.8 & 2.5 & 0.5 & 0.01 \\
\hline $3 / 16 / 06$ & Long-Term & Front Hopper & 0.8 & 0.8 & 2.4 & 0.4 & 0.01 \\
\hline $3 / 16 / 06$ & Long-Term & Back Hopper & 1.1 & 0.8 & 2.4 & 0.5 & 0.08 \\
\hline $3 / 26 / 06$ & Long-Term & Front Hopper & 1.0 & 0.8 & 2.4 & 0.4 & 0.02 \\
\hline $3 / 26 / 06$ & Long-Term & Back Hopper & 1.2 & 0.8 & 2.4 & 0.5 & 0.03 \\
\hline
\end{tabular}


There is very little difference in the concentration of most of the compounds in the fly ash samples from both periods. One surprise was that the baseline samples, collected when the $\mathrm{SO}_{3}$ injection system was operating, did not exhibit high levels of $\mathrm{SO}_{3}$. In fact, the $\mathrm{SO}_{3}$ concentration in the ash was no higher in the baseline samples than in the longterm samples.

The major change is in LOI. The baseline samples had about $10 \% \mathrm{LOI}$ in the front hoppers and $13 \%$ LOI in the back hoppers. This is not far from the normal values of $10 \%$ and $15 \%$ typically found at Lee 1 in previous testing. During the long-term test, the LOI content of the fly ash in the front hoppers didn't change much but the LOI content of the back fields jumped to over $25 \%$. It is unknown if this means that the sorbent is preferentially reporting to the back hoppers or if the native LOI content in the back hoppers was higher during the long-term test.

Additional fly ash samples from the long-term test at Lee 1 were also analyzed for LOI and mercury. The LOI analyses of all of the long-term fly ash samples are presented in Table 18. The fly ash LOI content for all of the samples analyzed confirms the finding of greatly increased LOI in the back hopper but a lesser increase in the front field.

\begin{tabular}{|ccc|}
\hline \multicolumn{3}{|c|}{ Table 18. Fly Ash LOl during the Long-Term Test } \\
\hline Date & Inlet Hoppers & Outlet Hoppers \\
3/9/2006 & $15.2 \%$ & $28.2 \%$ \\
$3 / 10 / 2006$ & $10.8 \%$ & $29.6 \%$ \\
$3 / 13 / 2006$ & $9.0 \%$ & $16.4 \%$ \\
$3 / 14 / 2006$ & $12.9 \%$ & $35.2 \%$ \\
$3 / 16 / 2006$ & $10.8 \%$ & $35.4 \%$ \\
$3 / 18 / 2006$ & $9.1 \%$ & $25.0 \%$ \\
$3 / 20 / 2006$ & $8.2 \%$ & $25.8 \%$ \\
$3 / 22 / 2006$ & $14.6 \%$ & $27.3 \%$ \\
$3 / 24 / 2006$ & $12.1 \%$ & $23.0 \%$ \\
$3 / 26 / 2006$ & $\underline{11.7 \%}$ & $\underline{27.8 \%}$ \\
Average & $\underline{\mathbf{1 1 . 4} \%}$ & $\mathbf{2 7 . 4} \%$ \\
\hline
\end{tabular}

The fly ash $\mathrm{Hg}$ data for the same samples is presented in Table 19. The mercury content during the long-term test was much higher than during the parametric testing. This is probably an artifact of the sampling method in that much less untreated fly ash was sampled during the long-term test. 


\begin{tabular}{|c|c|c|c|c|c|c|c|c|c|}
\hline Average $\frac{\mathrm{Tab}}{\mathrm{Hg} \mathrm{C}}$ & $\frac{19 . \text { Lee } 1 \mathrm{~F}}{\text { 19entration }}$ & fly as & $\frac{e r c u r}{1(n g}$ & g) & om th & $-1 \epsilon$ & & & \\
\hline & & & Inl & $\mathrm{Ho}$ & pers & $\underline{\mathrm{Ou}}$ & et Hop & ers & \\
\hline Date & Period & 16 & $1 \overline{7}$ & 18 & Average & $1 \overline{3}$ & 14 & 15 & Average \\
\hline $3 / 8 / 2006$ & Inj.W SO3 & 373 & 330 & 311 & 338 & 728 & 800 & 661 & 729 \\
\hline $3 / 10 / 2006$ & Inj.W SO3 & 272 & 304 & 309 & 295 & 782 & 917 & 595 & 765 \\
\hline $3 / 9 / 2006$ & During Inj. & 443 & 386 & 394 & 407 & 886 & 903 & 835 & 875 \\
\hline 3/11/2006 & During Inj. & 446 & 523 & 422 & 463 & 1265 & 1205 & 1155 & 1208 \\
\hline 3/12/2006 & During Inj. & 342 & 294 & 335 & 323 & 1135 & 1075 & 941 & 1050 \\
\hline $3 / 13 / 2006$ & During Inj. & 326 & 286 & 250 & 287 & 1075 & 645 & 764 & 828 \\
\hline $3 / 14 / 2006$ & During Inj. & 276 & 333 & 464 & 357 & 941 & 661 & 589 & 730 \\
\hline $3 / 15 / 2006$ & During Inj. & 324 & 309 & 283 & 305 & 910 & 745 & 652 & 769 \\
\hline $3 / 16 / 2006$ & During Inj. & 301 & 284 & 269 & 284 & 831 & 568 & 471 & 623 \\
\hline 3/17/2006 & During Inj. & 324 & 404 & 299 & 342 & 844 & 562 & 612 & 673 \\
\hline 3/18/2006 & During Inj. & 344 & 330 & 392 & 355 & 957 & 456 & 509 & 641 \\
\hline $3 / 19 / 2006$ & During Inj. & 378 & 343 & 377 & 366 & 524 & 829 & 635 & 663 \\
\hline 3/20/2006 & During Inj. & 402 & 381 & 274 & 352 & 736 & 791 & 671 & 732 \\
\hline 3/21/2006 & During Inj. & 386 & 328 & 356 & 356 & 909 & 842 & 729 & 826 \\
\hline 3/22/2006 & During Inj. & 485 & 388 & 354 & 409 & 921 & 878 & 787 & 862 \\
\hline $3 / 23 / 2006$ & During Inj. & 480 & 383 & 353 & 405 & 877 & 882 & 785 & 848 \\
\hline $3 / 24 / 2006$ & During Inj. & 415 & 329 & 317 & 353 & 991 & 801 & 779 & 857 \\
\hline $3 / 25 / 2006$ & During Inj. & 437 & 349 & 357 & 381 & 898 & 803 & 859 & 853 \\
\hline $3 / 26 / 2006$ & During Inj. & 486 & 355 & 376 & 406 & 868 & 841 & 781 & 830 \\
\hline $3 / 27 / 2006$ & During Inj. & 422 & 323 & 329 & 358 & 808 & 901 & 893 & 867 \\
\hline 3/28/2006 & During Inj. & 319 & 287 & 305 & 303 & 813 & 716 & 557 & 695 \\
\hline 3/29/2006 & During Inj. & 397 & 482 & 321 & 400 & 930 & 653 & 569 & 717 \\
\hline $3 / 30 / 2006$ & During Inj. & 365 & 296 & 314 & 325 & 846 & 649 & 508 & 667 \\
\hline 3/31/2006 & During Inj. & 359 & 269 & 344 & 324 & 829 & 687 & 657 & 724 \\
\hline $4 / 1 / 2006$ & During Inj. & 423 & 376 & 326 & 375 & 1015 & 1055 & 868 & 979 \\
\hline $4 / 2 / 2006$ & During Inj. & 572 & 374 & 403 & 450 & 1515 & 1650 & 914 & 1360 \\
\hline $4 / 3 / 2006$ & During Inj. & 692 & 550 & 438 & 560 & 1345 & 1080 & 1165 & 1197 \\
\hline 4/4/2006 & During Inj. & 446 & 415 & 458 & 440 & 1035 & 865 & 786 & 895 \\
\hline $4 / 5 / 2006$ & During Inj. & 379 & 327 & 311 & 339 & 1140 & 1130 & 931 & 1067 \\
\hline $4 / 6 / 2006$ & During Inj. & 383 & 338 & 328 & 349 & 1055 & 835 & 751 & 880 \\
\hline $4 / 7 / 2006$ & During Inj. & 268 & 207 & 236 & 237 & 947 & 933 & 784 & 888 \\
\hline Average & & & & & 366 & & & & 819 \\
\hline
\end{tabular}

Mercury Mass Balance

The coal and fly ash data can be used to calculate the percentage of the coal mercury captured in the fly ash and these values can be compared to those determined by the mercury monitor in order to provide a mercury mass balance. The coal data indicates that the fly ash mercury content would be about 533 ppm if $100 \%$ of the mercury were to have been captured. Assuming that $70 \%$ of the fly ash is collected in the front hoppers and $30 \%$ in the back hoppers, the calculated average fly ash $\mathrm{Hg}$ content generated during the long-term test would be $502 \mathrm{ppm}$. This calculation suggests that $94 \%$ of the mercury was captured during the long-term test as compared to the $85 \%$ measured by the mercury monitors. The difference could be in the coal mercury analyses which had a very large range of concentrations. 


\section{$\underline{\text { Halogen Data }}$}

URS Corporation performed a Method 26A halogen test on March 30, 2006, during the long-term test at Lee 1 . The halogen tests were conducted in triplicate simultaneously at the inlet and outlet locations. The results are presented in Table 20.

\begin{tabular}{|c|c|c|}
\hline \multicolumn{3}{|c|}{$\begin{array}{l}\text { Table 20. Lee } 1 \text { Long-Term Halogen Test Result } \\
\text { (All concentrations in ppm, by vol.) }\end{array}$} \\
\hline Component & Inlet & Outlet \\
\hline $\mathrm{HCl}$ & 77 & 7 \\
\hline $\mathrm{Cl} 2$ & $<0.1$ & $<0.1$ \\
\hline $\mathrm{HBr}$ & 0.5 & 1.4 \\
\hline $\mathrm{Br} 2$ & $<0.1$ & $<0.1$ \\
\hline
\end{tabular}

The chlorine and bromine contents of both the inlet and outlet flue gas were very low and the $\mathrm{HCl}$ content was very high, as expected. Somewhat expected was the finding that there was a small amount of $\mathrm{HBr}$ in the inlet flue gas. It has been found that very little $\mathrm{HBr}$ will be released from B-PAC at the Lee 1 flue gas temperatures $\left(<300^{\circ} \mathrm{F}\right)$ in air. However, it was discovered in the testing at the Detroit Edison St. Clair Plant that other flue gas species can apparently replace the bromine in the B-PAC ${ }^{\mathrm{TM}}$. At the St. Clair plant, there was an indication that HF was the cause of the replacement and release. HF was not measured in the Lee 1 flue gas and it is not known if this is a potential cause of the release there. In any case, the $\mathrm{HBr}$ concentration is still very low more than fifty times lower than the concentration of $\mathrm{HCl}$ in the flue gas.

\section{Fly Ash Leachate Testing}

The Fly Ash from the long-term test conducted at Progress Energy Lee 1 was evaluated for leachate characteristics using the standard EPA TCLP methods. Additional samples were sent to a DOE contractor for detailed testing. The results of the leachate testing are presented in Figure 21.

Figure 21. Lee 1 Fly Ash Leachate Data

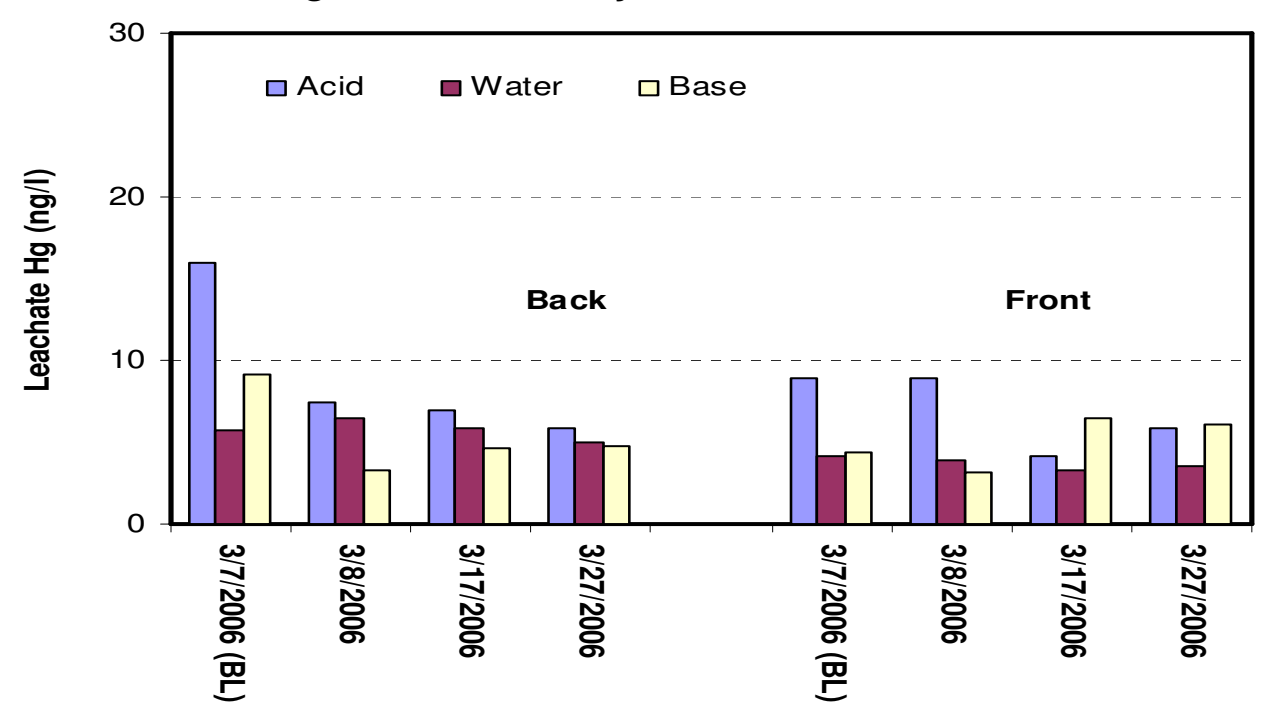


The concentration of mercury was very low in all of the leachates and, in most cases, the mercury concentration was below that of the blank. The mercury levels in the leachates were all well below all emissions standards.

\section{Boiler Operation}

There were no restrictions on Lee 1 boiler operations during the long-term test. The sorbent injection system was configured to follow the flue gas flow rate and adjust the $\mathrm{B}-\mathrm{PAC}^{\mathrm{TM}}$ injection rate to maintain $8 \mathrm{lb} / \mathrm{MMacf}$ throughout the test. Lee 1 varied load from the minimum of about $40 \mathrm{MW}$ to loads as high as $84 \mathrm{MW}$ during the long-term test.

The main focus of boiler operation during the long-term test was opacity since the boiler was operating without $\mathrm{SO}_{3}$ injection for most of the test. A plot of opacity and boiler load during the long-term test is presented in Figure 22.

Figure 22. Average Opacity during the Long-Term Test at Lee 1

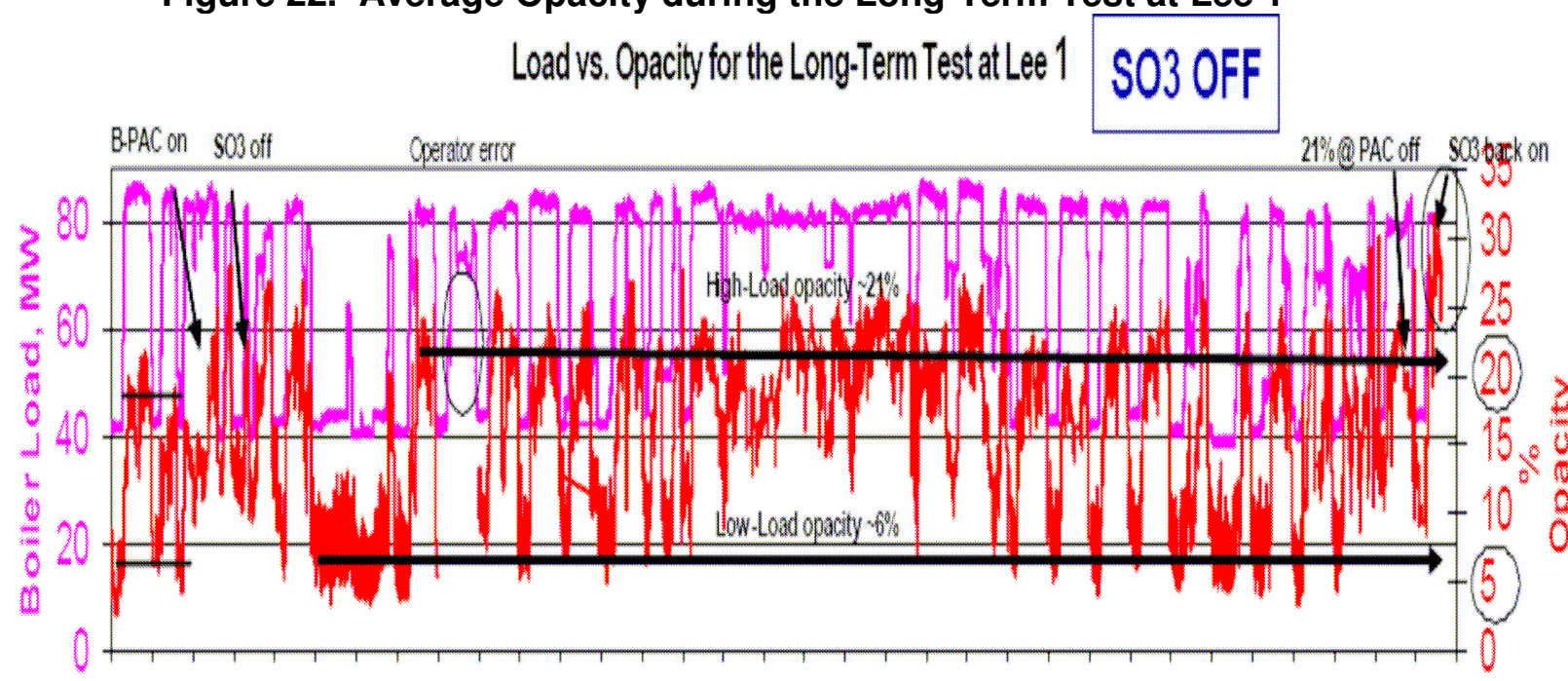

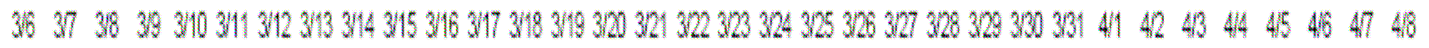

$$
\text { - Load - Load - Opacity - Opacity }
$$

The average opacity at Lee 1 increases with load. During the long-term test with B-PAC ${ }^{\mathrm{TM}}$ injection and without $\mathrm{SO}_{3}$ injection, the opacity was generally below $10 \%$ at low load. At full load, the Lee 1 opacity averaged $21 \%$ for the long-term test. This is better than was being achieved during the baseline period with $\mathrm{SO}_{3}$ injection. It should be noted that this was the first time that the opacity could be maintained at Lee 1 without $\mathrm{SO}_{3}$ injection. The positive impact of $\mathrm{B}-\mathrm{PAC}^{\mathrm{TM}}$ on opacity was very apparent at the end of the test program.

The opacity data for the end of the long-term test is shown in figure 23. 
Figure 23. Opacity Data after the End of the Long-Term Test at Lee 1

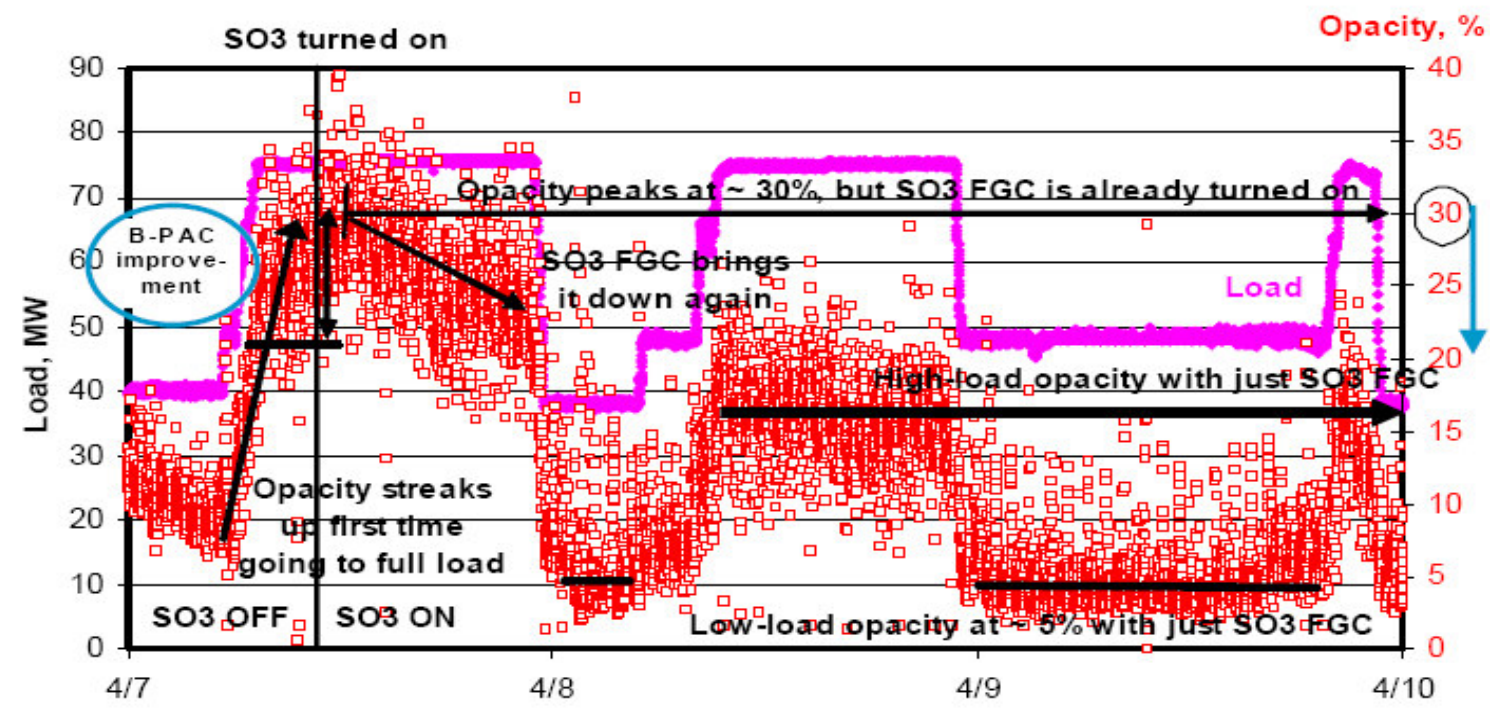

The long-term trial ended at night when the boiler was at low load and opacity was low. The next morning the boiler was brought up to full load without either $\mathrm{SO}_{3}$ injection or $\mathrm{B}-P A C^{\mathrm{TM}}$ injection in operation. The opacity soared to over $30 \%$ and could not be fully brought down to normal levels even with $\mathrm{SO}_{3}$ injection for about 24 hours.

The ability of B-PAC ${ }^{\mathrm{TM}}$ to act as a fly ash resistivity modifier to allow ESPs to operate more efficiently, as well as the ability to provide good mercury capture, is another milestone for this sorbent.

\section{Corrosion Testing}

As is the standard procedure, corrosion coupons were used to evaluate the corrosion occurring in the ductwork during the long-term test as compared to a baseline period. The duration of the exposure of the corrosion coupons was different for the two periods due to the availability of the corrosion coupons. Therefore, the corrosion rate is expressed in terms of $\mathrm{mg}$ of loss per day of exposure. The results are presented in Table 21.

\begin{tabular}{|c|c|c|}
\hline \multicolumn{3}{|c|}{ Table 21. Lee 1 Corrosion Testing Results } \\
\hline Period & Days Exposed & Weight Loss, mg/d \\
\hline$\overline{\text { Baseline }}$ & 23 & 1.674 \\
\hline Baseline & 23 & 1.748 \\
\hline Baseline & 23 & 2.348 \\
\hline Baseline & 23 & $\frac{1.617}{1.847}$ \\
\hline Long-Term & 12 & 0.383 \\
\hline Long-Term & 12 & 0.367 \\
\hline Long-Term & 12 & 0.308 \\
\hline Long-Term & 12 & $\frac{0.258}{0.329}$ \\
\hline
\end{tabular}


The corrosion loss per day was about a factor of six higher during the baseline period than during the long-term test. The reason for this is simple: $\mathrm{SO}_{3} . \mathrm{SO}_{3}$ is the main cause of corrosion in boiler ductwork. During the baseline period, $\mathrm{SO}_{3}$ was being injected to a concentration of about $15 \mathrm{ppm}$ on the hot-side of the air preheater. On the cold-side of the air preheater, where the corrosion coupons were located, the temperature was below the acid dew point and all of the $\mathrm{SO}_{3}$ condensed onto the fly ash or ductwork. During the long-term test, $\mathrm{SO}_{3}$ was not injected since the B-PAC was about to modify the fly ash resistivity and maintain the boiler opacity and, thus, there was less corrosion. 


\section{MIDWEST GENERATION CRAWFORD STATION}

The testing at Midwest Generation Crawford 7 began with equipment set-up on July 12 , 2006. The parametric testing was divided into two phases; the first using C-PAC ${ }^{\mathrm{TM}}$, the concrete friendly sorbent, and the other using non-concrete friendly materials. The first phase of the parametric tests was conducted before the long-term test. The second phase of the parametric testing was performed after the long-term test in order to avoid contaminating the fly ash containing the concrete friendly sorbents. All of the equipment was disassembled and the Albemarle Environmental $\mathrm{f} / \mathrm{k} / \mathrm{a}$ Sorbent Technologies and Western Kentucky University personnel departed the site on October 7, 2006.

The Midwest Generation Crawford Station is located in Chicago, Illinois. A photograph of the Crawford Station with the Albemarle Environmental $\mathrm{f} / \mathrm{k} / \mathrm{a}$ Sorbent Technologies' injection trailer and a sorbent tanker is shown in Photograph 14.

\section{Photograph 14. Crawford Station with Injection Trailer and Sorbent Tanker}

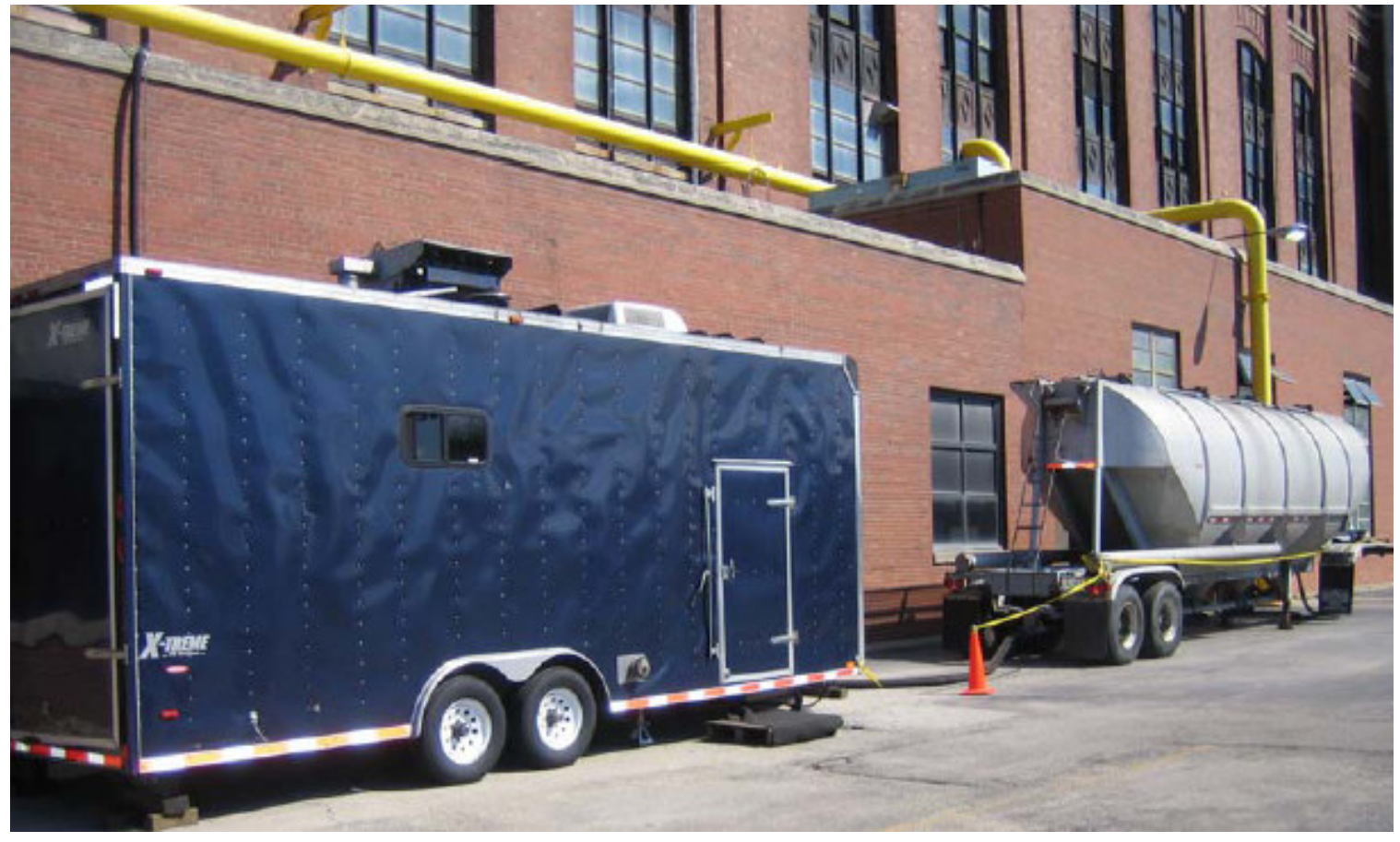

In this photograph, the injection hose can be seen to the left rear of the injection trailer as it rises to the injection location. Also shown in the right portion of this photograph is the Albemarle Environmental $\mathrm{f} / \mathrm{k} / \mathrm{a}$ Sorbent Technologies' sorbent tanker. This tanker was used instead of a silo for sorbent storage during the long-term test. The tanker was refilled from another tanker as needed.

\section{CFD Modeling}

Fuel Tech personnel took flow and temperature data from the Reheat Crawford 7 boiler in March, 2006. This data was used to calibrate a CFD model of the ductwork from the air preheater to the ESP entrance plenum. The model was subsequently used by Albemarle Environmental $\mathrm{f} / \mathrm{k} / \mathrm{a}$ Sorbent Technologies to predict the sorbent distribution of 
different injection arrangements in order to select the one that provides the best sorbent distribution with the fewest injection lances.

The ductwork studied is shown in Figure 24.

Figure 24. Crawford 7 Reheat Boiler Ductwork Modeled

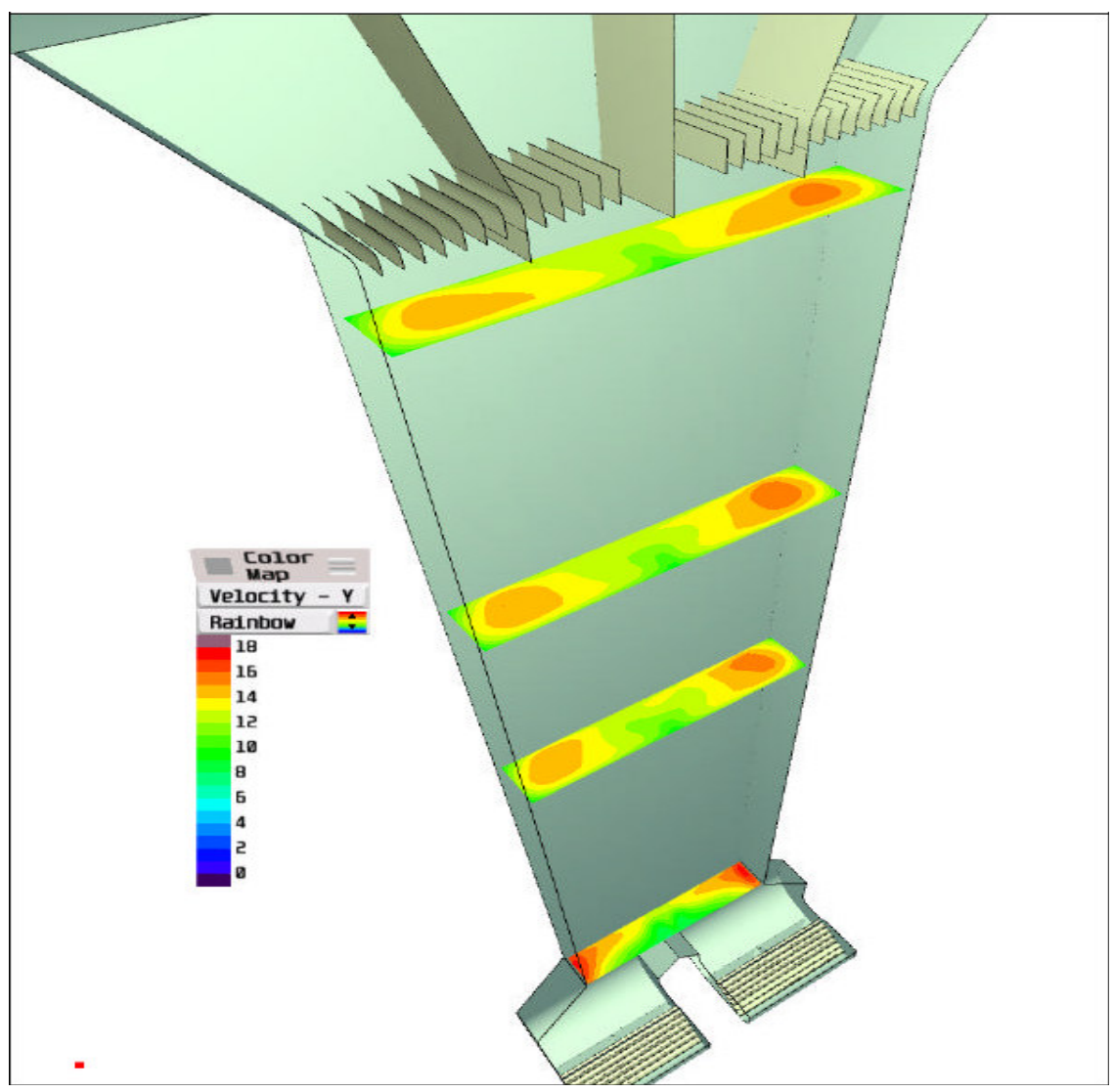

The duct run from the air preheaters to the ESP plenum at Crawford 7 combines two ducts into one. However, the single vertical duct still acts like it is two ducts with very little flue gas flow in the middle of the duct. The velocity profile of the flue gas in the vertical ductwork is shown in the Figure 24. The injection level was at elevation 129' 5" (second level from the bottom) with the ESP entrance being at 199'10". The reason for this distance is that the cold-side ESPs set on the roof of the building. The vertical duct leading to the ESP is 27 feet wide by five feet deep.

At the bottom of the ductwork, the gas velocity is highly skewed to along the outside walls due to the arrangement of the air preheaters. The high velocity areas move away from the end of the duct as the gas rises but the gas velocity never becomes uniform across the duct width.

Fuel Tech modeled numerous injection lance arrangements at the direction of Albemarle Environmental $\mathrm{f} / \mathrm{k} / \mathrm{a}$ Sorbent Technologies. It was found that the 10 lance arrangement was the best with standard lances. The sorbent distribution at three levels using the 10 lance arrangement is shown in Figure 25. 
Figure 25. Sorbent Distribution at Three Levels at Crawford 7 with a 10-Lance Arrangement

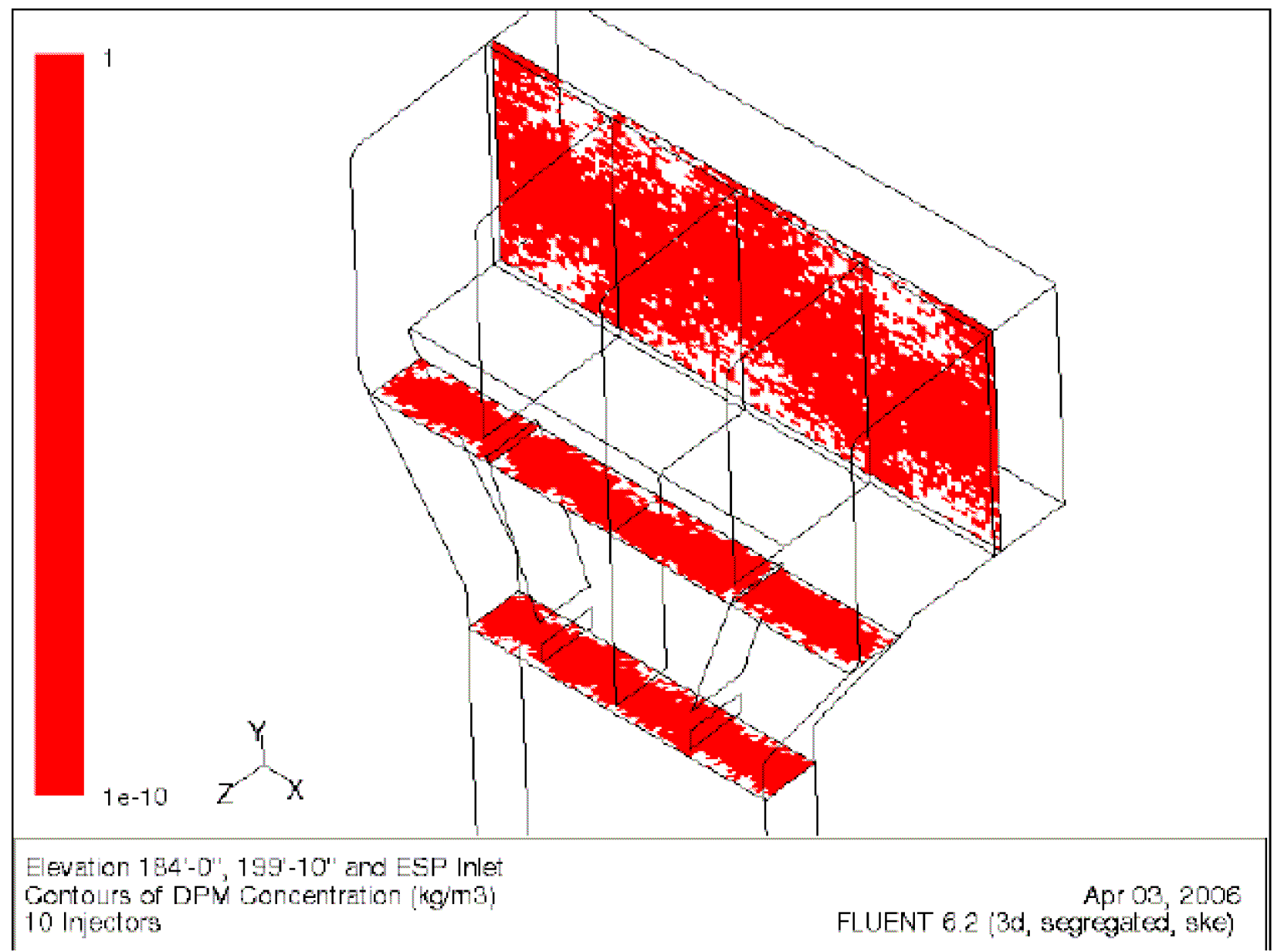

The sorbent exhibits a fairly good coverage pattern at all of the levels shown, but there are areas of no sorbent coverage especially after the sharp bend into the ESP plenum. The 10 regular lance arrangement was primarily used in the tests at the Midwest Generation Crawford Plant. A distributing lance arrangement with three ports per lance was evaluated in the second phase of the parametric testing. 


\section{Baseline Measurements}

\section{Mercury Monitor Data}

Due to Crawford 7 availability, the baseline testing was divided into three periods. The mercury data from the PS Analytical monitor for the first part of the baseline period is presented in Figure 26.

Figure 26. PSA Hg Data from the First Baseline Period at Crawford 7

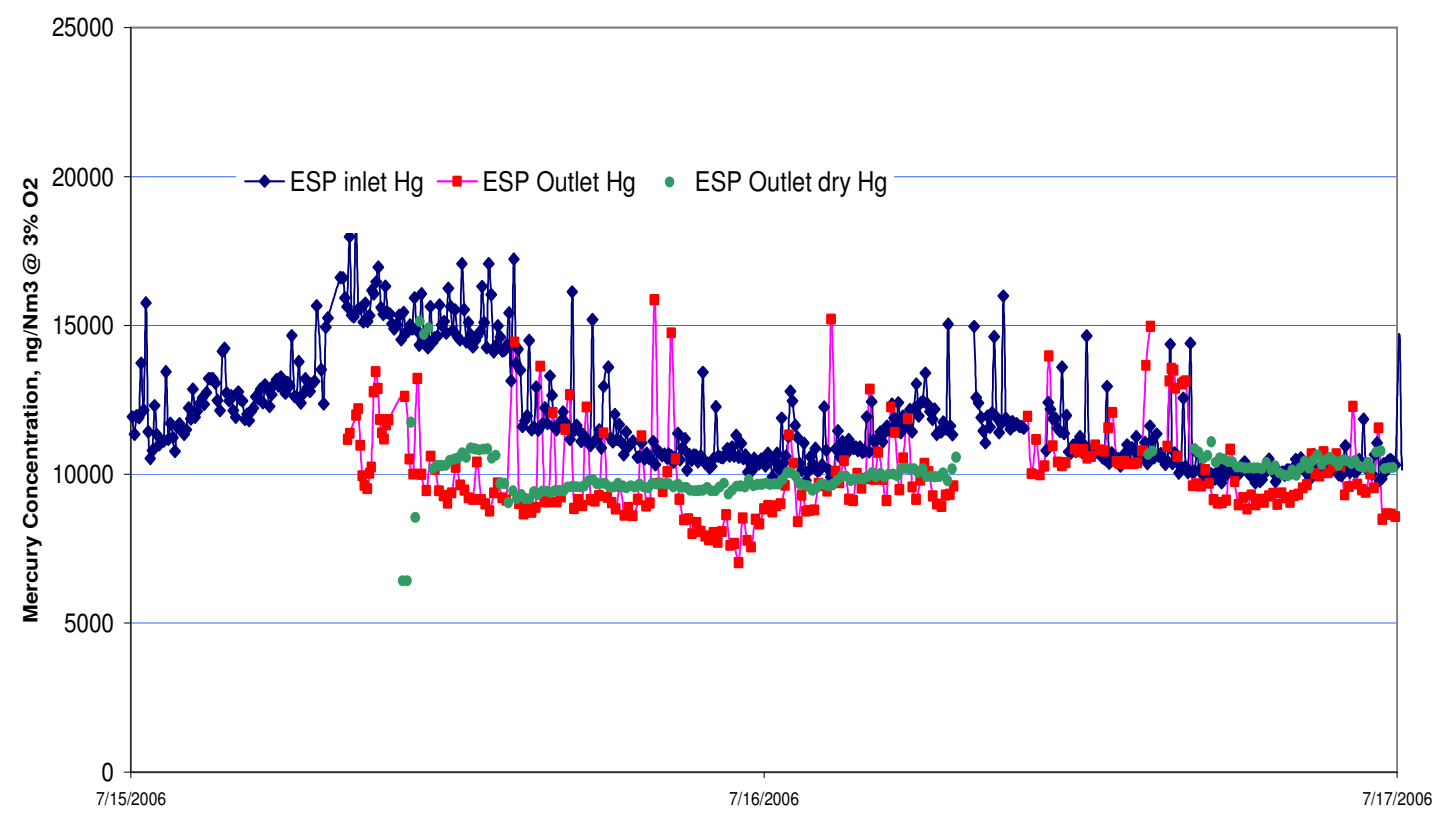

Crawford 7 operates in a manner such that the flue gas flow rate is fairly proportional to boiler load. As a result, the flue gas mercury concentration does not vary much with changing load. During the first baseline period, the total vapor phase mercury $\left(\mathrm{Hg}^{\top}\right)$ in the inlet to the ESP varied between about 10,000 to $15,000 \mathrm{ng} / \mathrm{Nm}^{3}$ at $3 \%$ oxygen. The outlet mercury concentrations were close to those at the inlet and, thus, there was not much native mercury removal during this period.

The PSA mercury conversion module at the inlet location was operated in the alternating wet/dry mode during this first baseline period. The mercury values using the dry conversion method compared favorably with those of the wet method during this period.

The average daily PSA mercury monitor data for the entire baseline period is presented in Figure 27, along with the measured native mercury removal. 
Figure 27. Average Daily PSA Hg Data from the Baseline Period at Crawford 7

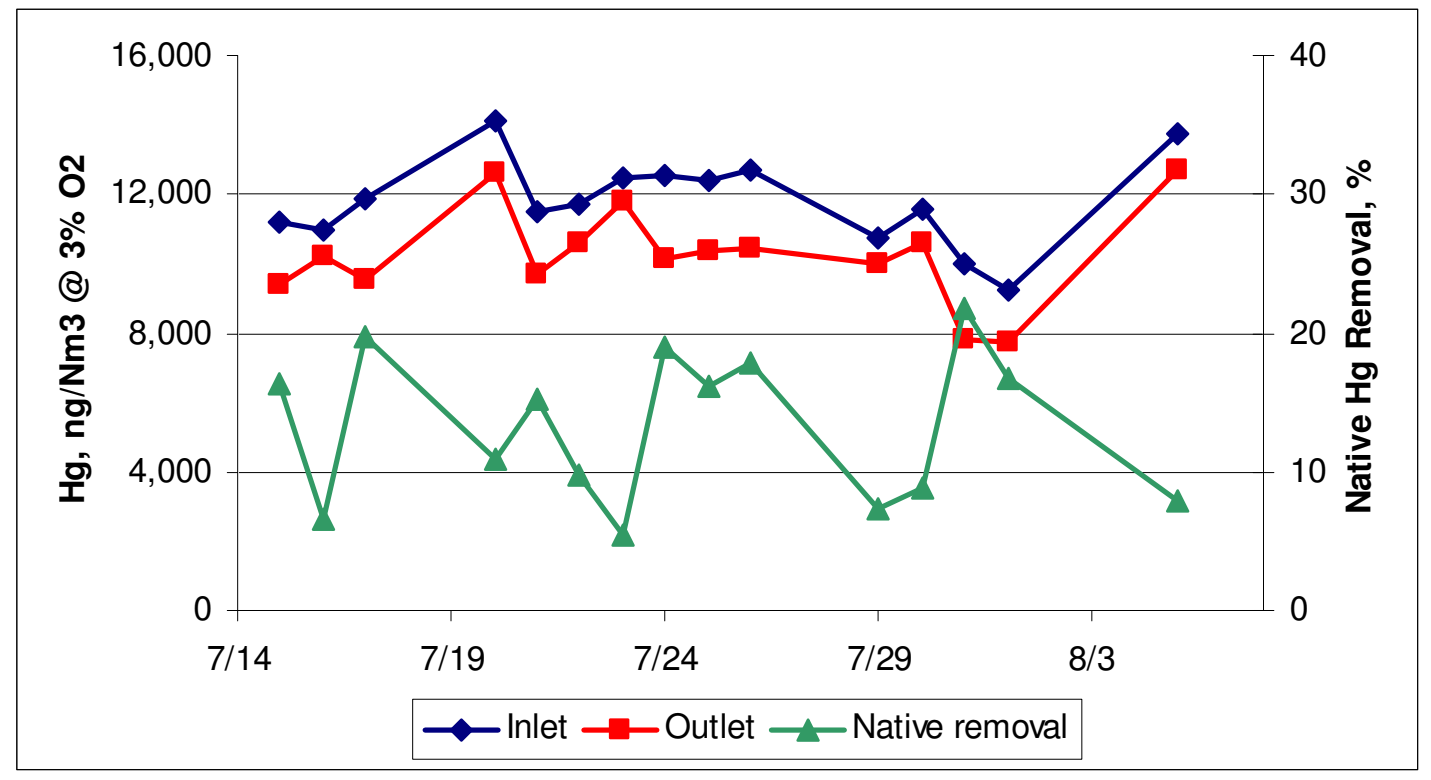

The native removal during the baseline period varied between $6 \%$ and $22 \%$ and averaged less than $15 \%$. This is common when firing a PRB coal which generates very little unburned carbon.

An experimental Ohio Lumex RA-915 monitor was also used to measure the inlet mercury during the baseline period. The data from this monitor and the PSA mercury monitor are presented in Figure 28.

Figure 28. PSA and Ohio Lumex Inlet Hg Data from the Baseline Period

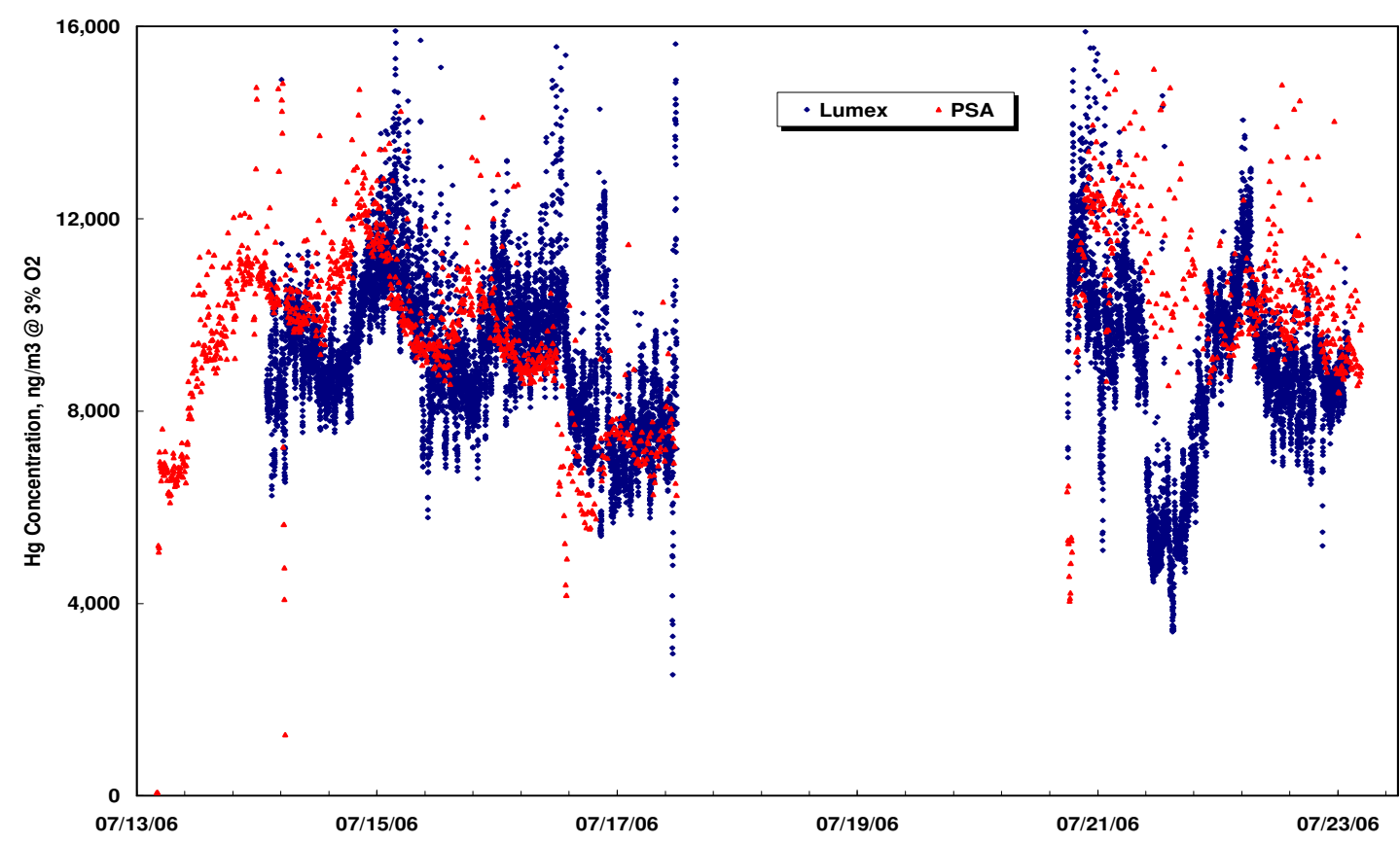


The Ohio Lumex instrument is based upon thermo-catalytic conversion and cold vapor atomic absorption spectroscopy with Zeeman background correction. The instrument, in its current configuration, can only be used to measure total vapor phase mercury.

The instrument has several potential major advantages over conventional semicontinuous $\mathrm{Hg}$ monitors. Most importantly the instrument is much closer to a true continuous emission monitor (CEM) such as used to measure other flue gas constituents. The Ohio Lumex $\mathrm{Hg}$ analyzer provides a measurement every 15 seconds rather than every five minutes as do the gold trap mercury monitors.

The agreement between the PSA and Ohio Lumex monitors was good in the baseline measurement period and the Ohio Lumex unit was used again during the long-term test.

\section{$\underline{\text { OHM Measurements }}$}

Simultaneous triplicate inlet and outlet OHM mercury measurements were made by GE Energy on Wednesday July 25. Crawford 7 was at full load (225 MW gross) during the OHM tests. The OHM results are presented in Table 22.

\begin{tabular}{|c|c|c|c|c|c|}
\hline \multicolumn{6}{|c|}{$\begin{array}{l}\text { Table 22. Crawford } 7 \text { Baseli } \\
\text { (All concentrations in ng/Nm3 at 3\% } \\
\text { O2) }\end{array}$} \\
\hline Location & $\mathrm{HgP}$ & $\underline{\mathrm{Hg}+2}$ & $\underline{\mathrm{Hg} 0}$ & $\begin{array}{l}\text { Total Vapor } \\
\text { Phase Hg }\end{array}$ & \multirow{2}{*}{$\begin{array}{c}\text { Total } \\
\underline{\mathbf{H g}}\end{array}$} \\
\hline Inlet & 24 & 312 & 12,806 & 13,119 & \\
\hline Inlet & 288 & 1,093 & 10,836 & 11,929 & 12,218 \\
\hline Inlet & 192 & 793 & 9,695 & 10,488 & 10,680 \\
\hline Average & $\overline{168}$ & $\overline{733}$ & $\overline{11,112}$ & $\overline{11,845}$ & $\overline{12,013}$ \\
\hline STD & 134 & 394 & 1,574 & 1,317 & 1,244 \\
\hline Outlet & 0 & 1,960 & 8,853 & 10,813 & 10,813 \\
\hline Outlet & 110 & 1,339 & 9,145 & 10,484 & 10,594 \\
\hline Outlet & $\underline{0}$ & 1,461 & 9,498 & 10,959 & $\underline{10,959}$ \\
\hline Average & $\overline{37}$ & $\overline{1,587}$ & $\overline{9,165}$ & $\overline{10,752}$ & $\overline{10,789}$ \\
\hline STD & 63 & 329 & 323 & 243 & 184 \\
\hline
\end{tabular}

Very little particulate mercury was present in either the inlet or outlet samples. The mercury was $94 \%$ in the elemental form at the inlet and $85 \%$ elemental at the outlet. The high level of elemental mercury in the flue gas is expected based upon the low halogen content of the coal being burned.

The OHM data is compared with the data from the PSA mercury monitor in Table 23. 


\begin{tabular}{|c|c|c|c|}
\hline \multicolumn{4}{|c|}{ Table 23. Crawford 7 Baseline OHM and Hg Monitor Data Comparison } \\
\hline & PSA & & \\
\hline Location & $\begin{array}{c}\text { Total Vapor } \\
\text { Phase Hg }\end{array}$ & $\begin{array}{c}\text { Total Vapor } \\
\text { Phase Hg }\end{array}$ & Total $\mathrm{Hg}$ \\
\hline Inlet & 12,821 & 11,845 & 12,013 \\
\hline Outlet & 11,460 & 10,752 & 10,789 \\
\hline Hg Removal & $11 \%$ & $9 \%$ & $10 \%$ \\
\hline
\end{tabular}

The OHM data and the data from the PSA mercury monitor compare favorably. The OHM total vapor phase data measured a native mercury removal for the test period of $9 \%$, whereas the OHM total mercury measurements finds a native mercury removal of $10 \%$. The PSA mercury monitor measured $11 \%$ native mercury removal.

\section{Coal and Fly Ash Data}

Midwest Generation Crawford Station uses a Powder River Basin (PRB) subbituminous coal. Coal samples were taken daily as the coal was being loaded into the Crawford 7 bunkers. The coal samples were sent to the SGS NA laboratories in the Chicago area for analyses. The coal analyses from the baseline period are presented in Table 24.

\begin{tabular}{|c|c|c|c|c|c|}
\hline \multicolumn{6}{|c|}{ Table 24. Crawford 7 Baseline Coal Data } \\
\hline & & As & Received & $\begin{array}{c}\text { Basis } \\
\text { Heat Content }\end{array}$ & \\
\hline Date & $\%$ Moisture & Ash, \% & Sulfur, \% & Btu/lb. & Hg, Dry \\
\hline $7 / 15 / 2006$ & 30.7 & 4.69 & 0.34 & 8,306 & 0.07 \\
\hline $7 / 16 / 2006$ & 29.9 & 4.39 & 0.23 & 8,413 & 0.08 \\
\hline $7 / 17 / 2006$ & 29.5 & 4.40 & 0.22 & 8,455 & 0.08 \\
\hline $7 / 21 / 2006$ & 32.2 & 4.07 & 0.23 & 8,205 & 0.08 \\
\hline $7 / 22 / 2006$ & 30.4 & 4.35 & 0.25 & 8,424 & 0.08 \\
\hline $7 / 23 / 2006$ & 28.6 & 4.84 & 0.26 & 8,590 & 0.09 \\
\hline $7 / 24 / 2006$ & 30.2 & 4.56 & 0.34 & 8,429 & 0.07 \\
\hline $7 / 25 / 2006$ & 29.7 & 3.83 & 0.19 & 8,451 & 0.09 \\
\hline $7 / 26 / 2006$ & 30.5 & 4.02 & 0.21 & 8,362 & 0.08 \\
\hline $7 / 27 / 2006$ & 28.6 & 4.34 & 0.39 & 8,639 & 0.08 \\
\hline $7 / 28 / 2006$ & 29.8 & 6.87 & 0.22 & 8,359 & 0.08 \\
\hline 7/29/2006 & 27.8 & 4.81 & 0.23 & 8,667 & 0.08 \\
\hline $7 / 30 / 2006$ & 29.9 & 4.85 & 0.20 & 8,281 & 0.10 \\
\hline $7 / 31 / 2006$ & 28.5 & 4.88 & 0.24 & 8,559 & 0.08 \\
\hline $8 / 1 / 2006$ & 29.0 & 5.34 & 0.32 & 8,506 & 0.09 \\
\hline $8 / 3 / 2006$ & 30.6 & 4.12 & 0.29 & 8,414 & 0.08 \\
\hline$\overline{\text { Average }}$ & $\overline{29.7}$ & $\overline{4.65}$ & $\overline{0.26}$ & $\overline{8,441}$ & $\overline{0.08}$ \\
\hline
\end{tabular}

The coal averaged about 30\% moisture during the baseline period. On an as received basis, the coal averaged less than $5 \%$ ash and $0.3 \%$ sulfur. The coal heat content averaged slightly below $8,500 \mathrm{Btu} / \mathrm{lb}$. The coal mercury content measured during the 
baseline period averaged $0.08 \mathrm{ppm}$, on a dry basis, and was very consistent throughout the baseline testing.

The ESP associated with Crawford 7 uses eight hoppers to collect fly ash. Samples were collected from all eight hoppers on each day of testing. Approximately $80 \%$ of the fly ash is collected in the front hoppers and $20 \%$ in the back hoppers. The LOI content of the fly ash in the back hoppers is slightly higher than in the front hoppers but the composite average is less than $0.5 \%$.

The results from the baseline fly ash mercury analyses are averaged for the front four hoppers and for the back four hoppers and shown in Table 25.

\begin{tabular}{|c|c|c|}
\hline$\frac{\text { Table } 25 \text { Crawford } 7 \text { B }}{\text { (Concentrations in pob) }}$ & ne Fly & Data \\
\hline Date & Front & Back \\
\hline $7 / \overline{15 / 2006}$ & $\overline{100}$ & 194 \\
\hline $7 / 16 / 2006$ & 102 & 147 \\
\hline $7 / 17 / 2006$ & 90 & 132 \\
\hline $7 / 22 / 2006$ & 191 & 198 \\
\hline $7 / 23 / 2006$ & 135 & 239 \\
\hline $7 / 24 / 2006$ & 180 & 189 \\
\hline $7 / 25 / 2006$ & 97 & 174 \\
\hline $7 / 26 / 2006$ & 101 & 202 \\
\hline $7 / 27 / 2006$ & 160 & 152 \\
\hline $7 / 28 / 2006$ & 145 & 233 \\
\hline $7 / 28 / 2006$ & 341 & 167 \\
\hline $7 / 29 / 2006$ & 191 & 209 \\
\hline $7 / 30 / 2006$ & 187 & 207 \\
\hline $7 / 31 / 2006$ & 104 & 148 \\
\hline $8 / 5 / 2006$ & 25 & 51 \\
\hline $8 / 15 / 2006$ & 78 & 289 \\
\hline $8 / 16 / 2006$ & $\underline{61}$ & 125 \\
\hline Average & $\overline{135}$ & $\overline{180}$ \\
\hline
\end{tabular}

The mercury content of the fly ash in the back hoppers is higher than in the front hoppers as expected, since the LOI of the fly ash collected in these hoppers is always higher than that of the fly ash from the front hoppers. The native capture of mercury is generally associated with the LOI content of the fly ash.

It is assumed that about $80 \%$ of the fly ash is deposited in the front hoppers and $20 \%$ in the back hoppers, as is typical of small cold-side ESPs. However, there is no definitive data on the fly ash distribution. With the $80 \% / 20 \%$ split, the average baseline fly ash would contain $144 \mathrm{ppb}$ on average. 


\section{Mercury Mass Balance}

The coal composition and the coal usage rate can be used to calculate the fly ash mercury content if $100 \%$ of the mercury were captured by the ash. This calculation indicates that the fly ash mercury content would be about $1200 \mathrm{ppb}$ in this case. The average fly ash composition in the baseline period was $144 \mathrm{ppb}$, indicating that the native mercury removal was $12 \%$. This corresponds well with the native removal measured by the mercury monitors and the OHM test data.

\section{$\underline{\text { Halogen Data }}$}

GE Energy measured the halogen content of the flue gas on July 26, during the baseline testing period. The results are presented in Table 26.

\begin{tabular}{|lcc|}
\hline \multicolumn{3}{|c|}{ Table 26 Crawford 7 Baseline Halogen Data } \\
\hline \multicolumn{1}{|c}{ Parameter } & $\frac{\text { Inlet, }}{\text { ppm }}$ & $\frac{\text { Outlet, }_{\text {ppm }}}{\text { ppm }}$ \\
Fluorine & $<0.005$ & $<0.005$ \\
Hydrogen Chloride & 0.74 & 0.98 \\
Chlorine & 0.31 & 0.28 \\
Hydrogen Bromide & $<0.005$ & $<0.005$ \\
Bromine & $<0.005$ & $<0.005$ \\
\hline
\end{tabular}

The concentration of three parameters in the flue gas (Fluorine, Hydrogen Bromide and Bromine) were below the method detection limit while the concentrations of chlorine and hydrogen chloride were below $1 \mathrm{ppm}$.

\section{Boiler Operation}

Crawford 7 is not a base loaded unit, but rather, operates at varying loads in order to meet demand. On most days, the peak period is from about 8:00 to 16:00. This boiler is also shuts down completely for periods of time due to lack of demand. The high demand periods are generally in the summer and winter.

Crawford 7 uses a cold-side ESP to capture the fly ash emissions. The opacity limits for Crawford 7 are no greater than $30 \%$ opacity on a six minute. The stack opacity at Crawford 7 is highly dependent upon load. The opacity is the lowest at low loads and the highest at high loads.

A plot of boiler load and the 6-minute average opacity data for part of the baseline period is presented in Figure 29. 
Figure 29. 6-Minute Average Opacity and Boiler Load for Part of the Baseline Period at Crawford 7

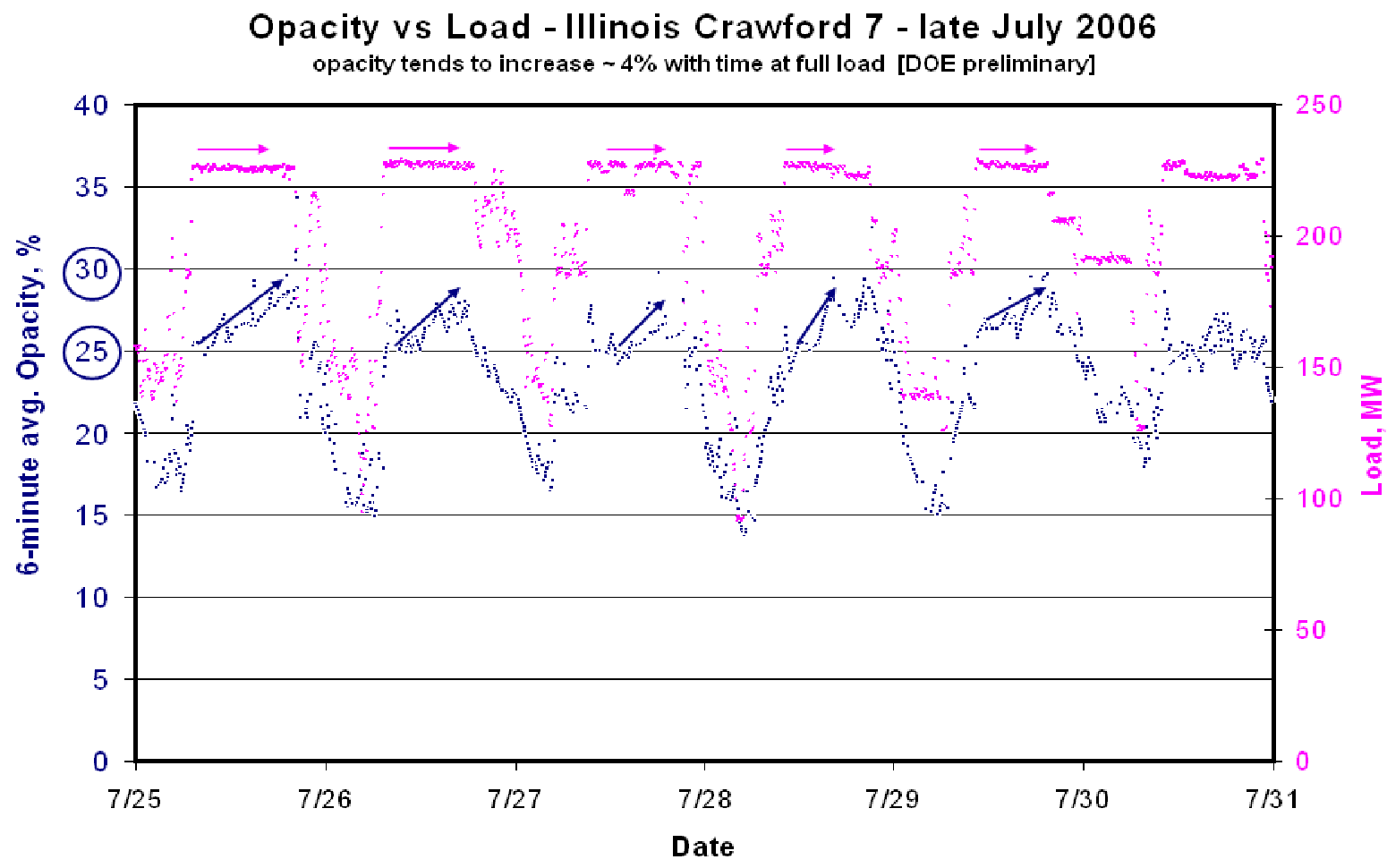

At full load, the opacity tends to increase over time by $3 \%$ to $5 \%$. The opposite is the case with increasing time at low load.

\section{Parametric Tests}

The first phase of the parametric tests at Crawford 7 was performed with C-PAC ${ }^{T M}$ sorbents in order to avoid contaminating the fly ash with non-concrete friendly materials. This first round of parametric tests began on August 5 and lasted until August 8, 2006. The second phase of the parametric testing began after the completion of the long-term test and ran from September 25 through October 4, 2006.

\section{Mercury Monitor Data}

The parametric injection tests were conducted using the PS Analytical mercury monitor as the only instrument measuring flue gas mercury. Coal and fly ash samples were taken during the testing but there was no attempt to calculate mercury mass balances since parametric fly ash samples are not representative of the fly ash which will be produced in a long-term test. The reason for this is that parametric fly ash samples are always diluted with an unknown amount of untreated ash. There were no Method 324 or $\mathrm{OHM}$ tests performed during the parametric testing.

The mercury data for one of the first parametric tests is shown in Figure 30. 
Figure 30. Mercury Concentration at the ESP Inlet and Outlet at Crawford 7 On August 5, 2006, during a Parametric Test Using C-PAC 1

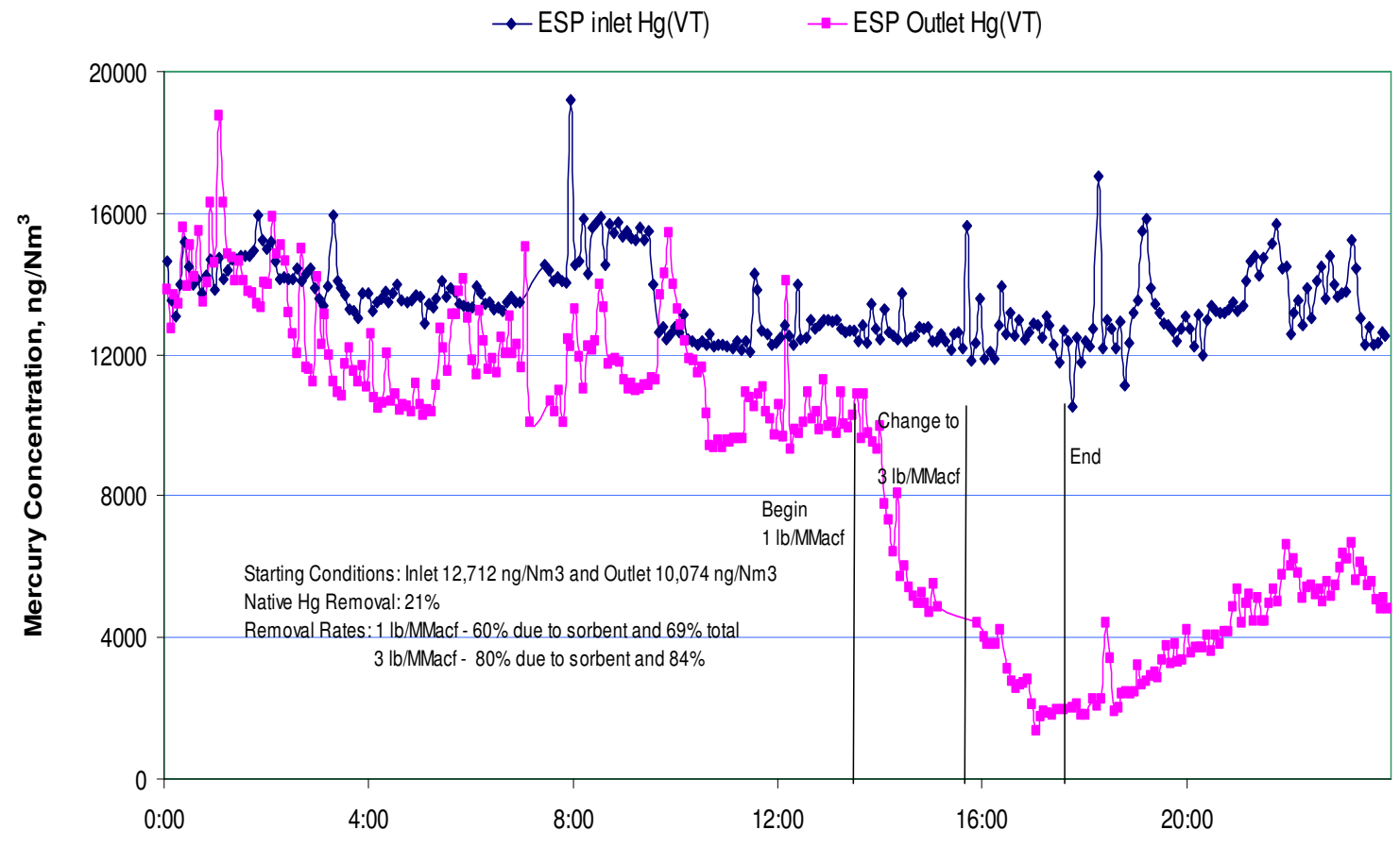

Before the parametric test began, the native mercury removal was about $20 \%$, within the range seen in the baseline period. The parametric test on August $5^{\text {th }}$ began with an injection rate of $1 \mathrm{lb} / \mathrm{MMacf}$ and, after a period to allow the mercury concentration to stabilize, the rate was increased to $3 \mathrm{lb} /$ MMacf. The $\mathrm{Hg}$ removal for this test was about $60 \%$ due to sorbent and $69 \%$ total at the injection rate of $1 \mathrm{lb} / \mathrm{MMacf}$ and $80 \%$ due to sorbent and $84 \%$ total for the $3 \mathrm{lb} /$ MMacf injection rate.

The first phase of the parametric tests was conducted at full boiler load of $225 \mathrm{MW}$ gross. The results for the first phase parametric tests are presented in Table 27

\section{Table 27 Crawford 7 Phase I Parametric Test Results Injection Rate, Native Mercury Removal, \%}

\begin{tabular}{|c|c|c|c|c|c|}
\hline Date & Sorbent & $\underline{\mathrm{lb} / \mathrm{MMacf}}$ & Hg Removal, \% & Due to Sorbent & $\frac{\text { Total Vapo }}{\text { Phase }}$ \\
\hline $8 / \overline{5 / 2006}$ & $\overline{\mathrm{C}-\mathrm{PAC} 1}$ & 1.0 & 21 & 60 & 69 \\
\hline $8 / 5 / 2006$ & C-PAC 1 & 3.0 & 21 & 80 & 84 \\
\hline 8/6/2006 & C-PAC 3 & 1.0 & 25 & 42 & 57 \\
\hline 8/6/2006 & C-PAC 3 & 3.0 & 25 & 71 & 78 \\
\hline 8/7/2006 & C-PAC 2 & 3.0 & 23 & 75 & 81 \\
\hline $8 / 7 / 2006$ & C-PAC 2 & 5.0 & 23 & 83 & 87 \\
\hline
\end{tabular}

It had been determined by means of pilot-scale duct-injection tests in the Albemarle Environmental f/k/a Sorbent Technologies' laboratories that the C-PAC ${ }^{\mathrm{TM}}$ products exhibited slightly lower mercury removal capabilities as compared to the standard B$\mathrm{PAC}^{\mathrm{TM}}$ product. Thus, the results of the parametric tests were pleasing, since two of the 
three concrete friendly C-PAC ${ }^{\mathrm{TM}}$ sorbents tested, exhibited mercury removal rates at or above $80 \%$ with an injection rate between 3 to $5 \mathrm{lb} / \mathrm{MMacf}$.

Based upon the results from first phase of the parametric testing, it was decided to perform the long-term test with $\mathrm{C}-\mathrm{PAC}^{\mathrm{TM}}$ at an injection rate of $5 \mathrm{lb} / \mathrm{MMacf}$ with the total mercury removal expected to be between $80 \%$ and $90 \%$.

The second phase of the parametric testing was conducted primarily with non-concrete friendly materials. All of these tests, except for those on the first day of the second phase tests, were performed at $215 \mathrm{MW}$, slightly below full load due to boiler load availability issues. The tests on the first day of the second phase parametric tests were performed at even lower loads.

The results of the second phase of testing are presented in Table 28.

\begin{tabular}{|c|c|c|c|c|c|c|}
\hline & Table 28 & $\frac{\text { Srawford } 7}{\text { Iniection }}$ & hase II Param & ic Test Re & & \\
\hline & & $\begin{array}{l}\text { Injection } \\
\text { Rate. }\end{array}$ & Native & Mercu & moval, \% & \\
\hline & & & Hg Removal, & Due to & Total Vapor & \\
\hline Date & Sorbent & & \% & Sorbent & Phase & Note \\
\hline 9/25/2006 & C-PAC $1 \mathrm{JC}$ & 3.0 & 35 & 80 & 87 & $176 \mathrm{MW}$ \\
\hline & & & & & & Lower Load \\
\hline 9/25/2006 & C-PAC 1JH & 3.0 & 35 & 83 & 89 & $182 \mathrm{MW}$ \\
\hline 9/26/2006 & B-PACR & 2.0 & 40 & 64 & 78 & \\
\hline 9/26/2006 & B-PACR & 4.0 & 40 & 79 & 87 & \\
\hline & & & & & & Open \\
\hline $9 / 26 / 2006$ & סחתמת & & & 05 & -01 & Ended \\
\hline $9 / 20 / 2000$ & D-PACR & 6.0 & 40 & $>05$ & $>91$ & Lances \\
\hline & & & & & & Distributing \\
\hline $\begin{array}{l}9 / 2 / / 2006 \\
9 / 27 / 2006\end{array}$ & $\begin{array}{l}\text { B-PACR } \\
\text { B-PACR }\end{array}$ & $\begin{array}{l}2.0 \\
4.0\end{array}$ & 43 & 62 & 78 & \\
\hline $9 / 28 / 2006$ & B-PACRJH & 2.0 & 34 & 68 & 79 & \\
\hline 9/28/2006 & B-PACRJH & 4.0 & 34 & 86 & 91 & \\
\hline 9/28/2006 & B-PACRJH & 6.0 & 34 & 91 & 94 & \\
\hline 9/29/2006 & B-PACRJC & 2.0 & 43 & 65 & 80 & \\
\hline 9/29/2006 & B-PACRJC & 4.0 & 43 & 82 & 90 & \\
\hline 9/29/2006 & B-PACRJC & 6.0 & 43 & 87 & 93 & \\
\hline $10 / 2 / 2006$ & Norit Hg LH & 2.0 & 0 & 65 & 65 & \\
\hline $10 / 2 / 2006$ & Norit Hg LH & 4.0 & 0 & 77 & 77 & \\
\hline $10 / 2 / 2006$ & Norit Hg LH & 6.0 & 0 & 83 & 83 & \\
\hline $10 / 3 / 2006$ & B-PACJC & 2.0 & 27 & 70 & 78 & \\
\hline $10 / 3 / 2006$ & B-PACJC & 4.0 & 27 & 84 & 88 & \\
\hline $10 / 3 / 2006$ & B-PACJC & 6.0 & 27 & 88 & 91 & \\
\hline $10 / 4 / 2006$ & B-PACJH & 2.0 & 23 & 70 & 77 & \\
\hline $10 / 4 / 2006$ & B-PACJH & 4.0 & 23 & 83 & 87 & \\
\hline $10 / 4 / 2006$ & B-PACJH & 6.0 & 23 & 90 & 92 & \\
\hline
\end{tabular}

Two different C-PAC ${ }^{\mathrm{TM}}$ sorbents, which had not been tested in the first phase of the parametric program, were tested on the first day of the second phase testing. These 
sorbents were injected at $3 \mathrm{lb} / \mathrm{MMacf}$ and provided mercury removal due to sorbent of $80 \%$ or more.

Next, a series of B-PAC ${ }^{\mathrm{TM}}$ sorbents were evaluated plus Norit $\mathrm{Hg} \mathrm{LH}$. The native mercury removal was generally much higher in the second phase of testing than in the first. The reason for this is unknown. The first B-PAC ${ }^{\mathrm{TM}}$ tested (B-PACR) provided $64 \%$, $79 \%$ and $>85 \% \mathrm{Hg}$ removal at injection rates of 2, 4, and $6 \mathrm{lb} / \mathrm{MMacf}$, respectively.

While this is good mercury removal performance, it was achieved at injection rates twice as high as seen in Detroit Edison St. Clair tests. The reason for this is thought to have been poorer sorbent distribution.

The possibility of poor sorbent distribution impacting the mercury removal results was examined by replacing the open ended lances with distributing lances where the sorbent is introduced at three locations across the duct instead of just one. The tests with the B-PACR sorbent was repeated with the distributing lances to see if there was a major impact upon mercury removal. There was not but this does not mean that poor sorbent distribution was not a contributing factor since even more lances may have been needed. This was studied further in subsequent work.

A series of tests with different B-PAC ${ }^{T M}$ sorbents followed. All of the B-PAC ${ }^{T M}$, sorbents had similar mercury performance, achieving about $70 \%, 80 \%$ and $90 \%$ mercury removal due to sorbent at injection rates of 2, 4 and $6 \mathrm{lb} / \mathrm{MMacf}$, respectively. The total vapor phase mercury removal was over $90 \%$ for several of the sorbents at one or more of the higher injection rates.

The Norit Hg LH sorbent did not perform as well as did the B-PAC ${ }^{\mathrm{TM}}$, sorbents. The mercury removal results for the sorbents are presented in Figure 31.

\section{Figure 31. Comparison of the Performance of Norit $\mathrm{Hg}$ LH to B-PAC ${ }^{\mathrm{TM}}$}

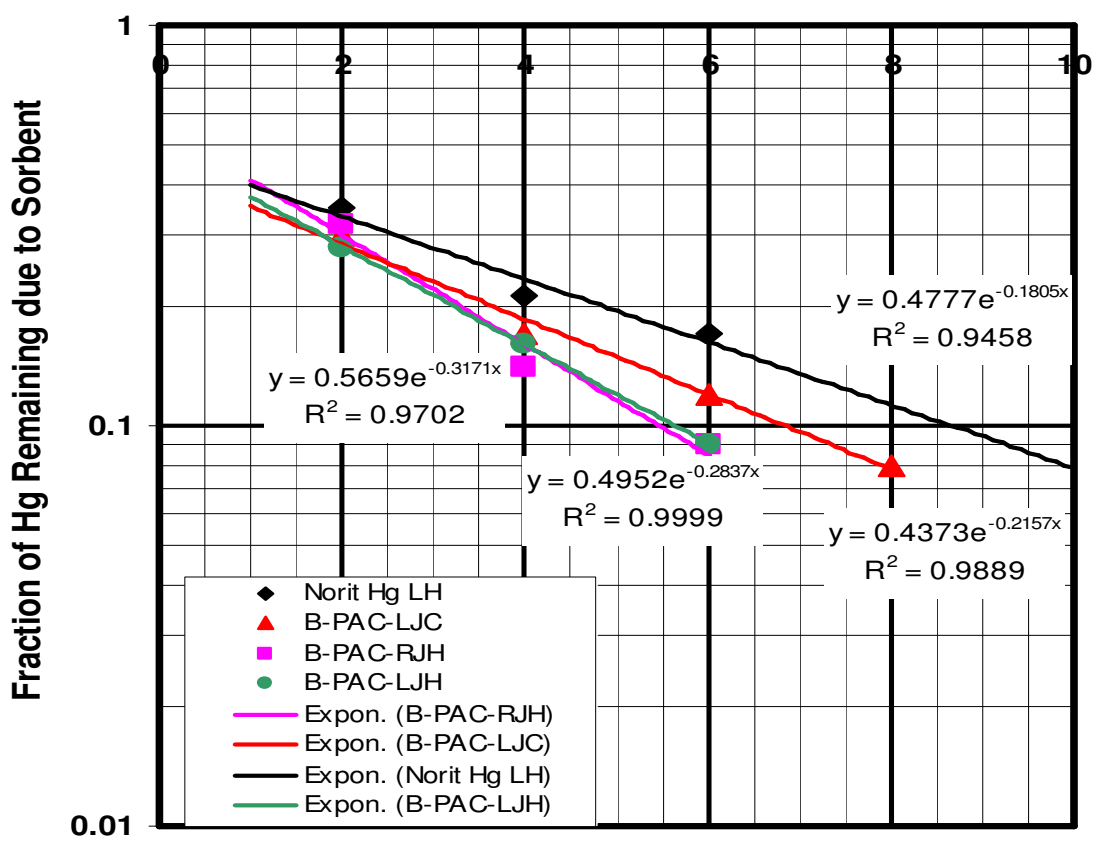

Injection Rate, Ib/MMacf 
It took $50 \%$ more of the Norit $\mathrm{Hg}$ LH sorbent to achieve $80 \%$ mercury removal than with the B-PAC ${ }^{\mathrm{TM}}$, sorbents. These findings have been confirmed by testing at the Duke Power Allen Station ${ }^{(3)}$ with bituminous coal and at the Great River Energy Stanton Station ${ }^{(7)}$ with subbituminous coal. The difference in performance is believed to primarily due to the differences in product manufacturing technique and chemistry. All of the Albemarle Environmental f/k/a Sorbent Technologies' sorbent are gas-phase brominated as compared to salt impregnated sorbents such as Norit $\mathrm{Hg} \mathrm{LH}$.

\section{Coal and Fly Ash Data}

Coal and fly ash samples were collected during both parametric test periods. These samples are of less importance than those collected during the baseline period and longterm test since mercury mass balances are not created but the data does provide an indication of the trend of the mercury behavior.

The results of the coal analyses from the first and second parametric test periods are shown in Tables 29 and 30.

\begin{tabular}{|c|c|c|c|c|c|}
\hline \multirow[b]{2}{*}{ Date } & \multicolumn{5}{|c|}{ As Received } \\
\hline & $\%$ Moisture & $\frac{\text { Ash }}{\%}$ & Sulfur, \% & Btu/lb. & Hg Dry, ppm \\
\hline $8 / \overline{5 / 2006}$ & 35.5 & $\overline{4.0}$ & 0.25 & 7,738 & 0.06 \\
\hline 8/6/2006 & 34.6 & 4.2 & 0.22 & 7,831 & 0.08 \\
\hline 8/7/2006 & $\underline{33.2}$ & $\underline{5.0}$ & $\underline{0.29}$ & $\underline{7,950}$ & $\underline{0.07}$ \\
\hline Average & 34.4 & $\overline{4.4}$ & 0.25 & 7,840 & 0.07 \\
\hline
\end{tabular}

\begin{tabular}{|c|c|c|c|c|c|}
\hline \multicolumn{6}{|c|}{$\begin{array}{c}\text { Table } 30 \text { Crawford } 7 \text { Coal Data from the Second Parametric Test Period } \\
\text { As Received }\end{array}$} \\
\hline Date & $\%$ Moisture & Ash, $\%$ & Sulfur, \% & Btu/lb. & Hg Dry, ppm \\
\hline $9 / \overline{25 / 2006}$ & 29.5 & 5.3 & 0.23 & $\overline{8,452}$ & 0.11 \\
\hline 9/26/2006 & 29.7 & 5.0 & 0.27 & 8,403 & 0.13 \\
\hline 9/27/2006 & 28.9 & 4.5 & 0.29 & 8,566 & 0.06 \\
\hline 9/28/2006 & 28.8 & 6.2 & 0.36 & 8,376 & 0.19 \\
\hline 9/29/2006 & 30.0 & 4.9 & 0.32 & 8,446 & 0.12 \\
\hline $10 / 2 / 2006$ & 30.3 & 4.7 & 0.35 & 8,436 & 0.06 \\
\hline $\begin{array}{l}10 / 3 / 2006 \\
10 / 4 / 2006\end{array}$ & 30.0 & 4.8 & 0.38 & 8,497 & 0.24 \\
\hline Average & 29.6 & 5.1 & 0.31 & 8,454 & 0.13 \\
\hline
\end{tabular}

The proximate analysis of the coal used during each of the two parametric testing periods was different to that used in the baseline testing in different characteristics. The coal used during the first parametric testing period had higher moisture content and slightly lower mercury content than the coal used in the baseline period. The coal used during the second phase of the parametric testing resembled that used in the baseline testing in all characteristics besides mercury content, which was highly variable and twice that used during the first parametric test. The mercury monitors did not exhibit this high mercury variability. 
The fly ash mercury analyses for samples from the first parametric test period are presented in Table 31.

\begin{tabular}{|ccc|}
\hline \multicolumn{3}{|c|}{ Table 31 Crawford 7 Fly Ash Hg Data from the1st Parametric Test Period } \\
\hline & Front Hoppers, ppb & Back Hoppers, ppb \\
8/5/2006 & 161 & 638 \\
$8 / 6 / 2006$ & 674 & 1410 \\
$8 / 7 / 2006$ & 791 & 1122 \\
\hline
\end{tabular}

The problem with parametric fly ash samples is clearly demonstrated by the results shown in Table 31. The problem is that parametric tests are short in duration and the fly ash sample collected each day has an unknown amount of untreated fly ash also. It appears from the data in this table that the fly ash $\mathrm{Hg}$ was increasing. The $\mathrm{Hg}$ content probably was not increasing in the sorbent treated fly ash but, merely, more representative samples were being collected as the test progress. The mercury in these samples is much higher than in the baseline samples, which all averaged much less than 200 ppb.

Because of the non-representative nature of the parametric fly ash samples, the data was not used for other analyses such as mercury mass balance calculations.

\section{Boiler Operation}

For the parametric tests, Crawford 7 was maintained at full load (225 MW gross) for the first phase of the parametric tests and near full load (215 MW gross) for the second phase of the parametric test program. Typically, the boiler would be brought to full load by $8: 00$ and maintained at this level until 16:00. The parametric testing was conducted during this time period, after the boiler and mercury monitors became stable.

It was noted in the first parametric tests that the injection of C-PAC ${ }^{T M}$ had a beneficial impact upon opacity. A plot of boiler load and 6-minute average opacity for one day of the first parametric tests are presented in Figure 32.

Normally, the opacity would increase $3 \%$ to $5 \%$ over a period of hours from the time that the boiler first reached high load first reached until the boiler load was reduced at night. This pattern can be clearly seen in Figure 29. For the parametric test of August $6^{\text {th }}$, the data for which is shown in Figure 32, the opacity began to rise after full load was achieved. The opacity dropped when the C-PAC ${ }^{T M}$ was turned on or when the injection rate was increased. This provided great deal of hope that there would not be an opacity increase during the long-term test. 
Figure 32. Opacity and Load at Crawford 7 during the First Parametric Test Period Opacity vs Load, MWGen Crawford Plant, Illinois, Parametrics

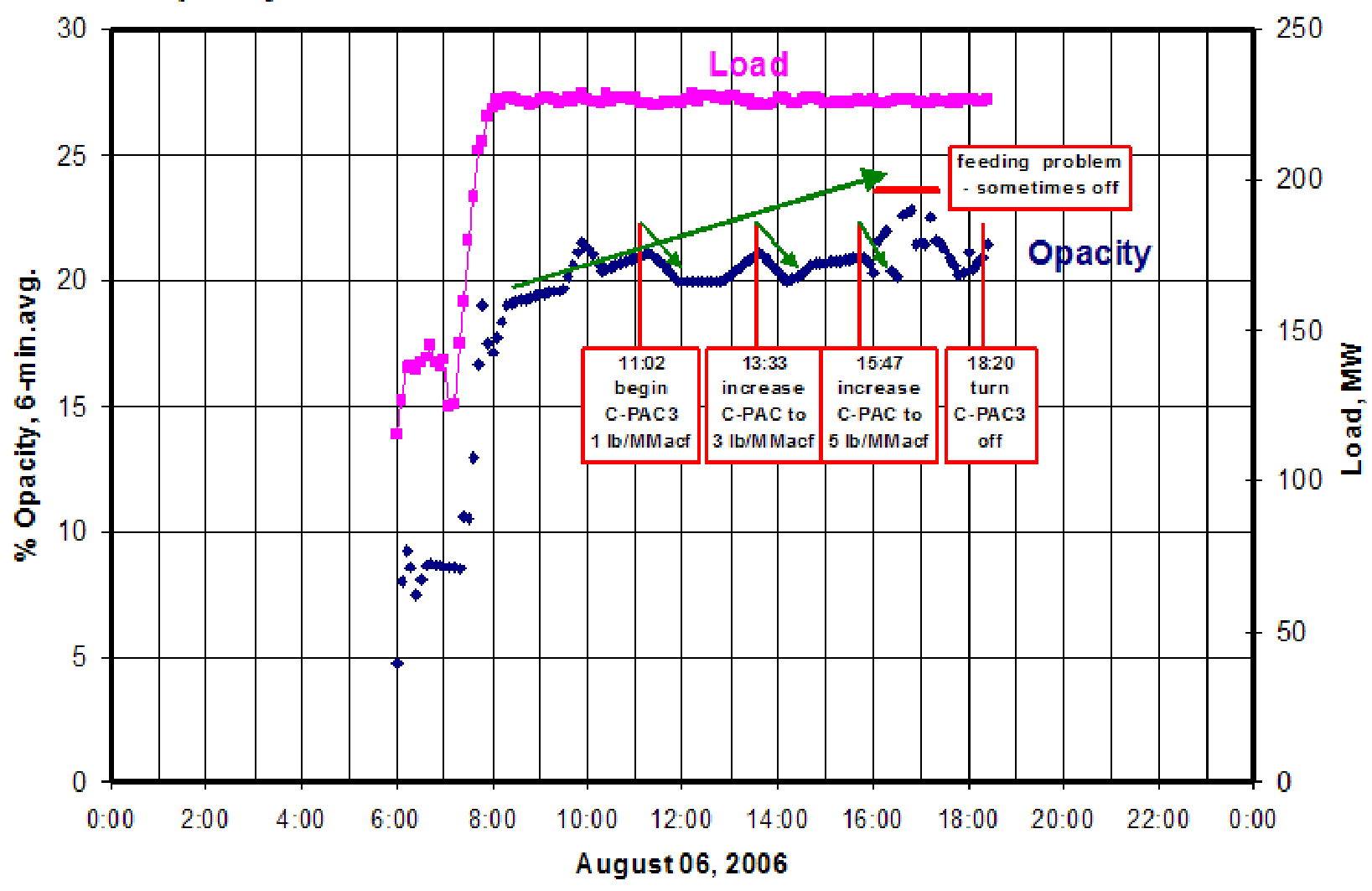




\section{Long-Term Test}

The long-term test at Midwest Generation Crawford 7 was conducted from August 17 to September 16, 2006. C-PAC ${ }^{\mathrm{TM}}$ was used for 27 of the 30-day test. Midwest Generation wanted to use B-PAC ${ }^{\mathrm{TM}}$ sorbents for three days of the long-term test and wanted to inject C-PAC ${ }^{\mathrm{TM}}$ at a rate of $6 \mathrm{lb} / \mathrm{MMacf}$ for two days. The testing order was C-PAC ${ }^{\mathrm{TM}}$ at $4 \mathrm{lb} /$ MMacf for the first 21 days, an increase in the C-PAC ${ }^{T M}$ injection rate to $6 \mathrm{lb} / \mathrm{MMacf}$ for two days, a return to the $4 \mathrm{lb} /$ MMacf injection rate for two days with C-PAC LC (a lower cost, lower quality sorbent), two days of the B-PAC ${ }^{\mathrm{TM}}$ sorbent at $4 \mathrm{lb} / \mathrm{MMacf}$, one day of B-PAC ${ }^{\mathrm{TM}}$ at $2 \mathrm{lb} / \mathrm{MMacf}$ followed by the use of C-PAC ${ }^{\mathrm{TM}}$, at $4 \mathrm{lb} / \mathrm{MMacf}$ for the last 2 days. The C-PAC ${ }^{\mathrm{TM}}$ injection rate turned out to be $4.6 \mathrm{lb} / \mathrm{MMacf}$ for the first 21 days due to issues with the duct flue gas flow feedback loop.

\section{Mercury Monitor Data}

During the long-term test, the PS Analytical mercury monitor was used to measure the ESP inlet, before sorbent injection, and ESP outlet flue gas vapor phase mercury concentration. The Ohio Lumex monitor was also used for part of this test period to measure the total vapor phase mercury at the inlet location. In addition, there were Method 324 sorbent trap mercury samples taken as well as one set of OHM mercury tests performed.

The PS Analytical data was used to calculate the total vapor phase mercury removal rate during the long-term test. The mercury monitor data and the mercury removal results are shown in Figure 33 for the first 21 days of the test when C-PAC ${ }^{\mathrm{TM}}$ was injected continuously at a rate of $4.6 \mathrm{lb} / \mathrm{MMacf}$.

Figure 33. First 21 Days of the Long-Term Test at Crawford 7

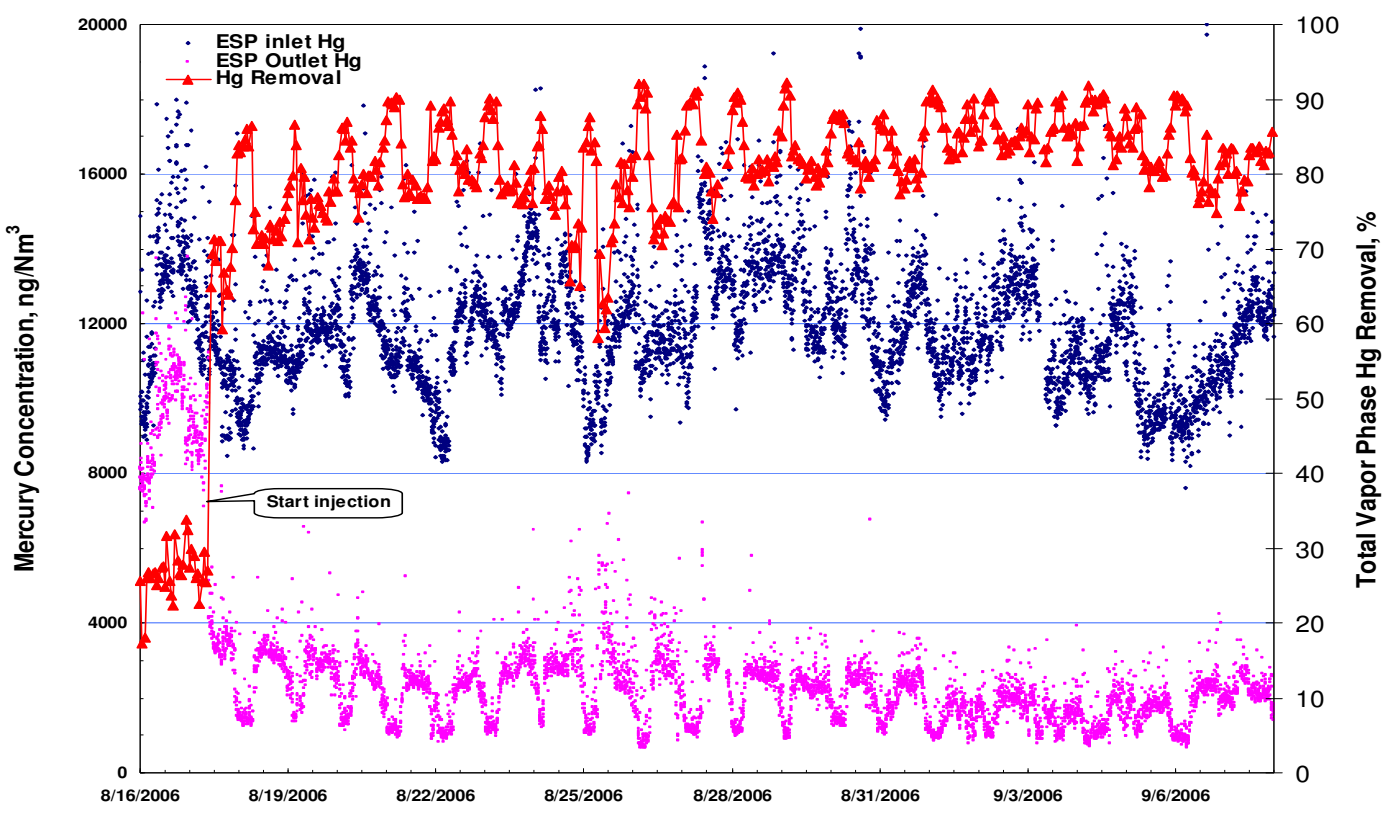

The native mercury removal just before the start of the long-term test was $27 \%$, which is higher than that observed in the baseline testing. Upon starting the injection of C-PAC ${ }^{\mathrm{TM}}$ 
the outlet mercury level rapidly decreased and the mercury removal rate, thus, rapidly increased. The inlet mercury concentration was generally in the range observed during the baseline testing while the outlet $\mathrm{Hg}$ concentration varied around $2000 \mathrm{ng} / \mathrm{Nm}^{3}$ during the first 21 days of testing. The average total vapor phase mercury removal for the first 21 days was $82 \%$.

The plot of the inlet and outlet mercury concentrations and the total vapor phase mercury removal for the last 9 days of the test is presented in Figure 34.

Figure 34. Last 9 Days of the Long-Term Test at Crawford 7

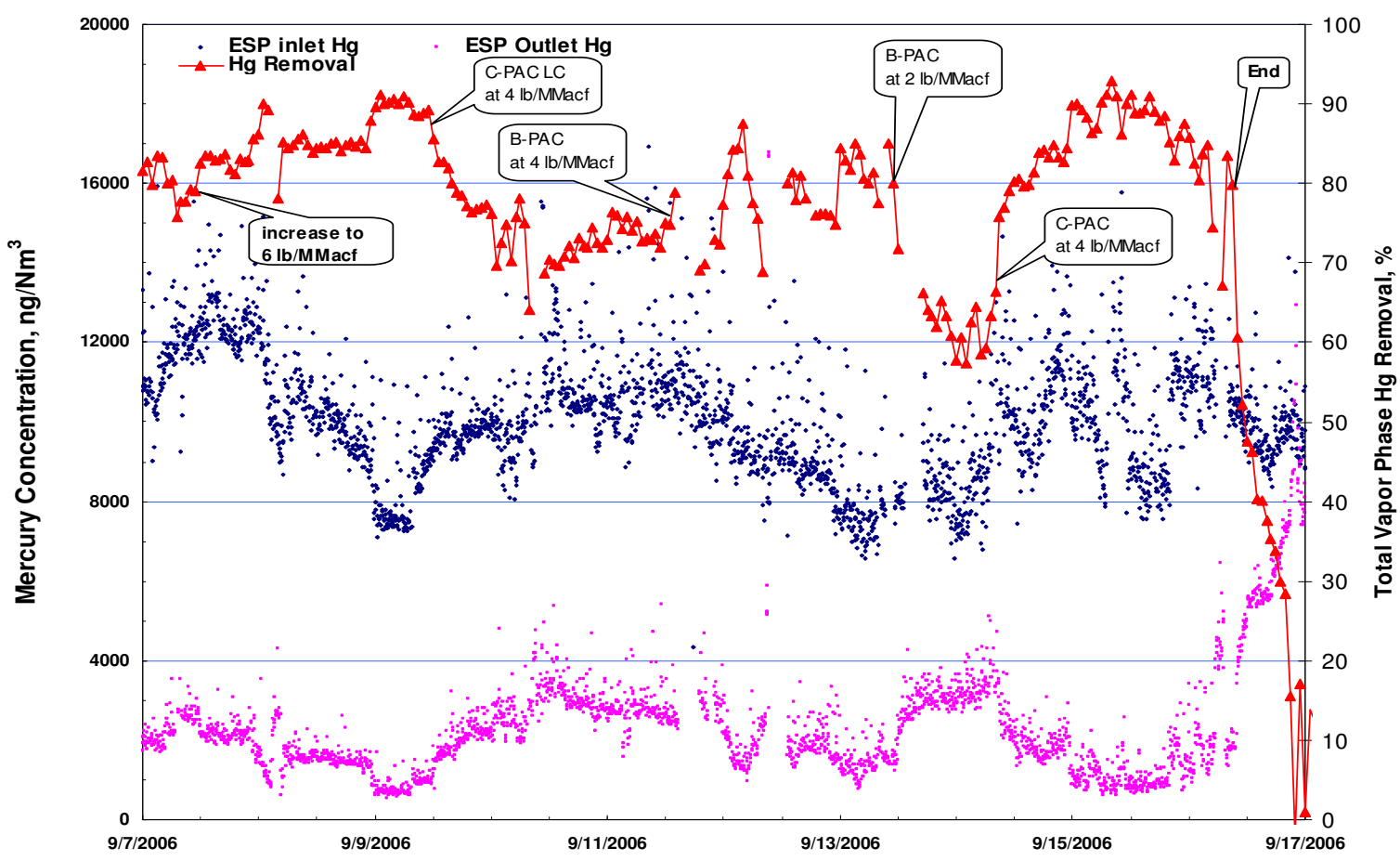

The last 9 days of the long-term test are more complicated due to the changes in sorbents and injection rates. The C-PAC ${ }^{T M}$ injection rate was increased to $6 \mathrm{lb} /$ MMacf on the morning of 9/7/06 and maintained there for two days. The total vapor phase mercury removal during this period increased but only to $86 \%$. It was expected that the increase in injection rate would push the mercury removal to $90 \%$ or above.

The C-PAC LC sorbent was next used for two days starting on the morning of 9/9/06. This material was identified as C-PAC 2 in the first parametric tests. It was hoped that it would perform better in a continuous application. It didn't providing a total vapor phase mercury removal of only $74 \%$.

Midwest Generation desired to see the application of B-PAC ${ }^{T M}$ during the long-term test. Thus, starting on 9/11/06, B-PAC ${ }^{\mathrm{TM}}$ was injected at a rate of $4 \mathrm{lb} / \mathrm{MMacf}$ for two days and at a rate of $2 \mathrm{lb} / \mathrm{MMacf}$ for one day. The results were not as expected. The B-PAC ${ }^{T M}$ sorbents in the parametric testing had achieved a total vapor phase mercury removal of about $90 \%$ at an injection rate of $4 \mathrm{lb} / \mathrm{MMacf}$ and about $70 \%$ at an injection rate of 2 
$\mathrm{lb} /$ MMacf. What was measured by the PSA mercury monitors was a total vapor phase mercury removal of $78 \%$ and $63 \%$ at the two injection rates, respectively.

On 9/14/06, the injection of C-PAC ${ }^{T M}$ at a rate of $4 \mathrm{lb} /$ MMacf was resumed for the remainder of the long-term test. The total vapor phase mercury removal was $85 \%$ for this period. The long-term injection test ended on the morning of 9/16/06. The outlet mercury concentration slowly recovered to the baseline level over a period of about 12 hours. The native removal after recovery to baseline was well below $20 \%$. The mercury recovery to baseline is slow since the sorbent, still in the ductwork, has to be saturated with mercury or covered over by fly ash first.

The Ohio Lumex monitor was used to measure the inlet total vapor phase mercury concentration during a portion of the long-term test. The Ohio Lumex data is present along with the data from the PSA monitor in Figure 35.

Figure 35. Ohio Lumex and PSA Inlet Vapor Phase Hg Data from the Long-Term Test at Crawford 7

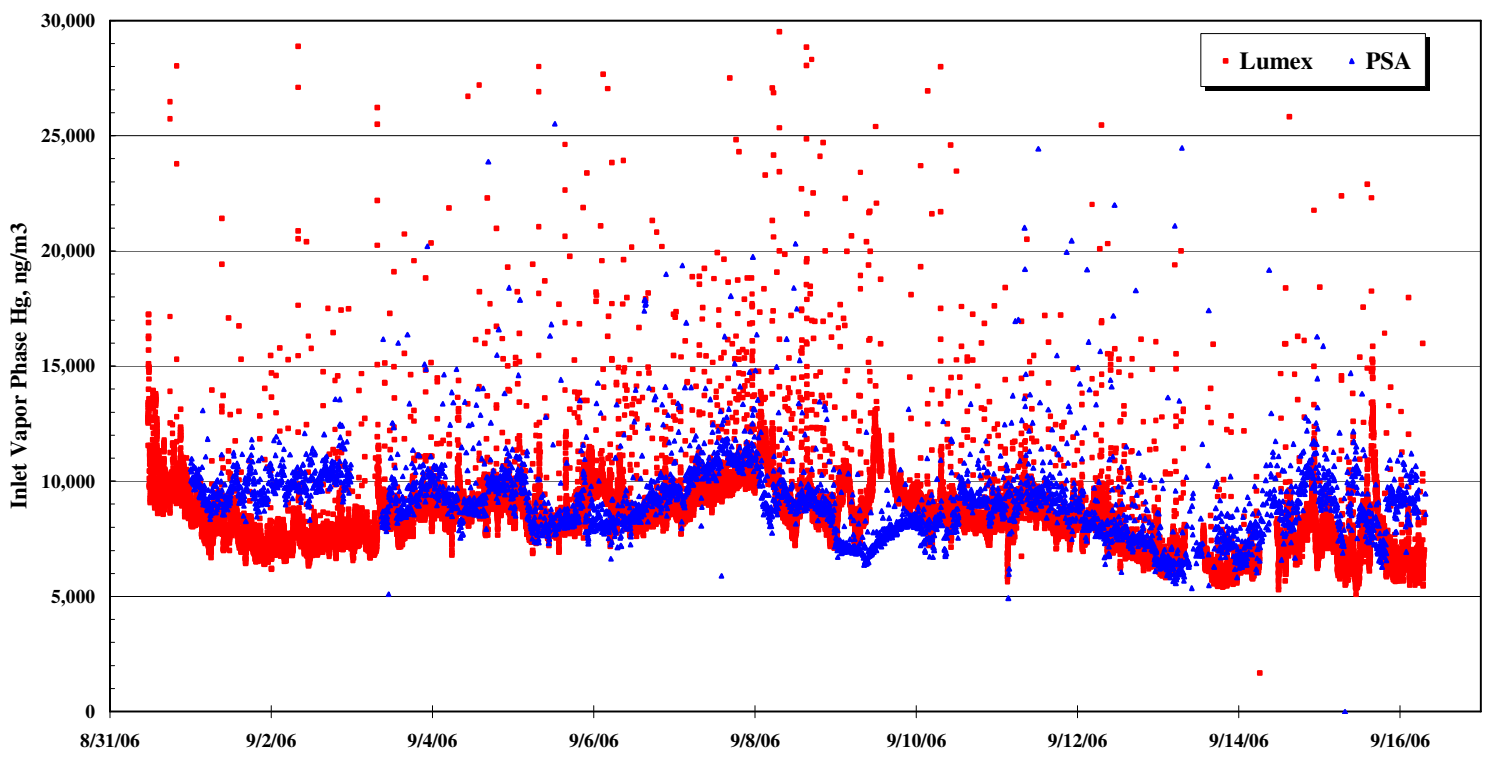

This data is presented at actual oxygen conditions since the oxygen content of the gas entering the Ohio Lumex is not measured. The data from the two monitors compare favorably, except for two days. The first of these days is on 9/3 when the Ohio Lumex readings are consistently about $2000 \mathrm{ng} / \mathrm{Nm}^{3}$ below the PSA readings. This was early in the use of the Ohio Lumex and may be related to a burn-in phenomenon. The second day when the monitors did not agree well was on 9/9 when the Ohio Lumex data went up and the PSA data went down. This may indicate that there may have been a problem with the PSA monitor on that day. It should be noted that the Ohio Lumex and PSA monitors showed $\mathrm{Hg}$ spikes at the same times, indicating that they are real.

$\underline{\text { OHM Data }}$

GE Energy performed the OHM testing on September 6, 2006, during the long-term test at Crawford 7 . The OHM tests were conducted in triplicate simultaneously at the inlet and outlet locations. 
The mercury results of the OHM testing at Crawford 7 during the long-term test are presented in Table 32.

\begin{tabular}{|c|c|c|c|c|c|}
\hline \multicolumn{6}{|c|}{$\begin{array}{l}\text { Table } 32 \text { Crawford } 7 \text { Long-Term OHM Test Data } \\
\text { (All concentrations in ng/Nm3 at 3\% O2) }\end{array}$} \\
\hline Location & $\underline{\mathrm{HgP}}$ & $\underline{\mathrm{Hg}+2}$ & $\underline{\mathrm{Hg} 0}$ & $\begin{array}{l}\text { Total Vapor } \\
\text { Phase } \mathrm{Hg}\end{array}$ & $\begin{array}{c}\text { Total } \\
\mathrm{Hg}\end{array}$ \\
\hline Inlet & $\overline{511}$ & $\overline{1023}$ & $1 \overline{0229}$ & 11,251 & $1 \overline{1,763}$ \\
\hline Inlet & 604 & 663 & 9182 & 9,845 & 10,449 \\
\hline Inlet & 291 & 918 & 9729 & 10,647 & $\underline{10,938}$ \\
\hline Average & $\overline{469}$ & $\overline{868}$ & $\overline{9,713}$ & $\overline{10,581}$ & 11,050 \\
\hline STD & 161 & 185 & 523 & 706 & 664 \\
\hline Outlet & 1303 & 134 & 1266 & 1,400 & 2,703 \\
\hline Outlet & 1705 & 158 & 1279 & 1,437 & 3,142 \\
\hline Outlet & 1084 & 110 & 999 & 1,108 & 2,192 \\
\hline Average & 1364 & 134 & 1,181 & 1,315 & 2,679 \\
\hline STD & 315 & 24 & 158 & 180 & 475 \\
\hline
\end{tabular}

The mercury in the vapor phase at the inlet location was over $90 \%$ elemental. There was a significant amount of particulate mercury ( $>4 \%$ of the total $\mathrm{Hg}$ ) measured at the inlet location. The inlet particulate mercury was nearly three times higher than that measured during the baseline testing. The total mercury measured at the outlet location was about $50 \%$ elemental and $50 \%$ particulate. Normally, there is no particulate mercury after the ESP. However, GE Energy believes that a small amount of fly ash or sorbent passed through the ESP and was captured on the OHM inlet filter. There it acted as a fixed bed filter capturing vapor phase mercury.

The mercury data from the OHM measurements is compared with that from the mercury monitor and the Method 324 sample in Table 33.

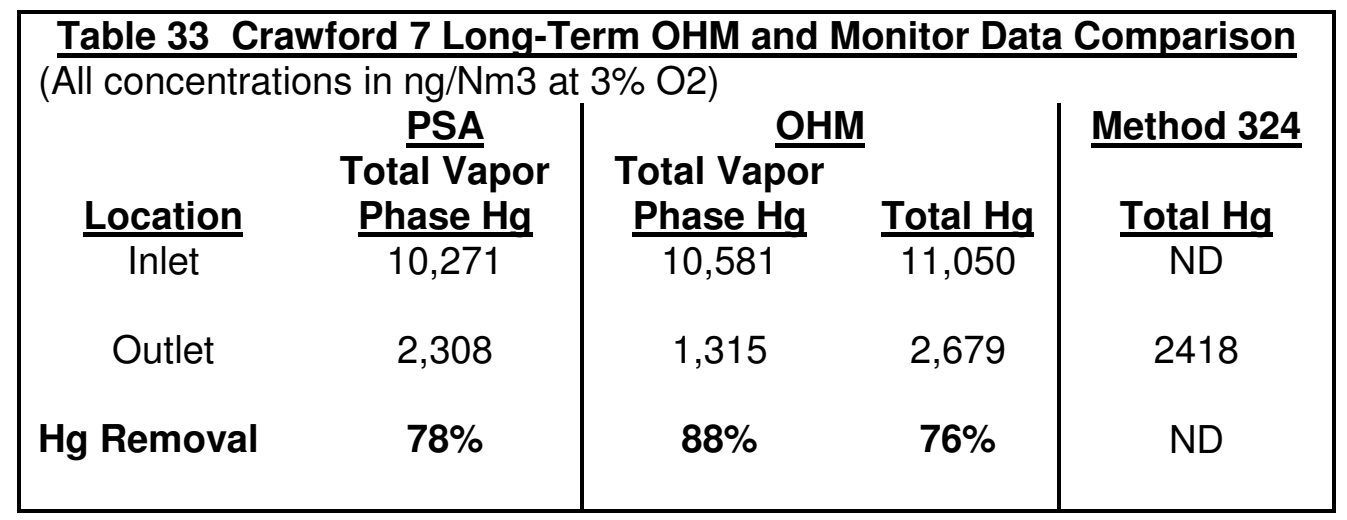

The inlet data for total vapor phase mercury from the OHM test and the PSA mercury monitor compares very well. The total vapor phase mercury at the outlet compares well between the PSA monitor and the Method 324 test but not the OHM test. However, 
assuming that everything measured by the OHM test at the outlet is in the vapor phase, then all three measurements compare favorably.

\section{Method 324 Data}

Method 324 mercury trap samples were collected periodically throughout the long-term test at Crawford 7. It was nearly impossible to collect a sample at the inlet location due to the sticky nature of the fly ash, which plugged the trap in a few moments. Only one Method 324 test was successfully conducted at the inlet location. Numerous Method 324 sample traps were collected at the outlet of the ESP. The results of the Method 324 tests are presented in Table 34, along with the mercury data from the PS Analytical monitor for the same time periods as the Method 324 testing.

\begin{tabular}{|c|c|c|}
\hline \multicolumn{3}{|c|}{$\begin{array}{c}\text { Table } 34 \text { Method } 324 \mathrm{Hg} \text { Trap Data } \\
\text { for the Long-Term Test at Crawford } 7 \\
\text { (Total Vapor Phase Hg @ } 3 \% \text { O2) }\end{array}$} \\
\hline Date & Outlet (PSA) & Outlet (Trap) \\
\hline $8 \overline{8 / 17 / 06}$ & 3845 & 2832 \\
\hline $8 / 17 / 06$ & 3594 & 2248 \\
\hline $8 / 17 / 06$ & 3275 & 2513 \\
\hline 8/18/06 & 3358 & 2091 \\
\hline 8/19/06 & 1958 & 1125 \\
\hline 8/20/06 & 1526 & 961 \\
\hline 8/20/06 & 2559 & 2348 \\
\hline 8/21/06 & 2309 & 2290 \\
\hline $8 / 22 / 06$ & 1054 & 807 \\
\hline $8 / 22 / 06$ & 2367 & 2216 \\
\hline 8/23/06 & 2692 & 2504 \\
\hline $8 / 23 / 06$ & 2725 & 2578 \\
\hline 8/24/06 & 2932 & 2789 \\
\hline 8/24/06 & 2568 & 2503 \\
\hline $8 / 25 / 06$ & 2739 & 2156 \\
\hline 8/26/06 & 2462 & 2168 \\
\hline 8/27/06 & 2042 & 2561 \\
\hline $8 / 28 / 06$ & 2764 & 3103 \\
\hline $9 / 1 / 06$ & 1610 & 1441 \\
\hline $9 / 2 / 06$ & 1717 & 1791 \\
\hline $9 / 3 / 06$ & 1401 & 1148 \\
\hline $9 / 4 / 06$ & 1601 & 1278 \\
\hline 9/5/06 & 1817 & 1716 \\
\hline 9/6/06 & 2351 & 2418 \\
\hline 9/6/06 & 2311 & 2393 \\
\hline 9/7/06 & 1951 & 2146 \\
\hline 9/8/06 & 1247 & 1702 \\
\hline 9/9/06 & 2468 & 2090 \\
\hline $9 / 10 / 06$ & 2869 & 2712 \\
\hline $9 / 11 / 06$ & 2785 & 3008 \\
\hline $9 / 11 / 06$ & 2633 & 1801 \\
\hline $9 / 12 / 06$ & 1701 & 1013 \\
\hline 9/13/06 & 3152 & 2190 \\
\hline $9 / 14 / 06$ & 1949 & 2008 \\
\hline $9 / 15 / 06$ & 1018 & 1022 \\
\hline
\end{tabular}


The total vapor phase mercury removal can be measured by using the PSA inlet mercury values and the different $\mathrm{Hg}$ outlet values (PSA or Method 324). The mercury removal values from this calculation are presented in Figure 36.

Figure 36. Total Vapor Phase Hg Removal as Determined by the PSA and Method 324 Data for the Long-Term Test at Crawford 7.

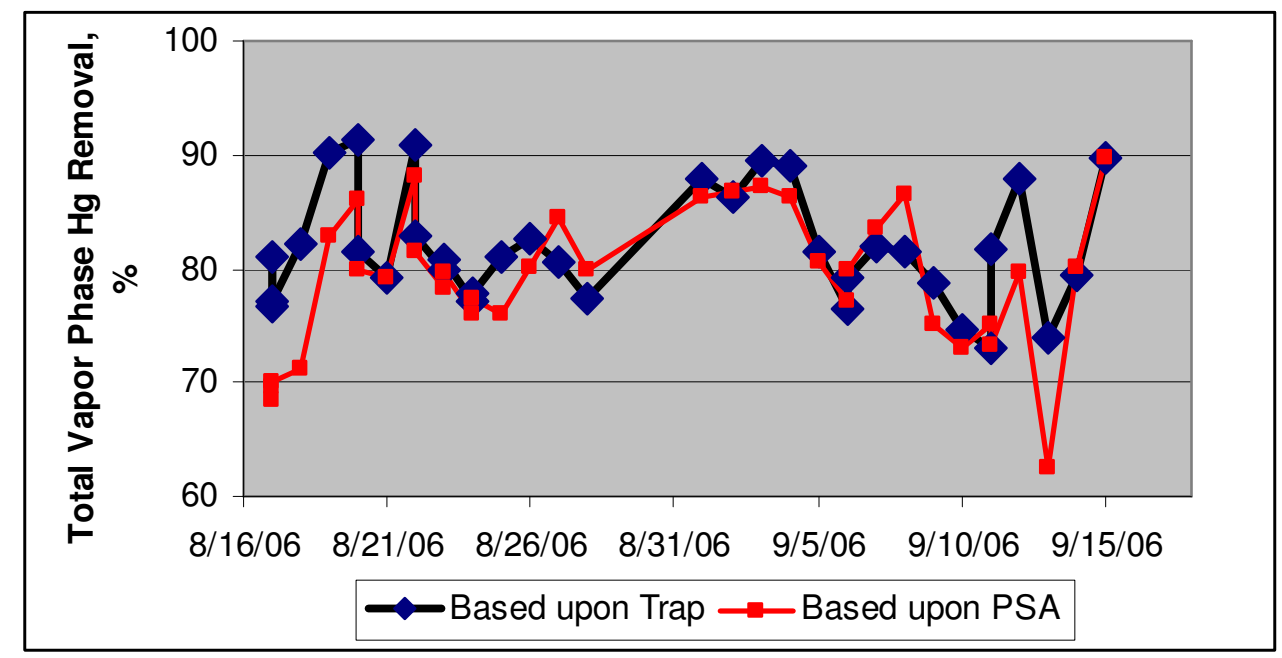

The measured total vapor phase mercury removal rates compare favorably for most periods of the long-term test evaluated. For all of the time periods evaluated, the Method 324 data measured a total vapor phase mercury removal rate of $82 \%$, three points higher than that determined by the PSA monitor.

There were two periods of time when the mercury removal rates as determined by these methods varied by more than $5 \%$. The first was during the first two days of the longterm test when the PSA monitor was measuring about $70 \%$ mercury removal while the Method 324 was measuring about $80 \%$ mercury removal. The second period when the data disagreed significantly was from 9/11-13/06. On those days, the PSA data indicated a mercury removal rate over $70 \%$ and the Method 324 indicated a mercury removal rate over $80 \%$. This latter period was during the three days of C-PAC ${ }^{\mathrm{TM}}$ at testing. The reason for these differences is unknown. However, without using the data from those days, there is virtually no difference between the removal rates measured by the two techniques.

Several of the sorbent trap tubes had the back sections spiked with a known amount of mercury. These traps are for Appendix K sampling. The mercury recovery from these spiked sections averaged more than $95 \%$ with a low of $90 \%$. All of the recoveries were within the acceptable limits. There was no breakthrough into the second section of any of the traps.

For comparison purposes, the inlet mercury concentration averaged about $8 \mathrm{lb} / \mathrm{TBtu}$ during the long-term test program and the emissions averaged about $1.5 \mathrm{lb} / \mathrm{TBtu}$, based upon the F Factor calculation method. 


\section{$\underline{\text { Coal Data }}$}

The analyses of coal samples taken during the long-term test at Crawford 7 are shown in Table 35.

\begin{tabular}{|c|c|c|c|c|c|}
\hline \multicolumn{6}{|c|}{$\frac{\text { Table } 35 \text { Crawford } 7 \text { Long-Term Test Coal Data }}{\text { As Received }}$} \\
\hline Date & Moisture & Ash, \% & Sulfur, \% & Btu/lb. & $\frac{\text { Hg Dry, }}{\text { ppm }}$ \\
\hline $8 / 17 / 2006$ & 29.0 & 4.4 & 0.19 & 8,489 & \\
\hline $8 / 18 / 2006$ & 30.9 & 4.0 & 0.24 & 8,322 & 0.07 \\
\hline 8/19/2006 & 28.7 & 4.2 & 0.27 & 8,661 & 0.08 \\
\hline 8/20/2006 & 29.1 & 4.9 & 0.31 & 8,548 & 0.07 \\
\hline $8 / 21 / 2006$ & 29.2 & 4.8 & 0.24 & 8,426 & 0.05 \\
\hline $8 / 22 / 2006$ & 29.0 & 5.1 & 0.24 & 8,372 & 0.09 \\
\hline $8 / 23 / 2006$ & 29.9 & 4.9 & 0.22 & 8,343 & 0.12 \\
\hline $8 / 24 / 2006$ & 29.2 & 5.2 & 0.31 & 8,871 & 0.10 \\
\hline $8 / 25 / 2006$ & 32.4 & 4.9 & 0.20 & 7,983 & 0.08 \\
\hline $8 / 26 / 2006$ & 31.7 & 4.6 & 0.28 & 8,148 & 0.07 \\
\hline $8 / 27 / 2006$ & 29.3 & 5.1 & 0.31 & 8,449 & 0.07 \\
\hline 8/28/2006 & 30.4 & 4.4 & 0.28 & 8,364 & 0.11 \\
\hline $8 / 29 / 2006$ & 29.9 & 4.1 & 0.28 & 8,513 & 0.08 \\
\hline $8 / 30 / 2006$ & 31.3 & 4.8 & 0.37 & 8,237 & 0.07 \\
\hline $8 / 31 / 2006$ & 30.2 & 4.9 & 0.33 & 8,346 & 0.08 \\
\hline $9 / 1 / 2006$ & 28.7 & 4.1 & 0.17 & 8,580 & 0.06 \\
\hline 9/2/2006 & 28.3 & 5.2 & 0.26 & 8,659 & 0.10 \\
\hline 9/3/2006 & 30.5 & 4.7 & 0.33 & 8,359 & 0.08 \\
\hline $9 / 4 / 2006$ & 28.7 & 4.5 & 0.25 & 8,554 & 0.09 \\
\hline 9/5/2006 & 29.6 & 4.8 & 0.20 & 8,302 & 0.07 \\
\hline 9/6/2006 & 30.1 & 3.7 & 0.20 & 8,425 & 0.08 \\
\hline $9 / 7 / 2006$ & 30.1 & 4.9 & 0.33 & 8,227 & 0.09 \\
\hline 9/8/2006 & 28.8 & 5.0 & 0.19 & 8,534 & 0.09 \\
\hline 9/9/2006 & 29.7 & 4.2 & 0.25 & 8,577 & 0.10 \\
\hline $9 / 10 / 2006$ & 30.6 & 4.4 & 0.27 & 8,358 & 0.11 \\
\hline $9 / 11 / 2006$ & 29.3 & 4.4 & 0.24 & 8,489 & 0.09 \\
\hline $9 / 12 / 2006$ & 29.0 & 4.4 & 0.18 & 8,592 & 0.09 \\
\hline $9 / 13 / 2006$ & 29.8 & 5.1 & 0.20 & 8,321 & 0.09 \\
\hline $9 / 14 / 2006$ & 32.1 & 4.3 & 0.24 & 8,130 & \\
\hline 9/15/2006 & 31.5 & 4.4 & 0.28 & 8,256 & 0.10 \\
\hline $9 / 16 / 2006$ & 31.0 & 4.1 & 0.24 & 8,398 & \\
\hline Average & 29.9 & 4.6 & 0.25 & 8,414 & 0.09 \\
\hline
\end{tabular}

The coal moisture averaged nearly $30 \%$, which is comparable to that measured in the baseline and Phase II parametric test periods but less than that in the first parametric test period. The as received coal ash, sulfur and heat content are similar to that measured in other portions of the test program.

The coal averaged 0.09 ppm mercury on a dry basis during the long-term test. There appears to have been a significant upward trend of coal mercury during the program. The coal mercury averaged $0.08 \mathrm{ppm}$ and $0.07 \mathrm{ppm}$ during the baseline and Phase I 
parametric test periods, respectively. The coal mercury was higher during the long-term test and even higher, $0.13 \mathrm{ppm}$, during the second parametric test period.

\section{Fly Ash Data}

At least one set of fly ash samples was taken from each of the eight hoppers on the Reheat boiler ESP each day of the long-term test. The average LOI and $\mathrm{Hg}$ values for the front and back hoppers are shown in Table 36.

\begin{tabular}{|c|c|c|c|c|c|}
\hline \multirow[b]{3}{*}{ Date } & \multicolumn{4}{|c|}{ Table 36 Crawford 7 Long-Term Test Fly Ash LOI and Hg Data } & \\
\hline & \multirow[b]{2}{*}{ Activity } & \multicolumn{2}{|c|}{$\underline{\text { LOI, } \%}$} & \multicolumn{2}{|c|}{$\underline{\mathrm{Hg}}, \mathrm{ppb}$} \\
\hline & & Front Hoppers & Back Hoppers & Front Hoppers & Back Hoppers \\
\hline $8 / 15 / 2006$ & Pre-Test & 0.4 & 0.77 & 78 & 289 \\
\hline $8 / 16 / 2006$ & Pre-Test & 0.4 & 0.5 & 61 & 125 \\
\hline $8 / 17 / 2006$ & Long-Term Test C-PAC & 0.32 & 1.21 & 117 & 1260 \\
\hline $8 / 18 / 2006$ & Long-Term Test C-PAC & 2.46 & 0.9 & 825 & 925 \\
\hline $8 / 19 / 2006$ & Long-Term Test C-PAC & 2.92 & 3.21 & 1143 & 1513 \\
\hline $8 / 20 / 2006$ & Long-Term Test C-PAC & 2.85 & 4.14 & 1253 & 2000 \\
\hline $8 / 21 / 2006$ & Long-Term Test C-PAC & 2.97 & 4.71 & 1215 & 1905 \\
\hline $8 / 22 / 2006$ & Long-Term Test C-PAC & 2.74 & 4.34 & 1330 & 1880 \\
\hline $8 / 23 / 2006$ & Long-Term Test C-PAC & 2.62 & 4.33 & 1177 & 2133 \\
\hline $8 / 23 / 2006$ & Long-Term Test C-PAC & 2.71 & 5.01 & 1127 & 2097 \\
\hline $8 / 24 / 2006$ & Long-Term Test C-PAC & 3.20 & 5.04 & 1380 & 2383 \\
\hline $8 / 24 / 2006$ & Long-Term Test C-PAC & 1.95 & 4.57 & 917 & 2563 \\
\hline $8 / 25 / 2006$ & Long-Term Test C-PAC & 2.80 & 4.54 & 1180 & 2237 \\
\hline $8 / 25 / 2006$ & Long-Term Test C-PAC & 2.08 & 4.54 & 883 & 2640 \\
\hline $8 / 26 / 2006$ & Long-Term Test C-PAC & 3.16 & 4.49 & 1225 & 2105 \\
\hline 8/26/2006 & Long-Term Test C-PAC & 3.50 & 4.70 & 1470 & 2200 \\
\hline $8 / 27 / 2006$ & Long-Term Test C-PAC & 2.41 & 6.26 & 992 & 2395 \\
\hline $8 / 27 / 2006$ & Long-Term Test C-PAC & 2.14 & 4.81 & 897 & 2455 \\
\hline $8 / 28 / 2006$ & Long-Term Test C-PAC & 2.22 & 3.89 & 990 & 2440 \\
\hline $8 / 28 / 2006$ & Long-Term Test C-PAC & 2.48 & 4.01 & 1300 & 2110 \\
\hline $8 / 29 / 2006$ & Long-Term Test C-PAC & 2.43 & 4.53 & 1273 & 2780 \\
\hline 8/29/2006 & Long-Term Test C-PAC & 2.40 & 4.13 & 1165 & 2160 \\
\hline $8 / 30 / 2006$ & Long-Term Test C-PAC & 2.84 & 4.04 & 1337 & 1943 \\
\hline $8 / 30 / 2006$ & Long-Term Test C-PAC & 2.14 & 4.35 & 1004 & 2387 \\
\hline $8 / 31 / 2006$ & Long-Term Test C-PAC & 2.83 & 4.01 & 1223 & 2990 \\
\hline $8 / 31 / 2006$ & Long-Term Test C-PAC & 2.35 & 4.70 & 1150 & 2560 \\
\hline 9/1/2006 & Long-Term Test C-PAC & 2.92 & 4.56 & 1513 & 3197 \\
\hline $9 / 1 / 2006$ & Long-Term Test C-PAC & 2.18 & 4.39 & 1223 & 3180 \\
\hline $9 / 1 / 2006$ & Long-Term Test C-PAC & 2.40 & 4.72 & 1233 & 2930 \\
\hline 9/2/2006 & Long-Term Test C-PAC & 1.99 & 4.52 & 1177 & 3380 \\
\hline 9/3/2006 & Long-Term Test C-PAC & 2.11 & 4.75 & 1360 & 3253 \\
\hline $9 / 4 / 2006$ & Long-Term Test C-PAC & 2.35 & 4.94 & 1513 & 3323 \\
\hline 9/4/2006 & Long-Term Test C-PAC & 1.88 & 4.75 & 1163 & 2793 \\
\hline 9/5/2006 & Long-Term Test C-PAC & 3.05 & 5.06 & 1880 & 3293 \\
\hline $9 / 5 / 2006$ & Long-Term Test C-PAC & 1.93 & 5.20 & 991 & 2825 \\
\hline 9/6/2006 & Long-Term Test C-PAC & 2.19 & 4.75 & 1232 & 2411 \\
\hline 9/6/2006 & Long-Term Test C-PAC & 1.67 & 4.42 & 989 & 2877 \\
\hline 9/7/2006 & Long-Term Test C-PAC & 2.61 & 3.99 & 1800 & 2972 \\
\hline
\end{tabular}




\begin{tabular}{|cc|cc|cc|} 
9/7/2006 & Long-Term Test C-PAC & 2.69 & 4.80 & 2037 & 3351 \\
9/8/2006 & Long-Term Test C-PAC & 2.98 & 4.29 & 1735 & 2565 \\
9/8/2006 & Long-Term Test C-PAC & 2.88 & 4.96 & 1555 & 2795 \\
9/9/2006 & Long-Term Test C-PAC & 3.47 & 5.54 & 1530 & 2515 \\
9/10/2006 & Long-Term Test C-PAC & 2.47 & 4.69 & 1235 & 2890 \\
9/10/2006 & Long-Term Test C-PAC & 5.16 & 4.77 & 2180 & 2335 \\
9/11/2006 & Long-Term Test B-PAC & 2.59 & 4.58 & 1235 & 2695 \\
$9 / 12 / 2006$ & Long-Term Test B-PAC & 2.81 & 4.26 & 1340 & 2575 \\
9/12/2006 & Long-Term Test B-PAC & 2.07 & 4.39 & 1045 & 2540 \\
$9 / 13 / 2006$ & Long-Term Test B-PAC & 2.95 & 4.04 & 1360 & 2910 \\
9/13/2006 & Long-Term Test B-PAC & 2.95 & 4.04 & 1800 & 2700 \\
$9 / 14 / 2006$ & Long-Term Test C-PAC & 1.11 & 3.04 & 871 & 2637 \\
9/15/2006 & Long-Term Test C-PAC & 2.15 & 3.35 & 1407 & 2193 \\
$9 / 16 / 2006$ & Long-Term Test C-PAC & 1.99 & 2.39 & 1853 & 2133 \\
9/17/2006 & Post Test & 0.53 & 1.70 & 599 & 2100 \\
9/18/2006 & Post Test & 0.30 & 0.70 & 187 & 987 \\
\hline
\end{tabular}

The pre-test fly ash LOI and mercury content are low, as was seen in the baseline period. As soon as the C-PAC ${ }^{\mathrm{TM}}$ injection began, the fly ash LOI and $\mathrm{Hg}$ levels jumped. It appears that these values continue to climb for a few days before leveling off. However, this is merely an artifact of obtaining more representative fly ash samples with time as less untreated fly ash is sampled. The fly ash LOI content drops very rapidly at the end of the test while the fly ash mercury content does not.

A better way to examine the fly ash data is graphically. The average fly ash LOI and $\mathrm{Hg}$ contents for the fly ash from the long-term test are presented in Figures 37 and 38, respectively.

Figure 37. Crawford 7 Long-Term Fly Ash Average LOI Content by Hopper

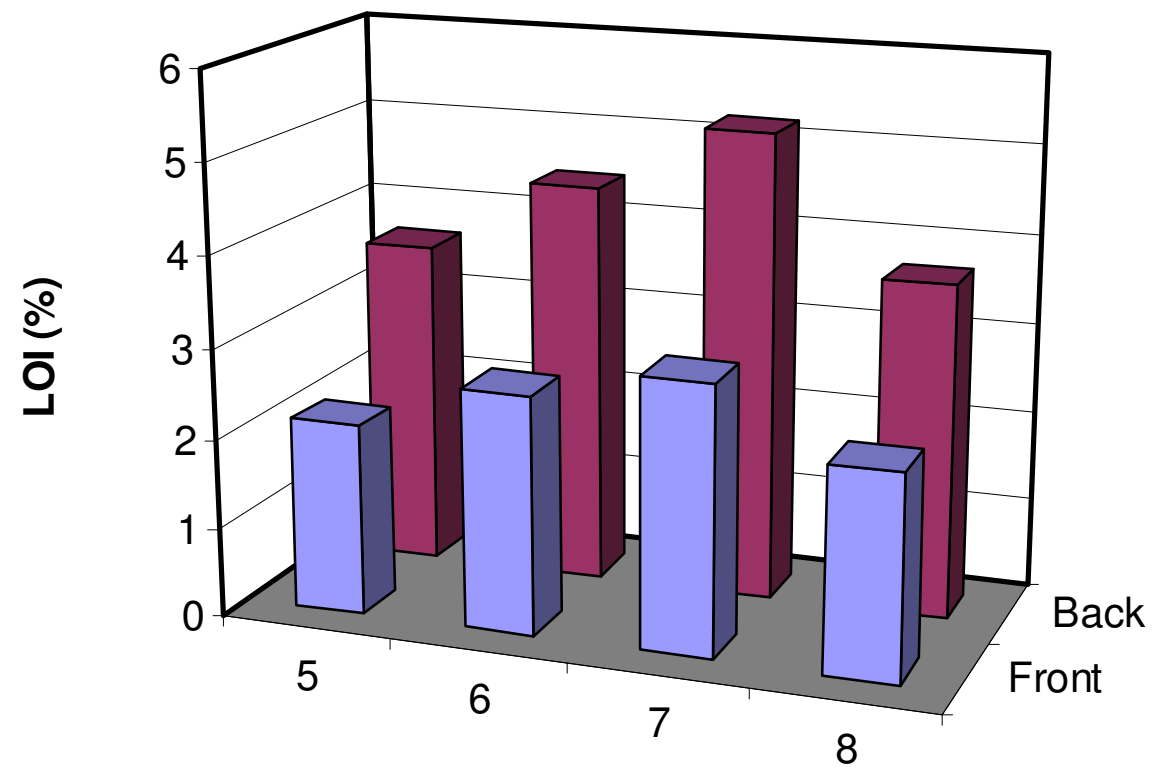


The long-term fly ash LOI is nearly twice as high in the back hoppers as it is in the back hoppers. This is expected since the back hoppers had a higher LOI in the baseline samples. The LOI data indicates a fairly uniform distribution of the sorbent within the fly ash, with slightly higher amounts in the center hoppers.

Figure 38. Crawford 7 Long-Term Fly Ash Average Hg Content by Hopper

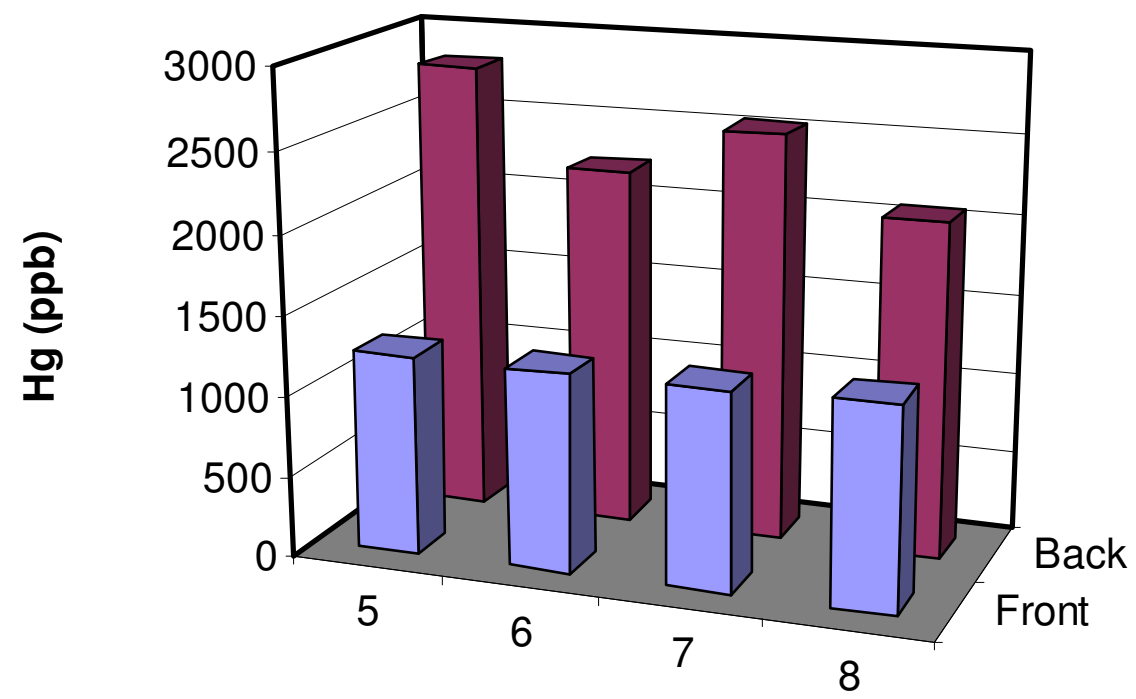

The long-term fly ash mercury content is even more evenly spread across the hoppers than the LOI content with the average mercury content in the front hoppers nearly being identical. There is higher mercury content in the back hoppers than the front due to the higher LOI content, but most of the mercury mass is collected in the front hoppers since there is four times more ash collected in the front hoppers.

The long-term fly ash LOI and $\mathrm{Hg}$ data is presented chronologically in Figure 40.

Figure 40. Crawford 7 Fly Ash LOI and Hg Contents during the Long-Term Test

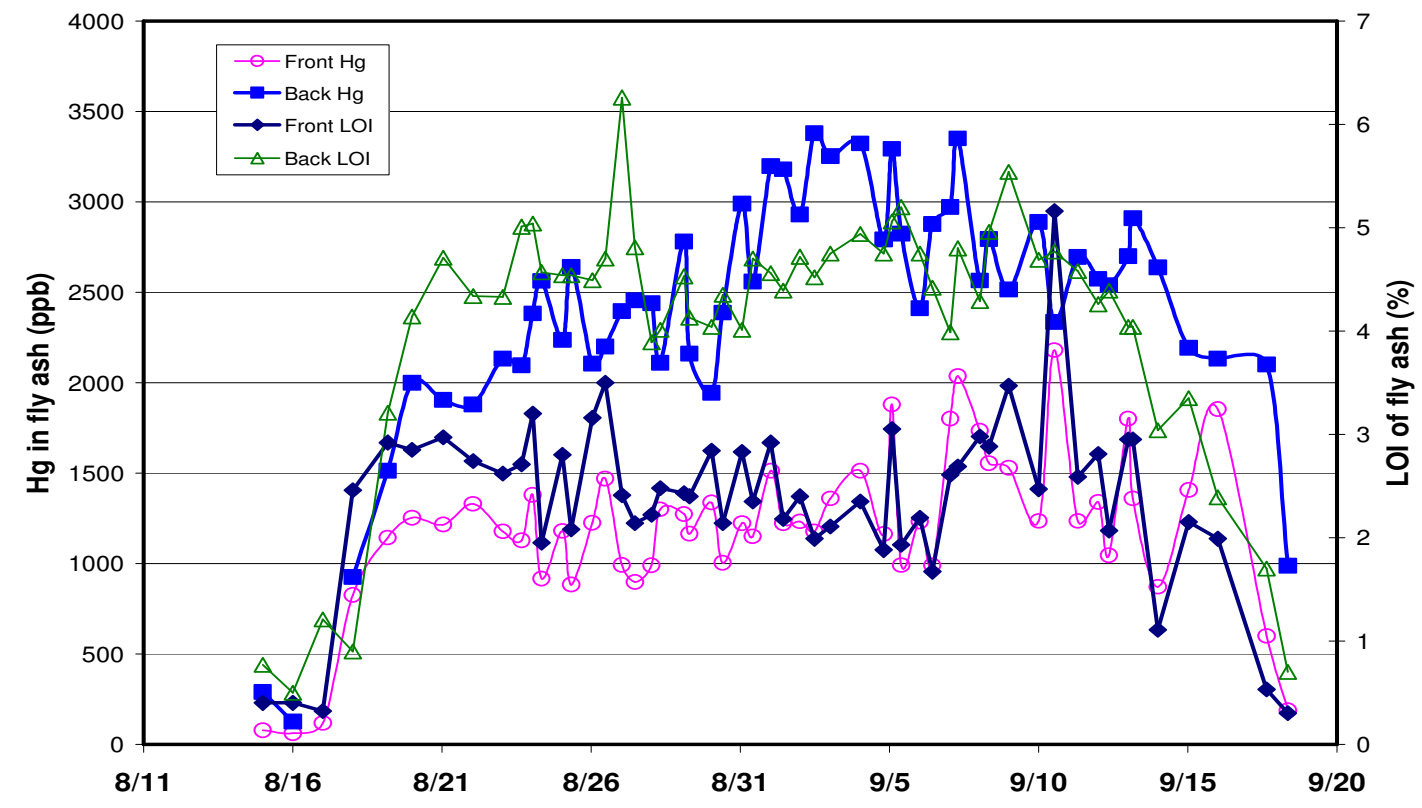


The instant and dramatic impact of the sorbent on the fly ash LOI and mercury contents can be seen in this figure. The LOI and mercury content of the fly ash from the front hoppers appears to be fairly stable throughout the long-term test while those values in the fly ash from the back hoppers appear to be increasing for much of the test. It is not known whether this increase in mercury content in the back hoppers is a result of the fact that the coal mercury increased over the duration of the long-term test.

There is interest in understanding whether mercury sorbents capture other trace metals besides mercury from the flue gas. Fly ash samples from the long-term test (9/5/06) and the second parametric tests (10/4/06 and 10/5/06), along with the sorbents used on those days were sent to SGS NA for selenium, barium and chromium analyses. The results are shown in Table 37.

\section{Table 37 Crawford 7 Fly Ash and Sorbent Selenium, Chromium and Barium Analyses}

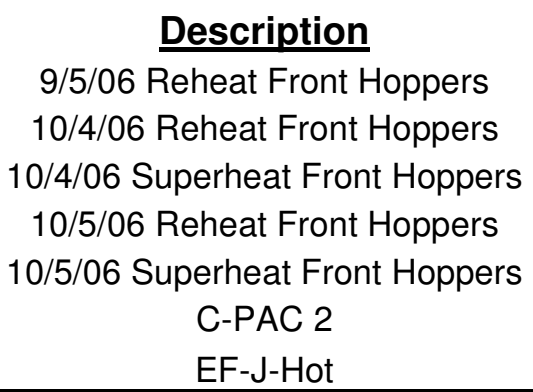

Description

9/5/06 Reheat Front Hoppers

10/4/06 Reheat Front Hoppers

10/4/06 Superheat Front Hoppers

10/5/06 Reheat Front Hoppers

10/5/06 Superheat Front Hoppers

C-PAC 2

EF-J-Hot

\begin{tabular}{c} 
Se, ppm \\
\hline 11 \\
16 \\
8 \\
8 \\
8 \\
$<4$ \\
10
\end{tabular}

\begin{tabular}{c} 
Ba, ppm \\
\hline ND \\
3700 \\
3400 \\
4300 \\
2500 \\
100 \\
100
\end{tabular}

\begin{tabular}{c} 
Cr, ppm \\
\hline ND \\
57 \\
53 \\
60 \\
51 \\
57 \\
17
\end{tabular}

The sorbent injection trials were all conducted on the Reheat boiler and, thus, samples from the Superheat boiler provide a baseline without sorbent content. The sorbents had low contents of all three metals and could not have been a source of a significant amount of these metals in the fly ash samples, considering that the sorbent was only about $2 \%$ of the fly ash mass. The fly ash samples from the Reheat boiler are comparable to those from the Superheat boiler, indicating that the fly ash did not capture these metals but rather they are native to the fly ash.

\section{Mass Balances}

The fly ash LOI and sorbent injection rates during the long-term trial can be used to calculate a carbon mass balance for the long-term test. Similarly, the coal and fly ash mercury data can be used to calculate a mercury mass balance in order to determine the percentage of the coal mercury captured in the fly ash. This value can then be compared to that determined by the mercury monitor.

The Crawford 7 Reheat boiler consumed about 33,000 tons of coal during the long-term test and about 67,000 pounds of sorbent was injected which would indicate that the fly ash should contain $2.82 \% \mathrm{LOI}$, including the baseline amount. The average fly ash LOI measured during the long-term test was $2.86 \%$, assuming that $80 \%$ of the fly ash is collected in the front hoppers and $20 \%$ in the back hoppers. This is an exceptional carbon balance.

The coal during the long-term test averaged $0.09 \mathrm{ppm}$ on a dry basis. Using this data, the fly ash mercury content would be calculated to be $1350 \mathrm{ppb}$ if the mercury removal rate were $81 \%$, as indicated by the mercury monitor. However, the fly ash mercury 
content averaged $1510 \mathrm{ppb}$ during the long-term test. There are two possible explanations for this discrepancy. First, the average coal mercury content could have been higher than measured. For example, if the average coal mercury content were $0.10 \mathrm{ppm}$ instead of the $0.09 \mathrm{ppm}$ measured, the predicted fly ash mercury content would have been $1500 \mathrm{ppb}$ at a mercury removal rate of $81 \%$. This mercury concentration is nearly the same as that measured in the long-term test.

The second explanation is that the mercury removal rate during the test was higher than $81 \%$, as measured by the mercury monitor. The fly ash mercury data would indicate a mercury removal rate of $90 \%$. The sorbent trap data did indicate that the mercury removal rate could be slightly higher than the $81 \%$ measured by the monitor, but not as high as $90 \%$.

\section{Fly Ash Cement Properties}

The Foam Index of fly ash sample is the first indication of the quality of the material in regard to its use in concrete. The foam index test is very simple and rapid. It involves adding an air entrainment admixture (AEA) drop wise to a solution containing a known amount of fly ash. The AEAs are essentially soaps used to generate bubbles in the final concrete. Without these air bubbles, the concrete would be susceptible to cracking during the freeze and thaw cycle. A high quality fly ash should have both a low foam index, but also, a very consistent foam index. In fact, the latter is usually more important than the former. If a fly ash varies widely in its foam index, the customer doesn't know how much AEA to add routinely. Adding a little more AEA is not a major concern since this material is inexpensive.

The foam indices of the fly ash for the first three weeks of full-scale testing at Crawford 7 when C-PAC ${ }^{\mathrm{TM}}$ was used exclusively are shown in Figures 40 with the Vinsol AEA.

Figure 40. Foam Indices of Fly Ash from the Long-Term Test at Crawford 7

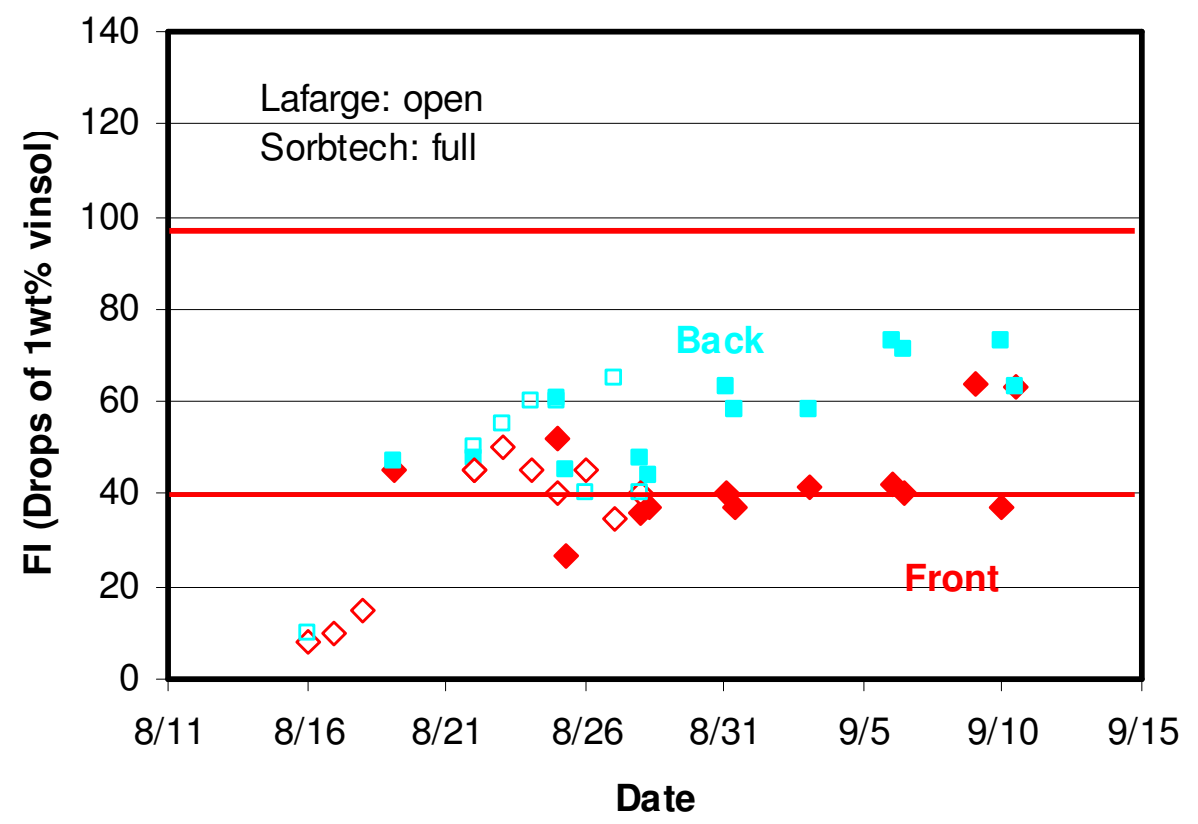


The Vinsol AEA was used in this evaluation since that is the one used in the Chicago market by LaFarge, the purchaser of the Midwest Generation fly ash. The fly ash foam index before the long-term test began was below 20 but increased to about 40 for the fly ash in the front hoppers, which accounts for at least $80 \%$ of the total fly ash generated. The foam index of the fly ash from the back hoppers was higher, averaging near 60 .

The distribution of the foam index values from the baseline period and the long-term test are shown in Figure 41.

Figure 41. Foam Index Distribution for Fly Ash from the Baseline and Long-Term Test Periods at Crawford 7

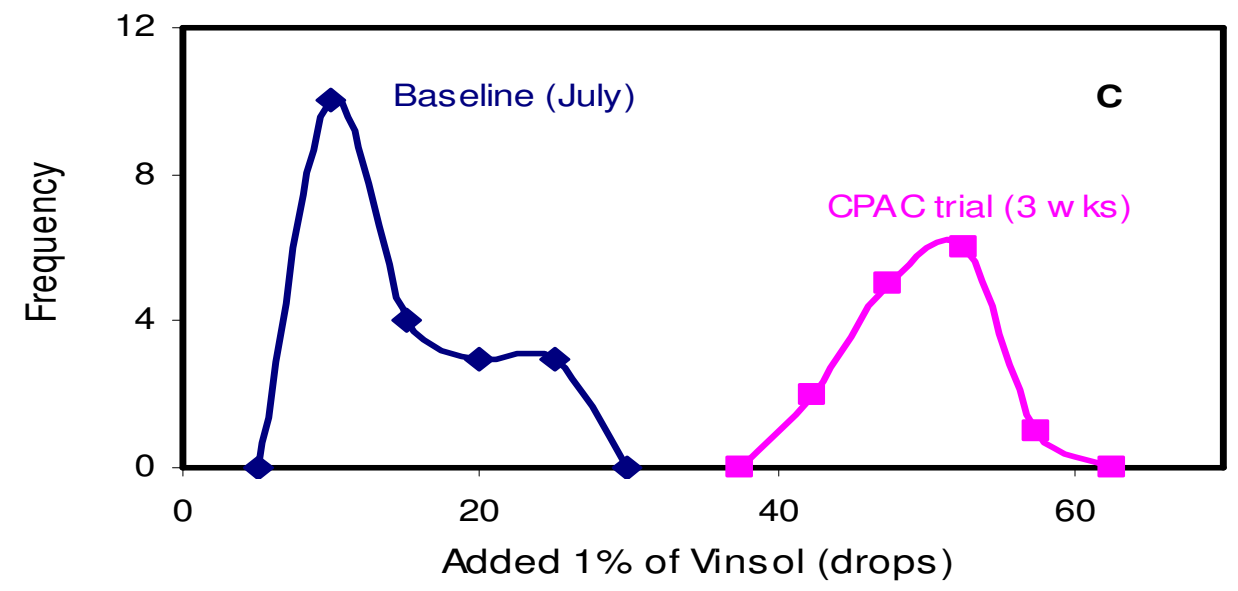

The distribution of the foam indices from the long-term test is narrower than that observed in the baseline period, which is good for the fly ash customer. Other AEAs were used to evaluate the long-term fly ash samples from the front hoppers and the results from these tests are presented in Figure 42.

Figure 42. Foam Indices of the Long-Term Fly Ash Samples Using Different AEAs

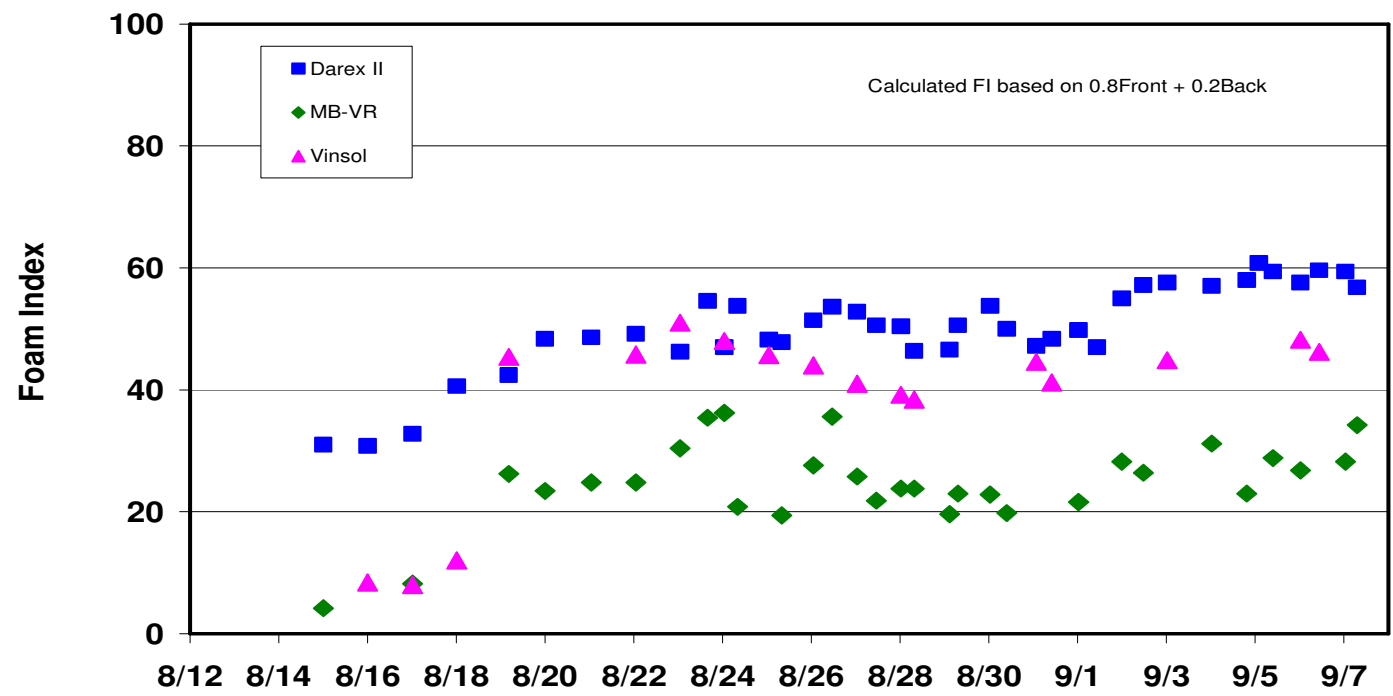


The fly ash from the front hoppers represents $80 \%$ or more of the fly ash generated, so this analysis focused on these samples. The general trend in foam index values of increasing when injection began for the long-term test and fairly stable throughout the period was observed for all AEAs. However, the other AEAs did not appear to be as sensitive to the presence of the sorbent in the fly ash since the foam index with these materials increased less than with the Vinsol.

\section{Concrete Testing with Crawford Fly Ash}

The impact of C-PACTM on the properties of concrete was investigated by both Albemarle Environmental $\mathrm{f} / \mathrm{k} / \mathrm{a}$ Sorbent Technologies and Headwaters Resources, a project partner. The properties evaluated include the concrete air content, air stability, air distribution, setting time, and strength.

The concretes were made with either $100 \%$ Portland cement (PC), as a control, or with a $3 \%$ replacement of the PC by Crawford fly ash from either the baseline or long-term test periods. The remaining ingredients of concrete mix consisted of sand, fine aggregate, coarse aggregate and water. The relative proportions of the concrete mix are shown in Figure 43.

\section{Figure 43. Ingredients of the Concrete Mix}

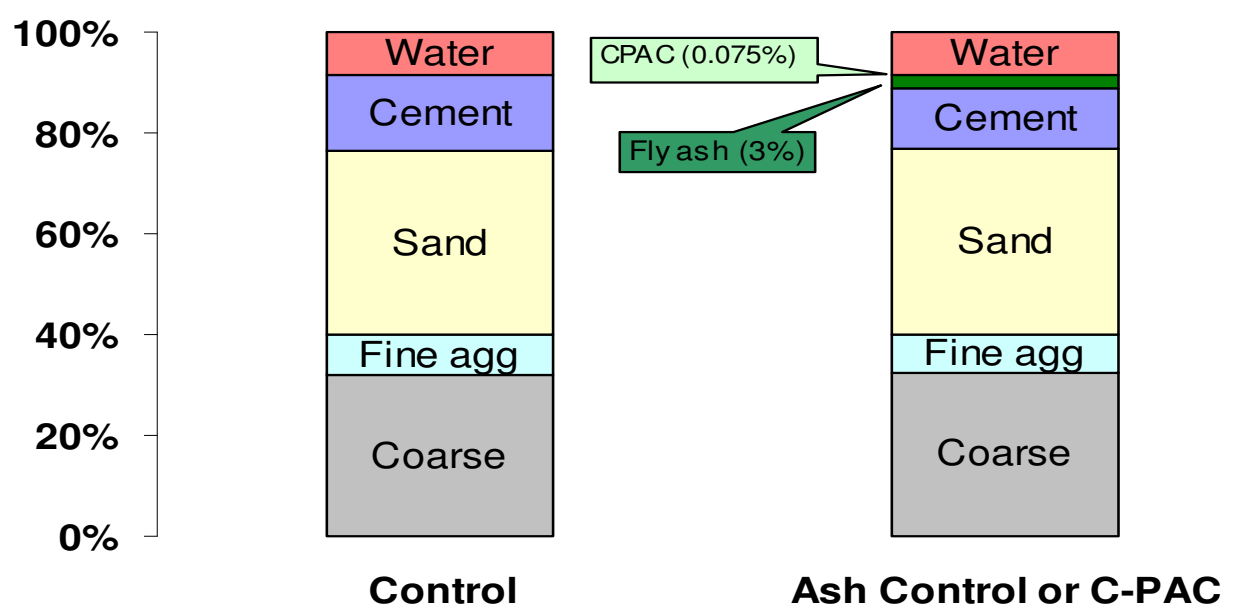

Concretes were made and cured following ASTM procedure C192. The air content of fresh concrete was measured using the ASTM C231 method. Air void analysis of hardened concrete was measured using the ASTM C457B, modified point count method. For air stability testing, the fresh concrete was initially made using ASTM C192, but after being made, slump and air content were measured at $\sim 30$ minute intervals, in static and dynamic states. Unconfined compressive strength was measured following the ASTM C39 procedure. The Penetration Resistance Method was applied to determine the setting time of the concretes.

The amount of AEA needed to reach a concrete target slump (6") and air volume (6\%) were determined before the concretes were made for each mix. The results are summarized in Table 38 for the concrete samples made with no ash, $3 \%$ replacement 
with Crawford baseline fly ash or $3 \%$ replacement with Crawford long-term fly ash containing C-PAC ${ }^{\mathrm{TM}}$.

Table 38. Air Properties of the Concretes

\begin{tabular}{cccc}
\hline Concrete & AEA (ml/100 kg Cement-ash) & Slump (inch) & Air (volume,\%) \\
\hline No Ash & 41 & 6.0 & 6.7 \\
Baseline Ash & 43 & 6.1 & 6.0 \\
Long-Term Ash & 87 & 6.3 & 6.4 \\
Salt-Br PAC & 349 & 6.0 & 5.5 \\
\hline
\end{tabular}

The no ash control sample required $41 \mathrm{ml} / 100 \mathrm{~kg}$ of cement mix to generate the desired slump and air volume. About the same amount was required for the sample containing the baseline ash. The sample containing the long-term ash from Crawford required about doubled the amount of AEA. Even though more AEA was used in concrete mix containing the long-term fly ash, the dosage still satisfies contractor specifications.

A bromine salt impregnated PAC (Norit Darco Hg-LH) was also evaluated in these tests. Approximately ten times the amount of AEA was needed for this material to generate the desired target slump and air volume, which was way out of the any contractor specification range.

The previous test proved that the desired air content (6\%) can be entrained in concretes with fly ash containing C-PAC ${ }^{\mathrm{TM}}$, as with the control ash concrete. However, it is necessary to not only achieve an equivalent amount of initial air content, but also to keep the air bubbles stable with time. In many cases, when large amounts of AEA are added to obtain the initial air content, the air content is not be stable over time.

The air stability of concretes containing just baseline fly ash or the long-term fly ash containing C-PAC ${ }^{\text {TM }}$ is shown in Figure 44 for both the static and dynamic tests.

Figure 44. Concrete Air Stability Data

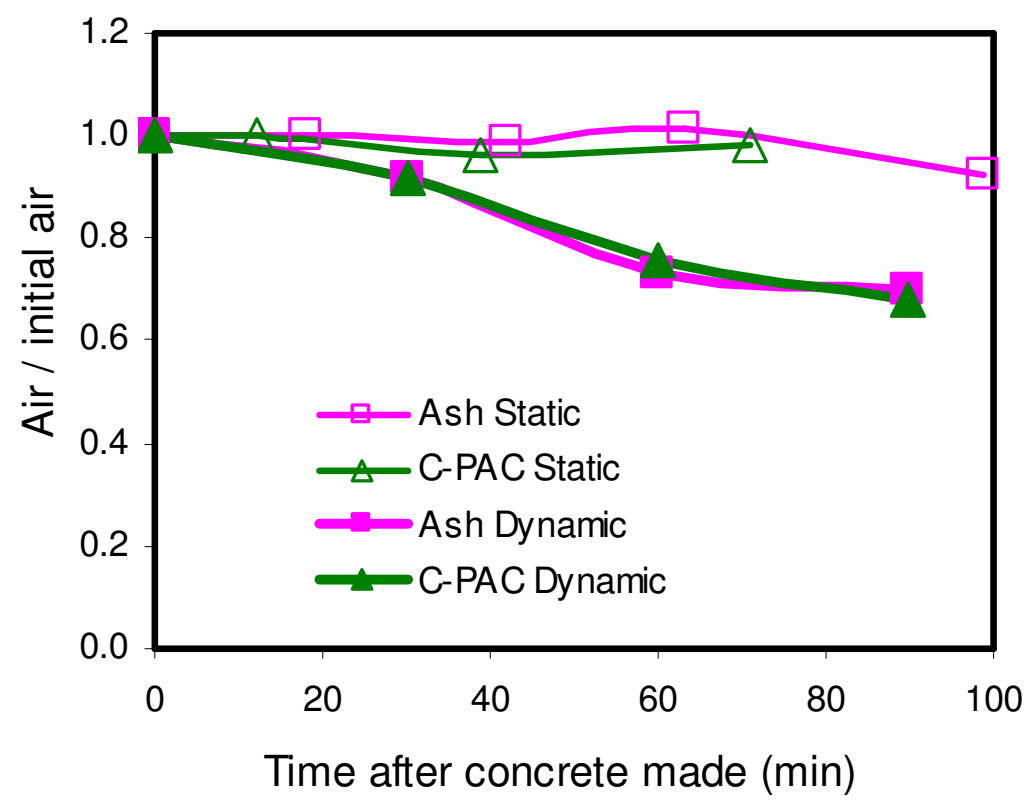

Albemarle Environmental f/k/a Sorbent Technologies Corporation $\quad$ DE-FC26-05NT42308 100 
The air content of both concretes was shown to be very stable over the 70-minute tests in the static test. The static test reflects ready-mix fresh concrete setting on the jobsite without mixing or agitation. In the dynamic case, some air was gradually lost with time from both materials. About $30 \%$ of the initial air volume was lost after 90 minutes, following the production and mixing of the concrete. The dynamic measurement simulates ready-mix concrete delivery to a site with continuous mixing or agitating. The stability of air contents in both concretes was precisely the same. This indicates that the C-PAC ${ }^{\mathrm{TM}}$ mercury sorbent in concrete does not influence the air content of the concrete even at the higher dosage of $A E A$ required.

In order to protect the concrete during exposure to the freeze-thawing cycle, the air-void system of concrete should have both the needed volume capacity (air content) and the geometric parameters (e.g. specific surface, spacing factor). It is important to obtain concrete with high air content and a low enough spacing factor to provide the protection. To characterize the air bubbles, the spacing factor (a parameter related to the maximum distance in the cement paste from the periphery of an air void) and the specific surface (the ratio of the surface area of the air voids to their volume) are typically used. In general, a good quality, frost-resistant concrete has a spacing factor $<0.0080$ inches and a specific surface of $>600 \mathrm{in}^{-1}$.

The results from this analysis are presented in Table 39.

Table 39. Concrete Air Void Content and Hardened Concrete Parameters

\begin{tabular}{|c|c|c|c|}
\hline Specimen & $\begin{array}{c}\text { Concrete with } \\
\text { Crawford } \\
\text { baseline fly ash }\end{array}$ & $\begin{array}{c}\text { Concrete with } \\
\text { Crawford long-term } \\
\text { C-PAC fly ash }\end{array}$ & Acceptable \\
\hline $\begin{array}{c}\text { Total air void content, \% ASTM } \\
\text { C457 (Fresh ASTM C231) }\end{array}$ & $4.49(5.05)$ & $5.56(5.48)$ & $4.0-6.0$ \\
\hline Spacing factor, in. & 0.0055 & 0.0054 & $0.004-0.008$ \\
\hline Specific surface, in $^{2} / \mathrm{in}^{3}$ & 984 & 865 & $600-1100$ \\
\hline Voids larger than 1 $\mathrm{mm}, \%$ & 0.71 & 0.65 & \\
\hline Voids frequency, voids/in. & 11.0 & 12.0 & \\
\hline
\end{tabular}

Overall, air void content and parameters indicate that both specimens are high-quality and frost-resistant concretes; the one including C-PAC ${ }^{\mathrm{TM}}$ perhaps even a little better.

Photographs of section of the two concrete samples are shown in Photographs 15 and 16. The photograph on the left (15) is from the concrete section made with Crawford baseline ash, while the photograph on the right (16) is from the concrete made from the fly ash from the long-term test at Crawford 7 which includes the C-PAC ${ }^{\text {TM }}$. The air voids are more uniformly distributed in the concrete containing the long-term fly ash than in control sample containing the baseline fly ash. 


\section{Photographs 15 and 16. Sections of Concrete Made with Either Crawford Baseline or Long-Term Fly Ash}
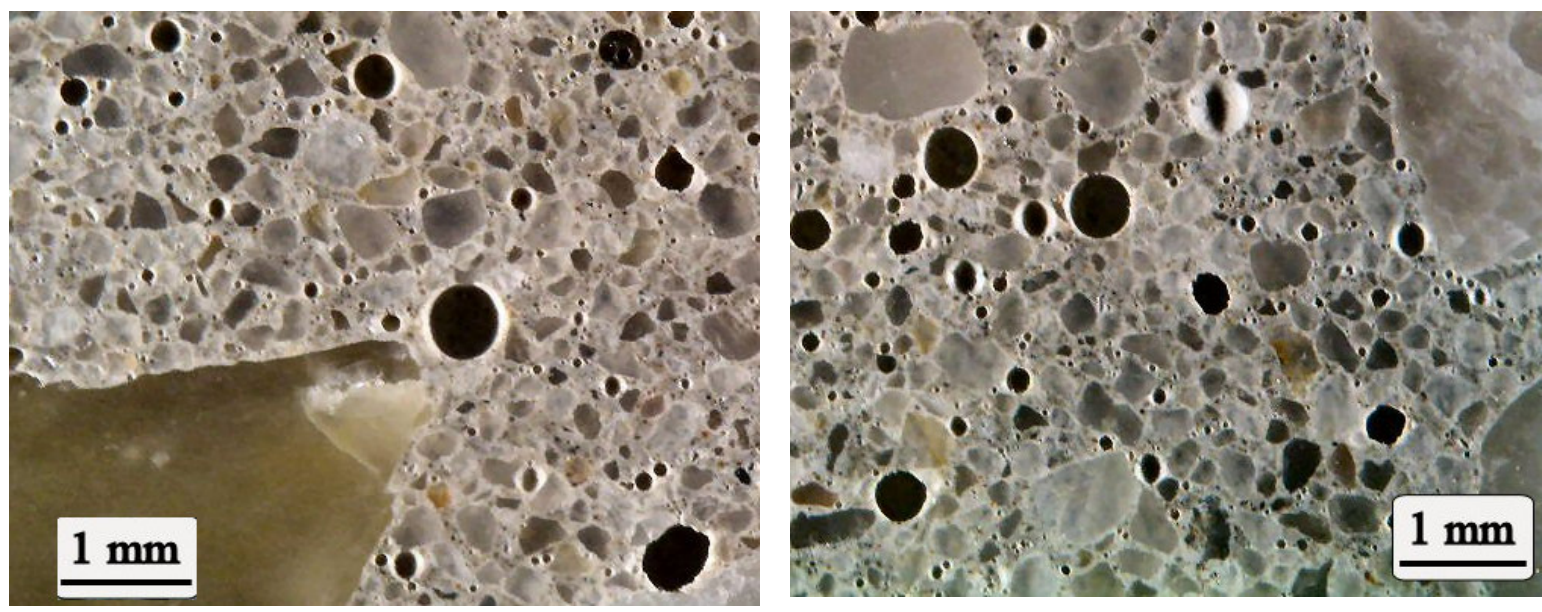

Setting of concrete is the gradual transition of its paste from liquid phase to solid phase. The setting correlates to the degree of chemical hydration. Temperature, cement type, and supplementary cementing materials (e.g. fly ash) affect the setting time of a concrete mixture. Tests were performed to examine if including C-PAC ${ }^{\mathrm{TM}}$ with the fly ash had any effects on setting, when all other conditions were identical.

The definition of the point at which the paste is considered to be set is relatively arbitrary. ASTM C403 defines the setting of the concrete in terms of an initial and final set. Based on this method, a mortar sample obtained by sieving the wet concrete is penetrated by needles of different sizes and the force required is measured. In the ASTM definition, initial setting occurs at a penetration resistance of 500 pounds per square inch (psi), which corresponds with the time when the concrete can no longer be vibrated. A penetration resistance of $4000 \mathrm{psi}$ is defined as the final set and the concrete compressive strength and stiffness development begin.

It has been determined that concrete can begin to carry measurable loads when the concrete has reached a compressive strength of as little as 80 psi. Knowing the time of set to each of the level of penetration resistance is of great value and can help workers plan how to optimize the construction project timing.

Concrete mixes containing either baseline fly ash from Crawford or the long-term fly ash containing C-PAC ${ }^{\mathrm{TM}}$ were evaluated by the penetration resistance method. The results from this evaluation are presented in Figure 45. 
Figure 45. Penetration Resistance of Concrete Mixes with Either Crawford Baseline or Long-Term Fly Ash

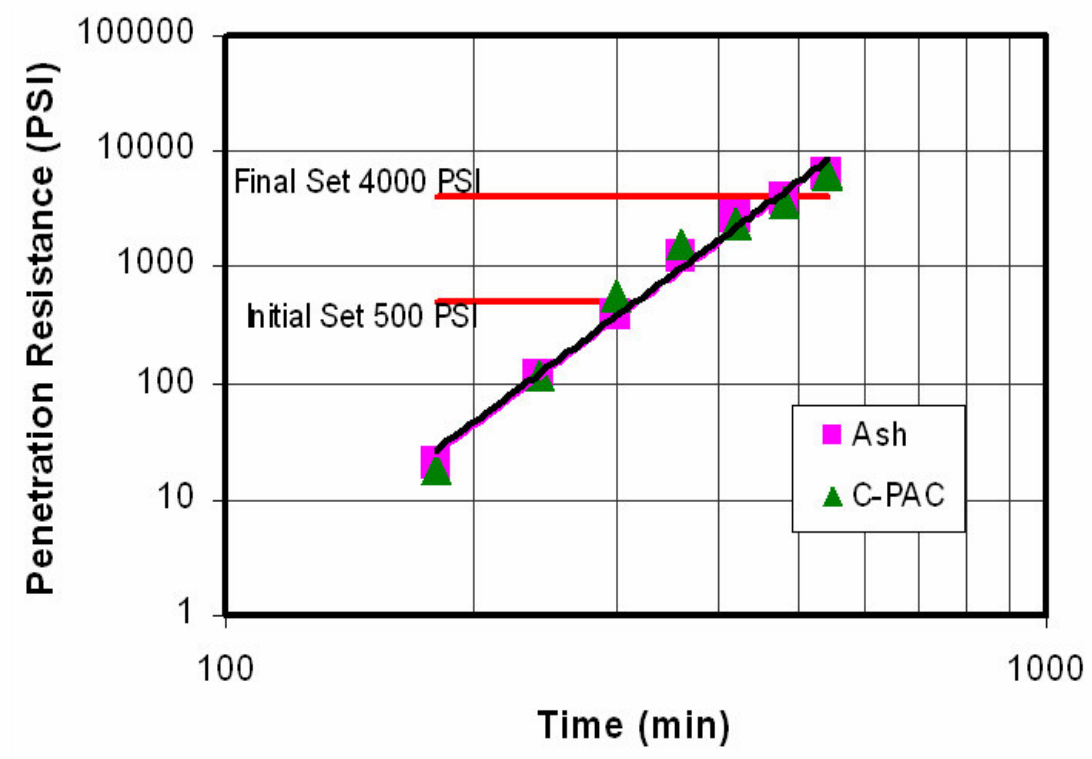

The penetration resistances of concrete mixes containing Crawford fly ash from either the baseline or long-term test period were almost identical. For both concretes, the calculated time to reach the initial set point (500 psi) and the final set point (4000 psi) were 315 and 466 minutes, respectively. This strongly suggests that C-PAC ${ }^{\text {TM }}$ does not affect the setting of concrete in comparison with regular fly ash materials.

Compressive strength is the capacity of the concrete to withstand axially-directed compressive forces. When the limit of compressive strength is reached, the materials fracture. For concrete exposed to the freeze and thaw process, a minimum-compressive strength must be developed, in addition to the securing adequate air void systems. Such strength should typically be greater than 4000 psi.

The compressive strength of concretes made with no fly ash, Crawford baseline fly ash or Crawford long-term fly ash which contained C-PAC ${ }^{\mathrm{TM}}$ were measured at set intervals by both Headwaters Resources and Albemarle Environmental $\mathrm{f} / \mathrm{k} / \mathrm{a}$ Sorbent Technologies. The results of these analyses are presented in Figure 46, where the top data set is from Headwaters Resources and the bottom data set from Albemarle Environmental f/k/a Sorbent Technologies.

The compressive strengths of all of the concrete samples at 14 days were higher than 4000 psi. The concretes made with fly ash (both baseline and long-term) had a lower early compressive strength than the non-fly ash concretes, in accordance with the well established conclusion that fly ash reduces early strength. However, by 14 days the fly ash containing concretes had caught up to that of the concretes made without fly ash and surpassed the no fly ash concrete in compressive strength thereafter. This is also in accordance with the general finding that fly ash enhances the ultimate strength of concrete. It appeared that the concrete made with the Crawford long-term fly ash 
containing C-PAC ${ }^{\mathrm{TM}}$ had improved the early strength by 10 to $15 \%$ compared to the ash control concrete.

The sample labeled CPAC* is a synthetic mixture with baseline Crawford fly ash and C-PAC ${ }^{\mathrm{TM}}$. This sample performed in a similar manner, as did the concrete made with the long-term Crawford fly ash.

Figure 46. Unconfined Compressive Strength of Concrete Samples Made by Headwaters Resources (top) and Albemarle Environmental f/k/a Sorbent Technologies (bottom)
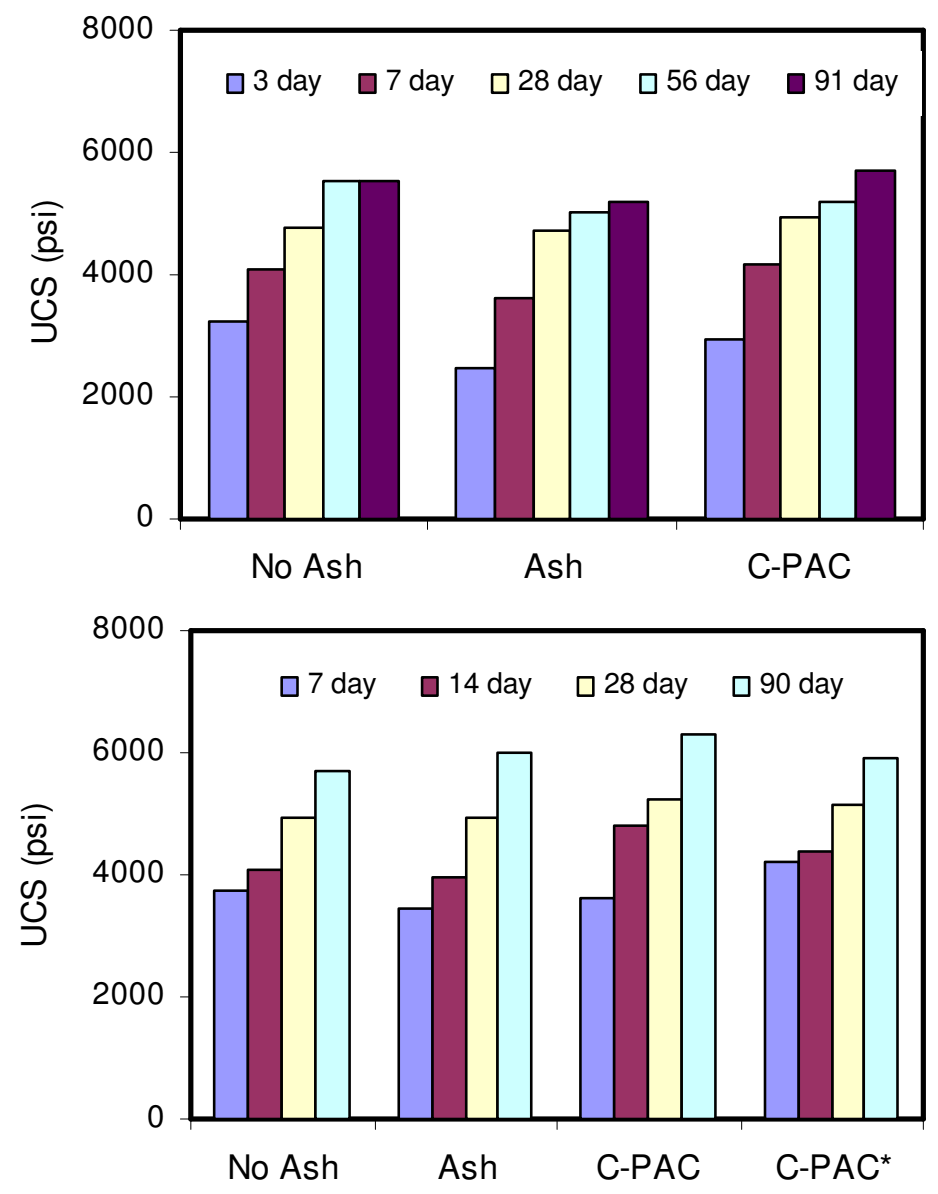

In conclusion, C-PAC ${ }^{\mathrm{TM}}$ does not appear to deleteriously affect any of the important properties of concrete. It may even improve some properties. The cost of the extra amount of AEA will be negligible compared to the technical, environmental, and economic benefits of utilizing fly ash containing the C-PAC ${ }^{\text {TM }}$ mercury sorbent in concrete, as opposed to the disposal of fly ash containing non-concrete-friendly activated carbons in landfills.

\section{Mercury Leaching Tests}

Fly ash samples from the baseline and long-term test periods at Crawford 7 were subjected to mercury leaching tests with de-ionized water (DI), and acetic acid solution 
per the Toxic Characteristic Leaching Procedure (TCLP) and with an alkaline $\mathrm{Na}_{2} \mathrm{CO}_{3}$ solution per the Synthetic Groundwater leaching Procedure (SGLP).

The results of the leaching tests appear in Table 40.

\begin{tabular}{|c|cc|cccc|}
\hline \multicolumn{7}{|c|}{ Table 40. Crawford 7 Fly Ash Hg Leaching Data } \\
\hline Sample & $\begin{array}{c}\mathbf{H g} \\
\mathrm{ppb}\end{array}$ & $\begin{array}{c}\text { LOI } \\
\%\end{array}$ & DI Water & Acetic Acid & Sodium Carbonate \\
\hline Extraction solution & & & 11 & 13 & 25 \\
\hline Baseline Front Hoppers & 25 & 0.3 & 18 & 7 & 37 \\
Baseline Back Hoppers & 51 & 0.5 & 12 & 11 & 30 \\
\hline Long-Term Front Hoppers & 917 & 2.0 & 9 & 6 & 9 \\
Long-Term Back Hoppers & 2563 & 4.6 & 27 & 7 & 13 \\
Long-Term Front Hoppers & 1380 & 3.2 & 18 & 4 & 31 \\
Long-Term Back Hoppers & 2383 & 5.0 & 51 & 8 & 8 \\
Long-Term Front Hoppers & 1163 & 1.9 & 5 & 3 & 9 \\
Long-Term Back Hoppers & 2793 & 4.8 & 19 & 6 & 12 \\
Long-Term Front Hoppers & 1513 & 2.4 & 15 & 5 & 11 \\
Long-Term Back Hoppers & 3323 & 4.9 & 36 & 4 & 14 \\
\hline Long-Term Average & \multicolumn{7}{c|}{22} & 5 & \\
\hline
\end{tabular}

The fly ash samples containing the mercury sorbent generally exhibited a lower rate of mercury release even though it contained as much as two orders of magnitude more mercury. In all cases except for distilled water, the mercury leachate concentration from the long-term fly ash samples was below that of the extraction water. These findings are understandable since the gas-phase brominated C-PAC ${ }^{\mathrm{TM}}$ bonds the mercury so it cannot be released and since the sorbent has more capacity with which to capture mercury in the solutions.

\section{$\underline{\text { Halogen Data }}$}

GE Energy performed Method 26A halogen tests on September 7, 2006, during the long-term test at Crawford 7. The halogen tests were conducted simultaneously at the inlet and outlet locations. The results are presented in Table 41.

\begin{tabular}{|lcc|}
\hline \multicolumn{3}{|c|}{ Table 41. Crawford 7 Long-Term Halogen Data } \\
Parameter & Inlet, ppm & Outlet, ppm \\
\cline { 2 - 3 } Fluorine & $<0.005$ & $<0.005$ \\
Hydrogen Chloride & 0.35 & 0.65 \\
Chlorine & 0.24 & 0.30 \\
Hydrogen Bromide & $<0.005$ & $<0.005$ \\
Bromine & $<0.005$ & $<0.005$ \\
\hline
\end{tabular}

The concentrations of three parameters in the flue gas (fluorine, hydrogen bromide and bromine) were below the method detection limit of the method, while the concentrations of chlorine and hydrogen chloride were below $1 \mathrm{ppm}$. These findings are identical to those obtained in the baseline period. This is another confirmation that the bromine is 
not released by Albemarle Environmental f/k/a Sorbent Technologies' brominated sorbents, in this case C-PAC ${ }^{\mathrm{TM}}$.

\section{Corrosion Data}

Corrosion coupons were installed in the ductwork at Crawford 7 at a location about 20 feet above the sorbent injection location. A set of four coupons were in place during the baseline period and another set in place during the long-term test. The coupons were removed at the end of end test period and sent to Pacific Sensor for weight loss analysis. The results of these analyses are presented in Figure 42.

\begin{tabular}{|lcc|}
\hline \multicolumn{2}{|c|}{ Table 42. Crawford 7 Corrosion Testing Results } \\
Period & Days Exposed & Weight Loss, $\mathbf{~ m g / d}$ \\
Baseline & 22 & 0.073 \\
Baseline & 22 & 0.082 \\
Baseline & 22 & 0.095 \\
Baseline & 22 & $\underline{0.095}$ \\
& & 0.086 \\
Long-Term & 30 & \\
Long-Term & 30 & 0.060 \\
Long-Term & 30 & 0.033 \\
Long-Term & 30 & 0.030 \\
& & $\underline{\text { Gain }}$ \\
\hline
\end{tabular}

The corrosion coupons experienced more corrosion during the baseline period than they did during the long-term test. In fact, one of the corrosion coupons from the long-term test showed a gain in weight. All of the corrosion coupons from the long-term test at Detroit Edison St. Clair showed a gain in weight, as did three of the corrosion coupons from the baseline period. The reason for the lower corrosion rate during the long-term test is not known but may be related to the boiler shutdowns during the baseline period. In any case, the corrosion during the baseline period was small and was not increased by sorbent injection.

\section{Boiler Operation}

There were no restrictions on Crawford 7 boiler operations during the long-term test. The sorbent injection system was configured to follow the flue gas flow rate and adjust the C-PAC ${ }^{\mathrm{TM}}$ injection rate to maintain the desired feed rate throughout the test.

Crawford 7 varied load from the minimum of about $90 \mathrm{MW}$ gross to as high as $225 \mathrm{MW}$ gross during the long-term test.

The main focus of boiler operation during the long-term test was opacity, since the ESP has a very small SCA of about 120 at full load. The opacity from the two boilers which make-up Crawford 7 varies with load, with the highest opacity occurring at the highest loads. The reason for this is simple. The flue gas flow and temperature is lower at lower boiler loads, which increases the effective SCA of the ESP and its performance. 
A plot of 6 minute average opacity for the combined boilers of Crawford 7 versus boiler load during the long-term test is presented in Figure 47.

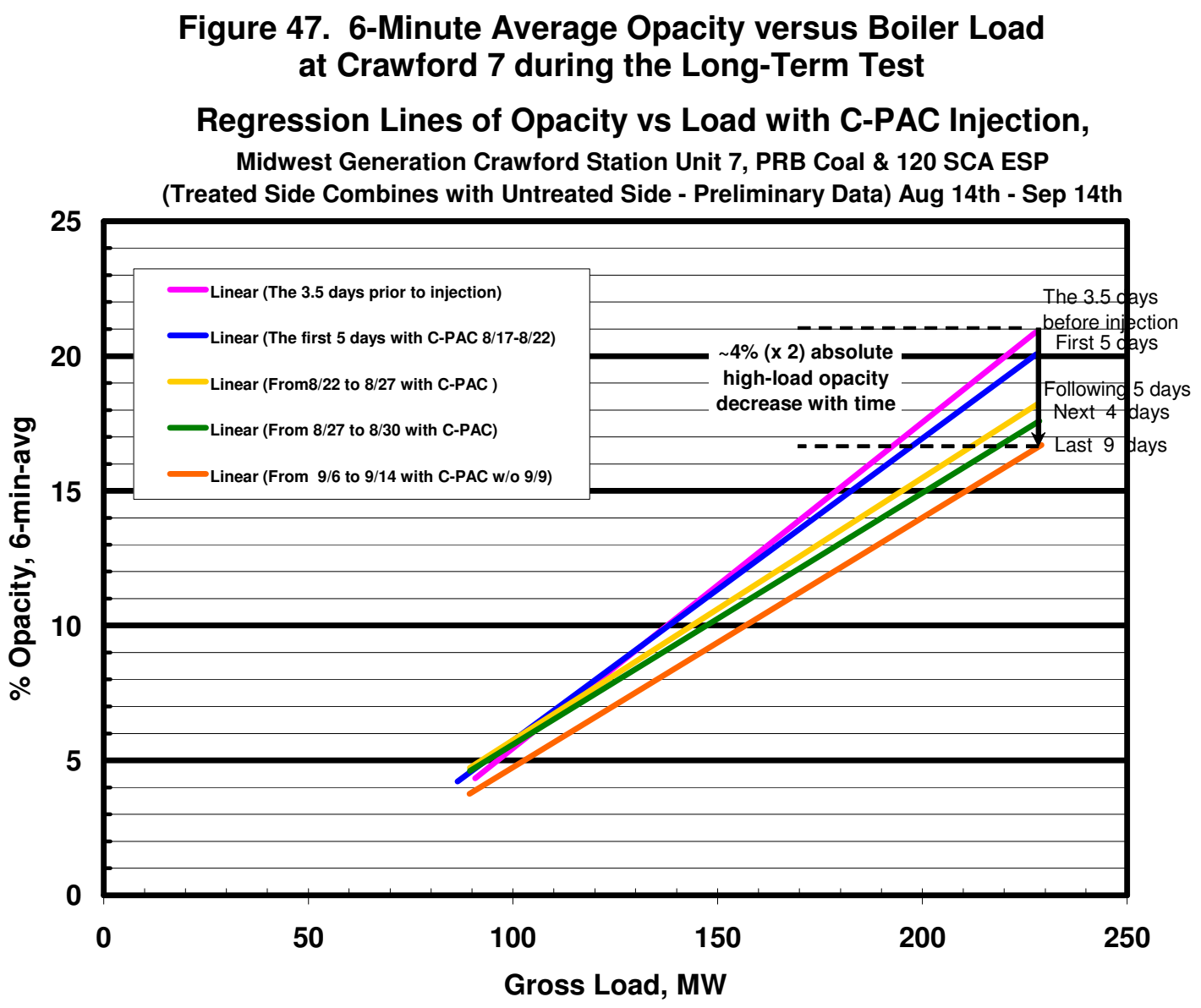

The data for each period of time was used to develop a linear regression line for that time period. For example, the top line is for the period of 3.5 days before the long-term trial began. For this time period, the average opacity at loads below $100 \mathrm{MW}$ gross was below $5 \%$, while it was $21 \%$ at full load. As the long-term test progressed, the opacity regression lines for each successive period was lower than the previous one, so that at the end of the test the opacity at full load was averaging about $4 \%$ below that before the injection began. This translates into an $8 \%$ reduction in opacity if both of the boilers that make-up Crawford 7 were being treated with sorbent.

This phenomenon of reducing opacity because of B-PAC ${ }^{\mathrm{TM}}$ or C-PAC ${ }^{\mathrm{TM}}$ injection was seen previously at the Progress Energy Lee Station, where the boiler could only operate without $\mathrm{SO}_{3}$ injection during the continuous injection of $\mathrm{B}-\mathrm{PAC}{ }^{\mathrm{TM}}$. 


\section{MIDWEST GENERATION WILL COUNTY STATION}

The testing at Midwest Generation Will County Unit 3 began with the arrival of the Albemarle Environmental $\mathrm{f} / \mathrm{k} / \mathrm{a}$ Sorbent Technologies' personnel, sorbent injection trailer and the mercury monitors on July 30,2007 . The duration of the testing at the Will County Station was reduced from that originally planned, due to a reduction in DOE funding. The biggest changes were the shortening of the baseline period and the switch from a long-term 30 day test to a short continuous injection run that lasted only a few days. The parametric tests before and after the continuous run were essentially unchanged. The mercury measurements were all made using monitors. No OHM Hg measurements were made.

The parametric testing was divided into two phases; the first using the high temperature version of C-PAC ${ }^{\mathrm{TM}}$, the concrete friendly sorbent, and the other using non-concrete friendly materials. The first phase of the parametric tests was conducted before the continuous run. The second phase of the parametric testing was performed after the continuous run in order to avoid contaminating the fly ash containing the concrete friendly sorbents. All of the equipment was disassembled and the Albemarle Environmental f/k/a Sorbent Technologies' personnel departed on August 31, 2007. As a cost reduction measure, Western Kentucky University personnel did not operate the mercury monitors at the Will County Station. Albemarle Environmental $\mathrm{f} / \mathrm{k} / \mathrm{a}$ Sorbent Technologies' personnel operated all of the equipment during this program.

The Will County Station is located in Romeoville, Illinois, a suburb of Chicago. A photograph of Will County Station with the Albemarle Environmental f/k/a Sorbent Technologies' injection trailer and the Albemarle Environmental f/k/a Sorbent Technologies' sorbent tanker is shown in Photograph 17.

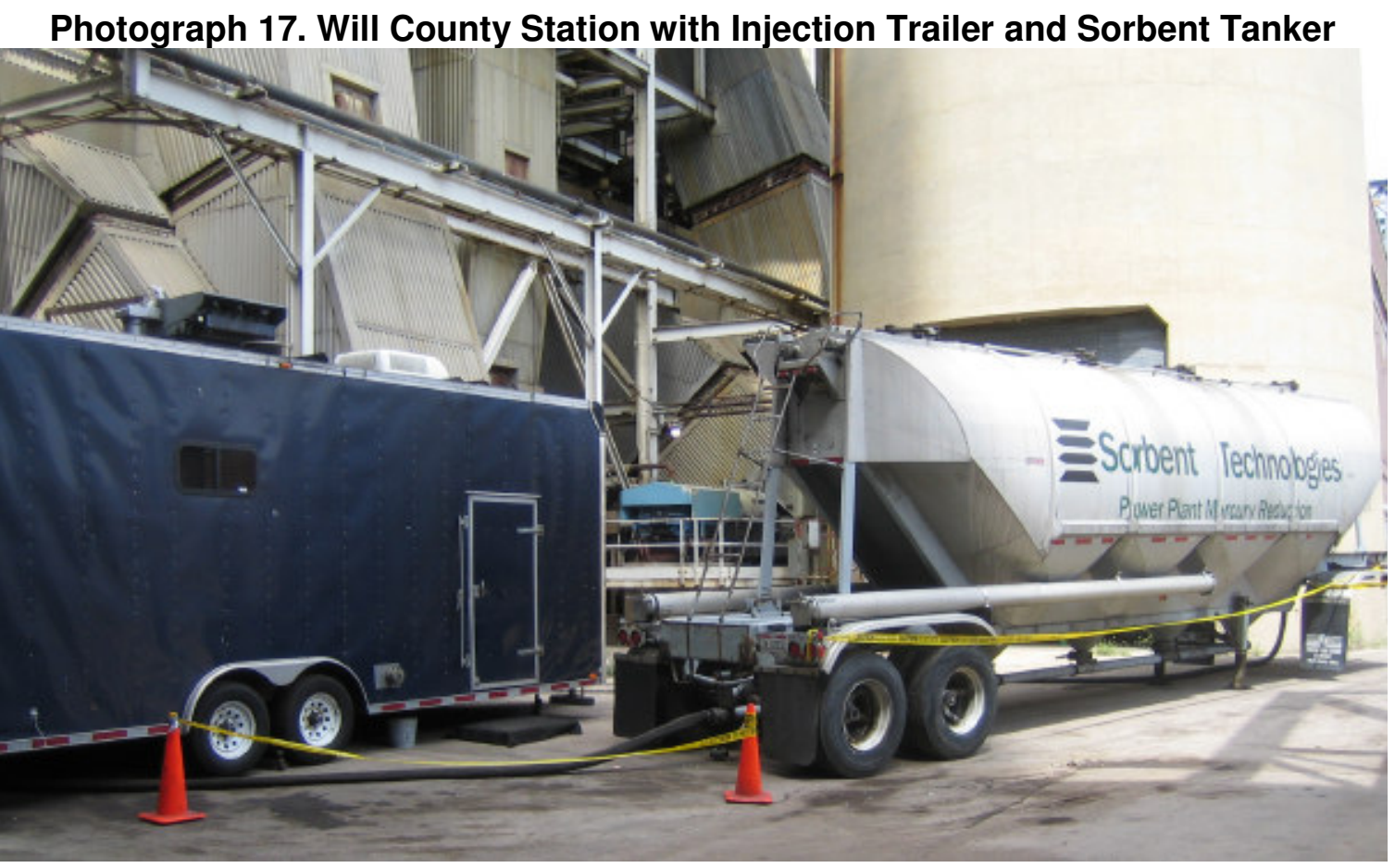

The tanker was used instead of a silo for sorbent storage during the continuous run. It was not necessary to refill the tanker due to the short test length. 


\section{CFD Modeling}

Fuel Tech personnel took flow and temperature data from the Superheat Will County 3 boiler in December, 2006. This data was used to calibrate a CFD model of the ductwork from the boiler exit to the ESP entrance plenum. Will County 3 has a hot-side ESP, so there is not air preheater before the ESP. The model was subsequently used by STC to predict the sorbent distribution of different injection arrangements in order to select the one that provided the best sorbent distribution with the fewest injection lances.

The ductwork studied is shown in Figure 48.

Figure 48. Will County 3 Superheat Boiler Ductwork Modeled

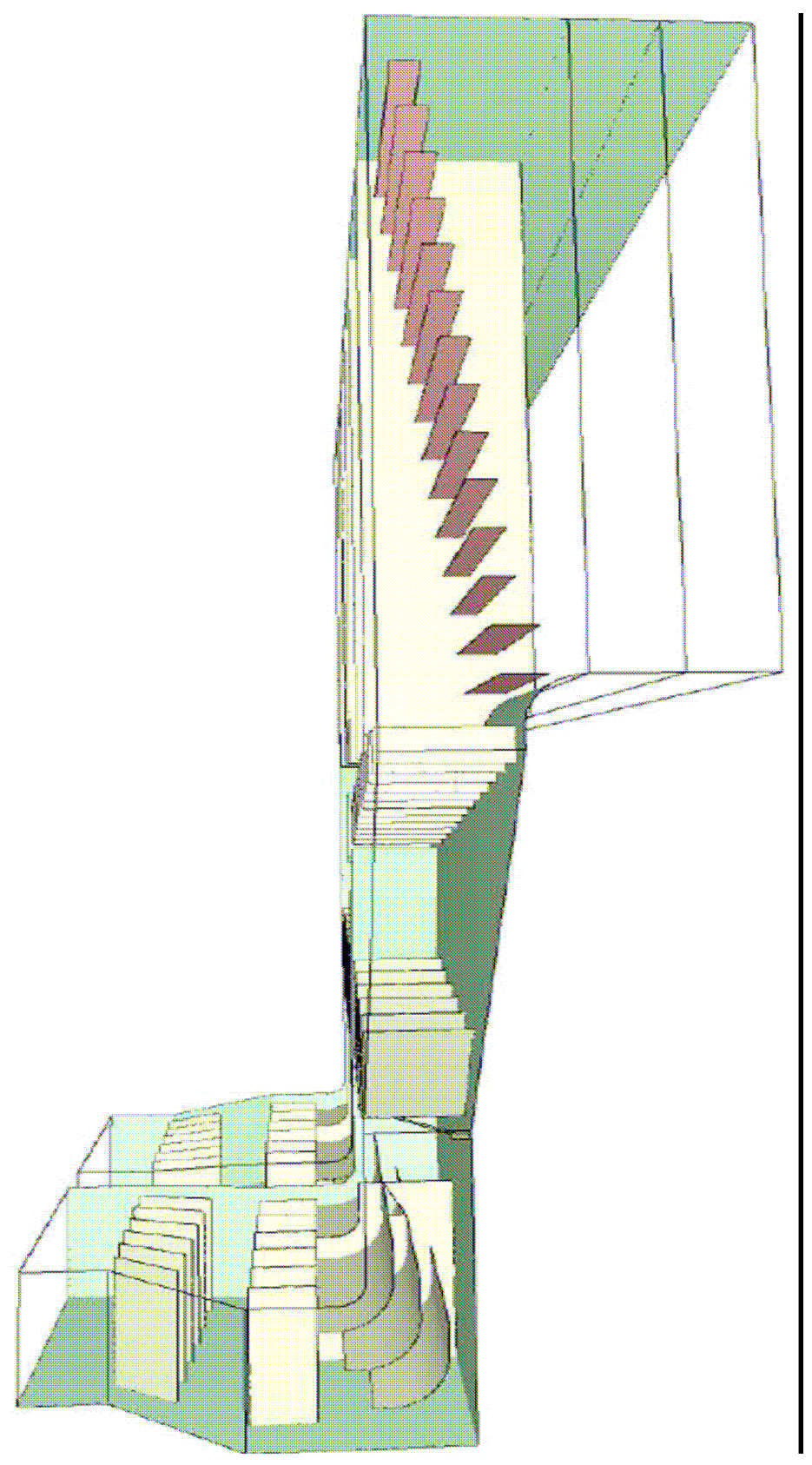


The duct run from the boiler exit to the ESP plenum at Will County 3 combines two ducts into one. However, the single vertical duct still acts like it is two ducts with very little flue gas flow in the middle of the duct. The velocity profile of the flue gas in the Will County 3 ductwork is shown in the Figure 49.

Figure 49. Velocity Profile in the Will County 3 Ductwork

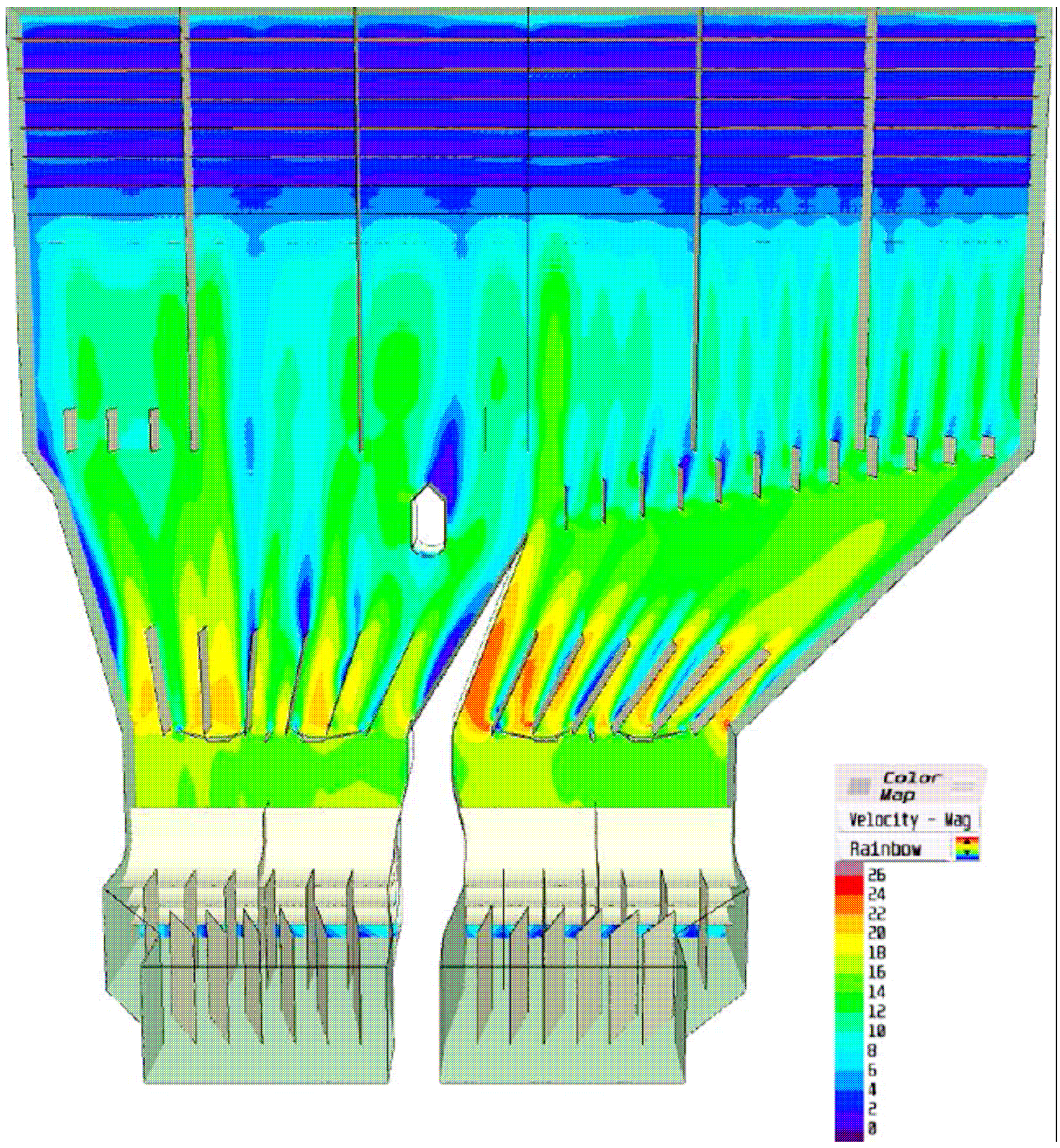

The flow pattern at Will County 3 is complex with some areas of very high flow and some of very low flow. The injection location first evaluated was just below the vanes in the vertical portion of the ductwork. This location was selected first since there were already ports installed in that location. This turned out to be a terrible injection location. The next location evaluated was in the horizontal ductwork in between the two set of vanes. 
At the direction of Albemarle Environmental $\mathrm{f} / \mathrm{k} / \mathrm{a}$ Sorbent Technologies, numerous injection lance arrangements were modeled. It was found that a 28 lance arrangement was the best fit at either the vertical or the horizontal injection locations. The sorbent distribution patterns injecting at one of the two locations with regular lances or X-aLances are shown in Figure 50.

\section{Figure 50. Sorbent Distribution at Two Locations at Will County 3 Using Either Regular Lances or X-a-Lances}
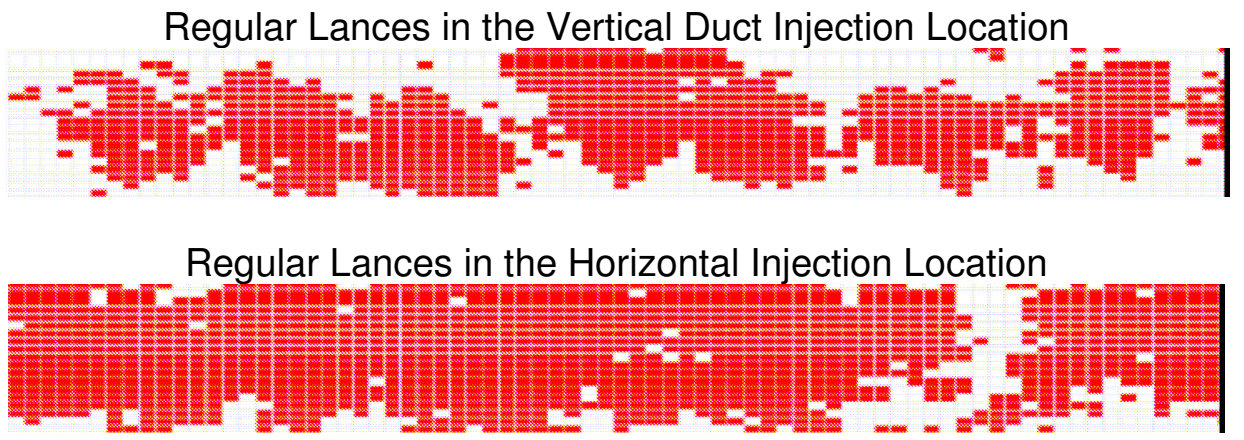

X-a-Lances in the Horizontal Injection Location

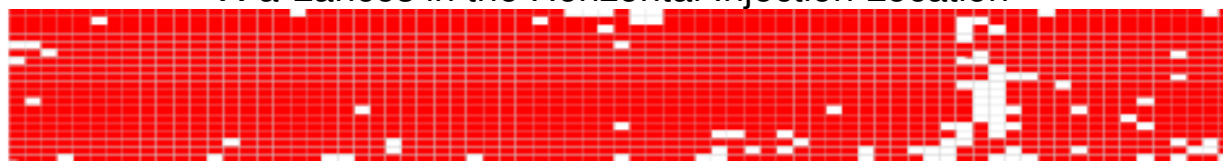

The sorbent distribution patterns are exhibited in coverage diagrams. These diagrams indicate if one or more sorbent particles of a theoretical number injected entered the grid box located at the test plane just before the ESP plenum. Red means that a sorbent particle entered the box while white indicates that one did not. Thus, the more red boxes the better the sorbent distribution. It is realized that there will be additional mixing of the flue gas and sorbent as it passes through the ESP plenum but better mercury removal results can be achieved when the sorbent is well distributed entering the plenum.

The use of regular open ended lances at the vertical injection location gave very poor results while the sorbent distribution was greatly improved by injecting at the horizontal injection location.

In the interim between the testing at the Midwest Generation Crawford and Will County Stations, Albemarle Environmental $\mathrm{f} / \mathrm{k} / \mathrm{a}$ Sorbent Technologies' personnel developed the $\mathrm{X}$-a-Lance for use in applications with short residence time and difficult duct geometries. These are a design of distributing lance that will not plug as many distributing lances do. Regular distributing lances had been tested elsewhere by Albemarle Environmental f/k/a Sorbent Technologies and found to have little impact upon mercury removal performance while having the great potential to plug. The use of the X-a-Lances at the horizontal injection location was modeled for the Will County test and found to improve the sorbent distribution significantly, as can be seen in the last coverage diagram in Figure 50.

It was decided to test both regular lances and the X-a-Lances in the first phase of the parametric testing and use the better performing lances throughout the rest of the test program at Will County. 


\section{Baseline Measurements}

\section{Mercury Monitor Data}

The baseline period began at Will County 3 on August 2 and ran until the first parametric test on August 8, 2007. The mercury data from the PS Analytical monitor for the baseline period, along with the Appendix $\mathrm{K}$ measurements from this period, are presented in Figure 51.

\section{Figure 51. PSA and Appendix $\mathrm{K} \mathrm{Hg}$ Data from the Baseline Period at Will County 3}

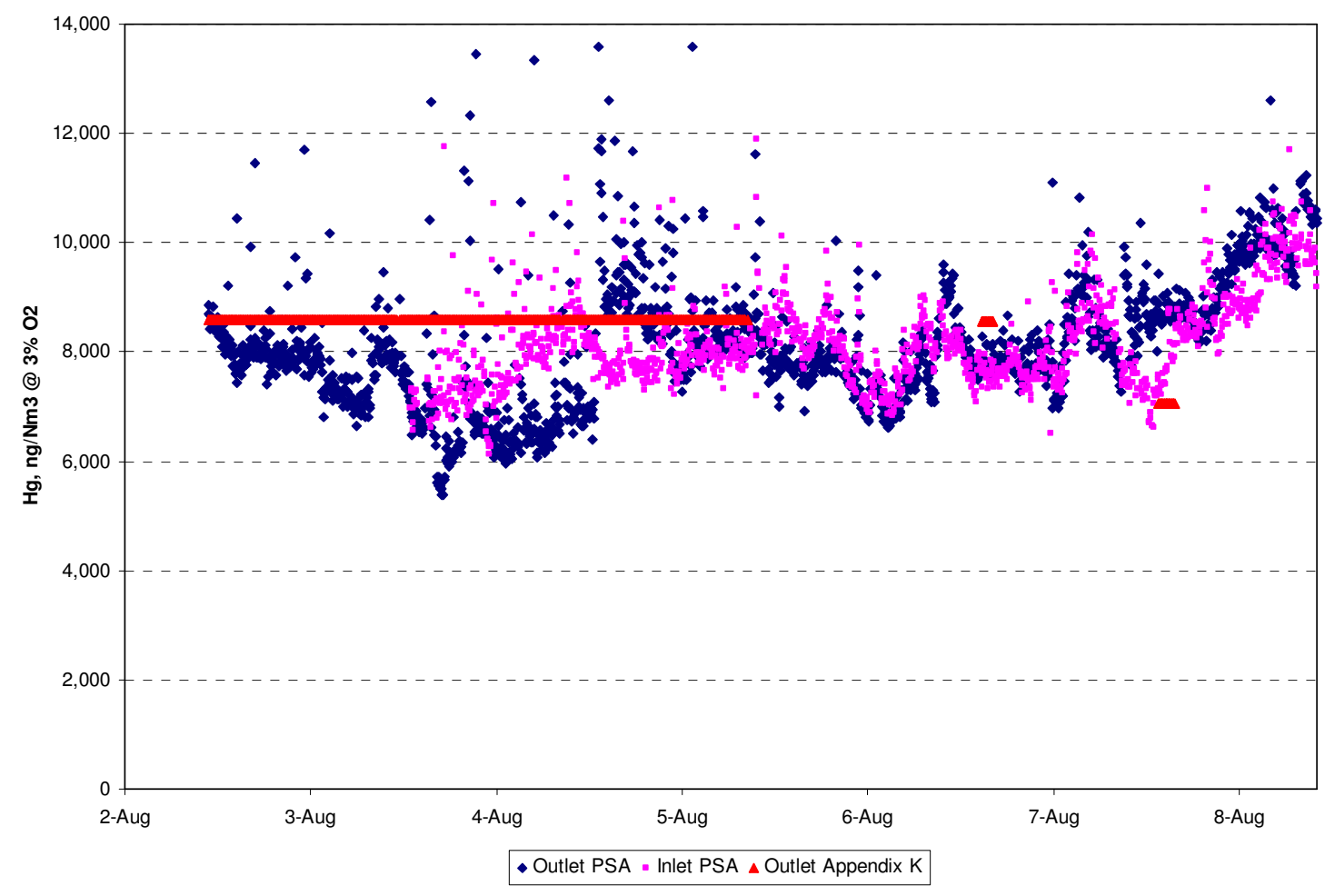

Will County 3 is a load following unit which typically is at full load during the day and at reduced load during the night. The boiler operates in a manner such that the flue gas flow rate is fairly proportional to boiler load. As a result, the flue gas mercury concentration does not vary much with changing load. During the first baseline period, the total vapor phase mercury $\left(\mathrm{Hg}^{\top}\right)$ in the inlet to the ESP was about $8,000 \mathrm{ng} / \mathrm{Nm}^{3}$ at $3 \%$ oxygen. The outlet mercury concentrations were close to those at the inlet and, thus, there was not much native mercury removal during this period.

There were three Appendix $\mathrm{K}$ measurements made during the baseline period. The first was very long, lasting over 3 days, while the last two measurements were of the more typical two hour runs. The first Appendix $\mathrm{K}$ measurement (the long duration test) provided a mercury measurement of $8595 \mathrm{ng} / \mathrm{Nm}^{3}$ at $3 \%$ oxygen. This was about $10 \%$ higher than the PSA Hg data for the same period which indicated that the mercury concentration was $7809 \mathrm{ng} / \mathrm{Nm}^{3}$ at $3 \%$ oxygen. 
The other two Appendix $\mathrm{K}$ measurements during the baseline period gave $\mathrm{Hg}$ values of 8558 and $7051 \mathrm{ng} / \mathrm{Nm}^{3}$ at $3 \%$ oxygen while the PSA monitor measured the mercury at 7823 and $8723 \mathrm{ng} / \mathrm{Nm}^{3}$ at $3 \%$ oxygen, respectively. It is unknown why the PSA data and the Appendix $\mathrm{K}$ data varied in this manner but this variation between measurements was consistent throughout the test program.

\section{Coal Data for All Test Periods}

Midwest Generation Will County Station uses a Powder River Basin (PRB) subbituminous coal. Coal samples were taken daily as the coal was being loaded into the Will County 3 bunkers. Selected coal samples were sent to the SGS NA laboratories in Ohio for analyses. The number of coal samples analyzed was drastically reduced in order to control costs of the program. The results of the coal proximate and mercury analyses for all portions of the test program are presented in Tables 43 and 44, respectively.

\section{Table 43. Will County 3 Coal Proximate Analyses (as received)}

\begin{tabular}{|c|c|c|c|c|c|c|c|}
\hline Date & Period & Moisture, \% & $\frac{\text { Ash }}{\%}$ & $\frac{\mathrm{VM}}{\underline{\%}}$ & $\frac{F C}{\%}$ & $\frac{\mathrm{S}_{1}}{\%}$ & Heat Content, Btu/lb \\
\hline $8 / \overline{8 / 2007}$ & Baseline & 27.3 & $\overline{4.8}$ & 31.3 & $3 \overline{6} .6$ & $0 . \overline{27}$ & 8,850 \\
\hline $8 / 9 / 2007$ & Parametric & 28.3 & 3.8 & 31.4 & 36.5 & 0.20 & 8,759 \\
\hline $8 / 11 / 2007$ & Continuous & 29.5 & 4.1 & 30.9 & 35.4 & 0.24 & 8,578 \\
\hline 8/23/2007 & Parametric & 28.8 & 4.0 & 31.2 & 36.1 & 0.18 & 8,679 \\
\hline 8/25/2007 & Parametric & 30.6 & 4.0 & 30.7 & 34.7 & 0.19 & 8,352 \\
\hline $8 / 27 / 2007$ & Parametric & 29.9 & 4.5 & 30.7 & 34.9 & 0.27 & 8,506 \\
\hline Average & & 29.1 & 4.2 & 31.0 & 35.7 & 0.23 & 8,621 \\
\hline
\end{tabular}

The baseline coal sample contained about $27 \%$ moisture, $5 \%$ ash, and $0.3 \%$ sulfur on an as received basis. The coal heat content was about $8,800 \mathrm{Btu} / \mathrm{lb}$, on an as received basis. These coal properties didn't vary much during the test program and are very similar to those measured by Will County in their daily coal sampling for all of the boilers and during the testing at the Midwest Generation Crawford Station in 2006. This is not surprising since the coal for both plants comes from the same source.

\begin{tabular}{|ccc|}
\hline \multicolumn{3}{|c|}{ Table 44. Will County 3 Coal Mercury Data } \\
Date & Period & Hg, ppm dry \\
8/8/2007 & Baseline & 0.08 \\
$8 / 9 / 2007$ & Parametric & 0.05 \\
$8 / 11 / 2007$ & Continuous & 0.06 \\
8/12/2007 & Continuous & 0.06 \\
8/13/2007 & Continuous & 0.07 \\
8/14/2007 & Continuous & 0.07 \\
8/23/2007 & Parametric & 0.05 \\
8/24/2007 & Parametric & 0.06 \\
8/25/2007 & Parametric & 0.05 \\
8/26/2007 & Parametric & 0.06 \\
8/27/2007 & Parametric & 0.06 \\
\hline Average & & 0.06 \\
\hline
\end{tabular}


The coal mercury content was also consistent throughout the test program at Will County 3 with the mercury level averaging 0.06 ppm on a dry basis.

\section{Baseline Fly Ash Data}

The ESP associated with Will County 3 uses eight hoppers to collect fly ash. The front hoppers (5-8) collect the ash from the front three fields of the ESP. Approximately 90\% of the fly ash is collected in the front hoppers and $10 \%$ in the back hoppers. Therefore, the fly ash sampling was focused entirely upon the front hoppers. While the back hoppers would be expected to collect ash with a higher LOI and higher mercury content, the percentage of the total mercury collected would be negligible due to the small amount of mass collected there. Some attempts were made to collect ash from the back hoppers with little success.

The fly ash $\mathrm{Hg}$ and LOI data from the Reheat and Superheat boilers that compose Will County Unit 3 are presented in Table 45.

\begin{tabular}{|c|c|c|c|c|c|c|c|c|}
\hline \multirow[b]{2}{*}{ Reheat Boiler } & \multicolumn{4}{|c|}{ Mercury, ppb } & \multicolumn{4}{|c|}{ LOI, \% } \\
\hline & $\underline{\mathrm{A5}}$ & $\underline{A 6}$ & A7 & $\underline{A 8}$ & $\underline{\mathrm{A} 5}$ & $\underline{A 6}$ & $\underline{A 7}$ & $\underline{A 8}$ \\
\hline $8 / 6 / 2007$ & $\overline{4}$ & $\overline{10}$ & $\overline{4}$ & $\overline{6}$ & $\overline{0.53}$ & $\overline{0.52}$ & $\overline{0.82}$ & $\overline{0.62}$ \\
\hline $8 / 10 / 2007$ & 5 & 5 & 4 & 5 & 0.65 & 0.57 & 0.83 & 1.15 \\
\hline $8 / 14 / 2007$ & 20 & 3 & 7 & 3 & 0.43 & 0.42 & 0.47 & 0.59 \\
\hline Overall Average $=$ & 6 & & & & 0.63 & & & \\
\hline Superheat Boiler & B5 & B6 & B7 & B8 & B5 & B6 & B7 & B8 \\
\hline $8 / 3 / 2007$ & 9 & 6 & 7 & $\overline{7}$ & & & & \\
\hline $8 / 4 / 2007$ & 5 & 9 & 8 & 5 & 0.41 & 0.47 & 0.49 & 0.60 \\
\hline $8 / 5 / 2007$ & 9 & 12 & 6 & 9 & 0.20 & 0.34 & 0.26 & 0.21 \\
\hline $8 / 6 / 2007$ & 7 & 10 & 5 & 9 & 0.21 & 0.39 & 0.27 & 0.20 \\
\hline 8/7/2007 & 8 & 5 & 6 & 6 & 0.35 & 0.35 & 0.32 & 0.36 \\
\hline Overall Average $=$ & 7 & & & & 0.34 & & & \\
\hline
\end{tabular}

The injection tests were conducted on the Superheat boiler of Will County 3 . Thus, fly ash samples from the Reheat boiler would provide baseline fly ash data, even during sorbent injection.

The fly ash LOI was below $1 \%$ in all samples, although somewhat higher in samples from the Reheat boiler as compared to the Superheat boiler.

The fly ash mercury content was very low at all times, averaging only $6 \mathrm{ppb}$ for samples from the Reheat boiler and $7 \mathrm{ppb}$ from the Superheat boiler. This would be expected for two reasons. First, a PRB coal was being fired which generates fly ash with a low unburned carbon content with which to capture mercury, as can be seen from the LOI data. Second, the fly ash is being captured in a hot-side ESP with temperatures near $700^{\circ} \mathrm{F}$. Unburned carbon has a very low mercury capacity at these temperatures. The low fly ash mercury content confirms the $\mathrm{Hg}$ monitor data which indicated very low levels of native mercury removal. 


\section{Boiler Operation}

Will County 3 is not a base loaded unit, but rather, operates at varying loads in order to meet demand. On most days, the peak period is from about 8:00 to 16:00. This boiler is also shuts down completely for periods of time due to lack of demand. The high demand periods are generally in the summer and winter. Will County 3 uses a hot-side ESP to capture the fly ash emissions. For this reason, the flue gas temperature leading to the ESP is near $700^{\circ} \mathrm{F}$ at full load and near $550^{\circ} \mathrm{F}$ at low load.

The opacity limits for Will County 3 are no greater than $30 \%$ for a six minute average. The stack opacity at Will County 3 is highly dependent upon load as it is at most boilers. The opacity is the lowest at low loads and the highest at high loads. This is normal for an ESP since the SCA (Specific Collection Area) of the device is the highest at low loads when there is a lower flue gas volume and lowest at high loads when the flue gas volume is highest. The flue gas flow rate at full load is about 500,000 acfm. The SCA of each of the ESPs which capture the fly ash from the two boilers that compose Will County 3 is $200 \mathrm{ft}^{2} / \mathrm{Kacfm}$. These are small ESPs by any standard but have the advantage of being hot-side ESPs where the fly ash is usually easier to capture.

A plot of boiler load and the 6-minute average opacity data for the baseline period is presented in Figure 52.

Figure 52. 6-Minute Average Opacity and Boiler Load for the Baseline Period at Will County 3

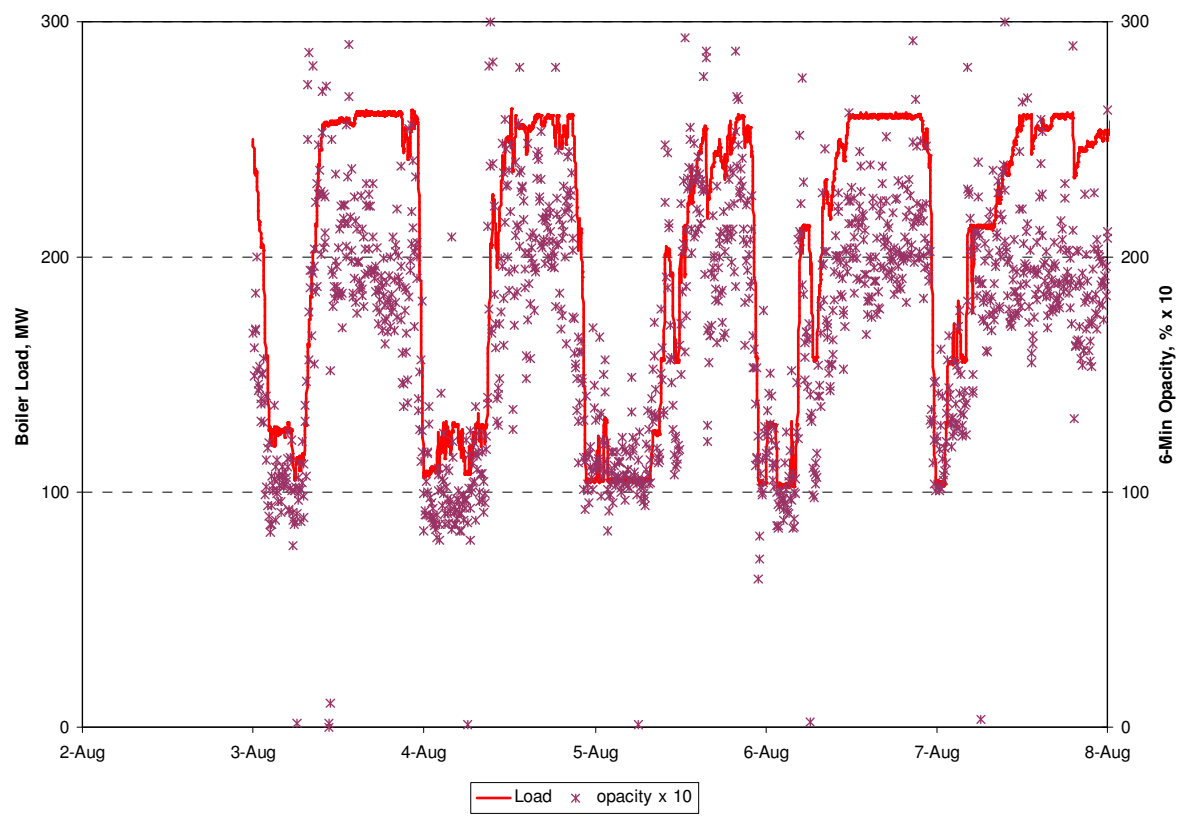

At low load, the 6-minute average opacity is near $10 \%$, while at full load the opacity is near $20 \%$ to $25 \%$. 


\section{Parametric Tests}

The first phase of the parametric tests at Will County 3 was performed with the high temperature version of C-PAC ${ }^{\mathrm{TM}}$ in order to avoid contaminating the fly ash with nonconcrete friendly materials. This first round of parametric tests was conducted on August 8-9, 2007. The impact of injection lance design was evaluated on these two days. On the first of these days, regular injection lances were utilized, while X-a-Lances were used on the second day. The second phase of the parametric testing began after the completion of the continuous run and after a boiler outage from August 24-28, 2007.

Four mercury sorbents were evaluated in the second phase of the parametric testing. These sorbents included H-PAC1, which is the standard high temperature version of the gas-phase brominated sorbent, and $\mathrm{H}-\mathrm{PAC} 2$, which is an experimental version of $\mathrm{H}-\mathrm{PAC}^{\mathrm{TM}}$. A second high temperature version of $\mathrm{C}-\mathrm{PAC}{ }^{\mathrm{TM}}$ (C-PAC 2B) was also evaluated.

Albemarle Environmental $\mathrm{f} / \mathrm{k} / \mathrm{a}$ Sorbent Technologies Corporation holds the patent ${ }^{(1)}$ on gas-phase bromination of sorbents. Other sorbents on the market that claim to be "brominated" are salt-impregnated with a bromine salt. The difference is in the manner in which the bromine is attached to the base PAC. A carbon-bromide bond is created on the PAC through the use of gas-phase bromination. The salt impregnated PACs have the bromine loosely physically absorbed. This is why the gas-phase brominated sorbents made by Albemarle Environmental $\mathrm{f} / \mathrm{k} / \mathrm{a}$ Sorbent Technologies have outperformed the salt impregnated PACs in most applications. ${ }^{(2-8)}$

A test was conducted in order to better understand the impact of gas-phase bromination on sorbents used in high temperature applications. A plain PAC (Norit Darco Hg) was brominated in the Albemarle Environmental $\mathrm{f} / \mathrm{k} / \mathrm{a}$ Sorbent Technologies production facility and tested at Will County. It is designated as H-PAC3. The salt impregnated version of the same plain PAC (Norit Darco Hg LH) was also tested at Will County for comparison.

The results of both phases of the parametric testing are discussed in this section. All of the parametric injection tests were performed at full load.

\section{Mercury Monitor Data}

The first phase of the parametric injection tests used only one sorbent (the high temperature version of C-PAC ${ }^{\mathrm{TM}}$ ) but different injection lances. Regular lances were used in the first day of this phase of testing and the X-a-Lances on the second day. The mercury removal results from the first phase of the parametric injection tests are shown in Figure 53. 
Figure 53. Mercury Removal Results from the First Phase of the Parametric Injection Tests at Will County 3

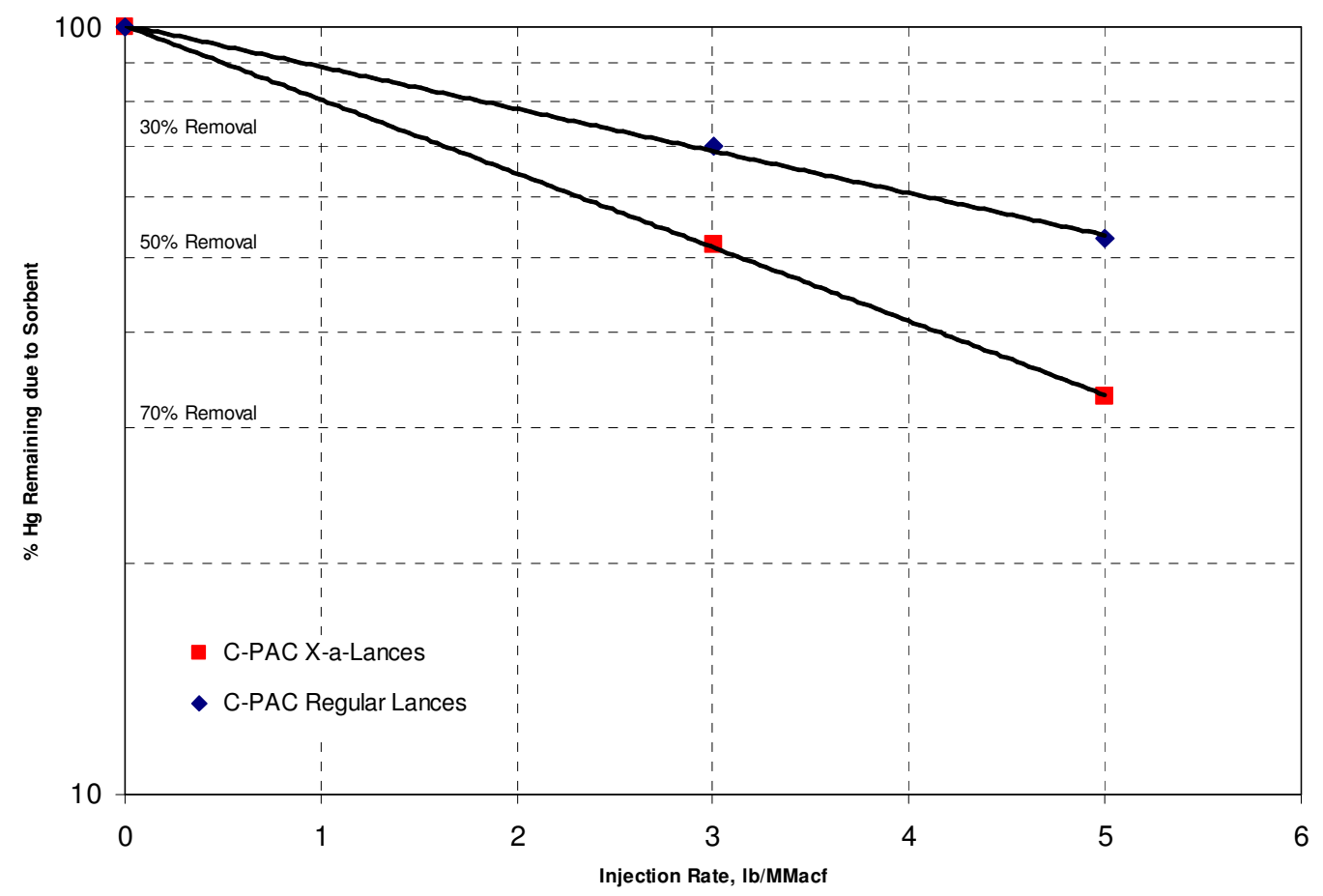

The injection of the high temperature version of C-PAC ${ }^{\mathrm{TM}}$ with regular injection lances provided mercury removal rates of about $30 \%$ and $45 \%$ due to sorbent at the injection rates of 3 and $5 \mathrm{lb} /$ MMacf, respectively. This is very good performance considering that the injection temperature is about $700^{\circ} \mathrm{F}$ at full load. However, the same sorbent at the same injection rates provided mercury removal rates of about $50 \%$ and $67 \%$ when the $X$-a-Lances were utilized. This is an improvement of about $50 \%$ relatively. As a result of these findings, the $\mathrm{X}$-a-Lances were used for the rest of the test program.

The second phase of the parametric testing was conducted primarily with non-concrete friendly materials. The results of the second phase of testing are presented in Table 46.

\begin{tabular}{|c|c|c|c|}
\hline Date & Sorbent & $\begin{array}{l}\text { Injection Rate } \\
\text { lb/MMacf }\end{array}$ & $\begin{array}{c}\text { Mercury } \\
\text { Removal, \% }\end{array}$ \\
\hline 8/24/2007 & H-PAC1 & 3 & $46 \%$ \\
\hline 8/24/2007 & H-PAC1 & 5 & $68 \%$ \\
\hline $8 / 25 / 2007$ & C-PAC2B & 3 & $17 \%$ \\
\hline $8 / 25 / 2007$ & C-PAC2B & 5 & $54 \%$ \\
\hline $8 / 25 / 2007$ & C-PAC2B & 5 & $58 \%$ \\
\hline $8 / 26 / 2007$ & H-PAC2 & 3 & $38 \%$ \\
\hline $8 / 26 / 2007$ & H-PAC2 & 5 & $62 \%$ \\
\hline 8/27/2007 & H-PAC3 & 3 & $33 \%$ \\
\hline 8/27/2007 & H-PAC3 & 5 & $39 \%$ \\
\hline 8/28/2007 & Norit Hg LH & 3 & $24 \%$ \\
\hline $8 / 28 / 2007$ & Norit Hg LH & 5 & $33 \%$ \\
\hline
\end{tabular}


The standard $\mathrm{H}-\mathrm{PAC}{ }^{\mathrm{TM}}$ sorbent, designated H-PAC1 in Table 46, performed in the same manner as did the C-PAC ${ }^{T M}$. Neither the experimental version of C-PAC ${ }^{T M}$ (C-PAC 2B) nor the experimental version of H-PAC ${ }^{T M}$ (H-PAC2) performed as well as the standard gas-phase brominated products. The performance of the Norit $\mathrm{Hg} \mathrm{LH}$ sorbent is compared with that of the C-PAC ${ }^{\mathrm{TM}}$ and $\mathrm{H}-\mathrm{PAC} \mathrm{CM}^{\mathrm{TM}}$ standard sorbents in Figure 54.

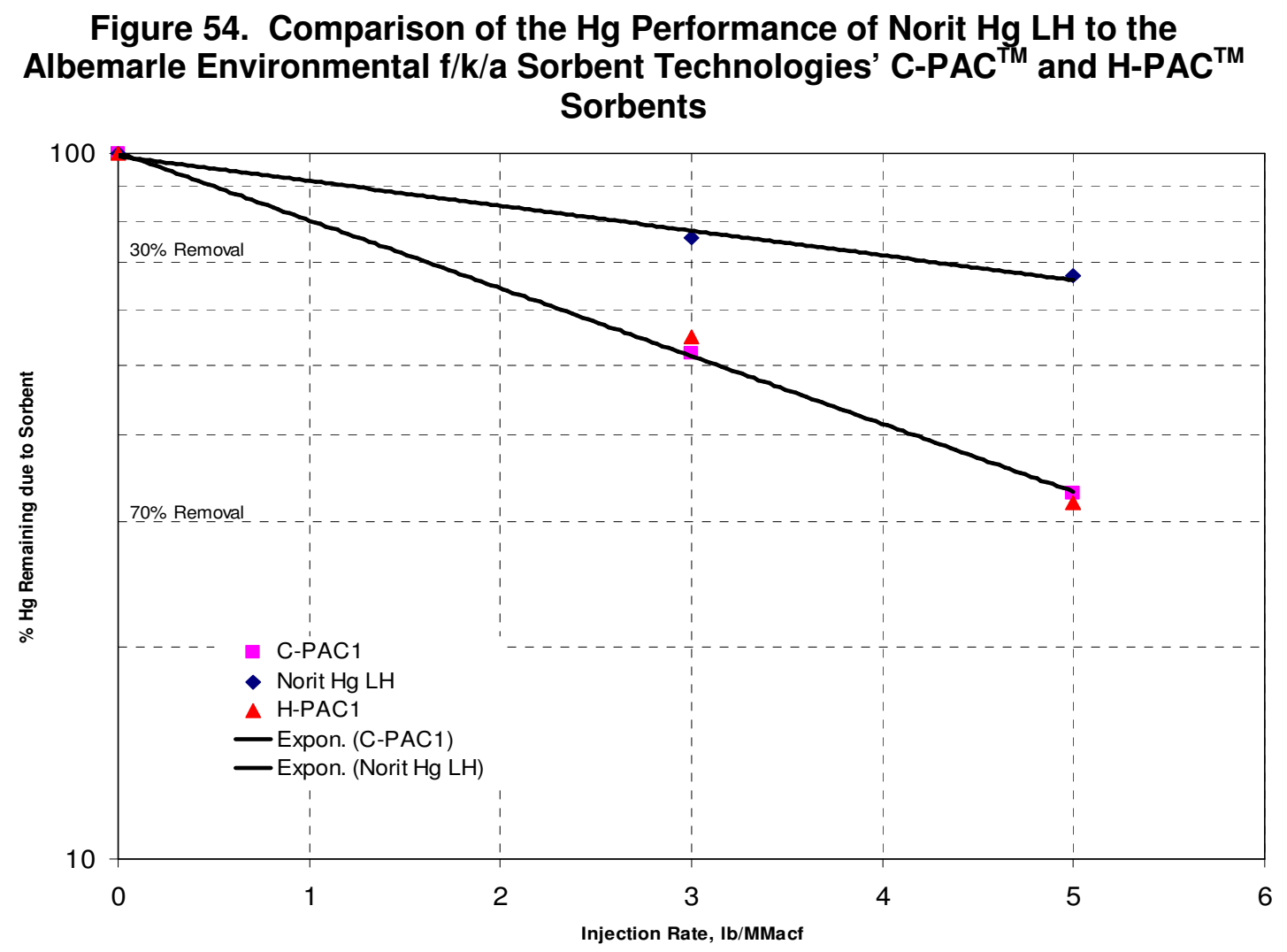

As stated previously, the C-PAC1 and H-PAC1 sorbents performed nearly identically, providing nearly $70 \%$ mercury removal at an injection rate of $5 \mathrm{lb} / \mathrm{MMacf}$.

Albemarle Environmental $\mathrm{f} / \mathrm{k} / \mathrm{a}$ Sorbent Technologies was interested in discovering which was more important in generating a good high temperature sorbent: the base carbon or the method of bromination. Therefore, plain Norit $\mathrm{Hg}$ was brominated at Albemarle Environmental $\mathrm{f} / \mathrm{k} / \mathrm{a}$ Sorbent Technologies using our patented gas-phase bromination process. The sorbent produced in this manner is titled H-PAC3 in Table 46.

By comparing the performance of these three sorbents, conclusions can be drawn as to which is more important, the base carbon or the method of bromination. From the results presented in Figure 54, it is already known that the standard H-PAC (H-PAC1) greatly outperformed the salt-impregnated Norit Hg LH sorbent. These two sorbents have different base carbons and different bromination methods. This test was devised so that two of the sorbents (H-PAC1 and H-PAC3) were produced by the same method, gas-phase bromination.

The mercury removal results of $\mathrm{H}-\mathrm{PAC} 1, \mathrm{H}-\mathrm{PAC} 3$, and salt-impregnated Norit $\mathrm{Hg} \mathrm{LH}$ are presented in Figure 55. 
Figure 56. Comparison of the Mercury Performance of Three Sorbents

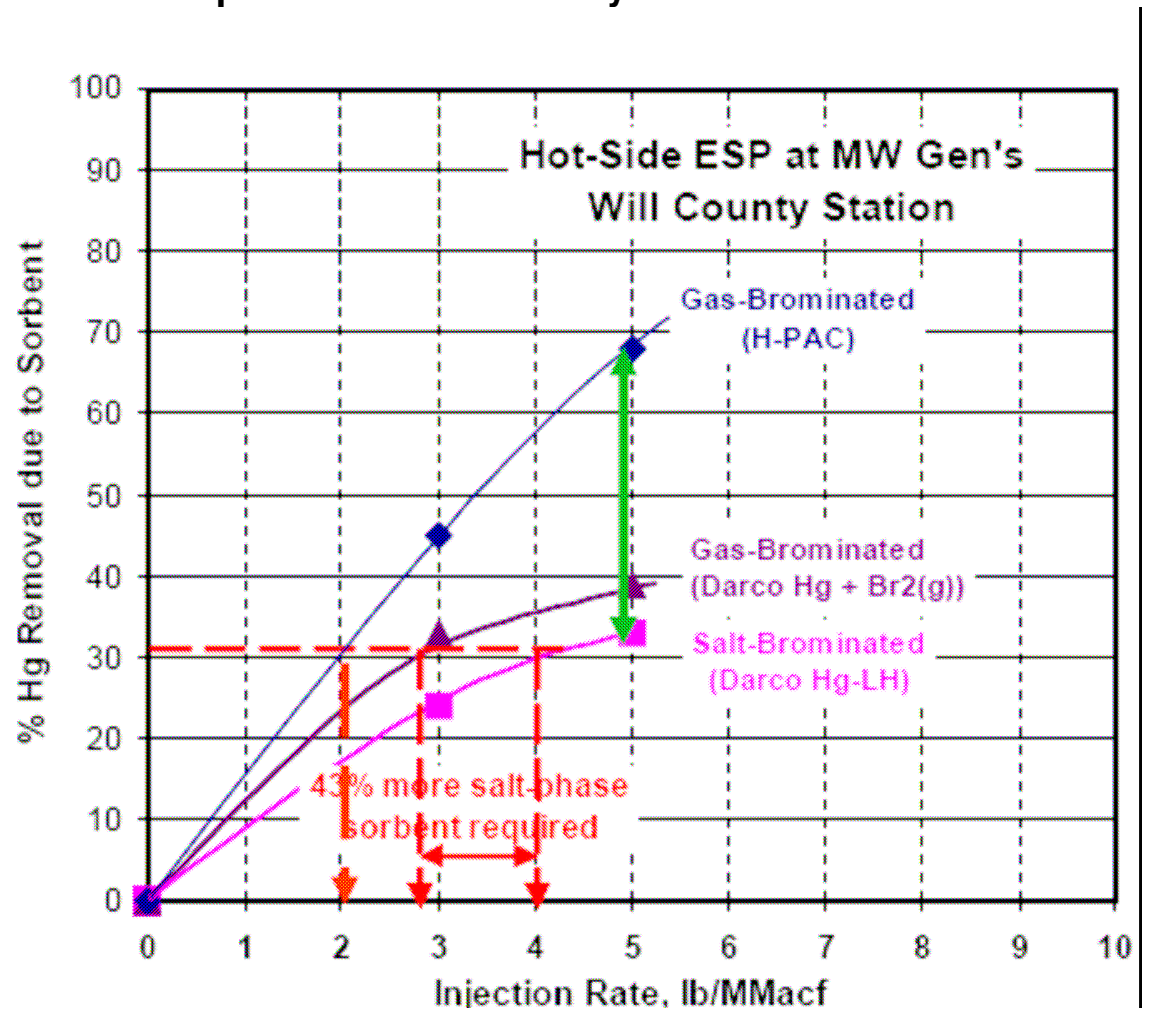

The gas-phase brominated Norit $\mathrm{Hg}$ (H-PAC3) performed better than did the saltimpregnated Norit $\mathrm{Hg} \mathrm{LH}$ but worse that the standard H-PAC1. The performance of the three sorbents can only be compared at low mercury removal levels since the Norit $\mathrm{Hg}$ $\mathrm{LH}$ only achieved a maximum of $33 \%$ removal at an injection rate of $5 \mathrm{lb} / \mathrm{MMacf}$. In order to achieve a mercury removal rate of $30 \%$, an injection rate of about $4 \mathrm{lb} / \mathrm{MMacf}$ of Norit $\mathrm{Hg} \mathrm{LH}$ was required compared to injection rates of $2.8 \mathrm{lb} / \mathrm{MMacf}$ for $\mathrm{H}-\mathrm{PAC} 3$ (gasphase brominated Norit $\mathrm{Hg}$ ) and $2.0 \mathrm{lb} / \mathrm{MMacf}$ of $\mathrm{H}-\mathrm{PAC} 1$ to achieve the same $30 \%$ mercury removal rate.

From these results, it is clear that gas-phase bromination is responsible for part of the improved mercury removal performance compared to the salt-impregnated Norit $\mathrm{Hg} \mathrm{LH}$ but that the base PAC selection appears to have a great impact.

\section{Fly Ash Data}

Fly ash samples were collected during both parametric test periods. These samples are of much less importance than those collected during the baseline period and the continuous run since it is impossible to know how much untreated fly ash is collected with the treated fly ash. Obtaining representative fly ash samples from a hot-side ESP is doubly difficult since the sample can begin to smolder and loose mercury as soon as it is exposed to air. Because of these issues and in an effort to reduce costs, only a few fly ash samples from the parametric testing were analyzed.

In spite of the sampling issues, it was observed that the fly ash samples collected in the parametric test portions of the program had mercury contents in the hundreds of parts per billion as compared to the $7 \mathrm{ppb}$ observed in the baseline fly ash. 


\section{Continuous Run}

Due to cost considerations, there was no 30-day long-term injection test conducted at Will County 3. Instead, a short continuous run was conducted from August 9-16, 2007.

\section{Mercury Monitor Data}

Both the high temperature version of C-PAC ${ }^{\mathrm{TM}}$ and $\mathrm{H}-\mathrm{PAC} \mathrm{C}^{\mathrm{TM}}$ were tested in the continuous run. The $\mathrm{Hg}$ monitor data for the continuous run is presented in Figure 56.

Figure 56. Hg Monitor Data During the Continuous Run at Will County 3

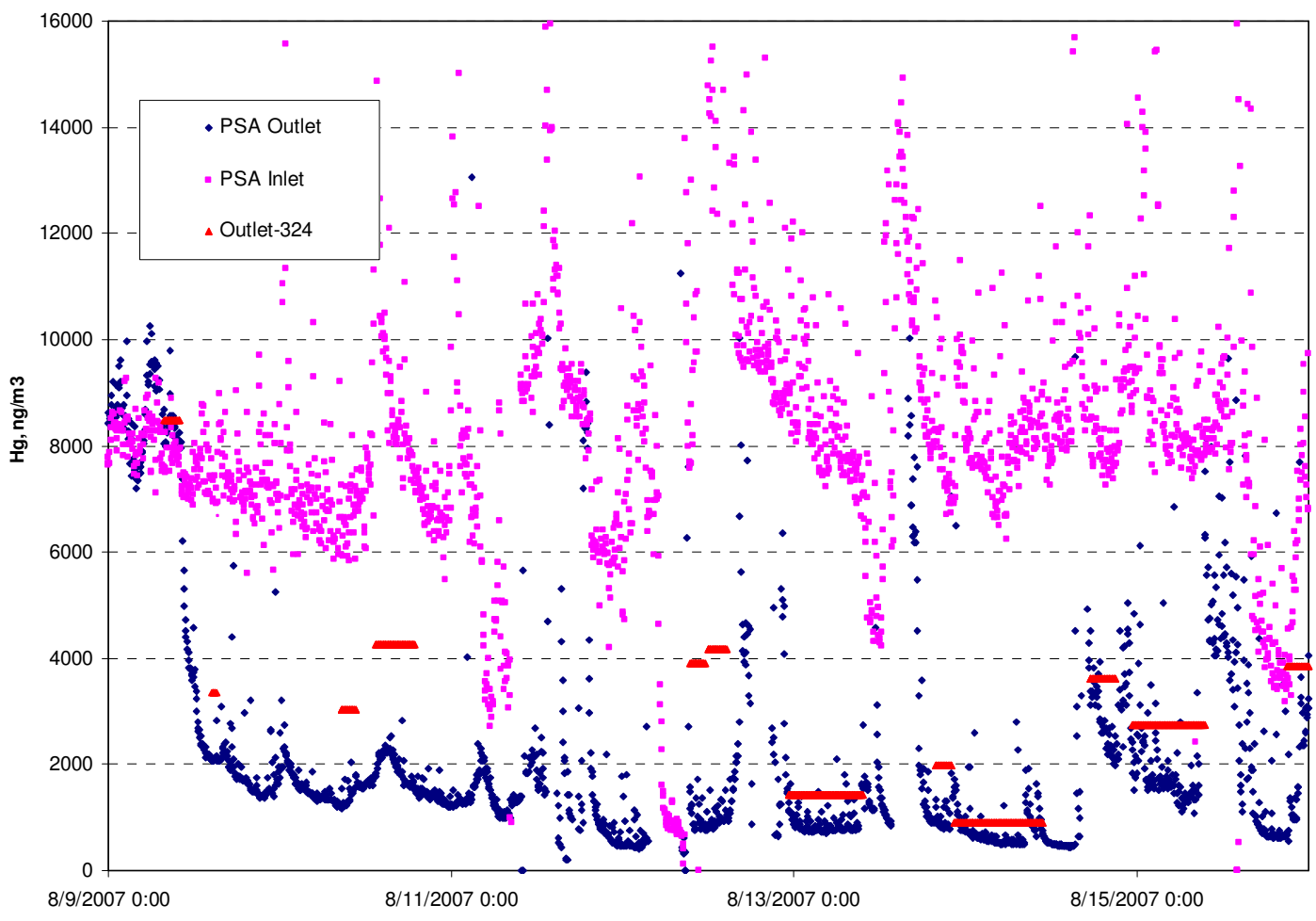

The continuous run began on August 9 and lasted as long as the boiler could maintain operation. The boiler was taken out of service on August 17 and was down a week for repairs. The operational problems began on August 12 and had a detrimental impact on the inlet $\mathrm{Hg}$ monitor. This data now became more scattered than it had in the baseline period and early in the continuous run. The outlet data was less scattered by the boiler operation but was impacted by two shorts outages of the injection system.

C-PAC ${ }^{\mathrm{TM}}$ was injected at a rate of $5 \mathrm{lb} / \mathrm{MMacf}$ continuously until August 14 when the injection of $\mathrm{H}-\mathrm{PAC} \mathrm{C}^{\mathrm{TM}}$ began. The PSA Hg data indicated that the mercury removal rate during the C-PAC ${ }^{\mathrm{TM}}$ portion of the continuous run was $74 \%$ compared to $67 \%$ as measured using the Appendix $\mathrm{K}$ data. $\mathrm{H}-\mathrm{PAC} \mathrm{C}^{\mathrm{TM}}$ injection at a rate of $5 \mathrm{lb} / \mathrm{MMacf}$ began on August 14 and ended on August 16. During this short period, the Appendix K data indicated a mercury removal rate of about $67 \%$. The performance of $\mathrm{H}-\mathrm{PAC}^{\mathrm{TM}}$ was confirmed in the second parametric test period when the boiler and the monitors were more stable. 


\section{Fly Ash Data}

Fly ash samples were taken from each of the front hoppers associated with the Superheat boiler ESP. The average $\mathrm{LOI}$ and $\mathrm{Hg}$ values of these samples are shown in Table 47.

\begin{tabular}{|c|c|c|c|c|c|c|c|c|}
\hline \multirow{3}{*}{$\frac{\text { Superheat Boiler }}{8 / 9 / 2007}$} & \multicolumn{3}{|c|}{ Mercury, ppb } & \multicolumn{5}{|c|}{ 니, \% } \\
\hline & A5 & $\underline{\mathrm{A} 6}$ & $\underline{\mathrm{A} 7}$ & $\underline{A 8}$ & $\underline{\mathrm{A} 5}$ & $\underline{A 6}$ & $\underline{\mathrm{A} 7}$ & $\underline{\mathrm{A} 8}$ \\
\hline & $\overline{101}$ & $\overline{94}$ & $\overline{183}$ & $\overline{275}$ & 2.02 & 2.02 & 2.97 & 3.49 \\
\hline $8 / 10 / 2007$ & 111 & 114 & 145 & 264 & 2.92 & 2.39 & 3.10 & 4.02 \\
\hline $8 / 10 / 2007$ & 81 & 61 & 115 & 170 & 3.13 & 2.55 & 2.85 & 3.55 \\
\hline $8 / 11 / 2007$ & 305 & 240 & 304 & 477 & 2.25 & 2.02 & 2.29 & 3.58 \\
\hline $8 / 12 / 2007$ & 422 & 388 & 324 & 257 & 1.59 & 1.65 & 1.41 & 1.80 \\
\hline $8 / 12 / 2007$ & 33 & 129 & 152 & 174 & 1.65 & 1.41 & 1.80 & 1.76 \\
\hline $8 / 13 / 2007$ & 216 & 144 & 271 & 438 & 2.60 & 2.12 & 3.45 & 5.33 \\
\hline Overall Average = & 267 & & & & 2.22 & & & \\
\hline
\end{tabular}

The pre-test fly ash LOI and mercury content are low averaging $0.34 \%$ and $7 \mathrm{ppb}$, respectively. As soon as the C-PAC ${ }^{\mathrm{TM}}$ injection began, the fly ash $\mathrm{LOI}$ and $\mathrm{Hg}$ levels jumped. It appears that these values continued to climb for a few days before leveling off. However, this is merely an artifact of obtaining more representative fly ash samples with time as less untreated fly ash is sampled.

The fly ash samples from the continuous run averaged $2.22 \% \mathrm{LOI}$ and $267 \mathrm{ppb} \mathrm{Hg}$, considerably more than the baseline samples. However, it is difficult to obtain a representative fly ash sample from a cold-side ESP and even more difficult to obtain one from a hot-side ESP where the ash is glowing hot. This issue caused the wide variation in mercury content of the fly ash samples.

\section{Fly Ash Cement Properties}

The Foam Index of fly ash sample is the first indication of the quality of the material in regard to its use in concrete. The foam index test is very simple and rapid. It involves adding an air entrainment admixture (AEA) drop wise to a solution containing a known amount of fly ash. The AEAs are essentially soaps used to generate bubbles in the final concrete. Without these air bubbles, the concrete would be susceptible to cracking during the freeze and thaw cycle. A high quality fly ash should have both a low foam index, but also, a very consistent foam index. In fact, the latter is usually more important than the former. If a fly ash varies widely in its foam index, the customer doesn't know how much to add routinely. Adding a little more AEA is not a major concern since this material is inexpensive.

The foam indices of the fly ash from the continuous run at Will County 3 when C-PAC ${ }^{\mathrm{TM}}$ was used exclusively are shown in Table 48. 


\begin{tabular}{|c|c|c|c|c|c|}
\hline \multirow[b]{2}{*}{ Superheat Boiler } & \multicolumn{4}{|c|}{$\frac{\text { Foam Index }}{\text { Using Vinsol }}$} & \multirow[b]{2}{*}{ Average } \\
\hline & $\underline{\mathrm{A} 5}$ & A6 & A7 & A8 & \\
\hline Baseline & $\overline{17}$ & $\overline{16}$ & $\overline{18}$ & $\overline{16}$ & 17 \\
\hline $8 / 9 / 2007$ & 74 & 52 & 48 & 84 & 65 \\
\hline $8 / 10 / 2007$ & 88 & 52 & 52 & 108 & 75 \\
\hline $8 / 10 / 2007$ & 102 & 86 & 64 & 72 & 81 \\
\hline $8 / 11 / 2007$ & 88 & 48 & 60 & 80 & 69 \\
\hline $8 / 12 / 2007$ & 56 & 40 & 38 & 42 & 44 \\
\hline $8 / 12 / 2007$ & 42 & 32 & 40 & 42 & 39 \\
\hline $8 / 13 / 2007$ & 72 & 44 & 56 & 82 & 64 \\
\hline Overall Average = & 62 & & & & \\
\hline
\end{tabular}

Vinsol was the AEA used in this testing since it is the AEA of choice of Lafarge the fly ash marketer for Midwest Generation. The baseline fly ash samples had fairly low foam indices. Once C-PAC ${ }^{\text {TM }}$ injection began the foam index of the samples increased. However, rather than staying constant, the foam index peaked on 8/10/07 and dropped back down. The reason for this is unknown. The first samples taken on 8/12/07 had nearly the lowest foam index but the highest mercury content, adding to the complex result. Later it was learned that the baseline foam index of the fly ash from this boiler can vary significantly which may have had an impact upon the results.

The overall average foam index was 62 , a value acceptable for use in concrete. The impact of C-PACTM on the properties of concrete was not investigated further due to the limitation of funds. However, based upon past experience, it is highly likely that the concrete properties including the concrete air content, air stability, air distribution, setting time, and strength would have shown no impact based upon the minimal impact upon foam index.

\section{Boiler Operation}

There were no restrictions on Will County 3 boiler operations during the continuous run. The sorbent injection system was configured to follow the flue gas flow rate and adjust the C-PAC ${ }^{\mathrm{TM}}$ injection rate to maintain the desired feed rate throughout the test. Will County 3 varied load from the minimum of about $60 \mathrm{MW}$ gross to as high as $260 \mathrm{MW}$ gross during the continuous run.

The boiler experienced operating problems during the continuous run that eventually caused the boiler to shutdown for a week for repairs before the second phase of the parametric tests could be conducted. On of the problems encountered during the continuous run was the loss of fields from the hot-side ESP. This was not caused by the sorbent injection but by operational problems.

A plot of boiler load and 6 minute average opacity for the combined boilers of Will County 3 during the continuous run is presented in Figure 57. 
Figure 57. Boiler Load and 6-Minute Average Opacity at Will County 3 During the Continuous Run

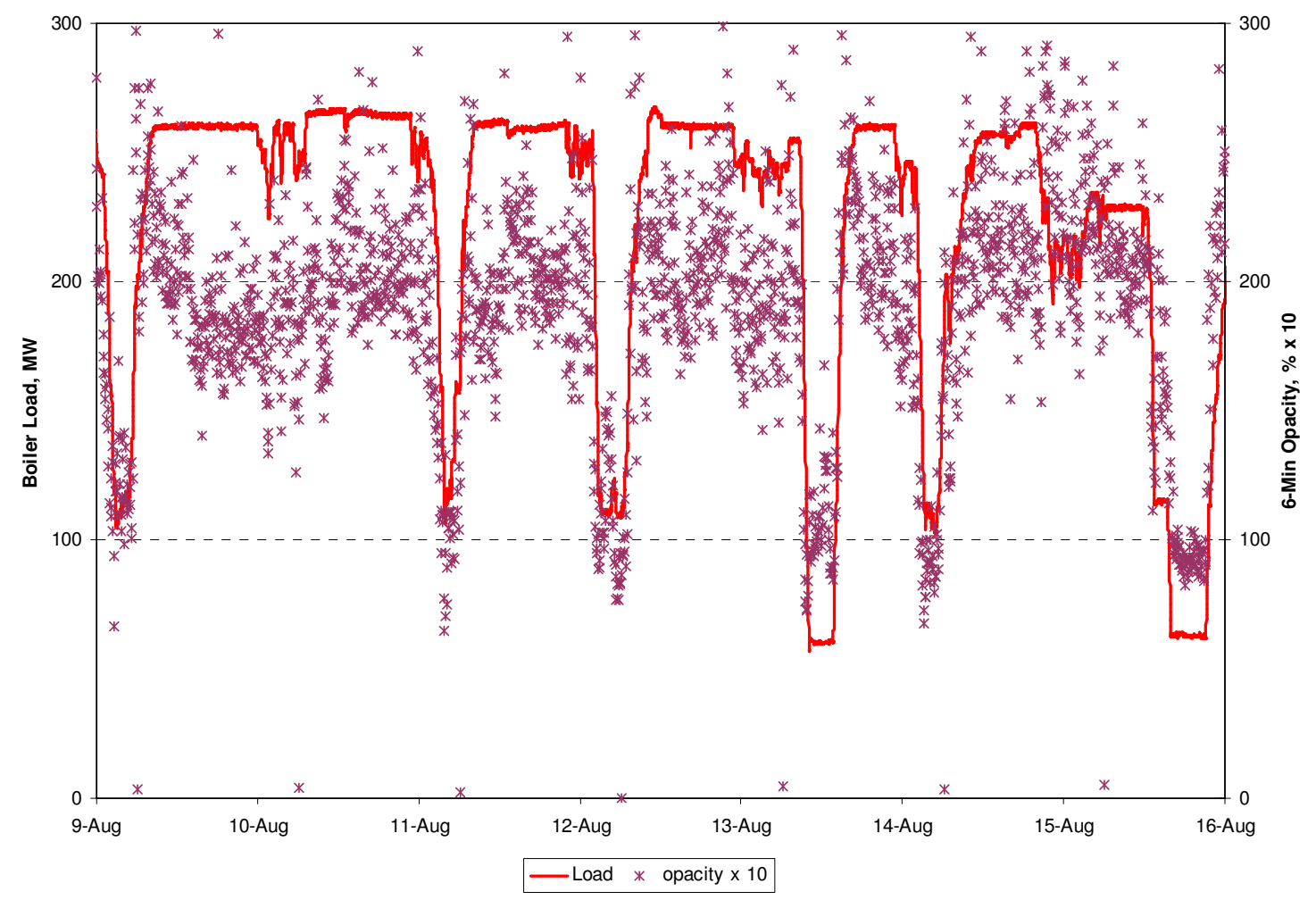

Will County 3 is not a base-loaded boiler but, rather, varies load to meet demand.

Normally, the boiler is at full load during the day and at reduced load during the night. During the continuous run, the boiler was seldom at reduced load and there were two days when the boiler load was not greatly reduced at night. The opacity of the boiler emissions was fairly stable despite the high load and the ESP problems. There was no indication that sorbent injection had a negative impact on ESP performance. 


\section{TECHNOLOGY TRANSFER ACTIVITIES}

The purpose of the technology transfer activities was to provide the results of the testing at the Progress Energy Lee Plant and the two Midwest Generation stations to the widest possible number of utilities for use in their planning and mercury control activities. This was accomplished by means of presentation of technical papers are several conferences. The main conferences used to convey the technical information were the Electric Utility Environmental Conference (EUEC) held every year, the Air Quality Conference and the Mega Symposium held on alternating years and the World of Coal Ash Conference held every year. The results of the mercury removal performance were the focus of the first three conferences while the impact of mercury sorbents on fly ash was the focus of the fourth conference.

Technical presentations were made at the EUEC in $2006^{(2)}, 2007^{(3-6)}$ and $2008^{(7)}$. A technical paper was presented at the Air Quality VI conference in $2007^{(8)}$. Technical papers were presented at the Mega Symposium in $2006^{(9)}$ and $2008^{(10)}$. A presentation was made at the World of Coal Ash in $2007^{(11)}$. In addition, Albemarle Environmental $\mathrm{f} / \mathrm{k} / \mathrm{a}$ Sorbent Technologies has presented an update on these tests at the annual DOE NETL Technology Transfer meetings in 2006 and 2007.

\section{CONCLUSIONS}

This program covered testing at three locations: Progress Energy Lee 1, Midwest Generation Crawford 7 and Midwest Generation Will County 3. The boilers in which the testing was conducted had different types of coals (bituminous and PRB), different types of particulate controls (cold-side ESPs and hot-side ESPs) and the fly ash from two boilers was sold for use in cement. One of the sites had to use $\mathrm{SO}_{3}$ injection in order to allow the ESP to work properly without sorbent injection and one boiler had an extremely small ESP. From this diverse test matrix, the following conclusions can be drawn:

\section{Progress Energy Lee 1}

1. Lee 1 used a bituminous coal with a fairly low mercury content $(0.06 \mathrm{ppm}$ on a dry basis).

2. Lee 1 had $20 \%$ to $30 \%$ native $\mathrm{Hg}$ removal.

3. Lee 1 required $\mathrm{SO}_{3}$ injection under normal conditions in order to allow their cold-side ESP to function properly.

4. Tests indicated that the performance of the mercury sorbents was greatly impacted by the $\mathrm{SO}_{3}$ concentration. A mercury removal rate of about $80 \%$ was achieved at a B-PAC ${ }^{\mathrm{TM}}$ injection rate of $8 \mathrm{lb} / \mathrm{MMacf}$. The mercury removal rate was reduced to about $33 \%$ at the same injection rate but in the presence of $15 \mathrm{ppm}$ of $\mathrm{SO}_{3}$.

5. Injection of $\mathrm{H}-\mathrm{PAC}{ }^{\mathrm{TM}}$ on the hot-side of the air preheater before the $\mathrm{SO}_{3}$ injection location provided better mercury removal than with injecting on the cold-side with $\mathrm{SO}_{3}$ injection. Consequently, one solution for plants like Lee, with $\mathrm{SO}_{3}$ injection, or plants with $\mathrm{SO}_{3}$ generated by the SCR catalyst, is to inject $\mathrm{H}-\mathrm{PAC}{ }^{\mathrm{TM}}$ on the hot-side before the $\mathrm{SO}_{3}$ is in the flue gas. 
6. It was discovered during the parametric portion of the test program that the injection of either B-PAC ${ }^{\mathrm{TM}}$ or H-PAC ${ }^{\mathrm{TM}}$ had a positive impact upon ESP performance. It was decided to perform a 3-day continuous injection run with $\mathrm{B}-\mathrm{PAC}{ }^{\mathrm{TM}}$ in order to determine whether Lee 1 could operate without $\mathrm{SO}_{3}$ injection. If the test proved positive, the continuous injection would continue as part of the long-term test.

7. It was found that the boiler could operate without $\mathrm{SO}_{3}$ injection and the longterm test was so conducted.

8. The total mercury removal for the 30-day long-term test, excluding the first day when $\mathrm{SO}_{3}$ was injected and the last day when a plain PAC was used, averaged $85 \%$. The achievement of $85 \% \mathrm{Hg}$ removal over the 30 days longterm test is another milestone in the history of achievement of the B-PAC ${ }^{\mathrm{TM}}$ sorbent.

9. The opacity during the long-term test averaged about $21 \%$ at full boiler load. This was considerable below the opacity level observed during the baseline period.

10. It was discovered during the parametric testing that grinding a sorbent to a finer size can slightly improve mercury performance but the benefit was more than offset by a dramatic rise in opacity caused by the finer sorbent passing through the ESP.

\section{Midwest Generation Crawford 7}

1. Before the parametric testing began, the native mercury removal was about $20 \%$, which is typical for boilers firing PRB coal.

2. The $\mathrm{Hg}$ removal, observed in the first phase of the parametric tests using only C-PAC ${ }^{\mathrm{TM}}$, was about $60 \%$ due to sorbent and $69 \%$ total at the injection rate of $1 \mathrm{lb} / \mathrm{MMacf}$ and $80 \%$ due to sorbent and $84 \%$ total for the $3 \mathrm{lb} / \mathrm{MMacf}$ injection rate.

3. The long-term test was conducted at a C-PAC ${ }^{\mathrm{TM}}$ injection rate of 4.6 $\mathrm{lb} /$ MMacf. A mercury removal rate of $82 \%$ was achieved.

4. $B-P A C^{T M}$ and other sorbents were tested in the second phase of the parametric test program. The B-PAC ${ }^{\mathrm{TM}}$ had a mercury removal rate of about $70 \%, 80 \%$ and $90 \%$ mercury removal due to sorbent at injection rates of 2,4 and $6 \mathrm{lb} /$ MMacf, respectively.

5. The Norit Hg LH sorbent did not perform as well as did the B-PAC ${ }^{\mathrm{TM}}$ sorbent. It took $50 \%$ more of the Norit Hg LH sorbent to achieve $80 \%$ mercury removal than with the B-PAC ${ }^{\mathrm{TM}}$ sorbent.

6. The impact of C-PAC ${ }^{\mathrm{TM}}$ on the properties of concrete was investigated by Lafarge, the seller of the fly ash, Albemarle Environmental $\mathrm{f} / \mathrm{k} / \mathrm{a}$ Sorbent Technologies and Headwaters Resources, a project partner. The properties 
evaluated included the concrete air content, air stability, air distribution, setting time, and strength. C-PAC ${ }^{\mathrm{TM}}$ does not appear to deleteriously affect any of the important properties of concrete. It may even improve some properties.

7. At Crawford 7 , the opacity would increase $3 \%$ to $5 \%$ over a period of hours from the time that the boiler first reached high load first reached until the boiler load was reduced at night. For the parametric test, the opacity dropped when the C-PAC ${ }^{\mathrm{TM}}$ was turned on or when the injection rate was increased.

8. During the long-term test, the opacity for each successive period was lower than the previous one, so that at the end of the test the opacity at full load was averaging about $8 \%$ below that before the injection began.

\section{Midwest Generation Will County 3}

1. There was essentially no native mercury removal at Will County 3 since the ESP operated at $700^{\circ} \mathrm{F}$.

2. During the first phase of the parametric injection tests different injection lances were tested: regular lances and X-a-Lances. The X-a-Lances were designed to provide better sorbent distribution in ducts with poor geometries and/or short residence times.

3. The injection of the high temperature version of C-PAC ${ }^{\mathrm{TM}}$ with regular injection lances provided mercury removal rates of about $30 \%$ and $45 \%$ due to sorbent at the injection rates of 3 and $5 \mathrm{lb} / \mathrm{MMacf}$, respectively. This is very good performance considering that the injection temperature is about $700^{\circ} \mathrm{F}$ at full load. However, the same sorbent at the same injection rates provided mercury removal rates of about $50 \%$ and $67 \%$ when the X-a-Lances were utilized. This is an improvement of about $50 \%$ relatively. As a result of these findings, the X-a-Lances were used for the rest of the test program.

4. Albemarle Environmental $\mathrm{f} / \mathrm{k} / \mathrm{a}$ Sorbent Technologies was interested in discovering which was more important in generating a good high temperature sorbent: the base carbon or the method of bromination. Therefore, plain Norit $\mathrm{Hg}$ was brominated at Albemarle Environmental $\mathrm{f} / \mathrm{k} / \mathrm{a}$ Sorbent Technologies using our patented gas-phase bromination process.

5. It was already known that the standard H-PAC ${ }^{\mathrm{TM}}$ greatly outperforms the saltimpregnated Norit Hg LH sorbent. These two sorbents have different base carbons and different bromination methods. This test was devised so that two of the sorbents were produced by the same method; gas-phase bromination.

6. The gas-phase brominated Norit Hg performed better than did the saltimpregnated Norit $\mathrm{Hg}$ LH but worse that the standard H-PAC ${ }^{\mathrm{TM}}$. The performance of the three sorbents can only be compared at low mercury removal levels since the Norit Hg LH only achieved a maximum of 33\% removal. In order to achieve a Hg removal rate of $30 \%$, an injection rate of 
about $4 \mathrm{lb} / \mathrm{MMacf}$ of Norit $\mathrm{Hg} \mathrm{LH}$ was required compared to injection rates of $2.8 \mathrm{lb} / \mathrm{MMacf}$ for gas-phase brominated Norit $\mathrm{Hg}$ and $2.0 \mathrm{lb} / \mathrm{MMacf}$ of $\mathrm{H}-\mathrm{PAC}^{\mathrm{TM}}$. From these results, it is clear that gas-phase bromination is responsible for part of the improved mercury removal performance compared to the salt-impregnated Norit Hg LH but that the base PAC selection appears to have a great impact also.

7. There was only a short continuous run conducted at Will County 3 due to cost considerations. The mercury removal performance was slightly better than in the parametric tests averaging about $70 \% \mathrm{Hg}$ removal at an injection rate of $5.0 \mathrm{lb} /$ MMacf. 


\section{SIGNIFICANT ACCOMPLISHMENTS}

Three very significant accomplishments have been achieved in the testing at Progress Energy Lee 1. The first accomplishment is the mercury removal rate achieved in the long-term test. An average mercury removal rate of $85 \%$ was achieved while injecting $\mathrm{B}^{-} \mathrm{PAC}^{\mathrm{TM}}$ at a rate of $8 \mathrm{lb} / \mathrm{MMacf}$ over the 30-day test. This removal rate is the highest yet in a long-term test in a boiler firing bituminous coal.

The second accomplishment relates to the ability of B-PAC ${ }^{\mathrm{TM}}$ to modify fly ash resistivity such that $\mathrm{SO}_{3}$ injection is not needed. The long-term test was performed without $\mathrm{SO}_{3}$ injection without any opacity issues. The opacity during the long-term test was at least as well controlled as it was during the baseline period during which $\mathrm{SO}_{3}$ was being injected. Once the sorbent injection was stopped, $\mathrm{SO}_{3}$ injection had to be resumed in order to control the opacity in Lee 1.

The third accomplishment is the use of $\mathrm{H}-\mathrm{PAC}^{\mathrm{TM}}$ injection for mercury control upstream of $\mathrm{SO}_{3}$ injection. This provides a mercury control solution for boilers like Lee 1, with $\mathrm{SO}_{3}$ injection, or plants with $\mathrm{SO}_{3}$ generated by the SCR catalyst, by injecting $\mathrm{H}-\mathrm{PAC}{ }^{\mathrm{TM}}$ on the hot-side before the $\mathrm{SO}_{3}$ is in the flue gas.

Three very significant accomplishments have been achieved in the testing at Midwest Generation Crawford 7. The first accomplishment is the mercury removal rate achieved in the long-term test averaged $82 \%$ at a C-PAC ${ }^{T M}$ injection rate of $4.6 \mathrm{lb} / \mathrm{MMacf}$.

The second accomplishment was that the fly ash from the testing at Crawford 7 could be used in cement by only increasing the use of AEA slightly. The concrete made from the fly ash containing the C-PAC ${ }^{\mathrm{TM}}$ had the same or better properties than concrete made with fly ash not containing the mercury sorbent.

The third accomplishment was that the C-PAC ${ }^{T M}$. was found to have a beneficial impact on opacity rather than a negative one. The opacity decreased during the long-term trial in the very small ESP at Crawford 7.

Three significant accomplishments were achieved in the testing at Midwest Generation Will County 3. The first was the development of the $X$-a-Lance sorbent distribution system which provided excellent sorbent distribution even in a duct with poor flow distribution and a short residence time.

The second accomplishment was the achievement of a mercury removal rate of $70 \%$ at an injection rate of $5 \mathrm{lb} / \mathrm{MMacf}$ using either the high temperature version of C-PAC ${ }^{\mathrm{TM}}$ or $\mathrm{H}-\mathrm{PAC}^{\mathrm{TM}}$. This was a hot-side ESP operating at $700^{\circ} \mathrm{F}$.

Finally, as at the testing at the Midwest Generation Crawford Station, the fly ash from the testing was found satisfactory for continued use in concrete. 


\section{REFERENCES}

1. Nelson, S. Jr., "Sorbents and Methods for the Removal of Mercury from Combustion Gases", United States Patent No. US 6,953,494 B2, 10/11/05.

2. Lockert, C., et al., "Update of Sorbent-Based Mercury Control in Hot-side Environments", $7^{\text {th }}$ Annual Electric Utility Environmental Conference, Tucson, AZ, January 2006.

3. Landreth, R., et al., "Recent Full-Scale Trials of H-PAC and B-PAC Mercury Control Sorbents", $8^{\text {th }}$ Annual Electric Utility Environmental Conference, Tucson, AZ, January 2007.

4. Nelson, B., et al., "Full-Scale Monthlong Testing of Concrete-Friendly Sorbent at Midwest Generation's Crawford Station", $8^{\text {th }}$ Annual Electric Utility Environmental Conference, Tucson, AZ, January 2007.

5. Liu, X., et al., "Lessons Learned in the Measurement of Mercury by Multiple Methods at Multiple Power Plants", $8^{\text {th }}$ Annual Electric Utility Environmental Conference, Tucson, AZ, January 2007.

6. Nelson, S. Jr., "Effects of Activated Carbon Injection on Particulate Collectors and Particulate Emissions", $8^{\text {th }}$ Annual Electric Utility Environmental Conference, Tucson, AZ, January 2007.

7. Landreth, R., et al., "Advantages of Gas-Phase Bromination", $9^{\text {th }}$ Annual Electric Utility Environmental Conference, Tucson, AZ, January 2008.

8. Landreth, R., et al., "Additional B-PAC, C-PAC and H-PAC Trial Results", Air Quality Conference VI, Arlington VA, September 2007

9. Landreth, R., et al., "New Full-Scale Results from B-PAC Control Trials", 2006 Power Plant Air Pollution Mega Symposium, Baltimore, MD, August 2006.

10. Landreth, R., et al., "Initial Commercial Experience with Gas-Phase Brominated Mercury Sorbents and Injection System Hardware", 2008 Power Plant Air Pollution Mega Symposium, Baltimore, MD, August 2008.

11. Zhou, Q., et al., "Concretes and Fly Ashes from a Full-Scale, Concrete-Friendly C-PAC Mercury Control Trial", World of Coal Ash, Lexington, KY, April 2007. 